\title{
IMPLICATIONS OF THE WTO - TRIPS AGREEMENT FROM A NATIONAL INNOVATION SYSTEMS PERSPECTIVE

\author{
THE PHARMACEUTICAL INDUSTRY IN EGYPT
}

$$
\text { by }
$$

Basma Ibrahim Abdelgafar, M.P.A.

\author{
A thesis submitted to \\ The Faculty of Graduate Studies and Research \\ in partial fulfillment of \\ the requirements for the degree of
}

Doctor of Philosophy

The School of Public Policy and Administration

\author{
Carleton University \\ Ottawa, Ontario
}

January 2003 
National Library

of Canada

Acquisitions and Bibliographic Services

395 Wellington Street Ottawa ON K1A ON4 Canada
Bibliothèque nationale du Canada

Acquisitions et services bibliographiques

395, rue Wellington

Ottawa ON K1A ON4

Canada
Your tile Votre nelderence

Our the Notre reiterence
The author has granted a nonexclusive licence allowing the National Library of Canada to reproduce, loan, distribute or sell copies of this thesis in microform, paper or electronic formats.

The author retains ownership of the copyright in this thesis. Neither the thesis nor substantial extracts from it may be printed or otherwise reproduced without the author's permission.
L'auteur a accordé une licence non exclusive permettant à la Bibliothèque nationale du Canada de reproduire, prêter, distribuer ou vendre des copies de cette thèse sous la forme de microfiche/film, de reproduction sur papier ou sur format électronique.

L'auteur conserve la propriété du droit d'auteur qui protège cette thèse. $\mathrm{Ni}$ la thèse ni des extraits substantiels de celle-ci ne doivent être imprimés ou autrement reproduits sans son autorisation. 


\section{Thesis Acceptance Form}

\section{DOCTORAL CANDIDATE}

The undersigned hereby recommend to the Faculty of Graduate Studies and Research acceptance of the thesis,

\section{Implications of the WTO-TRIPS Agreement}

From a National Innovation Systems Perspective:

The Pharmaceutical Industry in Egypt,

$$
\text { submitted by }
$$

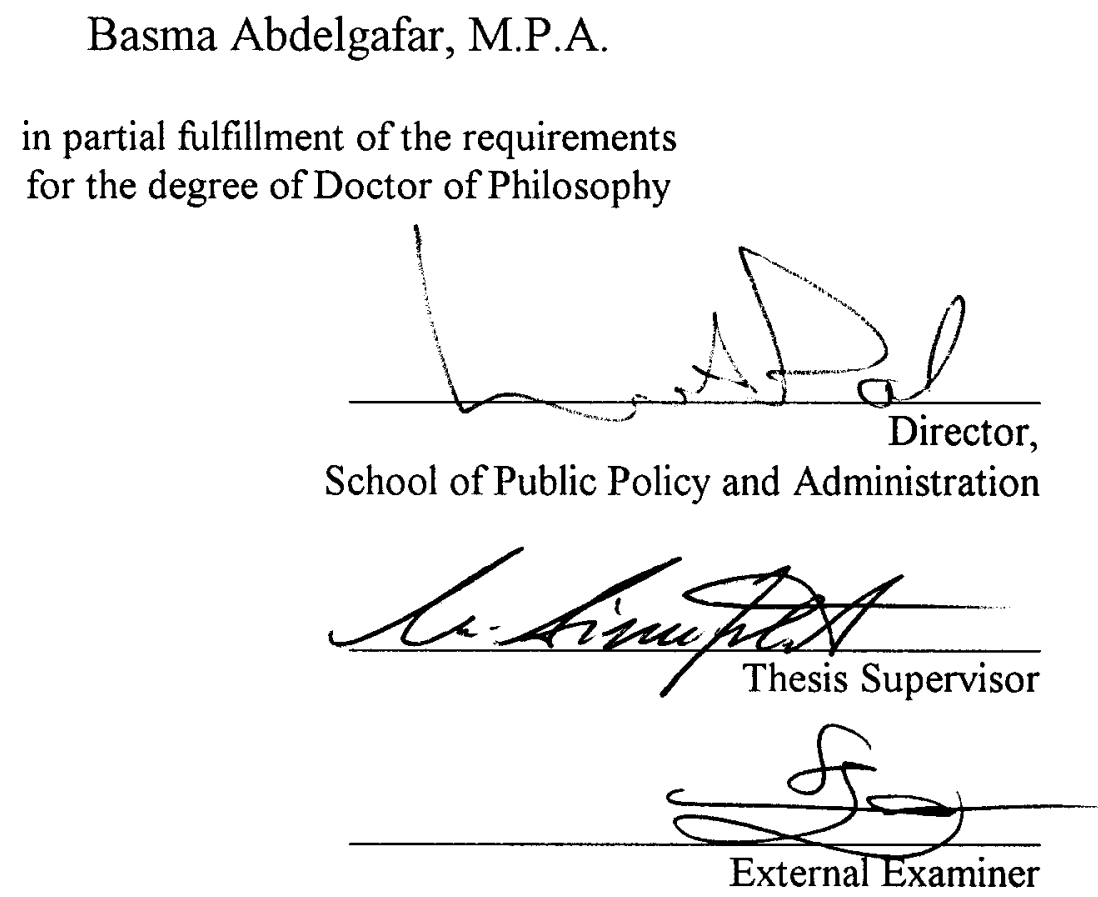

Carleton University
$\operatorname{jan} .20,2003$
Date




\begin{abstract}
This thesis analyzes the implications of the WTO-TRIPS Agreement for the pharmaceutical industry and public health sector in Egypt using a national system of innovation (NSI) approach. My main arguments are (i) that there is no robust method for determining the appropriate balance between innovation and technological diffusion, which subjects IPRs policy to political influence rather than economic calculation: (ii) that attempts to establish positive links between strong IPRs and research and development, foreign direct investment, trade and technology transfer through the use of conventional economic models have yielded few conclusive results; (iii) that adequately understanding the implications of stronger IPRs for the pharmaceutical industries of developing countries requires an examination of relevant aspects of their respective national systems of innovation.
\end{abstract}

Historically, Egypt had maintained a relatively lax pharmaceutical patent regime that was effective in expanding local manufacturing capabilities and stimulating competition. However, the development of key elements of the NSI that was necessary to enable the industry to move toward greater innovation was largely neglected. Thus, while the industry managed to capture a significant share of the local market, its growth remained heavily dependent on the imitation of foreign technologies. In order to curb competition in the 1990s foreign firms began to press the government for immediate changes to the IPRs regime. Although these demands were rejected, Egypt's accession to the WTO-TRIPS Agreement ensured that IPRs would soon be strengthened.

The choice to delay implementation of the Agreement reflects concerns over the appropriateness of its standards given the country's weak innovation and institutional capabilities. The industry's low levels of R\&D and heavy reliance on technology licensing have been reinforced by its limited ability to draw on the support of the science and technology system, which itself is characterized by weak R\&D efforts and poor financial services. These problems, together with the absence of effective technology and competition policies, present serious challenges to the industry's ability to benefit from stronger IPRs. Under these circumstances, the new IPRs regime is expected to act as little more than a rent transfer mechanism from local pharmaceutical producers and consumers to foreign titleholders. 


\section{ACKNOWLEDGEMENTS}

I would like to thank Professor Manfred Bienefeld, my supervisor, without whom I would not have taken this journey let alone completed it. I also owe a debt of gratitude to Professor Phil Ryan for his guidance and support in times of great need. Many thanks as well to Professor Bruce Doern for always making me feel confident through his encouraging comments.

I would like to thank my father and mother, Mr. Ibrahim and Mrs. Afaf Abdelgafar, for their infinite patience and encouragement, for helping me translate numerous documents, and in the last few months of writing, taking care of my son. I would like to thank Mr. Mohammad Zebian, my husband, for never accepting the possibility of my quitting. Thanks also to Mrs. Shrouk Abdelgafar and Miss Iman Zebian, my sister and sister-in-law, for their support throughout. This was truly a family affair.

There are so many people that have been an integral part of this five-year process that I want to acknowledge including my former boss at the Canadian International Development Agency, Mr. Bill Singleton, my friends who helped with various aspects of the research including Mr. Ayman Abdelaal, Mr. Mohamed Barakat and Mr. Ragui El Etreby, and the many wonderful individuals who facilitated my field research in Cairo. I would also like to acknowledge the administrative support and friendship of Mrs. Iris Taylor and Mrs. Jane Mac Arthur of the School of Public Policy and Administration at Carleton. Thank you all very much.

This research was facilitated by the generous financial support of Carleton University, The Social Sciences and Humanities Research Council of Canada, and the Health Services Research Foundation of Canada. 


\section{CHAPTER FOUR}

A NATIONAL SYSTEMS OF INNOVATION APPROACH TO UNDERSTANDING THE IMPLICATIONS OF STRONGER PHARMACEUTICAL PATENT

PROTECTION FOR DEVELOPING COUNTRIES ................................................. 86

THE CONCEPT OF NATIONAL SYSTEM OF INNOVATION ........................ 88

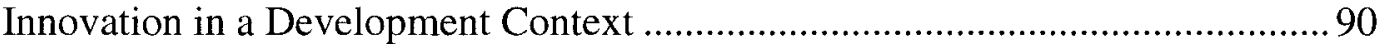

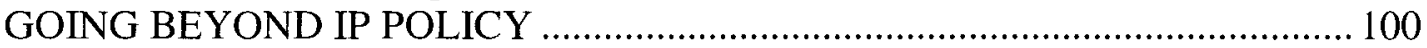

KEY ELEMENTS OF NATIONAL SYSTEMS OF INNOVATION .................. 103

The Structure and Capabilities of Firms in an Industry .................................... 103

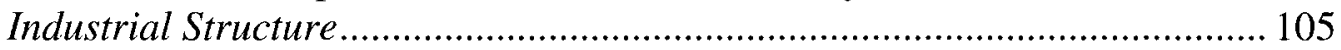

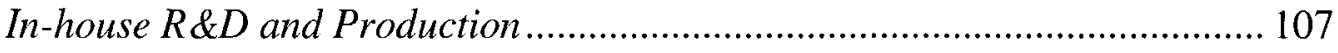

The Scientific and Technological Infrastructure ............................................. 111

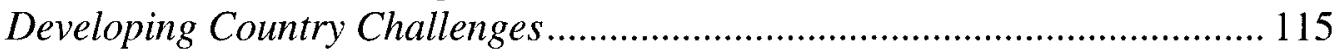

The Coherence and Suitability of Government Policies .................................... 117

Intellectual Property Policy and Its Implementation..................................... 118

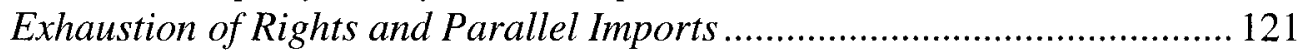

Exceptions to Rights Conferred............................................................. 123

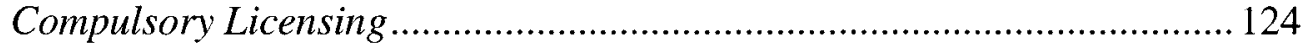

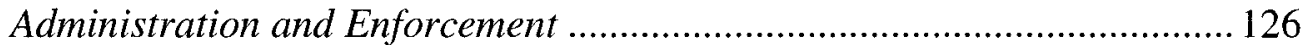

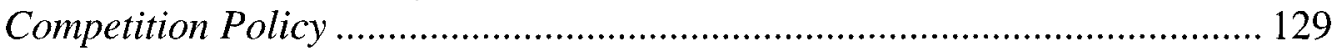

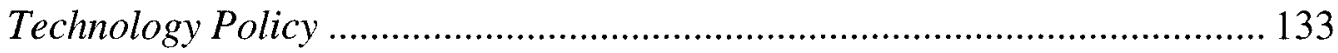

Policies and Regulations Specific to the Pharmaceutical Industry............... 138

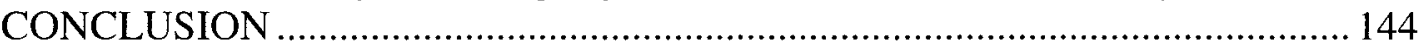

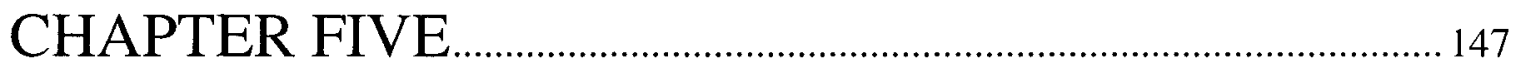

PATENT POLICY AND THE EVOLUTION OF

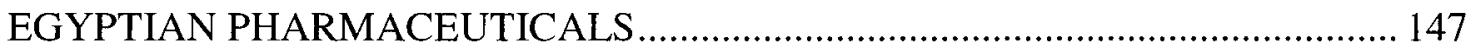

PHASE ONE (1933-1961): ESTABLISHING THE DOMESTIC INDUSTRY .... 148

PHASE TWO (1962-1975): NATIONALIZATION ........................................ 152

PHASE THREE (1976-1983): OPENING THE

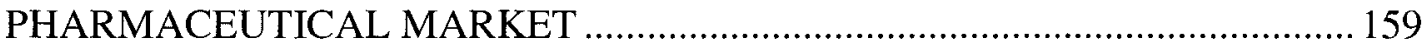

PHASE FOUR (1983-1992): EXPANSION WITHOUT FOUNDATIONS .......... 163

PHASE FIVE (1992-PRESENT): ALTERING THE BALANCE ......................... 168

CONCLUSION ................................................................................ 176 


\section{CHAPTER SIX}

STRONGER IPRS AND THE PHARMACEUTICAL INDUSTRY IN THE

CONTEXT OF EGYPT'S NSI AS IT RELATES TO PHARMACEUTICALS AND

HEALTH.

THE DEVELOPMENT OF THE PHARMACEUTICAL INDUSTRY.

CHALLENGES EMANATING FROM THE DEVELOPMENT OF THE

INDUSTRY.

CHALLENGES EMANATING FROM THE PHARMACEUTICAL/HEALTH

ASPECTS OF THE NSI ............................................................................. 201

Universities and Public Research Institutes .................................................... 202

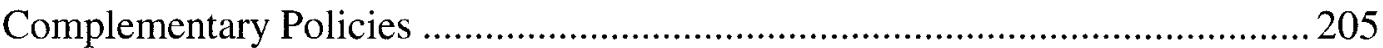

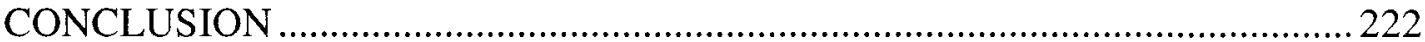

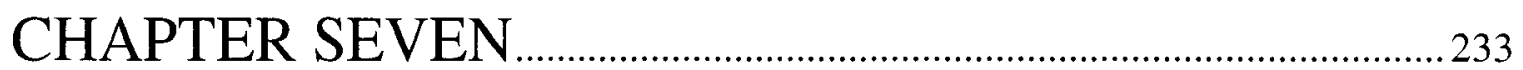

POLICY OPTIONS UNDER THE TRIPS: REALITY OR ILLUSION ....................233

THE DEMAND FOR CLARIFICATION OF THE TRIPS …..............................2236

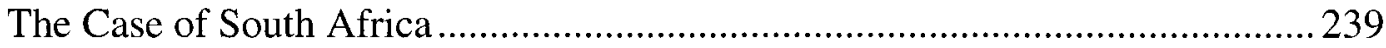

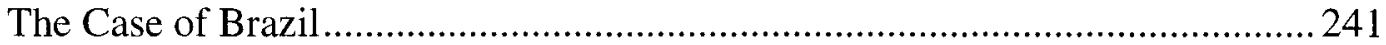

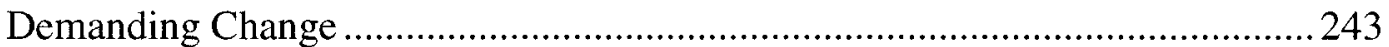

CLARIFYING THE TRIPS AGREEMENT …................................................2 251

A Brief Overview of the Negotiation Process................................................ 252

The Developing Country Position................................................................ 254

The Position of the US-led Coalition ................................................................. 258

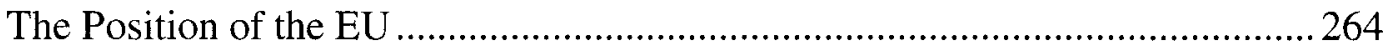

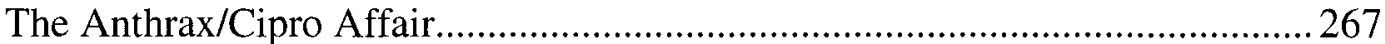

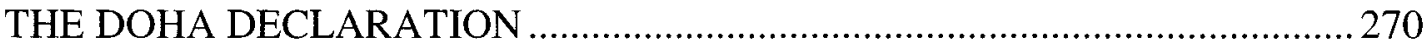

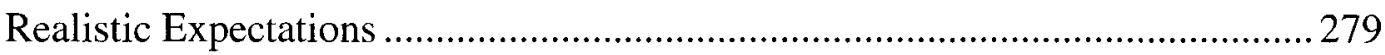

RECENT CHANGES IN EGYPTIAN PATENT POLICY .................................228

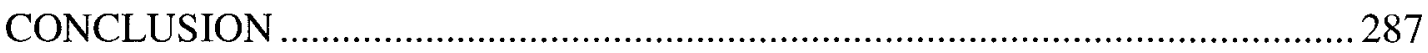

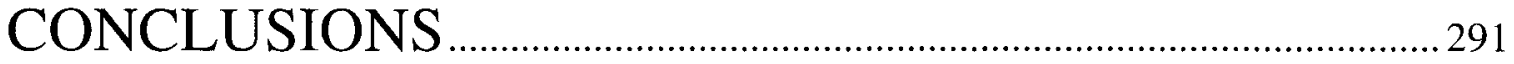

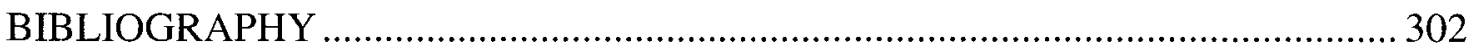

LIST OF PERSONS INTERVIEWED …...................................................... 318 


\section{LIST OF TABLES}

6.1 Changes in the Value of Production in the Public, Locally Owned and Foreign Owned Sectors

6.2 Capital Investment in the Egyptian Pharmaceuticals Sector

6.3 Changes in the Value of Drug Exports

6.4 Changes in the Value of Drug Consumption at Market Prices

6.5 List of Pharmaceutical Companies Operating in Egypt by Ownership 


\section{ACRONYMS}

CIPR - Commission on Intellectual Property Rights

EMR - Exclusive Marketing Right

FDI - Foreign Direct Investment

GATT - General Agreement on Tariffs and Trade

HIV/AIDS - Human Immunodeficiency Virus/Acquired Immune Deficiency Syndrome IFPMA - International Federation of Pharmaceutical Manufacturers Associations

IMF - International Monetary Fund

IPR - Intellectual Property Right

MNE - Multinational Enterprise

NSI - National System of Innovation

OECD - Organization for Economic Cooperation and Development

PhRMA - Pharmaceutical Research and Manufacturers of America

R\&D - Research and Development

SOE - State-owned Enterprise

S\&T - Science and Technology

TRIPS - Trade-Related Aspects of Intellectual Property Rights

UNCTAD - United Nations Conference on Trade and Development

UNDP - United Nations Development Programme

UNICEF - United Nations Children's Fund

USAID - United States Agency For International Development

USTR - United States Trade Representative

WIPO - World Intellectual Property Organization

WTO - World Trade Organization 


\section{CHAPTER ONE}

\section{INTRODUCTION}

\section{THE STUDY'S PRIMARY CONCERN}

From the mid-1980s to the conclusion of the Uruguay Round of multilateral trade negotiations in 1994, the governments of the developed countries, led by the United States, were strongly promoting the global harmonization of intellectual property rights (IPRs) against strong opposition from the developing countries. At the heart of the disagreement was a demand for the mandatory extension of patent protection for pharmaceutical products with its potentially serious implications for domestic pharmaceutical industries and health sectors in developing countries. Previously many countries, including Egypt, had been rather lax in their protection of IPRs for pharmaceuticals in the belief that this was conducive to the creation of a local industry. This is the case primarily because the early stages of such industrial development generally necessitate heavy reliance on imitation and the adaptation of existing technologies. Nevertheless, the demand for a stronger and more internationally harmonized IPRs regime by the industrial countries eventually resulted in the creation of the Trade-Related Aspects of Intellectual Property Rights (TRIPS) Agreement, which is widely considered to be the most ambitious and binding global IPRs agreement in history.

Stronger patent protection for pharmaceutical products is likely to affect the drug 
industries and health sectors in developing countries in many ways, due to its impact of prices, investment decisions, trade flows, local research and development (R\&D), and the scope for effective technology transfer. These effects could turn out to be negative both in the short and in the long term for all of those developing countries that will remain heavy technology and drug importers. In the short term, even the International Monetary Fund (IMF) accepts that benefits of stronger IPRs are most likely to accrue principally to those who own the existing intellectual property rights, and that their gains will come at the expense of those who must rely on their ability to acquire - or to use - those technologies at minimum cost (Harmsen and Subramanian 1994; 12). This bleak outlook is confirmed in an UNCTAD report that states that "numerous short- to medium-term impacts could well be negative for poor countries with respect to product prices and the terms of access to technologies..."(1997; 7).

The proponents of stronger IPRs, however, contend that these short-term negative impacts will be offset by long-term benefits. Thus, the UNCTAD report goes on to state that "...there could be significant long-term benefits to countries that work within the confines of the TRIPS Agreement to set new intellectual property regimes that adequately protect innovative activity and promote inward technology transfer... TRIPS may be employed in a broad programme of forward-looking technology development to promote beneficial dynamic competition" (1997; 7). Yet working within the framework of an agreement that furthers the dominance of the global pharmaceutical industry is likely to make it very challenging for developing countries to promote national industries and 
establish truly competitive national environments that are required for the materialization of long-term benefits. Moreover, even the proponents of stronger IPRs admit that "in those nations in which technological development is at a rudimentary stage and to which technology transfer and diffusion is limited, with little in the way of offsetting local innovation, there could be a net cost in the longer term" (UNCTAD 1997; 19).

This observation highlights the importance of studying national systems of innovation in order to better understand the implications of the TRIPS Agreement for developing countries. A national system of innovation (NSI) constitutes the framework that determines a country's potential for building and attracting knowledge-intensive industries, e.g., pharmaceuticals. The primary components of a NSI include the structure and capabilities of the firms in an industry, the scientific and technological infrastructure of an economy, and government policies. From this perspective IPRs are only one aspect in a country's complex set of institutional arrangements that are necessarily embedded in a historical, social, economic and political context. It follows that the implications of IPRs reform will depend on the specifics of national settings.

Therefore, this study examines the implications of the TRIPS Agreement for Egypt's pharmaceutical industry and public health sector using a national system of innovation approach. The case of Egypt is interesting because it provides fertile ground for such an assessment from a developing country perspective. It also provides an example of the impact that domestic and global political forces are having on the formulation of economic and technology policies in developing countries. 
The study centres on four main points.

1. There is no robust method of determining the appropriate balance between innovation and technological diffusion, known as the core intellectual property tradeoff, without specifying numerous parameters. This inevitably complicates the exercise and leads to a situation where intellectual property policies are especially subject to political influence rather than economic calculation. Thus, the standards espoused by the TRIPS Agreement are not based on sound economic knowledge.

2. Attempts to establish positive and reliable links between strong IPRs and R\&D, foreign direct investment (FDI ${ }^{1}$, technology transfer and trade have largely failed. In fact, claims that strong IPRs would yield major benefits for developing countries are not conclusively supported by the conventional economic models upon which they are based, or by the available evidence. Such claims are often qualified by references to other significant national factors.

3. In order to adequately understand the implications of stronger patent protection for the pharmaceutical industries of developing countries we must consider relevant aspects of each country's national system of innovation. A weak NSI means that stronger pharmaceutical patents will likely have adverse implications in both the short and long terms for a country.

4. Finally, the implications of stronger pharmaceutical patent protection for developing countries cannot be analyzed from an economic perspective alone. The intimate

\footnotetext{
${ }^{1}$ FDI is defined as the "act of establishing or acquiring a foreign subsidiary over which the investing firm
} 
relationship of this industry to public health also warrants consideration. It is feared that stronger patent protection may threaten drug accessibility (supply and affordability), which can lead to serious, even tragic, social consequences.

\section{THE CASE OF EGYPT}

Historically, Egypt's lax pharmaceutical patent policy did promote the development of a domestic industry. Law 132 of 1949 limited the protection of pharmaceutical processes to a period of ten years from the date of filing and only protected a product if it used the particular production process described in the patent application. As a result local manufacturers were often able to evade such patents by introducing minor molecular manipulations that qualified as new production processes, thereby expanding local manufacturing capabilities and increasing competition with foreign firms. In addition domestic producers could benefit from strict price controls and from a foreign trade policy that limited the number of pharmaceutical substitutes that could be sold on the Egyptian market at any one time. Such policies were not in violation of the rules of the General Agreement on Tariffs and Trade (GATT) since it allowed for infant industry exceptions, protection for industrial development purposes, and quantitative restrictions for the maintenance of balance of payments equilibrium (Hudec 1987; 27). In general, Egypt's pharmaceutical policy sought to develop a domestic industry and to foster its technological capabilities in order to provide affordable 
medicines for most of the country's poor citizens. A strong domestic pharmaceutical industry that was locally controlled was deemed most conducive to this end since reliance on foreign investments or imported drugs would be too costly, and in some cases, too unreliable.

The relatively unrestricted international availability of technology up until the mid-1980s for the development of indigenous R\&D and manufacturing capabilities in the pharmaceutical industry, coupled with a significant number of science graduates produced by President Nasser's education policy, facilitated the growth of a domestic industry initially dominated by the public sector. Later, President Sadat's market opening policies of the late 1970 s would pave the way for increased private investments. This had the effect of rapidly expanding local pharmaceutical production, which continued to benefit from the imposition of import controls on drugs with similar therapeutic composition.

Aside from these economic and technological aspects, this earlier pharmaceutical patent policy reflected the political and social conditions of the time. A strong historical legacy that extolled the virtues of socialist self-reliance put a premium on objectives such as national self-sufficiency in drug production. These goals were not only supported by state officials and by local investors, but also by society at large, since it appeared to benefit from the provision of cheap local substitutes for expensive foreign drugs. Surprisingly, opposition from foreign investors had remained relatively limited until the mid-1980s, largely because such policies were common in many other countries, and 
because patent owners actually enjoyed a form of tacit protection since the Minister of Health had generally taken a very pragmatic line, often delaying the approval of locally manufactured drugs based on the manipulation of foreign-owned patents, for considerable periods of time.

More important, however, was that Egypt's lax patent law, like that of other developing countries, was supported by the balance of prevailing global political forces. However, by the mid-1980s, the global pharmaceutical industry, together with other IPRsensitive industries, had begun accusing the developing countries of 'unfair' practices resulting in an alleged loss of billions of dollars in their 'rightful' profits. Their intensive lobbying gradually led the industrial countries, led by the United States, to demand that developing countries should reform their IPR regimes. Moreover, it was within this context that foreign investors in Egypt began to demand such changes, but vehement opposition from local manufacturers led to an intense struggle at the national level.

In effect, Egypt was getting caught in an international shift of political forces and interests, without which it would be impossible to understand why a battle over pharmaceutical IPRs developed in this particular country with its very small domestic industry and even smaller productive capacity. Of the entire global pharmaceutical market in the mid 1990s approximately 30 percent of sales were by US firms, 30 percent by EU firms, 21 percent by Japanese firms and the remaining 19 percent by the firms of all developing countries combined, with Egyptian firms accounting for a mere 0.3 percent (Al Ansari 1999; 13). Indeed, the Egyptian market as a whole spends less on 
pharmaceuticals in one year than the US does in four days (Pearl 1996; 1). In addition, the majority of pharmaceuticals that were being copied in Egypt were relatively older drugs whose patents had already expired even in places like the US and Europe with their stronger IPRs (Pearl 1996; 1). In fact, according to Subramanian and Abdel Latif, writing in 1997 , it could be said that the share of patent infringing activity - or of production based on 'illegal' imitation - had always been low and was then estimated at 4 percent of total sales $(1997 ; 10)$.

While it is clear that the recent shift in IPRs policy has resulted from global developments, the implications of these changes for Egypt's industry and consumers can only be assessed by analyzing the situation from a national perspective. Such an analysis must begin with recognition of the fact that Egypt's earlier pharmaceutical policy had produced some impressive results. While local manufacturers had supplied only 29 percent of the total quantity of drugs produced in Egypt in 1962, that share had gradually increased to over 65 percent of the market by 2000 as local manufacturers had gained experience over time. As a result, locally owned firms had come to provide consumers with affordable medicines as they had increased competition with the MNEs operating in Egypt. Moreover, as local companies do not operate under the sorts of restrictions usually imposed on foreign-owned subsidiaries by their parent companies, they had been the driving forces behind the growth of exports from this sector.

Despite these successes in terms of growth and market share, Egypt's pharmaceutical industry had failed to develop a capacity to innovate that could have 
assured its continued growth and evolution. In large part this was due to the small size of the industry and the high and rising cost of R\&D. The policy of self-sufficiency had compounded these problems by giving priority to increased production, while neglecting drug quality, and implementing pricing policies that were designed to make drugs affordable but that took inadequate account of commercial realities. This constrained the industry's ability to modernize and to invest in R\&D. Moreover, the same subsidies that protected the local industry and that allowed drug prices to be kept low, also served to eliminate much needed competition that may have diminished duplicative drug provision within the industry.

After more than forty years of development Egypt's pharmaceutical industry has therefore remained primarily one of formulation - or of assembly - largely because it has not developed the $R \& D$ capabilities required to manufacture the main active ingredients for more independent local drug production. But also because, foreign investors have not honoured their commitments to eventually begin producing some of these basic ingredients in Egypt. As a result, the industry continues to import over 85 percent of its raw materials, which leaves domestic producers in a very vulnerable position vis-à-vis foreign supply sources.

Moreover, Egypt's science and technology (S\&T) policies have not promoted appropriate linkages and relationships between national $R \& D$ institutes and the pharmaceutical industry. The results are an under-utilization of the country's scientific capacity and increasing reliance on foreign technology suppliers. In short, Egypt has 
neglected a fundamental requirement of technological progress - the creation of a strong NSI - which means that the industry's future capacity for growth was limited and that it remains extremely vulnerable to any adverse changes in the terms on which technology could be acquired and copied. It is this context that gives the TRIPS Agreement such special significance and that has led me to make it the central focus of this thesis.

On a more general level, the 1980s changed the economic and political conditions within which Egypt's pharmaceutical policy was made. As in so many other developing countries, by the mid-80s the two oil crises, a sharp rise in international interest rates, and the collapse of many commodity prices had left the economy with an unmanageable foreign debt and had forced it into negotiations with creditors who made continued access to credit conditional on an extensive package of market liberalizing policies. Among other things, this soon imposed severe constraints on the Egyptian government's ability to continue to support the modernization and development of its pharmaceutical sector. Faced with demands for privatization and for the removal of tariffs and subsidies, the government was forced to allow private market decisions to increasingly shape its industrial and innovation policies. This made it more and more difficult for the government to promote long-term investment for national development, or to protect the poor by ensuring continued access to affordable drugs.

In time, these developments have led to the emergence of major contradictions within the state apparatus. On one hand, the need to manage the foreign debt and the perceived need to attract more FDI have compelled the state to accept the market-driven 
policies being advocated by international creditors, led by the World Bank and IMF. On the other hand, the continued desire in some quarters to build a strong NSI suggested a need for greater (not lesser) government involvement in the economy. Moreover, the perceived need to ensure access to affordable drugs for Egyptians has led many government officials, particularly from the Ministry of Health, to oppose the elimination of subsidies, the liberalization of prices, and the removal of import restrictions on popular medicines. These dilemmas persist to date.

Meanwhile, the main condition that had made the growth of Egypt's pharmaceutical industry possible was being destroyed as weak IPR regimes in developing countries came under attack from the developed countries under pressure from their pharmaceutical lobbies. They charged that lax IPRs, in combination with improved information and communication technologies, were facilitating undue imitation and adaptation of technologies that had mostly been developed in the industrial countries. They argued that this had significantly heightened global competitive pressures in ways that would ultimately undermine much needed technological progress especially in research-and-development-intensive sectors like pharmaceuticals. In response, the developed countries now began to emphasize the need for stronger and more effective intellectual property protection. In the pharmaceuticals sector, patents are the most effective and the most widely used instruments for such protection.

This demand for stronger protection of IPRs was spearheaded by the United States which acted increasingly unilaterally targeting and punishing countries that refused 
to accede to its demand that countries trading with the US should harmonize their patent protection of pharmaceuticals with that prevailing in the US. Indeed, the US stood out in its willingness and its ability to take unilateral action in response to industry pressures, even when these violated existing international trade law. ${ }^{2}$ From the latter half of the 1980s into the 1990s the US made increasing use of its power to threaten, or to take, measures against developing countries that refused to grant more extensive patent protection to pharmaceuticals in line with US demands (Correa 1995, Nogues 1990, Primo Braga 1990). This was the context in which the developing countries gradually moderated their opposition to the proposed changes in the global rules on patent protection. In effect, they did so in order to avoid punitive, unilateral threats and sanctions from the United States in exchange for some semblance of international 'due process'. It is therefore misleading to suggest that their acceptance of these new rules implied that the developing countries believed these rules to be in their interests.

The TRIPS Agreement was eventually signed on April 15, 1994 as part of the Final Act of the Uruguay Round and it is administered by the World Trade Organization (WTO). In essence, the Agreement requires national treatment and most favoured nation treatment (MFN) to be extended to the nationals of other member states. ${ }^{3}$ It also

\footnotetext{
2 Prior to the creation of the WTO-TRIPS Agreement the GATT did not permit signatory states to use trade retaliation to protest against inadequate IPR systems of other signatory states. Moreover, even after the promulgation of the TRIPS in 1995 the developing countries still had until 2005 to implement the Agreement without external pressures or risking conflict with other trading partners who desired stronger IPR protection.

${ }^{3}$ National treatment means that each member will accord the nationals of other members treatment no less favourable than that it accords to its own nationals with regard to intellectual property protection. MFN
} 
demands the harmonization of the intellectual property policies of all member states, bringing them largely into line with US practice. Thus in pharmaceuticals, the TRIPS Agreement demands the granting of product and process patent protection for a term of not less than twenty years from the date of filing. These rights must be granted irrespective of the place of invention, or of whether the patent owner chooses to service the market in question through local production or through imports. The TRIPS also restricts the use of compulsory licensing, ${ }^{4}$ which has long been used by many member states to promote the domestic manufacture of pharmaceuticals. All countries were to implement the provisions of the TRIPS within one year, but developing countries were given five years to achieve full compliance, in light of their more vulnerable economic and social circumstances. In addition, they were granted another five years to extend full patent protection to all industrial sectors that had previously not been subject to patent protection under domestic law. In short, full compliance was required within ten years, or by 2005 .

In order to ensure compliance, the WTO established a dispute settlement mechanism to deal with any international conflicts over IPRs. All disputes that cannot be satisfactorily resolved at the national level can be referred to an integrated Dispute

means that if a member extends any special or preferential treatment regarding IPRs to another member then that same treatment will have to be accorded to all other members without discrimination.

4 A compulsory license entails the use of the subject matter of a patent without the authorization of the right holder. A national administrative or judicial authority usually grants this allowance. The right-holder normally receives $4-6 \%$ of sales in royalties when a compulsory license is granted to a third party. More will be said about compulsory licensing later in the study. 
Settlement Understanding (DSU) that is administered by the WTO. If a violation is established under this system, the 'wronged' country is given the right to retaliate against the offending country in any area covered by the WTO Agreement, not just in the sector where the violation occurred. This leaves developing countries in a position where noncompliance can become extremely difficult and costly, while their ability to threaten large industrial country offenders remains very limited.

Opinion over the economic implications of the TRIPS Agreement has been highly polarized. The developed countries have consistently claimed that a globally harmonized IPRs regime offers an impressive array of global benefits, including increased R\&D, FDI, trade flows and technology transfers to the developing countries. But the proponents of a globally harmonized IPRs regime were also careful to remind developing countries that they would be well advised to accept this new regime since these promised benefits were reinforced by the threat that any country which failed to comply would be increasingly isolated from access to global markets, and few countries could afford to allow themselves to be so isolated. At the same time, the developing countries argued for a more flexible global IPRs regime, one that would give countries substantial freedom to determine the appropriate design of national IPRs policy to reflect their national goals, circumstances, and priorities. Their greatest concern was the fear that their pharmaceutical industries and their public health systems could not respond constructively to the drastic patent reforms that were being proposed. However, the ability of the developed countries to neutralize these developing country demands was 
bolstered by their enormous advantage in information and power and by their ability to take advantage of the interplay of complex domestic interests in the developing countries themselves.

At the end of the day it is true that Egypt, like most other developing countries, acceded willingly to the WTO Agreement and is therefore committed to its implementation. Indeed many Egyptian policy-makers see the discipline imposed by the WTO as an integral and inevitable aspect of the state's current economic policy regime focusing on full integration into the global economy. But the state's bureaucrats do not unanimously share this view and it is definitely not shared by the local pharmaceutical industry. Moreover, there is widespread agreement that the TRIPS will be associated with serious costs in the short run because of the challenges that it poses for local industry and for public health. The government has therefore decided to take full advantage of the transition period that is provided for within the TRIPS. But without a national strategy of how to deal with these challenges and of how to use the transition period to maximize the benefit-cost ratio for Egypt, this transition will probably only serve to postpone the inevitable.

\section{METHODOLOGY}

This research was designed as an exploratory case study to gain greater insight into the likely implications of stronger patent protection for the pharmaceutical industries of developing countries in general, and of Egypt, in particular. The two major objectives 
of the analysis are: (1) to examine the likely impact of the TRIPS on national innovation and development and, more particularly, to study the response of local and foreign firms to this radical change in patent policy; and (2) to explore the likely implications of this policy shift on the public health system of Egypt, and of developing countries more generally. While it is acknowledged that the use of the case study method poses methodological problems with regard to extending the findings of the analysis to other developing countries, the method is crucial for understanding the complex dynamics that determine the impact of investment in the pharmaceutical sector, on innovation, on drug availability and on public health.

In this study I demonstrate why conventional economic theory, particularly that concerning IPRs, which has framed much of the debate about the TRIPS Agreement, is very limited in its capacity to better our understanding of the longer term implications of this policy shift for developing countries. To supplement its insights, I suggest that we must consider aspects of an institutional economics approach by drawing on national systems of innovation theory. As noted above, this theory treats IPRs as one component in a complex web of institutional arrangements and, as such, it allows us to examine the process of innovation and change more deeply than the more stylized approaches of conventional economic theory. For instance, rather than dealing with innovation and diffusion as relatively separate processes, NSI theory treats innovation as a gradual, cumulative and potentially self-perpetuating process, which necessarily encompasses diffusion as one of its elements. This understanding is particularly important in a 
development context because it forces us to question the logic of the core intellectual property tradeoff.

The study relies on both primary and secondary data, including a wealth of largely qualitative information gathered in four months of field research (December 1998January 5, 1999, July 5, 1999 - October 5, 1999 and January 15, 2000 - February 10, 2000 ) in Cairo. Data was gathered from interviews and from various official and unofficial sources. In all 54 interviews were held, including some eight follow-up interviews in November 2001. These systematically covered all of the parties directly involved in the patent debate in Egypt (the stakeholders) and especially those knowledgeable about the pharmaceutical sector. Interviews employed both structured and unstructured methods depending on the request of the interviewees, interview time constraints and the nature of the data being collected.

The interviews can be categorized as follows: Academia and Research Institutes; the American Chamber of Commerce; the US Embassy; USAID (Nathan Associates Inc. - consulting firm); Government Ministries; Local Industry; and Foreign Industry. Where it was deemed impossible because of the researcher's finite time to interview all of the individuals identified in a particular category, the most important personalities were selected based on the press and the opinion of other interviewees.

The interviews were all recorded by hand apart from one exception, which was taped on a cassette recorder (and later returned to the interviewee). Most of the interviewees did not feel comfortable in the presence of a tape recorder and some 
preferred to be interviewed off the work premises. While the majority of interviewees wished to remain anonymous, many of them agreed to be listed in the study's list of interviewees. Direct quotes have been used in the study only with the interviewee's express permission. Some quotes have been used without identification of the interviewee but still with their permission.

Apart from the interviews, information was gathered from a wide range of sources, including a variety of official, and including confidential, documents. These were used in addition to the secondary literature drawn from the extensive literature on IPRs, Egypt and developing countries. Although the study draws heavily on these secondary sources, much of the material concerning Egypt is original and the argument relies extensively on corroboration through interviews and original documents. The tables included in chapter six were provided by Dr. Galal Ghorab, Chairman of the Pharmaceutical Holding Company, by permission from Mr. Tarek Mohamed Ali Hassan who had compiled them for his master's thesis. ${ }^{5}$ The researcher was also the leading intellectual property policy analyst for the Canadian International Development Agency in the run up to the Fourth WTO Ministerial in Doha, Qatar (November 2001) and so relies extensively on this experience, particularly in chapter seven. During the course of the study the researcher has had to translate numerous government documents, newspaper articles, conference submissions, meeting minutes, and academic papers from Arabic to English.

\footnotetext{
${ }^{5}$ The researcher, however, included figures beyond 1997 when such information was available. Please see
} 


\section{ORGANIZATION OF THE STUDY}

Chapter two forms the background of this study and is concerned with the establishment of universal IPR standards, or the policy process through which the TRIPS Agreement was created. It discusses the role of MNEs, industrial country governments, in particular that of the US, and the World Bank and IMF in effectively transforming the global IPRs regime along lines largely defined by the United States. The chapter also discusses the arguments presented by the developing countries in opposition to these proposed changes and their eventual acquiescence to industrial country demands. With the Egyptian experience as our focus, we see how international and domestic political forces constrained the choices of the Egyptian Government during and after the Uruguay Round. The chapter illustrates how the pervasiveness of power and information asymmetries throughout the reform process had a definitive impact on the final outcome of the trade negotiations.

Chapter three explores whether there is an economic basis for the standards espoused in the TRIPS Agreement. This chapter is primarily concerned with conventional intellectual property theory, as this is the fundamental theory underlying the globalization of IPRs. To this end, I examine the core intellectual property tradeoff and the attempts that have been made by various scholars to determine optimal patent strength. The chapter also examines studies that have sought to establish links between strong IPRs and 
R\&D, FDI, trade and technology transfer. This discussion is instrumental for assessing the claims of the proponents of a stronger and globally harmonized IPRs regime. The chapter demonstrates that the substance of the TRIPS Agreement was not based on sound economic theory, particularly when considered from a developing country perspective, since these countries often face different opportunities and constraints when seeking to develop or acquire new technologies.

Chapter four outlines the way in which a national system of innovation approach could be used to assess the implications of stronger intellectual property protection for the pharmaceutical sectors of developing countries. It emphasizes the importance of understanding the specific characteristics of the innovation process within a development context and shows that these have far-reaching consequences for the plausibility of the core intellectual property tradeoff. The chapter argues that it is the strength of key pharmaceutical/health aspects of a country's national system of innovation that will determine the extent of innovative activities and hence the ability of the country's pharmaceutical firms to take advantage of the new IPR standards. National systems of innovation include three key elements: the structure and capabilities of domestic firms (in this case pharmaceutical firms), the scientific and technological infrastructure of the country, and the existence of suitable and coherent government policies. The chapter demonstrates that the innovative behavior of a country's pharmaceutical firms is affected by a whole host of factors and that the definition of a country's optimal IPRs regime ought to take such factors into account. 
Chapter five is the first of two chapters examining the case of Egypt. It focuses on key aspects of the historical evolution of Egypt's pharmaceutical industry. The aim of the discussion is to demonstrate (i) that a relatively weak pharmaceutical patent policy was instrumental in fostering the emergence of a vigorous domestic industry; (ii) that the industry that did emerge achieved this approximate self-sufficiency in ways that were desirable from a public health point of view; and (iii) that the industry had limited innovative capacities, which is not surprising given the economic strategy of the government beginning in the mid 1970s. These historical realities have conditioned domestic response to a strengthened patent regime today.

Chapter six is concerned with how the contemporary pharmaceutical industry was affected by the country's traditional IP policy given some of the key pharmaceutical/health aspects of the national system of innovation. It examines the achievements of the industry and the challenges facing it, which come not only from foreign sources but also from weaknesses in the scientific and technological support structure and from the development of the pharmaceutical industry itself. The purposes of the discussion are to assess the plausibility of the claims being made by the proponents of stronger IPRs and to offer explanations as to why certain outcomes are deemed more or less likely; and to identify those aspects of Egypt's NSI that require improvement or transformation in light of these circumstances.

Chapter seven presents an analysis of the recent international events that have transpired as a result of the continuing disagreement between the developing and the 
developed countries over the impact of the TRIPS on local pharmaceutical industries and public health systems. It also considers recent changes in Egypt's patent law within this context. It is argued that although the developing countries have come a long way since the Uruguay Round negotiations when they were pressured and threatened into accepting the TRIPS Agreement, they were still largely unable to counter the proposals of the industrial countries during negotiations concerning the TRIPS Agreement and public health that led to the creation of the Doha Declaration during the Fourth WTO Ministerial Conference in November 2001. This has given rise to a problematic acceptance of the core requirements of the TRIPS Agreement by the developing countries and has obscured the necessity of more critical negotiations regarding the impact of the core TRIPS requirements on innovation and technological diffusion in the developing world.

Finally, chapter eight presents the summary and conclusions of the study. 


\section{CHAPTER TWO}

\section{ESTABLISHING THE NEW GLOBAL IPRS REGIME}

This study was born out of an interest in examining the implications of an international agreement about which there continues to be considerable disagreement. This chapter is concerned with exactly how this agreement came into existence and to this end it will examine the policy process through which it was created. This discussion is important for several reasons. First, it will help to clarify why the developing countries acceded to the TRIPS Agreement, despite their significant reservations concerning the probable economic and social outcomes for them. Second, it will provide better insight into the weight of the various competing objectives that entered into the decision to adopt the new IPRs regime. In short, it will enable us to understand more fully the new global IPRs policy and the likelihood of its effective implementation in a development context.

In order to illuminate these issues this chapter is divided into five main parts. Part one examines the main forces that gave impetus to global IPRs reform with a special focus on the role of the pharmaceutical industry. Part two explores the involvement of the United States government in supporting the demands of its industries for a globally strengthened and harmonized IPRs regime, and examines the initially strong opposition of the developing countries to such changes. Part three examines the role of the World Bank and the IMF in bolstering the US position. Part four takes a particularly close look at the role of Egypt in the international negotiations that led up to the creation of the 
TRIPS Agreement. Finally, part five gives a brief account of the events that occurred in Egypt in the aftermath of the Uruguay Round in response to foreign pressure to forego the grace period for which provision is made in the Agreement.

\section{GLOBAL REALITIES}

\section{Coping with Competition}

Intensified efforts to establish a globally harmonized IPRs regime can be attributed to changing technologies, changes in the strategies of multinational enterprises responding to increasing global competition and changes in government policies. Commencing in the 1980 s, accelerated technological advance, resulting primarily from linking new information and communication technologies with the biological sciences, meant that high technology came to play an increasingly important role in shaping global competitiveness and trade flows in the global pharmaceutical market. In order for companies to participate in the new 'life sciences' industry with its rapidly moving technological frontier they had to increase their R\&D expenditures but, of course, with no guarantee that these investments would bear fruit. With R\&D expenditure allegedly ranging anywhere between 12 percent (Merck) and 18 percent (Pfizer) of pharmaceutical sales (Barr 1999; 38), companies strategically searched for ways to enhance the earnings to be generated by these investments. Hence they, and "their" industry analysts, argued that the key for ensuring $R \& D$ investments and progress in the pharmaceuticals field lay in the provision of strong intellectual property protection. 
Moreover, while the accelerating pace of technological change meant that more rapid and more innovative changes in pharmaceutical products and processes became feasible, it also meant that domestic and international competitors could imitate new technologies more quickly and easily and with higher levels of quality control than had been traditionally possible. In fact, the consequent growth in the strength of generic companies worldwide reflected this intensified competitive pressure and was a major reason for the global industry's discontent with prevailing intellectual property rights regimes in many countries. Generic drug firms offered the patient/consumer medicinal alternatives, similar or identical to their brand name counterparts, but at much more affordable prices. The existence of relatively lax patent provisions and/or lax enforcement of these provisions, as well as the imposition of strict compulsory licensing regimes in many developing countries, facilitated this growth. Moreover, the rapid evolution and expansion of generic industries in both the developed and developing countries, was further encouraged by the expanding cost containment policies of many governments struggling with public sector deficits.

Thus, during the 1980s, many of the governments in the industrialized world promoted competition by generic drug firms in order to lower public health expenditures. In 1984, for instance, patent reform in the United States encouraged competition between generic and brand name companies by no longer requiring the imitator to duplicate many of the pioneer's clinical tests in order to gain market approval. Instead, the generics only had to demonstrate bio-equivalency, which can be done much more 
readily and at relatively low cost (Grabowski and Vernon 1986; 195). This was soon followed by the elimination of anti-substitution laws, which had prohibited pharmacists from recommending generic drugs in place of equivalent but more expensive brand names thereby making consumers more aware of more affordable drug alternatives (Grabowski and Vernon 1986; 195, Nogues 1990; 94). Meanwhile, in Canada, prior to 1993, the existence of compulsory licenses allowed generic companies to compete with their brand name counterparts even before their patents had actually expired.

As a direct result, competition from generic drug firms escalated on a global scale. These firms soon came to play a significant role in the national health care systems of many developing countries, where they often were the primary health care and competitive instruments. Of even greater concern to 'big pharma' was the fact that they were also rapidly becoming integral parts of the health care systems in the developed world where the bulk of the world's markets are found. These concerns were exacerbated because the patents of many popular brand name drugs were due to expire at the end of the 1980 s so that the market for patent expired drugs reached $\$ 10$ billion $^{6}$ (Nogues $1990 ; 95$ ) and by the year 2001 , this was expected to rise to $\$ 30$ billion worldwide (Industry Canada 1997; 12). Not surprisingly, those drug giants who were about to see US patents expire on several of their most lucrative drugs, were seriously concerned about the resulting slow downs in earning growth.

In response to these pressures multinational enterprises began to source their

\footnotetext{
${ }^{6}$ Unless otherwise indicated, all dollar figures in this study refer to US dollars.
} 
scientific and technological operations strategically all over the world while setting up alliances with their major oligopolistic rivals (Chesnais 1992; 291). This led to a flurry of merger and acquisition activity in the 1990s, which served to concentrate the industry's structure dramatically and to bolster its global political power. At the end of this process the global industry was dominated by a small number of gargantuan MNEs headquartered in the US, UK, Japan, Germany, France, Switzerland and Sweden. By this time, the top ten corporations accounted for 47 percent of the $\$ 197$ billion global pharmaceutical market (Rifkin 1998; 68) and the industry remained consistently among the most profitable, as it has been ever since the Second World War. ${ }^{7}$

It was against this background that the global pharmaceutical industry, in concert with other IPR-sensitive industries, ${ }^{8}$ initiated its intense campaign against the inadequacy of the existing global IPRs regime. Gradually the weight of the industry was such that the industrial country governments, and in particular that of the United States, were very likely to listen. In fact, according to Stalson $(1987 ; 3)$, concerted pressures for stronger IPRs had commenced in the late 1970s when "the sponsors of this effort began to gather information, to supply the U.S. government with evidence of the alarming effects that international policy was having on legitimate production and trade, and to alert their counterparts in Europe and Japan of the losses facing their domestic industries if concerted efforts were not taken to halt infringement activities." By 1986 US industry

\footnotetext{
7 Today the global pharmaceutical market is estimated to be worth $\$ 406$ billion, $20 \%$ of which is accounted for by the developing countries (CIPR 2002; 37).

${ }^{8}$ This included the software, electronics, chemicals, publishing and film industries.
} 
alone claimed that it had lost $\$ 25$ billion in sales due to infringements of their IPRs, with the bulk of this activity allegedly taking place in the developing countries (Richards 1988; 93).

Yet, despite the leverage that the big business lobby could exert in the industrial countries, it seemed clear from an early date that pressures to reform national IPRs regimes in the developing countries would probably have to be externally imposed. This was the case since in most of these countries there was insufficient internal pressure for reform due to their lower levels of technological development and conflicting economic policy goals (Haagsma 1988; 66). However, the corporate giants had difficulty coordinating their own lobbying efforts in various developing countries, which was compounded by the fact that they generally made only limited contributions to economic and technological development in most of the developing world. These factors had traditionally led the developing countries to be very cautious when trying to attract foreign investments, especially in the pharmaceuticals sector, where public health objectives had to be seriously considered alongside the usual commercial priorities.

From the outset industry leaders insisted at both national and international levels, that stronger IPRs were needed to build the confidence of investors in $R \& D$, largely by reducing the threat of early competition from imitators. In other words, they claimed that stronger IPRs were necessary as incentives for continued investments in innovation; and to "encourage foreign investment from industries that otherwise would hesitate to expose their most important ideas and inventions to theft" (Leahy 1988; 78). This position was 
especially strongly put forth by the pharmaceutical industry, which argued that existing efforts to curb 'piracy' through individual litigation were highly inadequate and that the "deterrent value of a strong patent enforcement program" would be of great benefit to the industry (Clemente 1988; 134). In fact, they claimed, "there is very little an individual company can do on its own to improve the level of intellectual property protection in countries in which it operates. But in concert with each other through trade and professional organizations or, more important, in concert with the appropriate representatives of the US government, a company can help to achieve significant improvement" (Keefauver 1988; 149). Accordingly, the introduction and inclusion of IPRs in the GATT Uruguay Round agenda must be seen as a direct result of the strong and concerted efforts of US brand name multinationals, which succeeded in getting the US government to act on their behalf.

In fact, the executives from both Pfizer and IBM who sat on the President's Committee for Trade Negotiations had expressed particularly strong interest in bringing IPRs under the purview of the GATT. To this end, they had rallied other IPR - sensitive industries, including the creative arts, electronics, software and chemicals behind an Intellectual Property Committee (IPC) ${ }^{9}$ that was established initially to lobby the United States government but eventually extended its activities to Europe and Japan. The

\footnotetext{
${ }^{9}$ The IPC was a coalition of eleven to fourteen major US companies whose mission was to ensure that the TRIPS would respond to their needs. In 1986 the original members of the IPC included Bristol Myers, CBS, General Electric, General Motors, Hewlett Packard, IBM, Du Pont, Johnson and Johnson, Merck, Monsanto, and Pfizer. Rockwell International and Time Warner, Digital Equipment Corporation, FMC and Procter and Gamble joined in 1994 at which time CBS, Du Pont, and General Motors had ceased their
} 
proponents of stronger IPRs contended that weak and non-uniform IPRs regimes worldwide were a major source of trade distortion and, as such, should be dealt with by the GATT. Not only did industry leaders seek the imposition of higher IPR standards on developing countries but they also sought to obtain their commitment to enforce these standards at the national level. To encourage this, they sought the establishment of a dispute settlement mechanism that would legitimize cross-retaliation in cases of nonconformance. According to Sell $(1998 ; 137)$, "the three groups [delegations from the US, Europe and Japan] then worked together to produce a consensual document, rooted in industrialized countries' laws, on fundamental principles for a multinational approach to intellectual property protection."

\section{US Involvement and Developing Country Opposition}

By 1983 the United States was facing an erosion of its competitive advantage in high value added goods while experiencing massive trade deficits. Under these circumstances some critics of the liberal trading system emerged claiming that the GATT was becoming less and less consistent with US business interests. Since US exports had become increasingly characterized by high technology industries, they soon came to see themselves as the victims of a very lax global IPRs regime whose "failures" were becoming more apparent as countries around the world liberalized their markets. The persistent MNE lobby was therefore able to convince the US Congress "...that inadequate 
intellectual property protection in foreign markets [was] a real and tangible barrier to the growth of trade in copyrighted materials and patented inventions" (Leahy 1988; 78). ${ }^{10}$

In response to this, but also in order to stem possible rejection of its basic proGATT policy, the Reagan Administration sought to broaden Congressional support by increasing the scope of the GATT in ways that would promote additional US economic interests abroad. Thus, in January of 1985, the US President's Commission on Industrial Competitiveness had suggested that the "strengthening of intellectual property rights at home and abroad should be a priority item on the nation's policy agenda" (Benko 1987; 1) and this had led President Reagan to emphasize the importance of linking IPRs to trade. According to Hudec $(1991 ; 109)$, "in exchange for being able to use GATT trade retaliation to open and protect their foreign markets, the export industries benefiting from

\footnotetext{
${ }^{10}$ The process through which IPRs were incorporated in the Uruguay Round is very effectively theorized in hegemonic game theory in particular in the works of Alt et al (1986) and Keohane (1984). According to this theory the process of bringing IPRs to the Uruguay Round reflected the relative strength of states, the objectives of the leading country, and the various transaction and information costs that characterized the entire process. Using this theory it can be argued that because sufficient and clear cut gains were not perceived by the developing countries regarding the extension of patent rights to pharmaceutical products coercion was a pervasive factor in the final agreement. For this to occur, a hegemon, defined as a state powerful enough and willing to coerce weaker states, must exist to define the constraints that the nonconforming countries will face in the absence of cooperation. I believe the threat of sanctions by the United States was effective in persuading the developing countries to accept the new IPRs regime. Although the United States could have continued to sanction countries unilaterally, bringing the issue to the GATT or within a multilateral framework gave legitimacy to its demands. Thus, shared interests were forcibly created and collective action remained a rational option for the developing countries since the WTO was set up in such a way that countries could not refuse to implement any of its attendant agreements without being excluded from the entire trade regime. In other words, the WTO was an all inclusive deal comprised of approximately 60 agreements. Thus, it is believed that developing countries acted rationally given several factors: First, the linkage of IPRs with trade altered the value of state calculations. Second, the presence of implicit or explicit threats to comply impacted government calculations as well. Third, negotiating IPRs within the forum of the GATT played a role in altering the incentives faced by the developing countries. Fourth, the existence of networks of regimes impacted the choices they eventually made since abandoning the WTO or any part of it would have affected their standing with the World Bank and IMF that largely advocate the WTOLs policies. Finally, many developing countries wanted to maintain
} 
these new obligations could be expected to join the coalition in support of GATT." It was a judicious calculation.

The resulting criticism of the prevailing IPRs regime was focused on the Paris Convention and the Universal Copyright Convention, which would have to be strengthened to meet new more rigorous standards. According to this lobby, the minimum standards of the Paris Convention (patents and trademarks), the Berne Convention (copyrights), the Rome Convention (Neighbouring rights) and the Washington Treaty (integrated circuits) would all have to be raised. Moreover, acceptance of all of these changes was to be made mandatory for joining the new trade regime. In May 1986, the economic summit of the Group of 7 industrialized countries endorsed these proposals in Tokyo although this meeting did not necessarily support all of the substantive changes being proposed by the US. Moreover, concern regarding the appropriateness of having the GATT deal with matters of intellectual property, which had traditionally been the domain of the World Intellectual Property Organization (WIPO), began to emerge from both the developed and developing countries.

Indeed, developing countries had long been opposed to linking trade talks with IPRs. For instance, opposition to the inclusion of trade in counterfeit goods in the GATT $^{11}$ talks had once led to their abandonment by the developed countries. Despite the challenge posed by their limited power and resources, the developing countries again

or establish reputations as 'level players.'

11 This had occurred during the Tokyo Round (1974-1979). 
vehemently opposed the inclusion of IPRs in the Uruguay Round on this occasion. Led by India and Brazil, they voiced their concerns about the inclusion of IPRs in the trade agenda on a number of grounds ranging from divergent ideological beliefs to conflicting economic interests (Primo Braga 1991; 174). In general, they argued that their industries were not yet ready to comply with the international IPR standards being promoted by the United States and its industrialized allies. In fact, they suggested that the efforts of developing countries to catch-up economically were heavily dependent on their ability to imitate existing technologies, as had historically been done by the industrialized countries. Nationally specific IPR regimes were therefore needed to facilitate domestic innovation through reverse engineering and imitation based on liberal and affordable access to global technologies.

In the area of patenting many developing countries had established national regimes which excluded certain products or industries altogether from such protection. Thus, in order to protect the public interest, they had excluded areas like pharmaceuticals, foodstuffs and plant varieties from patentability. In those developing countries where IPR regimes did exist, enforcement was usually lax enough to permit the implementation of divergent policy initiatives that were considered of high national priority.

The developing countries insisted that trade negotiations were not an appropriate mechanism for altering the prevailing global IPRs regime. Instead, they proposed that the current regime should be reviewed within the framework of WIPO, suggesting that it play a more prominent role in the Uruguay Round, and that it should, in all cases, remain 
the primary forum for discussing international IPRs and their administration. Indeed, the strength of their opposition on this point temporarily brought the initiation of the Round to a halt in 1985.

In response, and to demonstrate the gravity of the situation, the US Administration made its participation in the Uruguay Round of trade negotiations conditional upon inclusion of the reform of the global IPRs regime in its deliberations. Even so, the developing countries maintained their strong opposition to negotiating IPRs within the GATT but by 1986, the US's total resolve to include IPRs in the discussion was made unambiguously clear when it threatened to use its right to call a special session with or without consensus if the developing countries did not acquiesce (Hudec 1991; 181). In the meantime, the United States government's behavior had given further indication of the hard line that it proposed to adopt on this question. Thus just prior to the GATT negotiations, the United States had held bilateral discussions with over thirty countries, in which the US had tied stronger intellectual property protection as a condition to a country's eligibility for the Generalized System of Preferences (GSP) benefits (Gadbaw and Richards 1988; 7). By the time the negotiations began, there was therefore little doubt that IPRs would play a large role in the trade negotiations.

The US's aggressive stance on IPRs was part of a wider strategy on trade reform, which became apparent when the US Congress enacted legislation to give the President the authority to use trade law to demand stronger intellectual property protection in foreign markets (Gadbaw and Richards 1988; 5). However, by far the most significant 
piece of legislation was the US Omnibus Trade Act of 1988 , which was clearly designed to enhance the usefulness of bilateral trade negotiations to open recalcitrant markets. The Act's amendment of Section 301 of the Trade Act of 1974 was the most important development in this regard since it legitimized US retaliation against “...unfair practices of foreign governments which can be unjustifiable, unreasonable, discriminating or which burden or restrict US commerce" (Nogues 1990; 84). Subsequently, the Office of the Trade Representative (USTR), the Department of Commerce, and the Department of State were given the lead in implementing this policy.

These actions were effectively unilateral since the use of sanctions under Section 301 , or the denial of GSP benefits under Section $502,{ }^{12}$ were being used to bring about policy change in the targeted country without multilateral consultation or approval (Haagsma 1988; 67). Moreover, "given that the GATT did not allow governments to use trade retaliation to attack inadequate intellectual property regimes, all the retaliation called for by the Special 301 appeared to be GATT illegal" (Hudec 1991; 227).

Nevertheless, the US persisted in its aggressive behavior, in part to impress big business and its trading partners with the potential benefits of greater GATT induced discipline. In fact, a comprehensive review of the effectiveness of trade sanctions imposed

\footnotetext{
12 In addition to the Section 301 cases the United States has successfully coerced countries that are GSP beneficiaries to reform their patent laws by threatening heavy penalties. For instance, in 1987 when Mexico refused to enact pharmaceutical patent protection it was denied US $\$ 500$ million in GSP benefits (Mossinghoff 1991; 76 in Sell 1998; 196). In 1989 Thailand lost its duty-free benefits under GSP arrangements at a cost of US\$165 million, when it refused to submit to the demands of the PMA for stronger protection. Also, in 1992 India lost US $\$ 80$ million in GSP benefits for similar reasons (Sell 1998; 196). All these governments had faced formidable local opposition and feared a rise in consumer prices.
} 
under Section 301 by Sykes $(1992 ; 263)$ found that they had been relatively successful in enforcing US interests abroad. This was not only so in cases where countries were overtly violating international agreements, but also where they were merely taking advantage of loopholes or ambiguities in the law, i.e., interpreting them in accordance with their national priorities, as opposed to those of the US. Moreover, the success of such sanctions was particularly evident in cases where the country was also a GSP beneficiary. Indeed, trade sanctions became so popular as a measure to open foreign markets that US industry feared that the GATT negotiations would actually undermine the level of intellectual property protection that could be sought via bilateral means (Bale $1988 ; 124)$.

Among the first successful cases in which the United States used these powers to challenge another government's weak pharmaceutical patent protection was that of South Korea in 1985. In this case, it did not take long before the South Korean government enacted product patent protection for pharmaceuticals and improved its enforcement procedures. According to Gerald Mossinghoff, President of the US-based Pharmaceutical Manufacturers Association, "the Korean case was a major step forward and set an important example of what could be accomplished using trade instruments to achieve intellectual property objectives" (in Sell 1998; 188). However, by 1989 South Korean firms were under fire again, this time because of charges brought against them by the pharmaceutical giant Bristol Myers Squibb, which led to the opening of a new Section 301 complaint laid by United States Trade Representative (Sell 1998; 190). 
In 1987 the threat of sanctions under Section 301 was actually carried out for the fist time when the Pharmaceutical Manufacturers Association (PMA) initiated a case against Brazil for "inadequate" patent protection for pharmaceuticals. When the Brazilians refused to reform their system accordingly, the US placed a 100 percent retaliatory tariff on a wide range of Brazilian exports to the US, including pharmaceuticals, paper products and consumer electronics, which totaled \$39 million (Sell 1998; 190). When patent reform was eventually introduced into the Brazilian legislature in 1991, it stipulated that stronger protection would only be afforded to drugs manufactured in Brazil but this did not satisfy the PMA, which insisted that Brazil remain on the USTR's Watch List (Sell 1998; 191). In general the threat of sanctions seems to have been enough in most cases to induce change (see Sell 1998).

Despite their reservations and in spite of domestic pressure urging opposition, the developing countries eventually concluded that, given the strength of corporate interests and their lobbying power in the US, they were likely to continue to confront endless 301 threats in the future, so that negotiating intellectual property rights in the GATT was probably the "lesser evil" (Hoekman 1994; 113). In fact, it is widely believed that the eventual willingness of many developing countries to increase the level of patent protection that they afford to pharmaceutical products is largely to be understood as a "response to trade retaliation, or the threat thereof, rather than a premeditated policy shift" (Primo Braga 1990; 47). 


\section{World Bank and IMF Support for US Pressures}

Perhaps the greatest support for US pressure to reform the global IPRs regime came from the World Bank and IMF. While it could be argued that the Bretton Woods Institutions have reflected US interests from their inception, in part because American policy goals and finance were a central driving force behind their creation, it was not until the debt crises of the early 1980s that these institutions would acquire the power and leverage to determine the direction of economic reforms in the developing countries. Now, as the developing countries became increasingly dependent on the assistance and approval of these institutions, their ability to resist US demands to strengthen their IPR regimes was seriously undermined by the fact that these institutions lent further support to these demands.

With the global recessions of 1973-1975 and 1979-1982 the developing countries had come under increasing pressures to accelerate their integration into the world capitalist system. Major external shocks, including rising real interest rates, falling commodity prices, and deteriorating terms of trade had led to endemic balance of payments difficulties, which forced these countries into an increasingly unfavourable position vis-à-vis the industrial countries. And this only got worse as the debt of the developing countries increased from $\$ 100$ billion to $\$ 800$ billion during the eighties (Frank $1989 ; 10)$ undermining their ability to honour their obligations.

The onset of a series of crises in the developing world triggered by several defaults on loan payments, led to a systemic crisis when private capital flows to the 
developing countries ended abruptly, leaving much of the third world unable to service its debts and facing huge net out flows of finance. Thus, whereas commercial bank disbursements to highly indebted countries had exceeded debt service flows back to those same banks in 1982, by 1987 debtors were repaying four dollars for every new dollar that they borrowed (Toft 1990; 39). This situation forced the developing countries to rely heavily on the assistance of the World Bank and IMF even though this assistance would come at a hefty price in terms of their policy autonomy. 
Moreover, these developments occurred just at the time when the major industrial countries, and especially the US, the UK and Germany, elected new governments with similar "neoliberal" policy agendas that accorded a significantly greater role to the operations of "free" markets in economic affairs nationally and internationally. The imposition of those same neoliberal polices in the developing world was justified by putting the major blame for the economic crisis that engulfed the developing countries in the early 1980s on domestic policy failures (particularly the widespread use of import substitution strategies) and not on the massive external shocks which appeared to provide a plausible explanation in view of the common timing of the economic crisis that befell this large and diverse group of countries. Indeed, there is no evidence to support the claim that the popular domestic policies of the time "should have been necessarily and systematically associated with macroeconomic disequilibrium, which is what the debt crisis represented" (Rodrik 1999; 77). Yet the conditional emergency loan programs of the World Bank and IMF (the so-called 'structural adjustment' programs) focused on the need to replace allegedly inappropriate domestic fiscal and monetary policies with neoliberal adjustment policies.

Over time, as these loan conditionalities were systematically imposed by both the Bank and Fund, the policy orientation of the recipient countries came increasingly to reflect the interests of the developed countries, in particular, the United States. In general, the World Bank and the IMF's lending activities called for standard policy prescriptions that strongly implied "an increase in the role of free markets and private 
enterprise as far as possible and a diminution in that of the State...[as well as] a close integration with the world economy" (Singh 1995; 1-2). Broadly based on the so-called 'Washington Consensus' (Williamson 1994; 26-28) these policies could be said to define the essence of the current economic world order and the domestic policy regimes that any country must adopt if it aspires to join the club of those with access to international finance.

Yet, even for those countries that might prefer to take a more gradual approach to global integration, heavy reliance on the Bank and the Fund almost guarantee that they will eventually have to accept the standard policy package irrespective of its appropriateness for national development goals. Indeed, "the ubiquitous role of the World Bank and IMF make it harder for governments dependent on these institutions to embark on economic strategies that depart from orthodoxy" (Rodrik 1999; 8). In this way, the reforms had the effect of setting many developing countries on the path to market liberalization and paved the way for their eventual support of, and membership in, the World Trade Organization.

For the developing world the Uruguay Round represented a further deepening of the market liberalizing policies that they had already begun to adopt at the behest of the World Bank and the IMF. New ground was broken with the inclusion of services and IPRs, as well as the more traditional sectors of agriculture, textiles and clothing in the negotiations, to create the new rules of the GATT. Ultimately it appears that the latter two traditional areas were included in the discussions in order to overcome the opposition 
of the developing countries to the inclusion of IPRs and services in the Round. Unfortunately, this 'low-tech' for 'high-tech' trade-off will probably impede future efforts of developing countries to catch-up economically and technologically to the industrial world.

The 1988 Ministerial Mid-term Review of the Uruguay Round in which the developing countries first agreed to expand the scope of the discussions must therefore be interpreted from this perspective. The agreement among ministers on what the TRIPS negotiations could and should include was not based on some newly found consensus as to its benefits, but rather reflected the circumstantial coercion of the developing countries to accept these demands. In other words, under these circumstances the members agreed in this review to discuss the applicability of GATT principles and of relevant IPRs conventions; the adequacy of standards concerning the availability, scope and use of trade-related IPRs; the most appropriate means of enforcement; dispute settlement between member states; and an interim agreement to encourage maximum participation of the developing world (Namfua and Yusuf 1991; 4).

However, the participation of the developing countries was marred by the frequent inability of their delegations to deal with the complexity of IPR issues or with the number of issues that were tabled during this Round more generally. Indeed, for most of the developing countries the Uruguay Round was a completely new experience. Although they had been a part of the GATT 'system' for some time, their marginal role in the negotiating procedures during the previous rounds meant that they were largely 
unprepared for the expanded role they would be asked to undertake during this latest phase of the Uruguay Round. The fact is that for most of the post war period these countries had been accorded rights of membership but with few reciprocal obligations demanded of them. They therefore had little historical experience on which they could rely during the negotiations that were triggered by these developments. ${ }^{13}$

\section{EGYPT DURING THE URUGUAY ROUND}

Egypt has been an active participant in the GATT negotiations since the early 1960s. Yet it was not until the Uruguay Round that such participation became premised on achieving certain trade and economic policy, as opposed to political policy, objectives. $^{14}$ Therefore, the Round was a totally new experience for Egypt's policy makers and foreign affairs specialists most of whom had very little knowledge of how such negotiations actually proceeded. Nevertheless, many of them believed that Egypt's active participation in this process and its eventual accession to the WTO would result in net benefits for the country. These benefits would largely result from subjecting the traditional areas of textiles and agriculture to GATT discipline, which Egyptian policy makers felt would serve as a counter balance to the simultaneous inclusion of IPRs and services.

\footnotetext{
13 See Hudec (1987) for a comprehensive review of the history of developing countries in the GATT system.

${ }^{14}$ A foreign affairs specialist noted that up until the 1980s, Egypt's interest in the GATT negotiations was largely in response to Israeli participation rather than as a means to achieve certain economic policy
} 
Egypt's delegation at the negotiations was comprised of officials from both the Ministry of Foreign Affairs and the Ministry of Economy. These officials were not technically qualified to handle many of the issues tabled during the Round, and they expressed surprise at the volume, complexity and scope of those issues and complained that there was very little time to prepare serious counter proposals. Moreover, their ability to call other national experts for assistance was constrained by several factors including certain systemic rigidities; ${ }^{15}$ difficulties in identifying the experts that were required; and financial constraints in bringing such experts to Geneva. Finally, internal divisions within the delegation between the two ministries on how to tackle some of the issues at hand made a daunting task even more difficult.

The apparent lack of coordination among the state's ministries also caused much confusion during the Uruguay Round. These were differences, not only between the two ministries that comprised the delegation, but also between other ministries that had a stake in the issues under discussion. The truth was that despite Egypt's initial rejection of the TRIPS, some internal interests were in support of it. These included, among others, Egyptian publishers, filmmakers, software developers and agricultural interests, all of whom argued that Egypt had a comparative advantage in these areas and that lax IPRs, especially in the Arab world, had cost them billions. They therefore insisted that Egypt

\footnotetext{
objectives.

${ }^{15}$ In Egypt the Ministry of Foreign Affairs monopolizes all international negotiations. The rules that govern who can participate in international negotiations on behalf of Egypt and how incumbents can do so are very strict. This systemic rigidity or inflexibility made it impossible for experts from civil society or industry to participate in the process directly.
} 
should support the proposed reform of the international IPRs regime. But their position was strongly countered by the Ministry of Health on the grounds that any such reform would have a significant impact on drug accessibility in Egypt and that, in turn, would adversely affect the majority of Egypt's poor and strain the country's limited health care resources. The internal struggle that emerged, therefore, reflected a wide range of different interests, and it was further compounded by the complexity of the Agreement and by the short time by which it would have to be implemented.

In addition, the national committee that was established by Cabinet to consider the various issues emerging in the course of the Uruguay Round negotiations was largely ineffective. According to one foreign affairs specialist, the people who were delegated to this committee by various interest groups were often incapable of providing the negotiators with timely and effective information. For instance, those representing the banking sector showed little enthusiasm for the issues at stake by remaining largely “"inward looking”. Other industries put forward representatives who had little knowledge of the negotiating process and hence the type of information they would have to provide if their views were to be given any weight.

In the end many believe that Egypt's negotiations were a "one man show", with some weak supporting actors. Although various domestic interests had submitted opinion papers to the Ambassador in charge of the negotiations, it appears that because of the weaknesses of these submissions and a lack of accountability to his domestic constituents, the Ambassador paid little attention to these. In fact, the concessions that 
were made during these negotiations were essentially made by the Ambassador, who then justified them to the government on the basis of studies done by the negotiating team, which relied heavily on discussions with other developing country delegations and the resources of UNCTAD. Indeed, the Egyptian delegation often found itself turning to foreign information sources such as the United States Agency for International Development (USAID), even when it knew full well that it did not necessarily share Egypt's interests.

In line with the general developing country stance, Egypt initially opposed the inclusion of IPRs in the Uruguay Round and then, once the issue was on the agenda, it was an active participant in seeking amendments to the industrialized country proposals regarding IPRs. However, when President Reagan made a personal appeal to the heads of state of recalcitrant developing countries, urging them to back down and to comply, the Egyptian government decided that it did not want to be among the opposition's front runners and therefore softened its stand. Of course they were further encouraged in this by sustained pressure from the multilateral financial institutions and from the US government which implicitly and explicitly suggested that continued strong opposition could call into question future US aid flows to Egypt which amounted to US\$815million per annum, military support and freedom from Section 301 threats. The carrot that was added to the stick took the form of a promise to push companies to invest in Egypt, but policy makers largely thought of this as inconsequential. As one government official put it "you can only give red lights to businesses thereby stopping investments; green lights 
mean very little."

With its arm twisted, the Egyptian government chose to play a limited role in the negotiations as a whole and allowed India and Brazil to take the lead and heat in matters of disagreement especially with the United States. In the final analysis, policy makers believed that membership in the WTO and acceptance of its attendant agreements, was necessary for the country's transformation into a fully-fledged outward-oriented market economy, driven by the private sector. It was a necessary step in Egypt's attempt to integrate with the global economy and to become an equal or 'level' player. At the same time, and maybe even more importantly, it was also seen as a necessary step if Egypt was to avert the threat of US economic sanctions for non-compliance.

\section{IN THE AFTERMATH OF THE ROUND}

Egypt signed the WTO Agreement on April 15, 1994 although it was not until April 16, 1995 that the People's Assembly (lower House of Parliament) ratified the TRIPS. ${ }^{16}$ As in other developing countries, Egypt's domestic pharmaceutical industry has been greatly troubled by the changes introduced by the TRIPS. Although its pharmaceutical industry is not nearly as significant as that of India or Brazil since it remains primarily one of formulation and exports very little, it is an important actor

\footnotetext{
${ }^{16}$ It is important to note that the TRIPS only provides guidelines for the formulation of domestic law, it does not replace it. Thus, ratification of the TRIPS is only the first step in the domestic reform process, after which there is the formulation of the new draft IPRs law, approval by Cabinet, debate and ratification by the People's Assembly, publication in the Official Gazette, and finally executive or presidential assent. This process was completed in May 2002, during the final stages of this study.
} 
because national manufacturers satisfy over two-thirds of Egypt's drug consumption needs. Manufacturers explain their relative success in this regard by pointing to Egypt's lax patent law (Law 132 of 1949), which only allowed for pharmaceutical process patents for ten years from the date of filing. This form of protection allowed manufactures to work 'around' patents by making minor molecular manipulations that potentially qualified as new processes.

This policy of limited patent protection allowed the pharmaceutical industry to develop to the point where approximately 93 percent of the domestic market of LE 4.7 billion ${ }^{17}$ was domestically produced, with locally owned and public sector firms supplying $2 / 3$ of this 93 percent, foreign owned firms supplying $1 / 3$, and with only 7 percent being met by imports. This suggests that the domestic industry has been a formidable source of competition, often providing drugs at a fraction of the cost of foreign equivalents primarily because of their ability to import raw materials from cheap international sources - one of the many things that will be restricted once Egypt changes its patent laws to conform to the TRIPS. This has naturally caused concern among Egypt's health authorities who are responsible for ensuring drug accessibility for the majority of Egypt's people and whose ability to meet this obligation will be greatly challenged as a result.

Partly in order to assuage such fear, the TRIPS Agreement allowed developing countries a "grace period" of five years, before they had to be in full compliance. But,

\footnotetext{
${ }^{17}$ This is approximately $\$ 1.34$ billion using the prevailing exchange rate of LE 3.50 per US dollar.
} 
despite this allowance, increasing pressure was brought to bear on the Egyptian government soon after ratification of the Agreement in 1995, for immediate implementation of its provisions. This gave rise to an intense struggle mainly between foreign and local pharmaceutical firms in an effort to sway government opinion. At numerous meetings, conferences and seminars the potential implications of the TRIPS Agreement on Egypt's pharmaceutical industry and on its health sector were hotly debated with each side calling on "their" international group of experts.

Foreign pharmaceutical firms have continued to demand immediate implementation of the TRIPS, on the grounds that the provision of strong patent protection will enhance technological development. In fact, according to the Pharmaceutical Research and Manufacturers of America's (PhRMA) ${ }^{18}$ website, Egypt will benefit from increased patent protection since it is "indispensable for economic development and growth." It goes on to state that the "historical record of industrialized countries, demonstrates that intellectual property protection has been one of the most powerful instruments for economic development, export growth and the diffusion of new technologies." Several factors, however, undermine the plausibility of these broad assertions.

First, one has to wonder why the foreign firms approached the situation with such a heavy hand if the economic benefits from early implementation were so indisputable.

\footnotetext{
18 PhRMA is an American organization whose membership is comprised of approximately 100 US pharmaceutical companies that primarily engage in research activities. The organization's main role is to act as the industry's watchdog.
} 
Thus, from the very start, they had drawn heavily on the resources and support of PhRMA, the US diplomatic representatives, the US-Egypt President's Council and the Pharmaceutical and Health Committee of the American Chamber of Commerce in Cairo, which had all been mobilized to exert pressures on the government. Moreover, through official diplomatic channels, US officials had repeatedly reinforced these efforts with strategic threats, which included placing Egypt on the Special 301 List, and then later on the Priority Watch List, which threatens a country with economic retaliation including the removal of GSP benefits, if they do not agree to deal with the complaint against them.

Second, the industry was unable to create a concerted lobby in order to offer significant commitments in the form of R\&D or other investments in exchange for early implementation of the TRIPS. Unlike in Brazil where it is estimated that early implementation attracted promises of $\$ 1.2$ billion in pharmaceutical investments (Pearl 1996 ; 12) the industry was unwilling to make similar commitments in Egypt. This inability greatly weakened the position of the foreign firms in relation to that of the local firms where the opposition was fierce and unified. As the prospects of increased investments in R\&D seemed less and less likely, only a couple of MNEs, Pfizer and Glaxo Wellcome, continued to put overt pressure on the government while the other MNEs chose a less confrontational stand. These factors combined to adversely affect the credibility of the foreign industry's arguments.

In contrast, the local firms mounted a relatively unified and well-planned campaign. Their two most outstanding tactics were: (1) to identify themselves as agents 
of the state and hence as being interested in social equity and justice; and (2) to use a lot of nationalist rhetoric to defame the leaders of the foreign firms. Both the Federation of Egyptian Industries and the Union of Pharmaceutical Industries organized conferences and seminars, which brought international experts from India, Argentina and Canada to warn against the dangers inherent in stronger patent protection for pharmaceuticals.

Throughout these debates the industry argued forcefully against the strengthening of patent protection under the TRIPS. Their strongest point of attack was the impact that they claimed that the TRIPS would have on drug prices, with some of their estimates reaching mythical proportions. They also argued that stronger patent protection would probably lead to market monopolization by foreign firms; that imports would likely rise; that the positive results from stronger patent protection were only likely to materialize in countries with higher levels of economic development; and that the strategic nature of pharmaceutical products meant that competition in this sector had to be expedited, not stifled. To convey these messages effectively, local industry leaders held closed-door sessions with the Prime Minister and with Ministers from departments with a direct stake in the TRIPS as it related to pharmaceuticals. Here they sought to convince the government of the country's need of the full grace period and these efforts were ultimately successful.

Consequently, in August of 1996, the Ministry of Scientific Research sent an official communiqué to the Prime Minister informing him of the conclusions that it had reached after several meetings with technical experts, industry leaders and representatives 
from the various ministries. The letter outlined the expected positive and negative impacts both of postponement (to the maximum period allowed) and immediate implementation. As for the expected positive impacts of postponement, the letter suggest that this would: (1) allow sufficient time for Egypt to absorb the costs of applying the Agreement; (2) protect the present low level of drug prices for a time; and (3) enable Egyptian firms to adjust constructively to the new IP regime. The negative implications of postponement included: (1) loss of foreign investment to other countries; (2) retarding the drive toward market openness; and (3) increasing the cost of a transformation that had to be undertaken. The positive implications of immediate implementation included: (1) possible attraction of FDI; (2) possible enhancement of strategic alliances and contracts with foreign technology suppliers; (3) creation of a healthy tension between local and foreign firms, thereby facilitating the transformation; and (4) for Egypt to become a regional leader on IPR issues. The expected negative effects of immediate implementation included: (1) the acceleration of adjustment pressures on all relevant national activities; and (2) having to deal prematurely with new international legal challenges.

The letter also included an attachment from the Chamber of Chemical Industries urging that the grace period should be fully utilized. The attachment stated that this would: (1) give drug companies a chance to develop further (raw material manufacturing capabilities, alliances and supplier networks); (2) enable firms to register products which would lose their protection during the grace period according to the old patent law (the 
number of these products was estimated at 300 and their price would be reduced to $1 / 10$ in the event that this was permitted); (3) allow time for the standard of living to rise so that people would be more able to afford the price increases that usually accompany stronger patent protection for drugs; and (4) enhance the possibility of coordinating the activities of drug manufacturers and research centres at the Scientific Research Academy and the schools of pharmacy and medicine. Finally, they demanded that the provisions of the Agreement not be applied to drugs registered before its signature dashing the foreign industry's hopes for 'pipeline' protection. ${ }^{19}$

In response to these arguments and concerns, the letter to the Prime Minister recommended that the government take advantage of the full five-year grace period allowed for all industries and the full ten years allowed for the pharmaceutical industry. This opinion was fully endorsed by the Ministry of Industry, the Ministry of Military Production, the Ministry of Economy and Exterior Commerce, the Union of Egyptian Industries, and the Drug Manufacturers. Indeed, Egyptian policy makers and leaders of the local pharmaceutical firms were not convinced of the potential advantages of stronger patent protection for pharmaceuticals and were aware of the difficulties that such a policy shift would have on the development of the local industry and on public health.

But the opposition did not fade away. Egypt's decision to take full advantage of

\footnotetext{
19 'Pipeline' protection is a type of retroactive protection preferred by the proponents of stronger IPRs. It basically means that 'pipeline' countries (those in the process of reforming their IPR regimes) grant patent protection to pharmaceutical products that had been patented in other WTO member states but had not yet been marketed domestically as soon as the TRIPS is given legal effect. The TRIPS, however, does not require this extension. The Agreement only applies to products created after its date of entry into force.
} 
the grace period merely led to an intensification of pressures by foreign interests. This led President Mubarak to try to put an effective end to these persistent demands and this bullying, especially by the United States, by making a public announcement that the full grace period would be taken. In this way he sent a clear signal that it was politically unacceptable for foreigners, including Americans, to overtly push the issue within Egypt since any attempt to do so would mean total disregard for the President's decree. Henceforth, US pressure would have to continue to be exercised through less visible channels, or to be exercised from abroad.

\section{CONCLUSION}

Since the 1980s the global pharmaceutical industry has been aggressively pursuing changes in the international IPRs regime. The intensification of these efforts can be attributed to changes in technology and to intensifying global competition from generic drug producers in the developed and the developing countries. Despite the fact that generic drug producers generally provide more affordable alternatives for consumers around the world, the strength of the global pharmaceutical industry when combined with that of other so-called IPR-sensitive industries, has allowed it to gain the upper hand in the international policy process. Indeed, it has allowed the industry to play an unprecedented role in the history of the GATT. ${ }^{20}$ Ultimately, however, it was the

\footnotetext{
20 According to James Enyart of Monsanto, "We (MNEs)went to Geneva where we presented (our) document to the staff of the GATT Secretariat. What I have described to you is absolutely unprecedented in GATT. Industry has identified a major problem in international trade. It crafted a solution, reduced it to
} 
willingness of the United States government to threaten, or to impose, sanctions on countries that refused to accept their demands for stronger patent protection, and the broad support of the World Bank and the IMF for such policy changes, that had a definitive impact on the creation of a stronger global IPRs regime.

Under such significant pressures, the developing countries only reluctantly accepted the negotiation of a new global IPRs regime in the Uruguay Round. Many countries, including Egypt, believed that the inclusion of the more traditional areas like agriculture and textiles would somewhat balance industrial country demands for new rules regarding IPRs and services. However, this did not alleviate major concerns over the potential adverse implications of stronger patent protection for local pharmaceutical industries and for public health. This is why the Egyptian government chose to take full advantage of the grace period allowed by the TRIPS Agreement.

The remainder of this study is dedicated to examining the implications of the TRIPS Agreement for the pharmaceutical sector and for public health in a developing country like Egypt. The next chapter assesses the economic arguments dealing with IPRs, and especially with patents, with a view to determining the extent to which this literature can further our understanding of the appropriateness and the potential impacts of the TRIPS Agreement for developing countries. commerce have played simultaneously the role of patient, the diagnostician and the prescribing physician." (quoted in Keayla 1998; 37 and in Sell 1990; 54-56). 


\section{CHAPTER THREE}

\section{IP THEORY AND THE TRIPS AGREEMENT}

In this chapter I analyze the theoretical foundation of intellectual property rights with a focus on patents. It is widely acknowledged that there exists a basic intellectual property trade-off between innovation and technological diffusion. Striking a balance between these two objectives depends on the specification of numerous parameters in any particular setting. Because of the complexity of this task different analysts often reach conflicting conclusions regarding the optimal strength of patents, i.e., the desirable extent of their duration and scope. This ambiguity means that in the real world patent policies cannot simply be derived from economic analysis but are significantly subject to the influence of competing special interests as demonstrated in the previous chapter.

From this perspective it becomes clear that the demand for pharmaceutical patents, as embedded in the TRIPS Agreement, was not primarily based on insights from economic theory. Economic studies that have sought to establish the link between stronger patent regimes and research and development, foreign direct investment, technology licensing and trade have failed to establish consistent or reliable conclusions and to provide a convincing economic justification for the new IPRs regime, particularly for the developing world. Instead, these studies have ultimately served to draw attention to the importance of the wide range of factors that collectively influence the nature of 
these four relationships.

The aim of this chapter is to identify an appropriate analytical framework for assessing the medium- and long-term economic implications of the TRIPS Agreement for the developing countries and their pharmaceutical industries. To this end, the chapter addresses the following four issues: the definition of the concept of intellectual property rights, with a special focus on patents and the relevant aspects of the TRIPS Agreement; the core intellectual property trade-off that is assumed to exist between innovation and diffusion and the problem of striking a balance between them; the extension of this tradeoff to the global level, with a focus on implications for the developing countries; and finally, the links between stronger and harmonized patent regimes and R\&D, FDI, technology licensing and trade. In all cases, special attention is paid to the relevance of these issues for the developing world.

\section{THE ECONOMICS OF INTELLECTUAL PROPERTY RIGHTS}

\section{What are Intellectual Property Rights?}

Intellectual property rights are regarded as temporary monopolies granted and regulated by the state to permit the commercial exploitation of intellectual creations. IPRs are classified in two main categories: (1) those applying to industrial property, which includes patents, trademarks and industrial designs among others; (2) and copyrights, which apply to property that is related to art, music and literature. Because pharmaceutical technologies are the primary focus of this study, we will be concentrating 
specifically on patent protection, the single most important intellectual property instrument in that sector.

A patent is a legal instrument that prevents others "from the unauthorized use, sale, or manufacture of the product or process claimed by the patentee, [patents] are intended to protect embodiments of inventive activity rather than abstract thoughts" (Lesser 1990; 6). As with other forms of intellectual property, a patent provides its owner with an exclusive monopoly over an invention for a finite duration within a given territory - or 'legal space'. Traditionally the basic design of patent law was determined at the national level but with the creation of the TRIPS Agreement the minimum standards of protection have been largely relocated to the international level.

In order for an invention to be patentable most patent regimes require that the invention exhibit three characteristics, namely: (1) novelty - the invention must be new; (2) utility - the invention must do what it is intended to do; and (3) non-obviousness - the invention must represent a non-trivial extension of the state of the art. The determination of these criteria is not detailed in the TRIPS Agreement and so remains completely within the purview of national authorities. These same authorities must also ensure that the inventor includes sufficient disclosure of the invention in the patent application so that, theoretically at least, any person skilled in the art could reproduce the invention. ${ }^{21}$ This requirement serves to enhance knowledge dissemination by making public the technical

\footnotetext{
21 It should be borne in mind, as we will see later in this study, that it takes much more than the availability of such information to reproduce an invention. Indeed, broader and deeper systemic capabilities and supports are required.
} 
features of a process or product that might otherwise be kept a secret by the inventor. This is intended to counter the inherently negative impact of patents on diffusion.

The extent of the privileges granted to a patentee depends on the strength of the patent, which is defined by its scope and duration. The scope of a patent is defined by the extent to which it provides a "protected sphere around the characteristics of the invention" (Dasgupta 1988; 7). Thus, a patent determines not only when an identical invention can be marketed, but also how similar an invention can be to the original, without infringing the latter's patent. A patent is strongest when it protects a product, since then it impedes others from finding different ways of producing, using or importing the patented product, and when it applies for a long period of time. A product patent confers monopoly rights over a product irrespective of the production technique, while a process patent merely confers monopoly rights over a particular production technique. The latter was a popular form of protection in the developing countries, because it permitted firms with limited resources to work around a patent by developing identical but cheaper products, using new processes.

Prior to the TRIPS Agreement, recourse against patent infringements could only be sought through national legal systems that provided for 'appropriate' sanctions and their enforcement. As noted earlier, however, with the arrival of the TRIPS national IPR regimes have become subject to the discipline of the WTO. Now, any disputes that cannot be satisfactorily resolved at the national level can be referred to the WTO's integrated Dispute Settlement Understanding and violations of the TRIPS Agreement can 
lead to trade sanctions in any area covered by the WTO.

\section{The TRIPS Agreement and Patents for Pharmaceuticals}

Before the WTO, intellectual property rights were not defined or managed at the international level to any significant degree. Even so, there was an international intellectual property regime, which was comprised of several treaties and conventions, that were administered by the World Intellectual Property Organization (WIPO) since 1970. But this system tended to be extremely flexible, with few substantive standards, with voluntary state membership, and with no effective dispute settlement or enforcement mechanisms, leaving countries free to adopt divergent national approaches to IPRs in general, and, to patents for pharmaceuticals in particular. Thus, some countries provided pharmaceutical product and process patents, others provided just process patents, and still others provided no protection at all. In addition, it was common to find wide discrepancies in the terms of patent protection between countries.

The TRIPS Agreement changes this situation dramatically. It requires all countries to adopt patent protection regimes that conform to the standards set in the leading industrial economies, irrespective of their appropriateness for the developing countries. Accordingly all Member States of the WTO now have to grant strong patent protection for pharmaceutical products and processes. Specifically the Agreement demands the following:

(1) Member States may not exclude any field of technology from patentability as a 
whole, and they may not discriminate as to the place of invention when the rights are granted as long as the invention meets the criteria of patentability, i.e., novelty, utility and non-obviousness (Article 27);

(2) national patent laws must provide for a minimum patent term of 20 years of protection from the date of filing (Article 33);

(3) the patentee's bundle of exclusive rights must include the right to supply the market with imports of the patented product (Article 28) which is subject to the principle of exhaustion (Article 6)

(4) compulsory licenses are permitted but only under highly restrictive conditions stipulated in the Agreement (Article 31).

As noted in the introduction, developing countries were given until 2005 to fully implement the TRIPS provisions relating to pharmaceuticals, and the least developed countries were given until 2006 , with the possibility of further extensions for the latter group. ${ }^{23}$ Countries that make use of these transition periods are obliged to set up a "mail" or "letter" box for accepting the filing of new applications for patents for pharmaceutical products during that period, and they are further bound to grant exclusive marketing rights to the applicants for a maximum period of five years or until the patent is either

22 The idea behind the exhaustion of an IP right is that once a product has been legitimately commercialized in any given market, the rights of the patent holder are exhausted since their rights have been exercised. The principle of exhaustion thus allows a Member State to then import the patented product from other countries where it has also been legitimately marketed. This is widely referred to as parallel importing. This is usually practiced to restore price competition. Article 6 has left the determination of IPRs exhaustion to national legislation, i.e., national decisions cannot be subject to dispute settlement under the Agreement. 
granted, or rejected, during the transition period (Article 70.9). These provisions will be referred to throughout the study.

\section{The Core Intellectual Property Trade-off}

This basic definition of patents tends to imply that knowledge is a standard economic good to which property rights can be clearly assigned and enforced. Yet, it is widely known that knowledge is actually a public good, which means that it is nonrivalrous and non-excludable. It is non-rivalrous because it has joint consumption properties, which means that the use of an idea by one person does not diminish its usevalue to others; it tends to be non-excludable because it is costly and difficult to prevent others from using an idea without paying for it.

Kenneth Arrow (1962; 609), who was one of the first scholars to discuss the ways in which patent protection might, or might not, be used to rectify the misallocation of resources associated with public goods like knowledge, argued that knowledge is characterized by three essential features: indivisibility, uncertainty, and inappropriability. Indivisibility here mans that the acquisition of a 'unit' of knowledge is a one-time event, after which that knowledge can be used repeatedly without incurring further costs (Dasgupta 1988; 2). Uncertainty is associated with knowledge production because it is especially difficult to estimate the required levels of investment in research and development (particularly in the early stages) or to foresee the potential outcomes or

\footnotetext{
${ }^{23}$ The Doha Declaration extends this period to 2016 for the least developed countries, see chapter seven.
} 
returns. Yet perhaps the greatest problem associated with the production of knowledge, and the one that has attracted the greatest interest, especially from mainstream economists, is its relative inappropriability. This means that, in the absence of legal protection, it is difficult or impossible to appropriate the returns generated by such investments in knowledge production.

The problem of inappropriability is exacerbated by the fact that the social and economic value of an invention often far exceeds the immediate, or direct, returns to the inventor due to the presence of positive externalities, or spillover effects. That is why the benefits of "increases in generally accessible new information" (Rosegger 1986; 129) are usually not adequately reflected in market prices, which impairs the ability of inventors to appropriate the full social value of their invention. This pervasive disincentive to investments in innovation is the main reason why market forces alone would usually lead to under investment in $\mathrm{R} \& \mathrm{D}$.

Mainstream theorists have extensively explored market failure in the production of knowledge. In the extreme case, if one assumes zero dissemination costs in a free market, once a piece of knowledge has been discovered, it would become freely available to all and the inventor would receive no compensation for the time and resources expended in making the invention in question. In theoretical terms, once a unit of knowledge exists in such a world, the market price for this unit of knowledge would tend to approach zero, preventing the innovator from appropriating any of the associated benefits. But in order for investment in "research and development to be worth 
considering, a firm must be able to sell its results, directly or indirectly, for a price. But who would be willing to pay for a commodity that once produced, becomes available to all in unlimited quantity?" (Mansfield 1988; 12).

Therefore, the challenge in attempting to provide incentives for the efficient development and production of new knowledge rests in balancing this need to provide incentives for the inventor with that of ensuring the efficient use of existing knowledge for the benefit of society. This is the basic tension or trade-off that is claimed to exist in any intellectual property system. According to UNCTAD (1997; 13): "On the one hand, static efficiency requires providing wide access to users at (probably low) marginal cost. On the other hand, dynamic efficiency calls for providing incentives to improve property or invest in new information for which the value exceeds development costs." If we accept this trade-off then the main challenge in designing appropriate patent systems lies in finding an appropriate balance between these two objectives.

\section{ATTEMPTS TO FIND A BALANCE}

Unfortunately, there is no robust method of determining such a balance as is clearly demonstrated in the literature on optimal patent duration and scope. One of the earliest systematic studies dealing with the optimal duration of patents was that of Nordhaus (1969) who treated it as a maximization problem given certain assumptions. He concluded that patents should be of finite duration and that the length of the period depended on elasticities of demand, the social discount rate, and the significance of the 
invention. While specifying these parameters is very complex and the results inevitably ambiguous, Nordhaus' most important conclusion was that a uniform patent duration across products and industries was never optimal. This conclusion has found widespread support from analysts like Stoneman $(1987 ; 106)$ who found that various detailed "observations suggest that different industries, different technologies, different market demands necessitate different optimal patent lives."

Attempts to determine the optimal scope of patents have faced similar challenges. According to Dasgupta $(1988 ; 8)$ the scope of a patent "should be defined as narrowly as is compatible with incentives on the part of the private sector to produce property." Gilbert and Shapiro $(1990 ; 111)$ concur with this finding, observing that the "optimal patent policy calls for infinitely lived patents whenever patent breadth [scope] is increasingly costly in terms of dead weight loss." In other words, longer patent lives are optimal so long as their scope is kept relatively narrow.

By pointing to the possibility of costly imitation Gallini (1992), however, suggests quite the opposite. She suggests that lengthy, narrow patents will invite competitors to invent around a patent, thereby displacing the patentee's output and thereby undermining the rewards, and incentives for research (Gallini 1992; 52). This leads to the conclusion that an optimal patent should eliminate entry completely for a time, which is best achieved by making the patent short and broad (Gallini 1992; 52).

Klemperer (1990) also concludes that the optimal scope of patents will vary across different classes of products but in his case it is because lengthy, narrow patents 
are less effective when consumers are easily able to substitute a "less-preferred" product for the protected one. In this case, the patent holder must lower prices to limit the number of consumers who would turn to other substitutes (Klemperer 1990; 115). Ultimately, determining the optimal scope of a patent must therefore come down to an empirical question depending on the feasibility of 'inventing around a product' in any particular case. Once again this implies that determination of the optimal scope of a patent will be extremely complex and inevitably ambiguous and it will differ for different products.

Finally, it is important to remember that the conclusions regarding the optimal scope and duration of patents will change if one drops the usual assumption that the existence of a patent does not affect subsequent innovations (Gallini 1992; 62, Gilbert and Shapiro 1990; 112, Klemperer 1990; 127). This assumption is indeed unrealistic, since in reality, innovation is almost always an incremental, cumulative, self-perpetuating and interactive process (Rosenberg 1976, Freeman 1987, Dosi 1988, Grossman and Helpman 1991, Lundvall et al 1992, Freeman and Soete 1997). In other words, innovation should be thought of as a process in which "resources and knowledge may be combined to produce new knowledge, some of which then spills over into the research community, and thereby facilitates the creation of still more knowledge" (Grossman and Helpman 1991; 17). Indeed, Dosi $(1988 ; 1138)$ suggests that these continuous, positive feedbacks are probably a major reason why we have not seen the emergence of a "stationary state" in the modern economy. 
This concern with the dynamic, path dependent nature of innovation has been the main focus of a body of work concerned with innovation as a process. The main significance of this work lies in the fact that it challenges the basic idea that there is a fundamental conflict between the need to accelerate the diffusion of existing knowledge and the desire to promote innovative activity through incentives. In fact, what this work suggests is that diffusion also accelerates innovation. Thus, Scotchmer and Green (1990; 132) conclude that the pace of innovation is dependent on the degree of protection granted to the original innovator, with less protection leading to more rapid innovation. In other words, since rapid disclosure of incremental technological improvements are socially desirable, they suggest that narrow patents are preferable since they permit subsequent additional innovations to be developed and patented without infringing prior patents $(1990 ; 144)$. Bessen and Maskin $(2000 ; 2)$ go further to suggest that when innovation is sequential and complementary, it follows that only limited intellectual property protection is desirable. Indeed, they argue that "imitation promotes innovation and that strong patents (long patents of broad scope) inhibit it" (Bessen and Maskin 2000; 2).

This discussion has shown that there is no robust method for determining the optimal duration or scope of patents. Conceptually, optimal patents will necessarily depend on the specification of numerous parameters in specific contexts. This undoubtedly raises serious concerns regarding the intellectual property framework, as established by the TRIPS Agreement, which demands that all countries wishing to 
participate in the global economy must now adhere to one relatively uniform set of IPRs, not only across products, but also across countries. Theoretically speaking, there is therefore no basis for the demand for uniform minimum standards of patent protection at the national and international levels.

\section{EXTENDING THE TRADEOFF TO THE GLOBAL LEVEL}

The international strengthening and harmonization of patent regimes is clearly aimed at reducing the extent of imitative activities in the developing countries, especially in pharmaceuticals, and this could have a significant negative impact on welfare in the developing countries, and on global welfare (Grossman and Helpman 1991). This follows from the single fact that the main purpose of a patent is to exclude others from the use of the protected knowledge, for a period of time, thereby making imitation - and competition - more difficult and costly. Moreover, since developing countries are major importers of technology, and since their firms and residents account for less than 5 percent of all patents (Primo Braga et al 1998; 6), changes in the international IPRs regime are going to affect these countries disproportionately. In fact, in these countries, stronger patent rights will inevitably tend to suppress industrial and innovative activities that are based on adaptation and imitation, forcing them to the sidelines not because they are inefficient, but because they are no longer allowed to compete.

In order for imitation to be commercially successful two conditions must be fulfilled: (1) the imitating producer must be able to command positive profits in 
competition with the pioneer; (2) patent laws must be lax enough to make this possible by not imposing prohibitive costs (Grossman and Helpman 1991; 281). Until recently, these conditions appear to have held in many developing countries with low manufacturing costs and lax patent laws. Grossman and Helpman $(1991 ; 281)$ contend that this situation can enhance 'global' welfare because developing countries have a comparative advantage in manufacturing and a comparative disadvantage in $R \& D$. Therefore, "the transfer of technology to these countries may cause resources to be released from the manufacturing sectors in high income countries which then find their way into industrial research labs" (Grossman and Helpman 1991; 282). This creates a win-win situation in which the shortterm benefit, from greater competition and lower prices are complemented by the longrun benefits of more rapid innovation. ${ }^{24}$

This discussion implies that patents should generally be designed to suit national priorities and capabilities, and for this they need to be limited geographically. Deardorff (1992) suggests that this should be the case even if stronger patent protection did accelerate the overall global pace of technological change. The reason is "that extending this [high level of] protection to other countries is very likely to be harmful to them, in spite of the fact that they may benefit form increased inventive activity. In those circumstances, if the world as a whole does gain from extending patent protection, it is only in the inventing countries that these gains are experienced, and in fact, they gain

\footnotetext{
${ }^{24}$ It is true that their theory has not been subjected to empirical testing, however, it does open the possibility that exclusion through the use of patents will have harmful international welfare effects not only on developing countries but developed as well.
} 
even more than the world as a whole because they gain at the rest of the world's expense" (Deardorff 1992; 36). Deardorff's model reflects the fact that patent protection leads to monopoly profits and a more concentrated market structure, so that consumer choice is distorted by higher monopolistic prices, while consumer surplus is diminished in the importing markets. Although this may lead to more innovation globally, this activity is likely to be concentrated in the industrialized countries. As such, its net impact on the developing world is likely to be negative since the costs of extending the monopoly privileges to those who own the technology are likely to exceed the benefits for the developing world (Deardorff 1992; 49).

Subramanian's (1995) models, based on pre and post patent reform market structure scenarios in several developing countries, confirm these insights. According to these models, the short-term impact of increased global patent protection on the pharmaceutical industries of developing countries is likely to be negative. Subramanian $(1995 ; 254)$ concludes that the biggest losers would be the larger developing countries that have significant domestic pharmaceutical industries that depend heavily on imitation of existing products. These countries would face grave difficulties with respect to the patentable drug market where they would incur heavy annual losses as a direct result of the introduction of significantly stronger patent protection (Subramanian 1995; 255). According to Subramanian's estimates Argentina would stand to lose anywhere between US $\$ 150$ million and US\$410 million annually; and India between US $\$ 475$ million and US $\$ 1.3$ billion. And Egypt is no exception, although it is in fact an example of a 
relatively small country. Thus, Subramanian and Abdel-Latif $(1997 ; 15)$ suggest that if Egypt were to implement the TRIPS Agreement it should expect drug prices to rise and welfare to fall as a result of a significant transfer of profits to the patent owners. Their estimates of the short-term losses that would result from reduced consumer and producer surpluses in Egypt range between US\$28 million and US\$ 114 million per annum. Although these particular estimates depend on certain assumptions about market structure and size, price elasticities, and the timing of the changes in the patent laws, they do suggest that the losses to Egypt would be significant, and that these losses would mirror the gains that would accrue to the foreign producers.

It is important to recognize that these studies only consider the impact of stronger patent regimes on industrial production in the developing countries. Other studies have suggested that a stronger and more harmonized global IPRs regime would have a positive impact on the behavior of multinational enterprises. Such benefits would potentially be shared with developing countries in the form of enhanced FDI flows, increased technology licensing, improved trade flows, and higher investments in research and development in knowledge-intensive goods. The following section considers each of these possibilities.

\section{PATENTS, FDI, TECHNOLOGY LICENSING, TRADE AND R\&D}

Proponents of a strong global IPRs system, including the International Federation of Pharmaceutical Manufacturers Associations (IFPMA) and the Pharmaceutical 
Research and Manufacturers of America, have made numerous claims with regard to the alleged benefits of such a policy shift for the developing countries. According to them the TRIPS Agreement should enhance FDI, technology transfer to, and trade flows from, the developing countries by bolstering the incentives for foreign enterprises. In addition, they claim that strong IPR regimes will promote national and international $R \& D$, with the former contributing to a better use of domestic resources.

\section{Patents and FDI}

An extensive review of the literature that has sought to test the hypothesis that there is a positive link between strong patent regimes and FDI has revealed that any such relationship is ambiguous at best, and contradictory, at worst. While there are some theoretical reasons to expect a positive relationship between patents and FDI, particularly for the pharmaceutical sector, that link turns out to be difficult to establish empirically, largely because so many other factors affect FDI, including productivity, education, skills, physical infrastructure, trade barriers and the transparency of government policies (Primo Braga et al 1998; 16, Maskus 1998; 11). On balance, "consensus seems to exist that the main factor explaining FDI flows is the 'economic environment' prevailing in a particular country" (Correa 1995; 175). It should not be surprising then that countries like South Korea, Taiwan, Singapore, Thailand, Brazil and Mexico, which have often been accused of providing inadequate IPRs, were the highest recipients of FDI during the 1980s, at least until their overall economic situation deteriorated, particularly in the two 
Latin American countries (Correa 1995; 175).

Other studies have suggested that the presence of strong patent regimes may actually diminish the level of FDI since FDI is sometimes used as a mechanism to maintain control over proprietary information in countries with weak patent systems (Primo Braga and Fink 1997; 113). Under these conditions, as patent strength increases "firms would tend to choose more technology licensing and joint ventures and less FDI" (Maskus 1998; 12) and in some instances they might reduce their involvement in a particular economy primarily to arms-length trade. Moreover, the incentive to invest directly in a country is also weakened by the TRIPS Agreement because it limits a host country's ability to grant compulsory licenses or to insist on the local working of patents.

\section{Patents and Technology Licensing}

Many analysts suggest that the strength of patent protection is a key determinant of technology licensing, which is preferred by multinationals when "location advantages favor production in the foreign country and title holders prefer to externalize their proprietary assets" (Primo Braga and Fink 2000; 16). These expected advantages include attractive profit opportunities, reasonable costs associated with the technology transfer and conducive regulatory policies, of which strong patents are just one aspect (UNCTAD $1999 ; 18)$.

Several surveys have indicated that US companies place a high premium on the availability of strong patent regimes when transferring advanced technologies (Primo 
Braga et al 1998; 9, Taylor and Silberston 1973; 258-259). Nevertheless, the legal strength of the licensing agreement and the estimated capacity of the buyer to absorb the technology are considered of even greater importance (Nogues 1993; 42). Because of the importance of factors other than strong IP regimes, the existing survey-based and econometric evidence on the link between patents and technology licensing suggests no more than a weak link at best (Primo Braga and Fink 2000; 17-18). It is also worth noting that this evidence tends to be based on revenues from royalties and licensing fees, which reveals little about the substance and nature of such contracts, particularly the extent to which knowledge and technology are actually transferred during the process. ${ }^{25}$ A major concern regarding the link between stronger patent protection and technology licensing is the cost implication that this may have for the developing countries, especially in the field of pharmaceuticals, where the vast majority of product and process patents, particularly those of synthetic drugs and fermentation techniques, are owned by MNEs. Although some analysts suggest that stronger patents can lead to lower licensing costs since it "becomes easier to discipline licensees against revelation or appropriation of proprietary technology..." (Maskus 1998; 16), others insist that when strong patents are the basis of technology transfer agreements, excessive direct and indirect costs are often imposed due to the frequent existence of too many restrictive clauses (Kirim 1985; 221, Van Wartensleben 1983; 173-174) and the reduced bargaining power of the technology purchaser.

25 This issue is further elaborated upon in the case of Egypt, see chapter six. 
In fact, a study commissioned by WIPO found that "the major cost implication" of the TRIPS Agreement for developing countries will result from expected increases in the cost of technology acquisition (Sherwood 1996; 12). These costs are comprised of two components: (1) the increased costs of technology that had been used previously but without the permission of the right holder or under a weaker patent policy; and (2) the costs of obtaining technology that could not be imitated previously and could not be acquired willingly from the right holder (Sherwood 1996; 12).

Moreover, these costs may be amplified when the effects of technology licensing arrangements undertaken by MNEs and their subsidiaries in developing countries are taken into account. In doing so rents are transferred from the developing country to the country of the parent firm in the form of royalty payments. ${ }^{26}$ As a result of these two outcomes, the costs of technology licensing between developed and developing countries is expected to constitute an increasing share of global trade and could double or even triple foreign exchange outflows from the developing countries (RAFI 1989 in de Almeida 1995; 222).

\section{Patents and Trade}

The impact of stronger patent protection is likely to be most apparent in the

\footnotetext{
26 Data on royalties earned by Germany, Japan and the United States for use of intellectual property indicated that the "export of technology is not a trivial activity for these economies" (Primo Braga et al $1998 ; 6)$. The US alone earned over US $\$ 20$ billion from trade in intellectual property with the rest of the world in 1995 of which approximately US $\$ 600$ million came from developing countries (Primo Braga et al 1998; 6).
} 
altered volume of international trade in technology sensitive goods. Strong patent regimes augment the market power of multinational firms and enlarge their market size by curtailing imitation. Although in theory, stronger patent protection should have an effect on both arm's-length trade and intra-firm trade, it is difficult to predict how a market is going to be supplied by the patent holder when imitation is suddenly displaced.

According to Primo Braga and Fink (2000; 5) the level of intellectual property protection in a particular country may influence trade in one of two ways: (1) by influencing firm decisions regarding how to supply the market; and (2) by prohibiting imports from sources where production is still based on imitation. Moreover, because of the ambiguity of these impacts, the authors point to the importance of empirical evidence to resolve this question.

However, those studies that have attempted to model the relationship between stronger patent protection and trade flows have resulted in few clear or robust conclusions. Thus, Ferrantino $(1993 ; 328)$ found that while a country's adherence to international IPR conventions had no effect on US inter-firm trade, there was a weak negative relation for US intra-firm exports. That is, intra-firm exports tend to be higher in countries with weak protection. In a replication of Ferrantino's study, Primo Braga and Fink $(2000 ; 6)$ found a significant positive co-efficient only for arm's-length trade, while those for intra-firm trade and establishment trade were insignificant. ${ }^{27}$

One study by Maskus and Penubarti $(1995 ; 244)$ did find that "the empirical

${ }^{27}$ Establishment trade includes sales by US foreign affiliates in host markets. 
results strongly suggest that exporting firms discriminate in their sales decisions across export markets, taking account of local patent laws." It also found that bilateral imports are larger for countries with stronger patent laws, especially among the larger developing countries. However a second study, using a different country set and data source, by Primo Braga and Fink $(2000 ; 6)$ found that the impact of IPRs on trade flows is weaker in larger developing countries and stronger in smaller ones. Inevitably these results are specific to the particular econometric approaches that were used and these were explicitly static in nature. It is clear, however, that there are few unambiguous predictions about the effects of patents on trade flows. ${ }^{28}$

\section{Patents and R\&D}

Perhaps the most important claim made by the supporters of the TRIPS Agreement is that strong patents are a necessary incentive for firms to carry out adequate levels of R\&D. By allowing for a limited period of exclusivity, patents enable firms to charge prices well above manufacturing costs and hence to earn adequate returns on their innovative investments to encourage continuing high levels of R\&D investment. Yet again neither the theory nor the evidence lend strong support to this argument. Moreover, relatively few studies have addressed the implications of such a policy change for $R \& D$

\footnotetext{
28 The effects of patents on trade flows have been variously modeled by many economists including Maskus and Penubarti (1994), Taylor (1993), Maskus and Eby Konan (1994), Flam and Helpman (1987), and Brown (1991) (in Maskus and Penubarti 1995; 230). All of these exercises have concluded that there are few unambiguous predictions about the effects of patents on trade flows.
} 
in developing countries.

Most analysts agree that there is some link between patents and $R \& D$, but there is little agreement over whether this relationship is beneficial or not. On the one hand, some believe that strong patents lead to an excessive duplication of $\mathrm{R} \& \mathrm{D}$ as firms compete for the patent prize (Barzel 1968, Loury 1979, Stiglitz 1986, Dasgupta 1986). Others, on the other hand, see patents as barriers to entry, which mitigate competitive pressures on innovative firms, leading to a reduction in duplicative R\&D (Loury 1979; 408).

There is also disagreement over whether patents are the most important incentive for investment in R\&D. For instance, it has been argued that commercial returns from being the first to invent are often sufficient to sustain $R \& D$ activities, even in the absence of patent protection (Rosenberg and Mowery 1989; 15). This implies that the probability of success, market size and the purchasing power of consumers are also significant factors. Indeed, de Almeida (1995; 221) observes that "in a wide variety of industries, investments in $\mathrm{R} \& \mathrm{D}$ are made by firms for maintaining their technological leadership and market position and they would do so regardless of the availability of patent protection." ${ }^{29}$ This conclusion seems to be supported by the evidence.

Thus we find that pharmaceutical R\&D in the United States continued to rise over the years without complementary changes in that country's patent policy. Nogues (1990;

\footnotetext{
29 This observation is based on the works of: (1) Scherer, F.M. (1980). Industrial Market Structure and Economic Performance. Chicago: Rand MacNally; and (2) Levin, R. (1986). "A New Look at the Patent System." American Economic Review, vol. 76, no.2, May, pp. 199-202.
} 
89) notes that in spite of more stringent industry regulations and the introduction of administrative procedures, which decreased effective patent duration between 1938 and $1962, R \& D$ continued to rise over this period. Moreover, during the 1980 s in the United States, the ratio of pharmaceutical R\&D investment to sales increased steadily from approximately 10 percent to 16 percent (Nogues $1990 ; 89$ ) despite the industry's persistent complaints of inadequate global IP protection.

Similar patterns have been observed in other countries. In Japan, a large survey of 2390 corporate researchers revealed that patents were considered less important when appraising R\&D decisions than competition and academic or technical interest (Evenson 1990; 39). More historically oriented studies reinforce these conclusions. Thus, Schiff (1971) found no evidence that the absence of patent laws in the mid- $19^{\text {th }}$ and early $20^{\text {th }}$ centuries led to a paucity of R\&D in the Netherlands or Switzerland (in Scherer 1977; 36). If anything he found that a lack of patent protection aided the industrialization process by enabling unrestricted importation of technology from other countries to support the development of stronger domestic industries. Indeed, even in sectors where technology was not borrowed, industry flourished and in many cases, excelled (Scherer 1977; 37). For instance, Switzerland had a very well developed chemical industry by the late $19^{\text {th }}$ century and its strength in pharmaceuticals continued despite very limited patent protection (Scherer 1977; 39).

Echoing these same observations, a comprehensive recent study sponsored by the US National Bureau of Economic Research, found that "despite the significance of the 
policy changes and the wide availability of detailed data relating to patenting, robust conclusions regarding the empirical consequences for technological innovation of changes in patent policy are few" (Jaffe $2000 ; 1)$. The study attributed these "disappointing results" to the extreme complexity of the economic environment within which the innovation process is necessarily embedded and suggested that this makes it extremely difficult to isolate the specific influence of changes in patent protection on either innovation, or profitability (Jaffe 2000; 1-2). In other words, the study ultimately highlights the difficulty of reconciling "patent theory" with history, and with the empirical evidence.

When it comes to the developing world, these problems are even more pronounced, in part because what little evidence does exist on the link between patent regimes and $R \& D$, tends to be drawn from the industrialized world. Yet those who have promoted the TRIPS Agreement have consistently claimed that a stronger, more harmonized global patent regime would increase R\&D spending by both domestic and foreign firms, in the developing world. It should be clear by now that such claims cannot be supported by means of the available empirical evidence. Indeed, they are particularly implausible when applied to the pharmaceutical industries that have grown up in some developing countries that have the necessary domestic capabilities. Almost without exception, such industries are heavily dependent on the production of existing drugs or compounds (imitation), which undergo little or no molecular manipulation. It is precisely these types of activities that will inevitably be curtailed by the TRIPS Agreement, with 
adverse effects on domestic R\&D capabilities, in so far as such imitative activities help to create the human and institutional capacities that are needed if $R \& D$ is to be strengthened and deepened in the these countries in the longer run.

This strengthening and deepening of $\mathrm{R} \& \mathrm{D}$ is an important issue in its own right since it ultimately determines the extent of the benefits that a national economy can hope to reap from its $R \& D$ activities. Many analysts believe that the $R \& D$ that is undertaken by multinational corporations in the developing world can be problematic in this regard because their global corporate interests will generally lead them to try to protect their IPRs and to ensure that it is they who reap the bulk of any technology rents. This means that, although MNEs will usually adapt the scale and type of their R\&D activities to a host country's market conditions and socio-economic circumstances (Chesnais 1992; 278 ), they will generally focus any local R\&D activities on the adoption or, at best, the adaptation, of their existing proprietary technologies (Correa 1995; 178), or possibly on the local provision of certain R\&D support services (Chesnais 1992; 278), including seminars, physician training and clinical trials. In both cases the gains to the local economy would tend to be relatively limited.

Of course, there remains the possibility that the developing countries could benefit substantially from the increased pharmaceutical R\&D that might occur in the industrial countries as a result of the strengthening of patent rights under the TRIPS. This is indeed a logical possibility but it is far from certain. First, as has been shown, there is no guarantee that implementation of the TRIPS would actually lead to increased R\&D in 
the industrial countries. Yet even if that were to occur, there is no guarantee that the health sectors or the people of the developing world would share significantly in the resulting benefits, either because such research will usually not address their health needs, or because the resulting drugs will be too costly for most consumers (or health services) in the developing world.

\section{CONCLUSION}

This chapter has considered various facets of patent theory. It has examined the basic intellectual property tradeoff, the problems inherent in determining optimal patent duration and scope, the implications of extending the patent regime to the global level, and the impact of patents on FDI, technology licensing, trade and R\&D. The aim of the discussion has been two-fold: first, to establish that the rules espoused in the TRIPS Agreement cannot be justified by invoking the most widely accepted theory of patents, or the available empirical evidence; and second, to demonstrate that patents cannot be analyzed or evaluated in isolation from their economic and social circumstances. Both the theory and the evidence that were reviewed, suggest that any serious evaluation of the likely impact of the TRIPS, must be based on a broad understanding of the ways in which a particular technology and sector is influenced by key aspects of the national environments within which they are embedded.

In so far as the question of patents is framed in terms of the basic intellectual property tradeoff, the task for the policymaker will be to find an optimal balance between 
the incentive to innovate and the need to promote technological diffusion for the benefit of society. This chapter has shown that this balance will ultimately depend on the particular characteristics of the industry, the product, the production process and the demand for that product, or process. This is true of both the optimal period, and the optimal scope, of a patent. Yet even this does not fully capture the complexity of the problem, since these relationships are also likely to be path dependent, so that the outcome also depends on whether one looks at innovation as a relatively discrete, one time event, or as part of a continuous process.

Not surprisingly, this complexity increases further when one tries to define optimal patents at an international, or global, level. Here the key question turns out to be whether "imitation" is deemed to beneficial or detrimental to innovation. Those who emphasize its benefits will argue for relatively lax patent regimes, which allow technology to be widely imitated at low cost in the developing world. They contend that this will potentially serve the interests of the developing world both in the short and the long run. In the short run it will mean additional employment, higher levels of investment and lower drug costs, in the case of the pharmaceutical industry. In the long run it may be an important part of the learning process through which people, and national economies, must develop the human skills and the institutional capacities that are needed to increase future productivity, to shape future patterns of comparative advantage and to increase the scope for future national R\&D. Those who emphasize its costs, will argue for stronger, more harmonized patent regimes because they claim that 
these will increase global $R \& D$, to everyone's benefit, while promoting FDI, technology licensing and trade to offset the acknowledged short-term costs to the developing world of shifting to such a regime. On balance it is clear that the short-term costs to the developing world of a shift to stronger patent rights, are clear and substantial, while the long-term benefits are ambiguous and uncertain. It should therefore come as no surprise that the developing world was far less eager to support such a policy shift than the industrial world and their corporate lobbies.

The deep divisions that have come to the fore in the debate about optimal patent regimes can therefore be seen to be rooted in the fact that the benefits, costs and risks associated with particular policy regimes differs dramatically for the various protagonists. Moreover, these competing interests are able to play an important role even in the most "scientific" policy discussions because the extreme complexity of the issue ensures that all conclusions will be relatively uncertain, and therefore legitimately contestable, especially when one is dealing with longer run outcomes. In this context it is the disproportionate power of some of the protagonists that has allowed them to impose a relatively uniform, harmonized patent regime in the form of the TRIPS, on a deeply divided and highly unequal world, even though it is well known that optimal patents depend on the specific characteristics of the product or process to be protected, as well as on the circumstances of the surrounding economy and the nature of the innovation process that it is seeking to influence. In other words, the emergence of the TRIPS must therefore be primarily understood by looking at the competing interests that have 
dominated this policy process (see Chapter Two). ${ }^{30}$

This does not mean that the TRIPS is necessarily undesirable for pharmaceuticals, or for the developing world in general, or for Egypt, in particular. In order to determine the answer to that question, it will be necessary to assess the implications of this agreement, with its relatively uniform, minimum requirements for strong patent protection to the particular circumstances of Egypt. In doing so, the paper will have to acknowledge the fact that the impact will differ depending on the state of the technology, industry and sector; the scientific and technological infrastructure of the country; and the administrative and political capacity of the government to design and implement suitable policies to complement any patent regime that it might choose.

Only by incorporating this wide range of factors in our analysis of the implications of the TRIPS Agreement for the pharmaceutical industry and the health sector of Egypt, as one representative developing country, can we hope to understand and explain how diametrically opposed conclusions can both appear as plausible outcomes of ostensibly scientific inquiries.

\footnotetext{
${ }^{30}$ In their book, Canadian Intellectual Property, Doern and Sharaput reach a similar conclusion. They state: "Clearly, such [IP] trade-offs in an international context are not the product of some set of benign processes of economic calculation or inevitability. The political interests of nation states or regional blocs, and political interests within countries, both help determine where and how a trade-off will be made and how it will be continuously adapted" $(2000 ; 20)$.
} 


\section{CHAPTER FOUR}

\section{A NATIONAL SYSTEMS OF INNOVATION APPROACH TO UNDERSTANDING THE IMPLICATIONS OF STRONGER PHARMACEUTICAL PATENT PROTECTION FOR DEVELOPING COUNTRIES}

Chapter three discussed the core intellectual property tradeoff that is commonly assumed to exist between innovation and technological diffusion and established that innovation is far too complex a process to be attributed to any one particular incentive, including patents, as most mainstream intellectual property models imply. In this chapter I will outline the basis of a national system of innovation (NSI) approach to assessing the implications of stronger patent protection for the pharmaceutical sectors of developing countries. The NSI approach views patents and IPRs more broadly, as only one element in the complex system of institutions and incentives that shape a country's technological and economic performance. It highlights the importance of three key factors that must all be assessed in order to determine whether a developing country will be capable of capturing some of the potential benefits (or of minimizing some of the potential costs) associated with stronger IPR regimes. They are the structure and capabilities of its pharmaceutical firms; the scientific and technological infrastructure, including its universities and public research institutions; and the existence of coherent and stable government policies, relating to the pharmaceutical industry. All three of these elements need to be considered and analyzed if one is to assess the chances of a beneficial and 
successful transition to a TRIPS compliant regime.

At one level, this implies that the effects of IPR reform will vary from industry to industry, and within an industry, from firm to firm. At the same time it also implies that the individual cases do not exist in isolation but as part of a system, such that the net effect of stronger IPRs on a country's pharmaceutical industry is more likely to be positive when its national system of innovation is relatively well developed.

This chapter is divided into three main parts. In the first part I define the concept of a national system of innovation, focusing on the particular characteristics of innovation in a developing country context where the core intellectual property tradeoff cannot be easily applied because in such a context innovation is largely based on the adoption, adaptation and improvement of existing knowledge, which is itself highly dependent on effective diffusion. Moreover, such a systemic approach emphasizes the need to go beyond looking at particular incentives, like IPRs, to understand the driving forces behind successful innovation. In the second part, I examine the three key components of any NSI - firms, scientific and technological infrastructure and government policies - with a focus on the conditions prevalent in many developing countries. In the final section I demonstrate how certain aspects of a country's national health system can overlap with national systems of innovation, to influence the innovative behavior of pharmaceutical firms. 


\section{THE CONCEPT OF NATIONAL SYSTEM OF INNOVATION}

It is difficult to define what is meant by a national system of innovation with great precision. Indeed, there are a number of approaches to the study of such systems as reflected in the works of authors like Freeman (1987), Porter (1990), Nelson (1993) and Lundvall (1992). Each approach differs in emphasis and focus, and each raises many problems and leaves many issues unresolved. What they have in common is that they are all based on the methodological premise that "the national system may represent a level of analysis that is not entirely reducible to its individual components" (McKelvey 1991; 121). Or, in other words, that the total is different than the mere sum of its parts.

For the purpose of this study, a national system of innovation "is constituted by elements which interact in the production, diffusion and use of new, and economically useful, knowledge and that national system encompasses elements and relationships, either located within or rooted inside the border of a nation state ${ }^{31}$ " (Lundvall 1992; 2). Moreover, the relationships are path dependent so that each country's historical experience, language and culture will influence the performance of its NSI (Lundvall $1992 ; 13)$. While such an approach to the study of innovation opens the door to new levels of understanding, it also increases complexity and reduces the scope for certain kinds of analytical rigour and for the generation of widely applicable generalizations.

In this study I emphasize 'national' systems, as opposed to regional or

\footnotetext{
${ }^{31}$ This means that foreign-owned firms are a part of both home and host country systems (Lundvall 1992; 18).
} 
international ones, largely because the specific design and implementation of public policy remains primarily a national function, although that is never exclusively so and it can be argued that in some cases this balance has gradually been shifting. As Nelson $(1996 ; 287)$ has observed, this reflects the fact that "much of the current interest in national systems of innovation reflects a belief that the innovative prowess of national firms is determined to a considerable extent by government policies." In turn, the success of any policy, and the likelihood of its being effectively implemented or institutionalized, will depend on local economic, social and political circumstances (Pack and Westphal $1986 ; 103)$. This makes it challenging when governments seek, or are obliged, to implement international obligations that conflict with national priorities and local circumstances.

What this means is that in this study innovation systems, production systems and the peculiarities of institutional set-ups will be regarded as largely national phenomena embedded in specific historical, social and cultural contexts (Lundvall 1992; 13, Porter $1990 ; 19)$. As a result, the implications of any pharmaceutical patent reform cannot be examined apart from the national system within which this reform is to be implemented.

It is important to recognize that there is no implied presumption that these national systems were/are being purposely constructed, or even that their constituent elements always function in a coherent or stable manner (Nelson and Rosenberg 1993;4). Nevertheless, a minimum level of coherence and stability is undoubtedly required if such 
a national system is to attract and retain investments in innovative activities, whether from domestic or foreign sources. Thus, according to the OECD $(1992 ; 22)$ the “...creation and diffusion of technology and its transformation into commercial products depends as much on the vitality of the whole set of relationships as on the individual performance of any given element of the system." From this perspective the implementation of the TRIPS Agreement in developing countries raises obvious concerns since it clearly takes little or no account of the specific circumstances or the basic logic of their innovation systems. In fact, in many senses this new regime has been effectively imposed on an often-reluctant developing world, without consideration of the specific nature of the innovation process, as it generally exists in such a context.

\section{Innovation in a Development Context}

It is essential to understand the specific characteristics of innovation in a development context for two primary reasons. First, it is important if one is to assess the relevance of the core intellectual property tradeoff under those circumstances; and second, if one is to ensure that the concept of a NSI is based on an appropriate conception of the innovation process for the developing world.

The core intellectual property tradeoff that is commonly assumed to exist between innovation and technological diffusion is more complex than is often suggested and this is particularly true in a development context where the innovation process differs radically from the one posited by mainstream theory. As has been shown, the economic 
literature on IPRs focuses centrally on this conflict between innovation and diffusion. The standard argument suggests that intellectual property protection acts as a critically important incentive for innovation by restricting the diffusion of technology for a limited time, thereby allowing innovative firms to appropriate returns on their investments. However, the concept of innovation that is embedded in this argument is highly restricted and does not take adequate account of the role that diffusion plays in the innovation process itself, particularly in the early stages of an industry's development. In fact, once a link between innovation and diffusion is accepted as a possibility, it becomes clear that under certain circumstances, stronger IPRs can actually inhibit important aspects of innovation, by inhibiting diffusion.

Standard intellectual property theory tends to take a linear view of technological change, assuming that it occurs progressively and discretely in independent steps in a unidirectional manner. The process as envisaged, begins with basic research, which eventually leads to innovation when it is applied to product and process development, and then to production and marketing and finally diffusion. Unfortunately this view is not only over-simplified, it is essentially incorrect and may lead to the creation of incompatible incentive systems.

The significant emphasis that this linear view has placed on research and its relation to other stages in the innovation process has had a profound impact on patent policy. Because the model implies that as research increases, so does innovation (Nelson $1996 ; 31)$ much mainstream analysis on innovation has simply focused on how to 
increase research, but without adequate consideration of other crucial aspects of the innovation process. Moreover, in this view research has been conceptualized as being clearly divided between basic and applied. Basic research is defined as an activity whose output is unlikely to be a finished product (Mowery and Rosenberg $1989 ; 11$ ) but which will generally be "used only as an informational input into other inventive activities" (Dasgupta 1988; 5). It is therefore likely to involve a search for fundamental, or pure, information for the advancement of science (Rosegger 1986; 6). Conversely, applied research is defined as an "activity whose informational output is an input in the production of commodities" (Dasgupta 1988; 5) and which therefore involves the search for 'practical' applications or technology (Rosegger 1986; 6).

In this view, basic research is treated as a public good since the payoff is uncertain and distant and partly because the results move rapidly into the public domain and the benefits are difficult to appropriate (Mowery and Rosenberg $1989 ; 10$ ). Nevertheless, such research is considered essential for technical progress because "it enlarges the pool of knowledge from which innovative activities draw, and is an essential input into the training of manpower for applied research and development activities" (OECD 1971; 14). For these reasons, such research is mainly carried out by publicly funded laboratories and universities where incentives are linked to career structures that reward the dissemination of knowledge as rapidly as possible. In some cases, however, private firms may undertake basic research to try to be the first to innovate (Malecki $1997 ; 54)$ but generally these actors tend to focus on research whose 'technical surety' is 
much higher (Ostry and Nelson 1995; 110) and which therefore promise specific results and profit opportunities in the relatively short run. In other words, as one moves from basic to applied research, both risk and uncertainty tend to decrease (Mowery and Rosenberg $1989 ; 11)$.

It is important to recognize that in reality the distinction between these two concepts is not so clear-cut. In many cases basic research is done for 'practical' purposes while applied research may have a significant basic component. Nevertheless, the distinction is important especially for understanding a significant inconsistency or "paradox" in traditional patent policy. The logic of patents applies most directly to situations where new knowledge is created in discrete, discontinuous steps that do not feed off each other. It applies less well, where innovation is part of a seamless, continuous process in which every advance is the outcome of a diffuse and interdependent process where it is often hard to determine who actually "made" a particular discovery. Now, the innovation process is never made up of discrete independent steps. It is always continuous and interdependent to a significant degree, but it is widely agreed that this is less true of basic research than of innovation, and yet traditionally patents have been much more widely applied to innovation (or applied research) than to basic research. Indeed, mainstream theorists have paid little attention to the way in which applied research is actually generated and diffused (Rosenberg 1976; 62), which is what would have to be done to derive truly effective incentives for such activities. In essence then, patents provide incentives based largely on an understanding 
of basic research for actors undertaking applied research without an adequate understanding of that process. Yet the influence of the analysis concerning basic research has been so great that it has become accepted for all innovative activities regardless of whether or not they have similar characteristics and determinants and this is a cause for concern.

It is also a cause for concern that although patent theory is based on an understanding of basic research it may not be the most appropriate tool for encouraging such research. After the passing of the Baye-Dole Act in 1980 in the US, which permitted universities to patent technologies they had developed, patents were being used more and more aggressively to protect research performed by these institutions. This trend, however, is highly contestable, as it does not seem to be responding to the need to stimulate basic research and the sharing of knowledge as university research increasingly adopts a commercial focus. Allowing the patentability of public research obscures incentives and career structures that had long been designed so as to maximize the speed with which information was transferred and shared, as careers depended on being the first to publish important new findings. According to McDonagh (2001) this raises concerns about intellectual property and technology transfer: "For instance, what is the relationship between patenting the products of research and the old, established way of getting information out of the lab and into circulation: publishing academic papers? There is a basic conflict between the goals of academia and industry when it comes to sharing knowledge." 
This problem is exacerbated by a recent trend that indicates a diminution of both government and corporate support for basic research (Ostry and Nelson 1995; 10), which is forcing universities to rely increasingly on themselves to secure adequate funding for research activities. According to Ostry and Nelson $(1995 ; 112)$, this trend is likely to create serious long-term problems as "...the rate at which new understandings open up broad new technological prospects [declines]."

Thus, the patent paradox is likely to result in designing patent systems that are stronger than necessary and that simply do not respond to the social need to generate adequate levels of basic research. This is partly due to a tendency on the part of corporate advocates to exaggerate the technical risks associated with $R \& D$. In one study by Mansfield (1971) firms reported that the majority of projects that they undertook were considered "relatively safe from a technical point of view" (in Bonin 1991; 276). On the other hand, the pharmaceutical industry, in particular, has continued to emphasize the high risks associated with $R \& D$ activities.

If the claim of exceptional risk were valid, we would expect an analysis of the data to show that risk and uncertainty, as opposed to other factors, exercised a significant influence on the profitability of drug firms; furthermore, we would expect the industry to show considerable fluctuations in its earnings relative to less risky industries and we would expect to find drug firms which were exceptionally unproductive of innovations to show relatively low returns. None of these factors are supported by the evidence: econometric analysis of the determinants of profits does not show that risk is a very significant variable; the industry has consistently earned profits higher than the average; and firms producing few innovations have nevertheless shown very high profits (Lall 1974; 156).

In fact, the pharmaceutical industry's exceptionally high profitability, which persists to 
this day, supports the hypothesis that long standing monopolies and high barriers to entry far outweigh the risks associated with their research activities. According to Bonin $(1991 ; 276)$ the probability of success of such research projects is normally between 50 and 70 percent. Moreover, in cases where a firm is not achieving desired results, or where the results are not likely to be as profitable as first anticipated, certain projects may be abandoned.

Thus, standards of patent protection for pharmaceutical products that are based on arguments of exceptional and exaggerated risks in undertaking research projects, rather than on an accurate understanding of the innovation process, risk being too strong to be effective. This is what seems to have happened with the formulation of the TRIPS Agreement. According to Joseph Stiglitz (2002):

In the final stages of the Uruguay negotiations, both the White House Office of Science and Technology Policy and the Council of Economic Advisers worried that we had not got the balance right - that the agreement put producers' interests over users'. We worried that, with this imbalance, the rate of progress and innovation might actually be impeded. After all, knowledge is the most important input into research, and overly strong intellectual-property rights can, in effect, increase the price of this input.

Stiglitz's concern highlights the necessity of balancing the interests of producers of new knowledge with those of users, not only in the developing countries but also researchers in the developed countries. When this knowledge is overpriced on account of "overly" strong IPRs, "we retard its diffusion and beneficial effects on living standards" (Stiglitz 2002).

Yet aside from various political factors, the lack of harmony between patent 
theory and policy may have arisen as a result of the fact that the linear model of technological change is an inappropriate way to categorize what is more appropriately understood as an evolutionary process. According to Rosenberg $(1976 ; 77)$ this model has created "artificial conceptual disjunctions between innovative activity and other activities with which it is not only linked, but which in fact constitute major parts of the historical process of innovation itself." By oversimplifying the relationship between research and technical advance (Nelson 1996; 31), this model has induced analysts to focus on some aspects of the innovation process, while neglecting the role of others that are equally important. This has led to IPR policies that are based on a poor understanding of the innovation process, particularly in the case of the developing countries.

Approaching the study of IPRs from an NSI perspective represents an alternative way of thinking that has much to recommend it. However, in doing so it is critically important to proceed on the basis of an accurate understanding of the innovation process. In this study the innovation process will be conceptualized as a pervasive and dynamic economic phenomenon following Lundvall's $(1992 ; 8)$ conceptualization: "In practically all parts of the economy, and at all times, we expect to find on-going processes of learning, searching and exploring, which result in new products, new techniques, new forms of organisation and new markets." Although in developing countries these activities are often happening at very different levels of sophistication than in the industrial countries, they are happening nevertheless.

This understanding fits well into the approach taken by Ernst, Mytelka and 
Ganiatsos' $(1998 ; 12-13)$ who suggest that when studying development it is useful to conceive of innovation as a "process by which firms master and implement the design and production of goods and services that are new to them, irrespective of whether or not they are new to their competitors - domestic or foreign." This emphasizes the importance of learning and of 'learning to learn' 32 which is defined as the development of "problem solving capabilities that enable the firm to improve its productivity, to imitate and to adapt product, process and organizational technologies already developed elsewhere to local conditions" (Mytelka 1998; 4).

Indeed, many of those who have studied imitation in developing countries have found that the process is akin to innovation in the industrial countries (Baba and Imai 1992, Grossman and Helpman 1991, Dosi 1988, Rosenberg and Mowery 1976). As Dosi $(1988 ; 1140)$ observes, “...the partly tacit nature of knowledge and its characteristics of partial private appropriability makes imitation, as well as innovation, a creative process, which involves search, which is not wholly distinct from the search for 'new' developments, and which is economically expensive - sometimes even more expensive than the original innovation... this applies to both patented and non-patented innovations." In the same vein, Mowery and Rosenberg $(1989 ; 15)$ argue that a significant research capability is required to "understand, interpret, and appraise knowledge that is placed on the shelf - whether basic or applied." It is therefore, widely agreed that as with innovation, there is substantial uncertainty and risk associated with

\footnotetext{
${ }^{32}$ Adapted from Stiglitz 1987 in Mytelka (1998; 4).
} 
adopting and adapting foreign technologies to different national circumstances (Nelson 1979 in Pack and Westphal 1986; 105, Rosegger 1986; 177). Indeed, from the perspective of the firms undertaking these activities, the decision to adapt an existing technology "may not look qualitatively different from a decision to innovate" (Rosegger $1986 ; 182)$.

Thus, in the developing countries imitation often has many of the characteristics that are normally associated with the innovation process in the industrial countries. Both involve ingenuity, scientific and technological skills, abilities to use specialized knowledge for problem solving, managerial abilities, and organizational effectiveness and flexibility. These, in turn, influence production costs, market competitiveness and hence the evolution of the industry (Pack and Westphal 1986; 105, Dosi 1988; 1120). Moreover, both activities improve the technological absorptive capacity of firms, which is defined as "the ability of firms to learn and use the technology developed elsewhere through a process that involves substantial investments, particularly of an intangible nature" (OECD 1992; 17).

The potentially close link between innovation and imitation is highlighted by the fact that innovation is, in large part, a self-reinforcing cumulative process. It is ultimately this characteristic that links innovation/imitation so closely with learning. Indeed, in many developing countries, the industrialization process has involved a significant accumulation of technological capability, despite the low levels of industrial and basic $\mathrm{R} \& \mathrm{D}$, as producers gained mastery over products and processes that were new to them 
and to the domestic economy (Grossman and Helpman 1991; 12, Pack and Westphal $1986 ; 105)$. The key to these developments has been the relatively uninhibited technological diffusion made possible, in part, by lax or even non-existent, IPR protection in many developing countries.

Many analysts would agree that the international diffusion of technology is closely linked to technological progress and economic growth especially in the developing world (Rosenberg 1976, Perez 1988, Brown 1981, Grossman and Helpman 1991, Romer 1994, Freeman and Soete 1997). In so far as this is true, the stronger patent laws that are embedded in the TRIPS will impede diffusion and the learning and innovation to which it gives rise. Indeed, some would argue that it is of paramount importance to allow the developing countries to benefit from the learning opportunities associated with effective technological diffusion.

\section{GOING BEYOND IP POLICY}

The dominance of the linear model of technological change tends to focus attention on individual policy measures, like intellectual property protection, at the expense of a broader and deeper understanding of the many other factors that ultimately make up the innovation process. It follows from this, that in order to understand the likely implications of the TRIPS Agreement on the pharmaceutical industry and on public health it is necessary to understand the pharmaceutical/health aspects of the national innovation system into which it is being introduced. According to Correa $(1998 ; 29)$, 
"the patent system as an incentive to local innovation is unlikely to work, except in those countries where a significant technological infrastructure already exists, and where there are big enough firms to engage in substantial R\&D efforts." In other words, it is the NSI of a country, combined with its public health system, which should be the basis for the design and implementation of appropriate national intellectual property policy.

On the other hand, although the suitability of IPR regimes will have a significant influence on the shape and the success of a country's innovation system, sustained success also requires suitable and supportive framework policies that protect the economy from developing major, disruptive imbalances. Thus, it is widely understood that the need for radical budget cuts, or dramatic devaluations, or the instability generated by largely speculative mergers and acquisitions, all have the potential for destroying accumulated knowledge and technological capabilities (OECD 1992; 38). Indeed, as Rath $(1990 ; 1434)$ reminds us, "performance can stagnate and in fact negative learning can easily result from adverse policy and environmental factors."

When patent policy is made without due regard for its appropriateness for the national setting, it is not difficult to see that it may meet with failure. Stronger pharmaceutical patents must be accompanied by a wide range of complementary policies and institutional reforms aimed at strengthening indigenous technological capabilities and safeguarding public health. Historically, the governments of the industrialized countries have complemented the often gradual introduction of stronger intellectual property rights with other domestic policies designed to ensure the continued development of their 
domestic pharmaceutical industries while also safeguarding public health.

In short, the development of national innovation systems is generally the result of a long and continuous process of technological appropriation and development (Chesnais $1991 ; 158$, OECD 1992; 17). This process is path dependent so that in the words of the OECD $(1992 ; 17)$, “the countries, firms and institutions which have been able to exploit the opportunities over many decades and create a base for technological accumulation are the best placed to adapt to the transitions and transformations of structural change" [emphasis added]. From such a perspective, the short transition periods granted by the TRIPS Agreement are not likely to give developing countries enough time to align their national innovation systems to their new international obligations, let alone to protect the ability of those systems to support and to strengthen indigenous technological capabilities within the context of the new global IPR regime.

The remainder of this chapter explores three key elements of national systems of innovation that are fundamental to technical progress and that will therefore influence the outcome of the policy reforms entailed in the TRIPS Agreement. These elements have been identified on the basis of the historical experience of several currently industrialized countries. Yet although there is widespread agreement that they play a significant role in technical advance, authors differ with regard to the relative significance of each. According to Nelson and Rosenberg $(1993 ; 5)$ : "In a way these understandings do provide a common analytic framework, not wide enough to encompass all of the variables and relationships that are likely to be important, not sharp enough to tightly 
guide empirical work, but broad enough and pointed enough to provide a common structure in which one can have some confidence."

This study focuses on Egypt's pharmaceutical sector within a national system of innovation framework. This means that it will consider those elements of the national system of innovation that most directly affect innovation in the pharmaceutical industry. A sectoral focus is important because differences between the innovation processes in different industries are significant, so that each industry has unique characteristics that determine (1) its need for, or dependence on various elements like public research laboratories and universities and (2) its interactions with these and the more general systemic elements like government policies (Nelson and Rosenberg 1993; 13). Ultimately the task of assessing the implications of pharmaceutical patent reform requires a critical examination of the structure and the capabilities of the firms that are involved in drug research and production in Egypt. It may therefore be more apt to describe such an approach as a national innovation 'meso' system (Chesnais 1991; 160).

\section{KEY ELEMENTS OF NATIONAL SYSTEMS OF INNOVATION The Structure and Capabilities of Firms in an Industry}

The role of the industrial firm is central to innovation no matter what definition of innovation is used. Although it is certainly not the sole contributor to technological change, the firm is nevertheless the main actor that transforms the knowledge gained from science and technology into products and services, 'hopefully' in response to 
market demand. Accordingly, it is quite appropriate that firms should be the primary targets of IPRs reform.

However, firms differ in terms of their habits and practices with regard to innovation and these will affect their response to any policy changes. According to Mytelka (1999; 19) firm strategies "depend upon the set of habits and practices they have developed to deal with the challenges of change and competition. When these historical habits, practices and routines are generalized across many firms and achieve some measure of longevity, they become important elements in determining policy dynamics and hence policy outcomes. Only by understanding the historical habits and practices of targeted actors can policies be devoted to strengthen or change them." What this means in practice, is that industrialists, who have long been dependent on the adoption and adaptation of foreign technologies, may respond negatively to a strengthening of intellectual property rights since that is likely to impede technological diffusion.

In assessing firm responses to the introduction of stronger IPRs in the pharmaceutical sector we need to look both at research and development and at production. As we do so, we need to bear in mind that the available evidence suggests that different types of firms will respond differently in many cases. Thus it is widely believed that the responses of multinational subsidiaries operating in developing countries will often differ markedly from locally owned firms, or from public sector firms. The discussion that follows will be sensitive to such systemic differences while recognizing that within each group there will inevitably be differences between 
individual firm responses. These are issues that will become increasingly evident in the following two chapters.

\section{Industrial Structure}

Despite a vast and rich tradition, the link between industrial structure and innovation has not been conclusively established. According to standard industrial organization theory, largely based on Schumpeter's (1942) hypothesis, greater market concentration is associated with high levels of innovation. Empirical research, however, has revealed that greater market concentration may lead to quite the opposite: a decline in innovation due to less competitive pressures (Pavitt and Patel 1988; 46, Aghion et al $2002 ; 1)$. Both proposed relationships lend support to Freeman and Soete's (1997; 229) observation that: "Statistical generalizations about size of firm, scale of R\&D, inventive output and innovation need to be heavily qualified... simplistic generalizations about lower or higher concentration leading to better innovative performance cannot be sustained."

In a recent study by Aghion et al (2002), it was found that when competition is intense, firms tend to limit investments in innovation for fear that they will not profit sufficiently from the outcomes. Alternatively, when firms have too much power, they tend to under-invest in innovation. Therefore, in situations of monopoly or high competition firms are less likely to innovate than those between these two extremes. This suggests that strong IP rules that guarantee supernormal profits are likely to decrease 
innovation rather than encourage it.

In a developing country like Egypt, where innovation levels are dismal, this possibility is quite problematic. In accordance with Aghion's study, strong IPRs would sharply and abruptly decrease competitive pressures on foreign firms operating in Egypt and would guarantee profit levels high enough so that local investments in R\&D would no longer be considered necessary even in the event of major improvements to the NSI. For locally owned and public sector firms, innovation would also decrease, but in this instance it would occur as a result of too much competition resulting from the premature imposition of strong IPRs. In effect, the TRIPS Agreement takes the level of competition far beyond that required to induce local firms to invest in innovation and may even deny them the possibility of building such capabilities.

Because of the complexity of the innovation environment in any country, and particularly in the developing countries where there are relatively few studies of the relationship between industrial structure and innovation, one cannot make broad generalizations. However, low levels of pharmaceutical R\&D and innovation are pervasive throughout much of the developing world irrespective of market structures. This may be an indication that the structure of firms in an industry only becomes an important factor in innovation when an overall environment conducive to such activities already exists, or is established within a country. 


\section{In-house R\&D and Production}

In-house research is an important feature of many modern pharmaceutical firms, whether brand name or generic (Dosi 1988; 1132), and the literature suggests four fundamental rationales for this. First, in-house R\&D augments the capacity of firms "to recognize, evaluate, negotiate and finally adapt the technology partially available from others" (Dosi 1988; 1132). In effect, it allows firms to understand the strengths and weaknesses of a technology, thereby permitting them to make improvements (Nelson and Rosenberg 1993; 10, OECD 1992; 17).

Second, performing in-house R\&D allows firms to draw more effectively on public research in order to adapt it to more 'practical' uses (Nelson and Rosenberg 1992; 10). In fact, although public institutes account for most basic scientific discoveries, the development of new technologies based on that research is largely the domain of the private firm.

Third, it is often suggested that in-house R\&D makes it is easier for a firm to integrate its R\&D activities with developments in production and marketing (Nelson 1996; 62; Nelson and Rosenberg 1993; 10). As research becomes more applied it has to be linked to production design and marketing considerations and these, in turn, need to conform to a firm's specific capabilities and experience. Indeed, effective R\&D tends eventually to be not only industry specific, but also firm specific. This is the main reason why there are limits to the effectiveness of separate stand-alone R\&D facilities like public or university laboratories. 
A final important reason for in-house $R \& D$ is to allow a firm to keep new knowledge secret for as long as possible thereby giving the firm a head start on its competition (Nelson 1996; 63). For this reason, firms may prefer to rely on tacit knowledge 'embedded' in its staff and organization and may avoid certain contractual relations even when these are otherwise desirable (Mowery and Rosenberg 1989; 6). Indeed, firms may even refuse to patent certain processes for fear that this would allow competitors to decode the new knowledge that they have "created."

The extent of R\&D undertaken by a national industry generally tends to depend on the country's level of economic development and the degree of its international specialization (Freeman $1987 ; 16$ ) so that there are significant differences in levels of R\&D in developed and developing countries. Moreover, the path dependency of the innovation process makes it very difficult to close this gap. Thus, according to Pavitt and Patel $(1988 ; 36)$ "lags in catching up with frontier technology often result from the lack of such [research] competence, rather than from legal, informational or other types of barriers to entry." This underscores the importance of R\&D in the early stages of development and the necessity of implementing policies and incentives that guarantee continued investments in R\&D as is the case in the OECD countries (Freeman 1987; 2).

This is not to imply that expenditure on $R \& D$ is synonymous with innovation, but it does tend to be the most commonly used indicator of innovative activity by both policy makers and academics (Pavitt and Patel 1988; 38). In fact, R\&D is only one input into the innovation process. Thus, while it is true that levels of $R \& D$ help to determine the 
ability of firms to exploit existing knowledge, or to generate new knowledge, they miss an important additional source of technological capacity, namely, production engineering. However, it is difficult to integrate this sphere into the analysis since the distinction between $R \& D$ and these related activities, including the problem solving that is part of the production process and keeping abreast of competitors' new developments, is not easy to delineate (Nelson and Rosenberg 1993; 11).

Production itself is therefore an important determinant of a firm's response to the introduction of stronger IPRs. Since innovation is a cumulative process that involves learning-by-doing, by-using and by-interacting, with both other producers and users (Freeman $1987 ; 2$ ), the system of innovation cannot be understood in isolation of the system of production. In this case, it is important to understand that the TRIPS Agreement is likely to change the structure of pharmaceutical production in many developing countries as patent policies that have tended to favour local producers, are amended in ways that strengthen the hand of foreign-owned enterprises.

Production always tends to have a significant learning effect on the firm and, over time, this can be expected to increase the firm's capacity to make use of scientific and technological research (Mowery and Rosenberg 1989; vii). Indeed, the resulting process of continuous innovation has been said to be "the prerequisite of radical innovations" (Andersen and Lundvall 1988; 14). A good example is reverse engineering, which can be considered part of the production process and which, involves "learning to produce by taking apart products and processes to find out how they work" (OECD 1992; 33). 
Although such activities are not generally classified as R\&D they are very similar and can lead to similar outcomes (OECD 1992; 33).

Thus, as firms gain experience by engaging in production, they are able to combine their own knowledge with foreign technology and this enhances their technological capabilities and strengthens their market position (OECD 1992; 263). ${ }^{33}$ Moreover, when there are learning effects, experience in production will lead to lower costs, and that will generally lead to increased markets and an expansion of employment and production (Henderson et al 1999; 282). This in turn creates better opportunities for innovation and the development of greater technological know-how (Rath 1990; 1434). The ability to gain experience in the production of new technologies by firms in the developing countries, however, may be curtailed by the relatively high minimum standards established by the TRIPS Agreement. In part, the development of technological capabilities in much of the developing world, as well as that which occurred historically in the industrial countries, was always based on their relative freedom to adopt and adapt the technologies that had been developed in the more advanced countries and this process was facilitated by the absence of strong IPRs (UNDP 2001; 102-3). From this perspective, the TRIPS Agreement can be said to threaten the possibility for continuous learning and innovation in the developing world. In doing so, it will diminish the emergence of competitors that could, one day, have the capabilities to

\footnotetext{
${ }^{33}$ Indeed, the successful firms are the ones that achieve such combinations (Pack and Westphal 1988; 106). Take for instance the recent move by an Indian generic drug manufacturer to combine triple therapy HIV/AIDS treatments in one drug making it easier to administer. This innovation would not be possible
} 
exploit frontier technologies, but that may be denied the opportunity under this new regime.

\section{The Scientific and Technological Infrastructure}

The scientific and technological infrastructure of a national economy is composed of a myriad of actors, including industry, relevant government departments, banks, public research institutes, and university laboratories. The need to understand the actions and interactions of these various actors arises from the fact that technological advance proceeds through the efforts of this complex community of actors, which always has a distinct national character (Nelson and Rosenberg 1993; 15). The effectiveness of these actors and of the "system" of which they are a part, will determine the level of support that is available to knowledge-intensive industries like pharmaceuticals, which will help to determine the likelihood of such activities thriving in a particular location. In many developing countries, the weakness of this scientific and technological infrastructure impedes innovation and that, in turn, helps to explain the resistance of their national firms to stronger intellectual property rights. In other words, the weakness of that infrastructure makes it difficult for them to take advantage of the potential benefits of those rights because the transition from imitation to innovation becomes more difficult and this increases their dependence on foreign technology and imitation.

When examining the pharmaceutical sector, emphasis in the literature is often 
placed on the important role of universities and public research laboratories, which influence the innovation process in three main ways. First, universities are relied upon for the training and retraining of scientists, engineers and technically qualified personnel. Thus, it is important that university programs reflect the changing demands of the economy so that the skill composition of the labour force remains consistent with the demand for labour (OECD 1992; 268). Accordingly, in much of the developed world (and now in some developing countries) various arrangements and understandings have established closer links between industrial laboratories and the universities. ${ }^{34}$

Second, universities and national laboratories are relied on for the performance of basic research. Research and development is generally considered the heart of the science and technology complex that "...originates a large portion of the new and improved materials, products, processes and systems, which are the ultimate source of economic advance" (Freeman and Soete 1997; 5). In the early stages of technological development, public R\&D institutions play a particularly critical role in this process, by assimilating and diffusing foreign technologies at a time when dependence on such technologies is the strongest (OECD 1992; 265). The importance of their role is especially great in the health sciences because health is largely a public good. There is much evidence to suggest that the discovery of new drugs is generally given strong

\footnotetext{
${ }^{34}$ It has been duly noted by Professor Phil Ryan that universities also function to "prepare people for citizenship, for making a 'productive' contribution to public reflection on political and other matters." Indeed, it was not my intention to imply that the sole purpose of universities is to respond to the changing demands of the economy, but rather, it was to emphasize the importance of this function for the pharmaceutical, among other, industries.
} 
impetus by public sector research, though often with interaction with the private sector. Indeed, it has been observed that "all the countries that are strong and innovative in fine chemicals and pharmaceuticals have strong university research in chemistry and in the biomedical sciences" (Nelson 1996; 288).

However, to be effective, these institutions must be dynamic and flexible so that, as private capabilities increase, they continue to be able to generate appropriate knowledge inputs. It is important to keep in mind that the ability to establish and maintain this dynamism depends on the historic evolution of national science and technology institutions (OECD 1992; 267) and on available resources. Once more this underscores the need for much longer transition periods and much greater resources for the developing countries than the TRIPS currently provides.

Finally, public research institutes and university laboratories impact innovation through their interaction with industry and society at large. The presence of a professional $\mathrm{R} \& \mathrm{D}$ system is considered insufficient in the absence of viable linkages with other knowledge-intensive industries, industrial production, marketing and the science and technology network in general (Freeman and Soete 1997; 275). In the advanced countries "university programs are not undifferentiated parts of a national innovation system broadly defined, but rather are keyed into particular technologies and particular industries" (Nelson 1996; 278). For instance, in the US and Germany universities are the home of institutes designed to help particular industries (Nelson and Rosenberg 1992; 12). When these public institutions are supporting national firms, there tend to be 
direct interactions between faculty members or research teams and the relevant industries, often through various consulting arrangements (Nelson 1996; 288-9). The important point is that in such situations, "the transfer of knowledge between science and technology is mainly person embodied: in other words, it takes place through people talking to one another, or through people moving from one institution to another" (OECD $1971 ; 14)$. This leads many to suggest that in order for scientists and industrialists to benefit really significantly from one another, it is necessary to create structures and incentives that are conducive to personal interaction and collaboration (Mowery and Rosenberg $1989 ; 13)$.

Ultimately, science and technology can only flourish where there is a critical mass of professionals, backed by good facilities, effective information flows, and sustained funding. These are the main factors that are necessary for the continual advancement of knowledge and science (Rosenberg 1976; 167, Segal 1987; 87). In light of this, most governments fund basic research and higher education to a significant degree, but the organization, the means of funding and the orientation of the research differ widely across countries (Nelson and Rosenberg $1992 ; 12$ ). Nevertheless, they all have to face the same challenge, namely that of integrating science and society, so that science can be responsive to social need, because science in isolation, is likely to become "sterile and unproductive" (Mowery and Rosenberg 1989; 113). 


\section{Developing Country Challenges}

Relative to the situation in the advanced industrial countries, the scientific infrastructure in the developing world tends to be weak and deficient. According to Chambers $(1983 ; 171)$, "some universities resemble old-fashioned factories turning out a standard, third rate, out-of-date product - people with skills but no originality, with an ability to remember and repeat rather than to create." In such situations, there seems to be a particular lack of understanding of how science should be taught and learned, which results in a "poor knowledge base about the conceptual nature of science, an inadequate understanding of contemporary developments in science and technology, and unsuitable skills and training for the Third World's development needs" (Shahidullah 1991; 116).

The inadequacy of the science and technology complex in most developing countries can be partly attributed to major institutional and organizational problems (Shahidullah 1991; 75) but also reflects the acute shortage of resources that characterizes this part of the world. It comes as no surprise, therefore, that "only a handful of [developing] countries have been able to successfully proceed from the transfer of technology to the establishment and extension of indigenous science and technology generating capabilities" (Segal 1987; 1).

In many developing countries science remains very isolated from industry and society and this has often led to situations where imported technologies "remain stagnant; knowledge and skills learned remain unutilized; priorities of basic research are misdirected; technological dependency is increased; and brain-drain is worsened" 
(Shahidullah 1991; 5). Indeed, several scholars have pointed out that the relative isolation of science and technology institutions from social needs, and from industry, can easily lead to a 'vicious circle' which ultimately serves to reinforce the preference for foreign technology (Malecki 1997; 275).

The truth is that, although the developing countries need the science and technology that is produced in the more advanced countries, they first need to develop systems that can create the skills needed to adopt and adapt this knowledge to benefit their economies and to suit their socio-cultural circumstances. In most cases, this will require an overhaul of existing university training and education systems, the establishment of better communication networks between academia, industry and society and the creation of stable long term funding sources.

The science and technology complex of an economy is relied upon to play a significant role in the innovation process. Whether by producing professionals, performing research, or responding to specific industrial and social needs, it provides an environment that nurtures the development of indigenous technological capabilities. Where these factors are missing or weak it is likely that innovation will suffer and the application of stronger intellectual property rights will therefore be ineffective. This seems to be the case in many developing countries. Weak science and technology infrastructures provide poor support for innovative industries and thereby reinforce reliance on foreign technology suppliers. In such an environment stronger intellectual property rights are likely to meet with strong resistance from many quarters, including 
local industrialists who see them as a threat, eroding one of their traditional methods of coping - namely imitation based on lax IPRs.

\section{The Coherence and Suitability of Government Policies}

The third key factor of any NSI that must be examined in order to assess the likely impact of stronger intellectual property protection on a developing country is the coherence and suitability of its government policies. This is so, because the dynamics of government policies have an important influence on the "resources, incentives and barriers" relating to all aspects of the innovation process (OECD 1971; 14). The idea is that intellectual property policy, and innovation or technology policy more generally, must be seen as part of a broader set of policies that may complement, or contradict, them, thereby affecting the opportunities and constraints within which innovative firms must operate (Mytelka 1999; 9). Moreover, this broader policy framework is itself embedded within a set of socio-political conditions, which further determine the acceptability and effectiveness of different forms of government intervention (Pack and Westphal 1986; 103).

This approach highlights the importance of examining policies that have an impact on crosscutting issues like innovation, investment, competition, technological diffusion, trade, and in the case of pharmaceutical innovation, public health. Our task is to understand the main policies and public institutions that have traditionally served as effective complements to IPRs in the developed countries and that may therefore deserve 
to be incorporated (in an appropriate form) into the national systems of innovation of certain developing countries. The discussion that follows will focus both on a number of general policy areas, including IPRs policy, competition policy and technology policy, and some specific policy areas, or those that are aimed specifically at the pharmaceutical industry.

\section{Intellectual Property Policy and Its Implementation}

The level of intellectual property protection has traditionally reflected a country's level of technological and economic development, together with its national socioeconomic priorities. Thus, according to the UNDP 2001 Human Development Report, “many of today's advanced economies refused to grant patents throughout the $19^{\text {th }}$ and

early $20^{\text {th }}$ centuries, or found legal and illegal ways of circumventing them - as illustrated by the many strategies used by European countries during the industrial revolution. They formalized and enforced intellectual property rights gradually as they shifted from being net users of intellectual property to being net producers..." (UNDP 2001; 102).

It is not surprising that the economies that have performed well historically, especially in pharmaceuticals, have inevitably done so in an environment of lax IPRs, complemented by supportive government interventions that often included FDI restrictions and significant, selective trade barriers (Rodrik 1999; 1, Romer 1994; 65). The logic of these policy regimes was disarmingly simple. Relatively limited IPRs encouraged the rapid adoption of existing technologies and this was conducive to the 
development of local pharmaceutical industries. Indeed, the formative years of the pharmaceutical industry in the industrialized countries were characterized by extensive international imitation. Many countries, including Japan, Switzerland and Germany, actually delayed the extension of full patent protection to pharmaceuticals until their drug industries had become well established both in world and domestic markets (Frischtak 1990; 89-90). Other industrial countries, like Canada, only reformed their patent laws as late as the 1990s, with several others not doing so until the conclusion of the Uruguay Round, ${ }^{35}$ and then only on account of political pressures from stronger trade partners and certain domestic interests. Thus, the creation of stronger national IPRs regimes generally came rather late in the process of economic development and cannot therefore be credited with triggering the process of economic or industrial development.

In view of this historical reality, it is possible to say that the developing countries in general, are not currently ready for the changes that are implied in the TRIPS Agreement, or for the costs of their implementation. Until now their national systems of innovation and their socio-economic priorities have rightly tended to favour lax IPR regimes. In those cases where patent protection for pharmaceuticals was provided, the scope and duration tended to be limited. By limiting the scope of patent protection, they

\footnotetext{
${ }^{35}$ England extended patent protection in 1949, France in 1960, Germany in 1968, Japan in 1976, Switzerland in 1977 and Sweden and Italy in 1978 (Nogues 1990; 82). The countries that refused to grant any patent protection until the Uruguay Round included Australia, Brazil, Columbia, Malawi, Mexico, New Zealand, Zambia and Zimbabwe (Nogues 1990; 82). Those countries that refused to grant product but granted process patents for pharmaceuticals included Argentina, Bolivia, Bulgaria, Canada, Chad, China, Cuba, Czechoslovakia, Ecuador, Egypt, Finland, Ghana, Greece, Hungary, Iceland, India, Iran, Korea, Lebanon, Libya, Monaco, Mongolia, Morocco, Norway, Pakistan, Peru Poland, Romania, Russia, Syria, Thailand, Tunisia, Turkey, Uruguay, Venezuela, Vietnam and Yugoslavia (Nogues 1990; 82).
} 
made it easier for local firms or inventors to invent around a patent, which served to encourage appropriate local R\&D. In general, a relatively limited patent term enhances knowledge diffusion by reducing the time between the introduction of a new technology and its legitimate imitation. This encouraged the rapid emergence of multiple suppliers of any new technology, which served to restore price competition. On balance, as Arrow $(1962 ; 614)$ has observed, this tended to ensure that knowledge was more widely and effectively exploited within any given society and the same could be said to have been true of the global economy.

Theoretically, the TRIPS Agreement provides countries with various policy options to partially address these and other concerns, particularly those related to public health. Thus, although the TRIPS Agreement demands stronger patent protection levels than most developing countries have traditionally provided, especially for pharmaceuticals, it nevertheless does allow some limited room for interpretation and hence for adaptation to national interests. In other words, there is no one correct way to interpret and implement the TRIPS Agreement. Each country, whether developed or developing, must therefore determine which interpretation of the TRIPS will best address its needs, especially in the pharmaceutical sector, which is linked to so many issues ranging from industrial development to drug access and public health. Neglecting, or relinquishing this right to adapt the Agreement to their national circumstances in response to international political pressure, will mean that the adverse impact of stronger patent rights on their industrial development and public health will be greater than it needs to be. 
Thus, the following sections first consider the three main provisions in the TRIPS Agreement that are particularly important in this regard including parallel imports, exceptions to exclusive rights, and compulsory licensing. After this some administration and enforcement issues concerning the implementation intellectual property policies will be examined.

\section{Exhaustion of Rights and Parallel Imports}

Parallel imports involve the import of goods that are legitimately produced and marketed by a patentee in another jurisdiction without the authorization of the patentee. In other words, "the title holder has no right to control the use or resale of goods which he has put on the market or has allowed a licensee to market" (Correa 2000; 8). This is referred to as the principle of exhaustion since the rights of the IP holder become 'exhausted' once they have marketed their product.

Parallel importing, or more accurately the principle of exhaustion, is dealt with under Article 6 of the TRIPS Agreement. According to this provision, the determination of IPRs exhaustion is left to national legislation and members do not have the right to subject each other to dispute settlement under the Agreement regarding the principle of exhaustion adopted under such legislation. There are two important decisions that national authorities must make in this regard. First, it must be determined whether the law will require the consent of the IP holder before the protected good can be imported into the country, as is the case in many common law countries, or whether exhaustion is 
not subject to the discretion of the IP holder, as is the case in Continental Europe and the United States. In the latter case, the IP owner is considered to have been rewarded, or adequately compensated, by the first sale.

Second, national authorities have to determine whether exhaustion will be associated with the domestic, regional or international market. According to Correa $(2000 ; 9)$ the concept of exhaustion was traditionally limited to the domestic market, which placed an effective import ban on the patent protected product. To avoid the market fragmentation that such a policy could create, however, the European Communities extended the principle to the entire common market. Other countries, like the US and Japan, further extended the principle of exhaustion to the international market, which "means that whichever the exporting country may be, the IP title-holder is not granted the right to prevent the parallel importation of a product that was put on the market in the said country with his consent or otherwise in a lawful manner" (Correa 2000; 9).

Developing countries are best off to adopt an international exhaustion regime where imports do not depend on the consent of the IP holder. As we will see in chapter seven, their right to do so is being contested by various international interests, particularly the pharmaceutical industry, who want to eliminate or reform Article 6 of the TRIPS Agreement which effectively gives countries the freedom to use parallel imports as an instrument to restore competition and improve access to patented drugs, thereby enabling smaller markets to benefit from larger more competitive ones. This right needs 
to be protected even in the face of today's strong opposition.

\section{Exceptions to Rights Conferred}

The 'exceptions to rights conferred' is dealt with in Article 30 of the TRIPS Agreement. This means that members may, in formulating their patent legislation, define conditions or events that effectively limit the monopoly rights of the patent owner. In doing so, however, members have to accept that the exceptions are to be limited, that they do not unreasonably conflict with the normal exploitation of the patent, and that they do not unreasonably prejudice the legitimate interests of the patent owner. Thus, the right to limit patent rights is itself limited and provides that exceptions must be 'adequately' justified through a demonstration that the interests of third parties are otherwise being violated.

Within the above conditions members may justify their decisions to limit IP rights on a variety of grounds. According to Correa $(2000 ; 14)$ such exceptions may include: acts done privately for non-commercial purposes; use of the invention for research purposes; experimentation on the invention to test or improve it; preparation of medicines under individual prescriptions; experiments made to obtain regulatory approval in order to market the product immediately after patent expiration, and so on. These are all arguably legitimate and permissible grounds for placing limits on patent rights.

Exceptions related to research are particularly important for developing countries as it may open opportunities for subsequent innovations. Yet, as Correa $(2000 ; 15)$ 
observes, many developing countries do not seem to have taken advantage of this allowance whether for scientific or commercial purposes (Correa 2000; 15). Also important is the exception regarding experiments made to obtain regulatory approval, commonly referred to as the "Bolar" exception. The Bolar exception allows generic drug manufacturers to commence pharmaceutical testing to obtain regulatory approval for the generic version of a patented drug before the relevant patent has expired so that it may be possible to market the product immediately upon patent expiration. In exchange for this facilitation for generic drug manufacturers, some countries, like the US and Japan, provide patent term restoration (an additional period of protection of usually five years) for the IP holder, while others, like Canada, do not. There is no need for developing countries to consider patent extensions unless concessions like local production of the drug, application of the state of the art technologies, training personnel, and price reductions are obtained from the IP holder in exchange. Without such arrangements patent extensions will only serve to weaken the development of the local industry, delay competition and deny consumers affordable alternatives to the patented drug.

\section{Compulsory Licensing}

A compulsory license is a license granted by an administrative or judicial authority that allows a third party to employ a patented invention without the express permission of the IP holder. These grants are usually premised on the protection of the public interest and have been widely used in the developing countries to facilitate generic 
drug competition with brand name products even before a patent has expired.

Compulsory licensing, or 'use without authorization of the right holder', is the subject of Article 31 of the TRIPS Agreement. The purpose of this Article was to set limits on the use of compulsory licensing especially in the developing countries. It achieved this aim by stipulating a series of conditions that must be met in order for a compulsory license to be considered legitimate under the rules of the TRIPS Agreement. These conditions include the following: (1) the authorization of each case must be considered on its individual merits; (2) all reasonable efforts must have been made to obtain the authorization of the right holder within a reasonable period of time and on reasonable commercial terms; (3) the scope and the duration of the license are to be limited for each specific case; (4) use of the license shall be non-exclusive; (5) the license shall be non-assignable; (6) use of the license shall be limited to "predominantly" serving the local market; (7) the license is to cease when the conditions that prompted its issuance cease; and (8) the right holder is to be compensated according to the economic value of the invention.

Despite these procedural limitations, the TRIPS Agreement does not limit the grounds on which compulsory licenses can be granted, although reference is made to public non-commercial use, addressing public health emergencies and remedying anticompetitive practices. This seems compatible with the fact that compulsory licensing is widely used in North America, Japan and Europe for diverse purposes. Indeed, the US government has national provision to use or authorize third parties to use patents for 
virtually any public use without negotiations. According to Correa $(2000 ; 19)$, compulsory licenses have also become a "typical feature" of developing country laws. Some of the procedural conditions in the TRIPS, however, are creating major problems for these countries. For example, limiting the use of compulsory licenses to 'predominantly' serving the local market means that countries without manufacturing capacity cannot make use of this tool. In other words, without being able to import products under compulsory licenses many countries would not be able to benefit from Article 31. And those countries that could not export products under compulsory licenses because of this provision would not be able to take advantage of economies of scale. The problem is discussed in greater detail in chapter seven.

\section{Administration and Enforcement}

In addition to the imposition of these new IP policy constraints, the TRIPS also entails significant direct costs associated with its administration and enforcement in the developing countries. In fact this was a major concern for many developing countries during the Uruguay Round (Namfua and Yusuf 1991; 6) who made it clear during the negotiations that they were concerned with how they would obtain the resources to fulfill the administrative and enforcement requirements of the new global IPRs regime, given their already limited public resources. It is noteworthy that the United States spends \$1 billion annually on its Patent and Trademark Office, with Europe and Japan trailing close behind. Yet "despite these investments in rich countries, the quality of US patent 
examinations is poor" (Love 2001). Of all the patents litigated to judgement, Lemley and Allison (1998) found that 54 percent were found to be valid while 46 percent were found to be invalid (in Love 2001).

Part of the problem is due to the impossibility of giving a precise definition to the criteria for patentability, namely, novelty, inventiveness and usefulness. "Thousands of patents are granted each year by patent offices in the world for minor, purely trivial developments or for substances (including genes) that already exist in nature and which have merely been discovered but not invented by the would-be 'owner"' (Correa 2000; 17). For many developing countries, which have had little opportunity to develop local expertise in applying standard patentability criteria in ways that can effectively balance private and public rights, such problems are likely to be magnified. It is likely that the poorly funded and staffed patent offices in these countries will simply accept the decisions of the industrial countries in "the mistaken belief that an examination conducted by the patent office of a highly industrialized country is a sound guarantee" that the criteria for patentability have been truly met (Correa 2000; 17-18). But this is not so, and at the end of the day, the granting of frivolous or obstructionist patents jeopardizes technological diffusion in the medium term and innovation and growth in the long run.

According to UNCTAD $(1999 ; 20)$ developing countries have to deal with the following issues in order to comply with the TRIPS Agreement: (1) bring their legal frameworks in line with the Agreement's general obligations; (2) staff the necessary 
administrative offices; (3) strengthen enforcement mechanisms; (4) increase training; and (5) enhance capabilities to monitor technology transfer agreements and to guard against potential IPR abuses. The extent of the burden that this imposes differs between countries. For some, it means establishing entirely new administrative and enforcement systems, while for others, it merely implies reforming and strengthening existing systems. But in both cases substantial initial investments will be needed.

Although some of these costs can be recouped by governments through filing, examination, publication, registration and maintenance fees (UNCTAD 1999; 36), most of the initial costs of establishing the new system and of training the needed personnel will have to be assumed by each country from within existing budgets. The TRIPS Agreement recognizes the extent of the difficulty that such costs may entail and therefore provides for some technical and financial assistance to defray some of these costs. Critics, however, have argued that these provisions are too vague and do not make cooperation mandatory for the developed countries. There is some irony in this situation since it is clearly in the interest of developed countries to have these new rules implemented effectively. Indeed, in 1997 UNCTAD, "remind[ed] industrialized countries that it is in their own interest to assist developing countries in their efforts to implement the Agreement through technical and financial support..." as "it is evident that the primary and immediate beneficiaries of the implementation of the TRIPS Agreement are likely to be technology and information developers in the industrial countries" (UNCTAD 1997; 4). 


\section{Competition Policy}

Of all the related policy areas examined in the literature discussing IPRs in the context of developing countries, competition policy ${ }^{36}$ receives the greatest attention, which is not surprising, since patents are instruments to curtail competition. Experience suggests that several conflicts may emerge between competition policy and IPRs, including instances where intellectual property rights are used in a manner that violates the objectives and principles of such protection, which includes the extension of protection beyond its intended purpose, the restraint of trade, and the inhibition of technology transfer (UNCTAD 1997; 53). The fact that developing countries are net technology importers, with weak or non-existent competition rules, raises legitimate concerns that stronger intellectual property rights may facilitate anti-competitive practices, or abusive behavior, by patent right holders. ${ }^{37}$

The introduction of stronger patent protection will alter the competitive environment within which domestic firms must operate. It is plausible to argue that the premature imposition of stronger patent regimes is similar to the premature opening of markets to international competition, where 'potential opportunities' cannot be taken advantage of by a firm or industry because they are not yet in a position to do so. In this

\footnotetext{
${ }^{36}$ According to Singh and Dhumale (1992; 2 in Correa 2000;2) competition policy may be defined as "a body of laws, administrative rules and case law which are employed to deter restrictive practices so as to maintain fair competition."

${ }^{37}$ Such behavior includes: cartel-like restraints, exclusionary conduct, monopoly leveraging by dominant firms, practices or mergers that may dampen innovation and the impact of overly broad IPRs (UNCTAD $2001 ; 3)$
} 
regard, it has been observed that in a number of Latin American countries, the premature opening of markets had significant adverse effects (Mytelka 1999; 22). Without adequate systems to facilitate the adjustment of domestic firms many competitive enterprises went bankrupt, declined, transformed production to imports, or replaced some of their innovative activities with licensing (Mytelka 1999; 22). Similarly, the premature imposition of stronger patent rights may lead to the misallocation of R\&D resources and to the loss of dynamic gains that had traditionally resulted from the reverse engineering and sequential innovation through which local producers had been able to access existing technologies. Competition laws should therefore be designed to address these possibilities.

It is noteworthy that the strengthening of IPRs in the developed countries has generally taken place within a "framework of effective application of competition policy" (Correa 2000; 2). These countries have an extensive tradition of developing competition rules that are related to IPRs through legislation, case law and enforcement procedures (UNCTAD 2001; 4). The developing countries, on the other hand, have little or no such experience partly because their ability to make coherent policy is often compromised by lack of resources, and a lack of sovereignty due to their frequent inability to resist excessive foreign interference in their policy process.

Competition policies vary according to place and time and it is widely acknowledged that economic, social and cultural interests influence competition laws (Ullrich 1998; 12 in Correa 2000; 3). In general, however, it is possible to say that the 
determination of anti-competitive behavior depends on several factors, including the extent of IPR protection, the economic and social significance of the product (or process) that is being protected, market structure, the nature of competitors and the national goals that have been defined (UNCTAD 1997; 3). This makes the task of developing suitable competition policies very difficult, especially since the developing countries cannot simply emulate developed country regulations both because their circumstances are so different and because developed country policies continue to be hotly contested and problematic.

Yet despite the many difficulties, competition policy must be used to remedy anticompetitive practices that may arise with stronger IPRs (Correa 2000; 4). Hence, as the TRIPS Agreement is implemented in the developing world, we have seen most countries develop new competition policies. However, these are not always uniform and serious enforcement problems remain. Actually, one of the main enforcement problems stems from the fact that most of the intellectual property that is being protected in the developing world is owned by foreign enterprises. The enforcement of competition rules is therefore most likely to affect such firms and this means that developing countries will be unable to enforce those rules without international assistance and cooperation (UNCTAD 2001; 21), which is unfortunately not easy to obtain.

Currently there is no international competition framework, although the EU has repeatedly called for one. Ironically, progress has been slow in part because developing countries worry that such a framework would restrict their ability to formulate suitable 
national competition policies. Ultimately they are right to be concerned, though they must balance this fear against the fact that they need international cooperation to enforce 'their' national regulations. This goes to the heart of the contradiction that confronts developing country policy makers time and time again. For the moment governments are largely free to decide on the appropriate interface between IPRs and competition policy, although their IPR regimes must take account of the TRIPS. In this regard, Article 8.2 of the TRIPS Agreement accepts that appropriate measures may be "needed to prevent the abuse of intellectual property rights by right holders or the resort to practices which unreasonably restrain trade or adversely affect international transfer of technology." But the Article also stipulates that any remedies that are devised must be consistent with the general provisions of the Agreement. Similarly, Article 40.1 acknowledges that IPRs "may have adverse effects on trade and impede the transfer and dissemination of technology," but it also establishes clear limits to the types of national action that can be taken in response to such adverse outcomes. In short, there is autonomy, but it is clearly and explicitly constrained.

Notwithstanding these limitations, it is crucial that developing countries devise effective competition policies that conform to their national priorities and that address the potential problems that can arise with stronger patent rights under their circumstances. Indeed they must understand that "defining and enforcing an adequate competition policy regarding the unilateral exercise or the contractual exploitation of intellectual property protection is not a secondary concern that might await the establishment of a TRIPS- 
compatible intellectual property system, but rather must go hand-in-hand with it" (UNCTAD 1997; 4).

\section{Technology Policy}

In this study we have noted that the basic rationale for IPRs - to inhibit the diffusion of new technology in order to guarantee the rapid development of new technology to be diffused in the future - is largely inapplicable to the conditions that characterize the early stages of development when innovation and diffusion are largely complementary processes. We have also noted that one of the most outstanding outcomes of the TRIPS Agreement will be the inhibition of diffusion for prolonged periods and an increase in the cost of technology acquisition for developing countries. This highlights the vital importance of active technology policies in the developing world to counter or minimize these adverse consequences.

Technology policy may be narrowly defined, in which case it is primarily concerned with the promotion of $R \& D$, or it may be broadly defined, in which case it overlaps with elements of competition, trade and financial policies. In reality, the diversity of government policies makes it difficult to make any broad generalizations. However, it is important to explore some of the more popular instruments in use in many developed (and increasingly developing) countries today to encourage innovation and technology transfer.

Although the adoption, adaptation and creation of new technologies is largely the 
responsibility of private actors, governments do have an impact on this process through their diffusion/technology policies. According to Stoneman and Vickers (1988; ix) diffusion policy should be thought of as extending beyond the simple provision or dissemination of information, to include subsidies and any other incentives that speed up the adoption of new technologies and encourage investments in R\&D. Indeed, as noted in the previous chapter, knowledge has many of the characteristics of a public good and therefore too much competition will tend to lead to an under investment in such activities. For this reason governments in both the developing and developed countries have tended to promote such investment in a variety of ways. According to Ostry and Nelson (1995; 87) jointly funded R\&D consortia by government and private firms are a standard feature of domestic technology policies in Japan, the US and Europe. This is also the case in the Newly Industrialized East Asian economies. For example, in South Korea the government encourages private firms to establish research facilities to promote industrial restructuring and technological development and in Taiwan scientists are encouraged to set up their own firms in order to commercialize the results of their R\&D (OECD 1992; 268).

The provision of adequate funding for innovation is obviously critical for building technological capabilities (Segal 1987; 28), which makes it an important focus of state intervention in many industrial countries. State supports, which include the provision of matching funds and the co-financing of $R \& D$ through technology funds where loans are only repaid if projects succeed (UNDP 2001; 83), can encourage firms to make risky 
R\&D investments. Such measures, however, are increasingly contested as the 'standard' view claims that discretionary subsidies are necessarily inefficient and undesirable. They are therefore strongly discouraged by new international agreements, while being treated as anathema in most mainstream economic discussions. Moreover, many economists and policy makers argue that such direct supports give national firms an unfair advantage over rivals in other countries (Ostry and Nelson 1995; 30) and violate the concept of national treatment. From this standpoint support for universities and public research institutes that have direct links to industry seem more attractive if only because they are less visible politically (Nelson 1996; 289).

Many governments have also been active in creating or reforming financial structures and services to better serve innovative enterprises (Nelson 1996; 287). "The role played by national banking systems in the financing of $R \& D$ and intangible investments is now considered an important factor in shaping structural competition in each country" (OECD 1992; 20). Some governments have even played an important role in establishing venture capital industries to stimulate innovation. However, most developing countries lack the sophisticated financial systems that are a prerequisite for attracting large volumes of venture funds (UNDP 2001; 84).

Another way that national authorities can enhance the diffusion and adoption of new technologies is by designing and enforcing regulations that ensure effective technology transfer. Several countries, including many from the developing world, have specific regulations for the control and facilitation of technology transfer agreements. 
For many developing countries these regulations were put on the agenda by the failed negotiations over an International Code of Conduct for the Transfer of Technology in the 1970s under the auspices of UNCTAD. Before they collapsed, these negotiations had identified certain practices as unacceptable, given the technological needs of the developing countries. This included the charging of excessive royalties, the inappropriate charging of other costs, the imposition of restrictions on research or on the commercial and industrial activities of the licensee, including export restrictions, price, quantity or geographical limits on operations. Unfortunately, "many of such laws [in the developing countries] were substantially modified or repealed during the $1990 \mathrm{~s}$, as part of a process of liberalization of economies" (Correa 2000; 13). The problem is that while these regimes were gradually being dismantled, competition policies were not being formulated to regulate the resulting restrictive practices and technology transfer abuses (Correa 2000; 13).

In this regard, the TRIPS Agreement claims to encourage the transfer of technology from the developed to the developing countries and explicitly allows for national legislation that aims to control undesirable technology transfer practices. ${ }^{38}$ Nevertheless, it leaves the direction and rate of such transfers up to the negotiating abilities of the parties involved and makes no recommendation on how such transfers should take place nor does it define clearly when the spirit of this requirement is being violated. Developing countries must therefore press for adequate commitments from the

\footnotetext{
${ }^{38}$ The TRIPS Agreement cites exclusive grant back provisions, obligations not to challenge the validity of
} 
developed countries to ensure the flow of technology.

Other policies that may affect innovation and technology transfer include those related to trade, education and training and government procurement policies. Export subsidies or protection from imports may enhance local production and technological capabilities and give local firms an advantage over foreign rivals (Stoneman and Vickers 1988; x). Education and training policies help ensure the quality and availability of scientific personnel both for industry and for the domestic science and technology complex. Finally, procurement policies may act as a hidden form of protection for the purpose of technological advancement (Stoneman and Vickers 1988; $\mathrm{x}$ ).

This discussion highlights the importance for developing country policy makers to realize, as they embark on the design of policies to accommodate the TRIPS Agreement, that arguments to adopt laissez faire/laissez 'innover' approaches to technology development are not well supported by the evidence. The creation of good framework regulations including well defined property rights, effective contract enforcement, the rule of law and reasonable equality of application (Lipsey 1991; 5) is very important, but it is not enough. In promoting their high technology industries, the developed countries have complemented such measures by a diverse array of interventions including policies dealing with science and technology, industrial competitiveness and exports (Malecki 1997; 239, Ostry 1990; 53, Ostry and Nelson 1995; 61). 


\section{Policies and Regulations Specific to the Pharmaceutical Industry}

In addition to the above policies that can help to determine the implications of stronger global pharmaceutical patents for developing countries, it is also necessary to consider specific policies designed to impact the pharmaceutical industry in particular. This includes all those measures that governments use to rationalize drug expenditures in accordance with their health care needs and their current level of development. Such measures are important for various reasons. They not only influence the supply and demand of pharmaceutical products, which in turn affects the profitability of firms and their strategies regarding innovation, they also aim to ensure that the pharmaceutical industry plays a constructive role in the achievement of national health goals. This once again draws attention to the fact that the intellectual property rights regime is only one of many regulatory measures that determine the behavior of the pharmaceutical industry. Moreover, it serves as a reminder that it is necessary to go beyond strict definitions of national systems of innovation when studying the pharmaceutical sector because that industry is also distinguished by its primary role in national health care systems.

Regulation of the pharmaceutical market is very complex and differs from country to country. There are, however, several policies that seem to be prevalent in many countries, irrespective of their level of income or industrialization (Saxenian 1994; 1). These include: essential drug lists or formularies, rules on competitive procurement or bulk purchasing, rules governing generic drug substitution, various forms of price control, user fees, and the provision of better information for health care workers and 
patients. While all such regulations have a significant impact on competitiveness, efficiency and innovation in the pharmaceutical industry, it is important to bear in mind that their primary goal is to enhance the welfare of those who are ill.

In all countries, governments are responsible to some degree for designing and administering public health systems and insurance schemes, and in regulating private health care firms. In doing so, one of their concerns is to ensure that the costs of medical treatments, including the cost of drugs, remain affordable for most citizens and groups. As a result, governments invariably end up being heavy, if not the main, purchasers of drugs, as they seek to obtain the best possible prices for off-patent drugs, by restricting the monopoly rents accruing to patented drug owners (Jacobzone 2000; 9).

Formulating appropriate pharmaceutical policies requires a lot of detailed information, which may often be challenging for developing countries to acquire and to update on a continuous basis. In addition, it requires policy makers who are knowledgeable about factors that influence demand, like user fees and physician prescribing behavior, and supply, like $\mathrm{R} \& \mathrm{D}$, marketing, patent protection and changing production costs (Jacobzone 2000; 15). Regulating demand first involves 'defining' the market, i.e., determining the rules for market authorization and eligibility for reimbursement. All countries have specific market authorization guidelines. However, “most developing countries lack well-functioning drug regulatory systems, backed up by a quality control laboratory, that can keep nonsensical drugs, ineffective drugs, and poorly made products out of the market" (Saxenian 1994; 2). On account of such 
difficulties some developing countries rely on the safety and efficacy procedures of the advanced industrial countries.

Strict regulatory regimes that serve to ensure the safety and efficacy of pharmaceutical products, however, have often been the subject of intense criticism by the industry whether in the developed or developing countries. Procedures to gain market approval for products tend to be both costly and time consuming. This is why some industrial countries, under pressure from their pharmaceutical industries, have agreed to grant patent term extensions or patent term restoration for alleged 'time lost' in the regulatory process.

In addition to market authorization policies, most countries have a universal system of drug coverage or insurance. It is common to find health authorities in developing countries using essential drug lists or formularies to guide the selection of products and to determine the quantities that should be kept in stock in various institutions, or for which patients can be reimbursed. In some developed countries, like Canada for instance, private insurance bodies are however permitted to define their own drug lists. Laing (1990 in Saxenian 1994) has observed that, when combined with education, essential drug lists or formularies can contribute to a significant decrease in drug expenditures.

Because demand tends to be price inelastic for many drugs, it can be influenced by physician prescribing behavior, government procurement and price controls. Public policies and guidelines that influence physician-prescribing behavior include information 
provision and even financial penalties on providers prescribing too many drugs or overly expensive drugs (Saxenian 1994; 3). In developing countries these efforts may be of limited value since a high proportion of drugs consumed are self-prescribed. However, the brand name pharmaceutical industry nevertheless tends to expend large sums in its efforts to influence physician-prescribing behavior.

Governments and large purchasers can also influence the demand and the availability of drugs through competitive procurement methods and bulk purchasing which enables them to obtain drugs at low cost. Through these mechanisms, organizations can often obtain steep discounts on brand name and patented drugs (Saxenian 1994; 7). However, competitive procurement systems require specialized technical skills as well as access to comprehensive pharmaceutical information (Saxenian 1994; 7) and these requirements may be challenging for many developing countries which may be why so few of them take advantage of international competition or international agencies, like the International Dispensary Association and UNICEF, in pharmaceutical purchasing. For some the main problem may, however, be largely due to short-term liquidity constraints (Saxenian 1994; 8).

Many countries, in both the developed and developing worlds, also have regulations that control the prices of pharmaceutical products directly. Price controls are largely designed to counter the monopoly power of firms enjoying patent protection, although they may also be applied to generic drug substitutes. The two main methods used to control prices are profit control or "cost-plus" regulations, which are based on 
production costs while allowing for a certain profit margin, and "fixed" price systems, which involve fixing prices and allowing for free supply behavior (Jacobzone 2000; 33). In the case of Egypt, limits are also generally placed on the number of allowable substitutes on the market at any given point in time.

In most OECD countries, with the exception of the US, Germany and Denmark, governments usually combine systems of free and fixed pricing. Several factors are usually considered when fixing the price of a drug including its therapeutic value, reference to existing products, reference to international comparisons, and the contribution of the pharmaceutical industry to the economy (Jacobzone $2000 ; 34)$. In contrast many developing countries base their price control regimes on 'cost-plus' formulations despite the method's numerous problems (Saxenian 1994; 12). These problems include the need for extensive data review to verify the true costs of production. Multinational enterprises often use transfer pricing to manipulate the calculation of production costs or attempt to continuously re-introduce the same product with minor variations, to get price increments approved. However, if price controls do not take adequate account of inflation or of changes in production costs, products may be discontinued or quality may suffer. Finally, there are problems of transparency in the application of such price controls, with negotiations always being vulnerable to corruption.

The supply and demand for pharmaceutical products is also influenced by generic drug substitution policies, which substitute less expensive drugs with similar or identical 
therapeutic effects for expensive brand name, or on patent, drugs. Many countries are active in fostering the use of generic drugs to curb health care expenditures despite strong opposition from the brand name pharmaceutical industry. Generic substitution can have a significant impact on the profitability of brand name firms, particularly as their best selling products go off patent. Governments usually rely on the dissemination of information and economic incentives to promote the use of lower-priced generic drug substitutes. They may also pass regulations, as in the US, that allow pharmacists to fill prescriptions with generics and/or that require both the brand and generic names of a product to be included on the packaging to facilitate substitution.

Although not strictly considered part of a national system of innovation, these aspects of health policy, through their impact on supply and demand in the pharmaceutical sector, can have a significant influence on the innovation strategies of pharmaceutical firms. As such, these policies may impact or mitigate the implications of stronger IPRs in particular national settings. It is important to recognize, however, that these efforts can only be as effective as a country's institutional enforcement mechanisms. They are also dependent on a country's "health care finance and delivery system, its level of trained manpower, including pharmacists and physicians, the capacity of the drug regulatory agency, features of the pharmaceutical distribution system, and pharmaceutical spending levels" (Saxenian 1994; 3). All of these factors are likely to influence the outcomes of the TRIPS Agreement as they relate to the pharmaceutical industries of developing countries and particularly as they relate to their public health. 


\section{CONCLUSION}

This chapter developed a national system of innovation approach to assessing the implications of stronger IPRs for the pharmaceutical sectors of developing countries. The national system of innovation was defined to include all aspects of a national economy that interact to influence innovation including history, language and culture, which are considered to have an important impact on the dynamics of policy change. Inevitably the diversity of such an approach makes generalizations regarding the specific implications of the TRIPS Agreement very difficult. However, it does permit a contextualization of patent policy reform and offers a more realistic view of the complexity of the innovation process.

Our discussion of innovation has brought to light two major issues. First, the linear view of technical change that is implicit in most mainstream intellectual property analyses fails to distinguish clearly enough between patent theory and patent policy. Thus, although the theoretical foundation of mainstream intellectual property rights theory is basically designed to deal with the circumstances surrounding basic research, intellectual property policy is mainly used to encourage more applied research activities in which risk and uncertainty tend to be much less. This confusion may easily lead to inappropriate patent policies that do not adequately disentangle private and public rights.

Second, our discussion has revealed that this misleading conceptualization of the innovation process as a linear one, obscures the very important fact that it is actually an 
evolutionary process that is based on a complex and interactive process of learning, searching, exploring, and utilizing existing knowledge. From such a perspective diffusion is not something separate that happens after innovation has occurred, but something that tends to play a significant role in innovation itself. In fact the international diffusion of technology is almost certainly closely related to innovation, technological progress and economic growth, especially in the developing countries where innovation is initially generally based on imitation, which is facilitated by the existence of lax patent regimes, among other things.

Thus, in order to understand the full implications of the TRIPS Agreement for developing countries, we must look beyond the resulting changes in intellectual property regimes to consider other national factors that will influence the process of innovation and the operations of the pharmaceutical industry more generally. To this end, this chapter has considered three key elements of national systems of innovation including the innovative strength of firms, the scientific and technological infrastructure of a country and the coherence of government policies dealing with innovation or the operations of the pharmaceutical industry in the interests of public health.

Although these three key elements were discussed separately, it is critical to recognize that their harmonious interaction is central to economic and technological development. Indeed, innovation depends on the quality and number of components in a national system of innovation, as well as on the relationships between firms, suppliers, markets, public institutions, financial and banking institutions, education and training and 
infrastructure (OECD 1992; 22).

In the remainder of this study we will be applying the framework developed in this chapter to assess the likely implications of the TRIPS Agreement on the pharmaceutical and health sectors of Egypt. Although some commentators have argued that it is too early for such assessments, since many developing countries, including Egypt, have not fully applied the Agreement at this time, the NSI approach outlined here should give us a reasonable idea of what to expect with regard to pharmaceuticals and public health when that Agreement is fully implemented. This approach will also enable us to identify the complementary policy changes that might allow this policy shift to yield significant net benefits for the developing world. 


\section{CHAPTER FIVE}

\section{PATENT POLICY AND THE EVOLUTION OF EGYPTIAN PHARMACEUTICALS}

This case study will seek to assess the implications of the TRIPS Agreement on Egypt's pharmaceutical industry, and on its health sector, from a national system of innovation perspective. This requires some understanding of key aspects of the evolution of Egypt's pharmaceutical industry, since that has shaped the context for contemporary responses and outcomes of TRIPS related patent policy reforms. There are basically five

phases that characterize the evolution of Egypt's pharmaceutical industry. ${ }^{39}$ An examination of each phase shows that Egypt's domestic industry has undergone quite revolutionary changes as it sought to cope with the radically different policies of three different military regimes, ranging from state led import substitution policies to market led export promotion policies. Yet in spite of these dramatic policy shifts, successive governments have remained focused on the need to avoid excessive reliance on foreign manufacturers in order to more effectively manage society's public health needs.

There are three basic aims of this brief historical and contextual account. First, it aims to demonstrate that a relatively weak pharmaceutical patent policy has been instrumental in fostering the emergence of a vigorous domestic industry that has come to satisfy a great proportion of domestic demand. However, it was only during a brief episode in the 1960 s, when this patent policy was complemented by a comprehensive 
pharmaceutical plan, that the innovative potential of the industry was revealed.

Second, that the industry that did emerge in this process achieved this approximate national self-sufficiency in ways that were desirable from a public health point of view, in the sense that it supplied needed drugs relatively reliably and at affordable prices. And finally, that the industry that emerged in this way had relatively limited innovative capacities, which is not surprising given the strategy that was adopted starting with the 'open door' policies of the Sadat regime. These historical realities have conditioned the most likely domestic response to a strengthened patent regime today.

\section{PHASE ONE (1933-1961): ESTABLISHING THE DOMESTIC INDUSTRY}

The first phase begins with the birth of the domestic pharmaceutical industry which occurred when the coming of the Second World War triggered the growth of Egyptian financial capital because it reduced the exporting capabilities of multinational firms based in the industrial countries (Galal 1983; 237). As a direct result, two specialized pharmaceutical plants were initially established in Egypt: Misr Company (Misr Bank) in 1939 and C.I.D. Company (the Industrial Bank) in 1940. Soon thereafter, other private companies sprang up, with Memphis Pharmaceuticals joining the two original ones to become one of the three largest locally owned firms. By the end of this phase, 16 medium sized enterprises and 22 small drug laboratories had joined these three

\footnotetext{
${ }^{39}$ The Egyptian Academy of Scientific Research has determined these historical divisions.
} 
companies. The state's role during this initial phase was relatively limited. Weaknesses in the system of drug registration, inspection and testing by laboratories run by the Ministry of Health, reinforced the state's 'laissez faire' approach. In fact no special protectionist measures had been introduced to foster this emerging local industry, which faced intense competition from foreign-owned firms who constituted the primary source of domestic supply (approximately 90 percent).

To make matters even more challenging for the local industry, in 1949 the government adopted a new patent law as part of its preparations to become a member of the Paris Convention for the Protection of Industrial Property ${ }^{40}$ two years later. Law No. 132 "Concerning Letters Patent and Industrial Drawings, Models and Inventions," provided patent protection only for pharmaceutical processes for a period of ten years from the date-of-filing. To its supporters, the law was designed to fulfill four main objectives. First, it was a necessary measure for Egypt to fulfill its pending obligations under the Paris Convention. Second, it was hoped that the availability of this form of protection would stimulate the search for new methods of production, which would encourage $R \& D$ efforts that were thought to be commensurate with local capabilities and resources. Third, it sought to promote effective competition between drugs with the same therapeutic effect, which could be expected to lower market prices. Finally, because the law only provided process as opposed to product protection, local technology importers

\footnotetext{
${ }^{40}$ Among other things, membership in the Paris Convention would guarantee minimum standards of intellectual property protection for Egyptian nationals who wished to apply for patent protection in other member states.
} 
could avoid certain licensing restrictions that dictated raw material and intermediate goods supply sources, allowing them to keep their costs down. However, critics of the law claimed that it was nothing more than a measure aimed at inhibiting the industry's development since it restricted the previously free use of foreign technologies.

By the time of Gamal Abdel Nasser's 1952 Revolution the development of the national pharmaceutical industry had remained relatively limited, especially in comparison to its foreign counterparts. Market structures, in which multinational interests were still heavily entrenched, significantly restricted the growth of local producers by discouraging many of them from investing in much needed expansion of their own facilities (Galal 1983; 237). Thus, the domestic industry remained primarily a collection of small laboratories 'formulating' imported raw ingredients into pills, syrups, and vitamins, based on products developed elsewhere by MNEs. Moreover, quality levels remained low, as there was no effective mechanism for monitoring or enforcement. And incentives for the performance of indigenous research and development remained woefully inadequate.

However, by 1956 this sluggish performance was set to change, again under the impetus of war. In this case, the economic blockade of Egypt by England and France during the Suez Crisis, demonstrated the urgent need for Egypt to develop a significant local pharmaceutical industry by highlighting the risks of being totally dependent on external suppliers for critical drugs. At the time the only company manufacturing a treatment for schistosomiasis, commonly known as bilharzia, was a British-owned one 
and it ceased production during the blockade, allegedly because of poor sales. Although the health authorities attempted to persuade the company to continue production by agreeing to a higher price, the firm remained unrelenting, leaving Egyptian authorities no choice but to find ways to manufacture the drug locally. Ironically, those local efforts eventually resulted in a drug that was 80 percent purer than the original British version.

This incident was significant in shaping the future course of Egyptian pharmaceuticals policy for two main reasons. First, it demonstrated that in an uncertain world it was very dangerous for Egypt to rely too heavily on foreign suppliers for its key pharmaceutical needs. Second, the success of this attempt suggested to Egyptian policy makers that Egypt probably had the capability to greatly expand and improve its homegrown industry, even within the framework of the new IP law. As a result, the market share of local firms began to grow steadily even as local consumption increased, so that by 1962 the domestic industry was supplying approximately 29 percent of domestic consumption.

This era introduced many far-reaching changes in the structure and operation of the industry - a legacy that has not fully dissipated even today. The first significant measure of the Nasser regime was to place a ceiling on the profits of distributors, although according to Galal $(1983 ; 237)$ this was quickly neutralized by false export prices which in turn led the state to take action to regulate import purchasing and transfer pricing. Specifically, the state concluded that the high cost of the raw materials imported 
by small individual firms was a major problem and was largely due to their inability to obtain more favourable terms through concerted action. To remedy this problem, the state established government monopolies for the importation and distribution of drug ingredients and products in an effort to negotiate more favourable prices and to improve quality control. The Supreme Organization for Drug Planning and Control, established by Law 290 of 1960, was to rationalize importation to the local formularies. In retrospect it seems that this decision did strengthen Egypt's capacity to make good pharmaceutical policy, partly by enhancing local knowledge of the international pharmaceuticals market, including different supply sources and price opportunities. Furthermore, it allowed health regulators to become more familiar with the generally accepted quality standards for the materials required in the drug production process, and to learn about the formal standards used in other countries, or the industrial standards used by firms, to establish the relative quality of materials obtained from different sources of supply.

\section{PHASE TWO (1962-1975): NATIONALIZATION}

The second phase (1962-1975) of the industry's evolution is generally considered the most significant one in the development of the pharmaceutical sector. During this period the state made no changes to its pharmaceuticals patent policy but rather complemented its IP regime with the introduction of a comprehensive plan for the development of the industry. Indeed, it is widely accepted, even among leading mainstream economists like Eggertson, that the thrust of Egypt's pharmaceutical policies 
during this era was "well suited for the mobilization of resources, forced industrialization, and for taking advantage of economies of scale in various basic industries" (Eggertson $1990 ; 334){ }^{41}$

The resulting short-lived golden age of pharmaceutical development began in 1962 when the state intervened dramatically to reorganize the trade and production of drugs. This took the form of a comprehensive nationalization program that was introduced partly in response to the disintegration of Egypt's relations with its traditional drug suppliers. For this purpose, the government created a General Organization for Drugs, Chemicals and Medical Appliances, and fostered and encouraged the merger of smaller enterprises into larger, more viable, economic units.

The 'General Organization' monopolized the importation, production, distribution and planning of pharmaceuticals, under the auspices of the Ministry of Health. Its primary goal was to achieve national self-sufficiency in drug production. In order to achieve this goal the state began a program of import substitution seeking to develop local production to the point where it would account for the greatest possible share of local consumption. To this end, it established a domestic company, El Nasr Chemicals Company, for the manufacture of the main raw material ingredients needed for local pharmaceuticals production. The Organization also allowed for the local production of drugs that were not categorized as essential, like vitamins and painkillers, after full consideration was given to their socio-economic importance.

\footnotetext{
41 This was the case with many 'Soviet-type' economies at the time.
} 
Imports were to be based on necessity only. This meant that if local production of a drug was possible, it would not be imported, and that in all cases, imports would be limited to essential drugs only. Moreover, in order to curb transfer pricing by MNEs, all imports would henceforth have to be approved by the Organization. In the event that a multinational company refused to lower its prices when requested to do so, and this was common on account of fears that other countries would follow Egypt's lead, the General Organization frequently resorted to importing the needed products from cheaper markets.

As critical as these policies were, Dr. Essam Galal, the Organization's second director, insists that the most significant role of the General Organization was in regard to its emphasis on the importance of $R \& D$ for industrial development. Under his directorship, the General Organization created a major research center that was financed by mandatory contributions ( 1 percent of sales) from local and foreign companies. Researchers were sent to train in MNEs both in Egypt and abroad and needed equipment was readily purchased from these companies. Soon research projects were initiated to find treatments for schistosomiasis, rheumatism and certain endemic infectious diseases. According to Dr. Galal, every pharmaceutical firm at the time had an active research and development facility. Local firms were actively encouraged to approach researchers in the General Organization before resorting to MNEs for licenses. In many cases research teams were capable of developing drugs based on foreign technologies by using different processes in order to conform to Egypt's IP law. This not only had the effect of saving the local industry unnecessary licensing costs and much needed foreign exchange, but 
also greatly enhanced learning opportunities for local researchers.

However, the very success of these policies also ensured strong opposition from those producers who were potentially threatened with being displaced from this growing market. Thus, soon after the end of the war of 1967 with Israel, many projects in the country's pharmaceutical sector came to an abrupt halt as various economic sanctions were imposed on Egypt. The main multinational companies showed their displeasure by refusing to contribute to the training of personnel or to the $R \& D$ operations of the General Organization. In addition, the MNEs also refused to make their technologies available under license or to sell needed equipment to locals. They also increased the price of their raw materials and refused to extend normal trade credit for the drugs that Egypt still needed to import so that all such imports had to be paid in cash. These sanctions had a great impact on the General Organization which was forced to slow its expansion and to discontinue some of its research projects. However, although the golden age was brought to a close by these events, they nevertheless served to heighten the state's determination to achieve greater national self-sufficiency in pharmaceutical production. But the resulting excessive and growing preoccupation with political objectives tended to divert attention away from scientific and economic exigencies, and this soon took its toll.

The Sadat government which took power in 1971, succeeded in expanding local production of pharmaceuticals dramatically by developing a complete pharmaceutical industry based on seven public sector firms: two for the production of raw materials and 
packaging; two for handling all imports, storage and distribution; and three joint ownership firms (Egyptian and foreign) ${ }^{42}$ to expand local production, so that by 1975 the local industry was supplying 84 percent of domestic consumption, when just two decades earlier it had been supplying less than 10 percent. However, there were many problems associated with this spectacular growth. First, under wartime conditions concerns about quality were simply overwhelmed by the demand for quantity as pharmaceutical production was increased dramatically within a very short period of time to achieve selfsufficiency. In this context, a general lapse in drug quality occurred partly because the state did not want effective quality controls to impede growth and therefore allowed the industry to treat such controls as voluntary.

Second, pricing policies were largely driven by the desire to make drugs affordable given the country's social realities, but this resulted in an almost total neglect of commercial realities. The result was that although the provision of high subsidies did ensure a level of pricing that was commensurate with social needs, it also tended to eliminate much needed competitive pressures that might have promoted more indigenous $R \& D$ and that, in turn, might eventually have diminished the industry's heavy focus on duplicative drug provision (Galal 1983; 239).

Added to this were the growing problems associated with the state's national policy of guaranteed employment, or its "graduates policy." Although this had initially facilitated the rapid growth of a local industry, it soon began placing significant pressures

\footnotetext{
${ }^{42}$ These fïrms included Hoechst Orient (Germany/Egypt), Pfizer (US/Egypt) and Ciba and Sandoz
} 
on the public sector, which had to absorb an excessive number of graduates, relative to its ability to utilize such labour. These problems were exacerbated by the fact that the links between university research and potential commercial users of this knowledge, were very weak partly because the state tended to be rather concerned about the unpredictability of professors and students whose views it considered suspect if only because they often failed to take 'adequate' account of the 'realities' within which the state's policy decisions ultimately had to be made. This fundamental lack of trust undermined the contribution that academia could have made to industrial and technological development. Indeed, within the prevailing political climate, the government seemed to prefer to treat the pay of faculty and students as sinecures, actively discouraging them from making effective connections off campus. Moreover, this same basic lack of trust was also pervasive between academia and industry (see Box 1 below).

\section{BOX 1: Mistrustful Relationships between the Research Community and Industry}

In the early 1970s the National Academy of Sciences developed a drug called Proximol for the relief of urinary tract colic resulting from the presence of stones. The drug was also effective in dissolving the stones and expelling them from the tract. Researchers had obtained the herb from its original locality in Luxor (southern Egypt) where natives had been using it for millennia for the treatment of urinary tract problems. Back in the laboratory the researchers succeeded in extracting and isolating the herb's chemical constituents and subjected them to pharmacological examinations - a process that led to the identification of the active chemical ingredient with the reputed biological effect. Several clinical trials by urologists in the Faculty of Medicine at Cairo University confirmed their findings. 
The results of this research were then taken to the Cairo Pharmaceuticals Company for commercialization. In their excitement the researchers had neither obtained a patent nor had they signed a contract. One researcher confided: "We were young. We thought we were going to be rich... We were so overwhelmed with joy that an industrialist was interested in our research that we were content that our work was market worthy and commercializable on a national scale. We were content that our drug would heal people. It was a great moral reward!" The company demanded greater information about the technological know-how involved in the production of the drug after having been impressed with the initial laboratory results that the researchers had provided. This information was readily turned over and the company began to manufacture the drug for domestic use. As the drug gained popularity the researchers thought it wise to obtain patent protection. However, upon approaching the chairman of the company for royalties their request was denied. There was no contract and the company insisted that the researchers should be content with the 'moral' gratification.

With the help of the media this incident came to be highly publicized within the research community. Aside from feelings of betrayal and mistrust, the incident fostered a feverish attitude of self-interest as researchers began to turn their attention to research for academic rather than commercial purposes. But as the research community turned inward the domestic industry increasingly turned to foreign technology suppliers. Eventually industry was not turning to or supporting local research institutes at all. Instead, local industrialists kept their attention focused on licensing the technologies of foreign brand name companies.

Finally, and related to the former point, the integration of the various elements of this national innovation system was very weak. As just noted, linkages between industry and academia were highly inadequate with both operating in almost exclusively separate spheres. Even “the [local pharmaceutical industry's] coordination with supportive industries and services was always laborious and often ineffective" observed Galal (1983; 239). In addition, transfers of technology, know-how and experience were limited both between public sector and joint-ownership firms. In the public sector annual competitive assessments of individual companies hindered cooperation of this sort and prevented the 
harmonization of production lines, which led to the frequent duplication of popular overthe-counter drugs, and serious shortages in less rewarding more specialized drugs (Galal 1983; 239). Meanwhile the behavior of the international firms, as noted above, was largely influenced by wartime loyalties and a general disapproval of Egypt's pharmaceutical development plan.

These problems combined with financial constraints stemming from the industry's high levels of indebtedness and low profitability, partly on account of the government's pricing policies, contributed to a notable decline in pharmaceutical R\&D and a weakening of the national system of innovation more generally. The waning drive of the Sadat government to effectively implement the pharmaceutical policy developed by Dr. Galal under the Nasser regime, meant that the further spectacular expansion of the industry was based on increasingly fragile foundations. One of the greatest problems was that the government no longer tied industrial development to research, so that the promise of institutions like the General Organization could not be realized. Under these conditions, the ability of the local industry to continue to benefit from Egypt's relatively lax IP regime was greatly compromised.

\section{PHASE THREE (1976-1983): OPENING THE PHARMACEUTICAL MARKET}

Although the political shift from Nasser's regime to that of Sadat's had occurred in the early 1970s, the sweeping economic changes that began Egypt's transformation 
into a market-based economy did not commence until the mid 1970s. The goals of Sadat's so-called 'open door' policies, which characterize the third phase of the pharmaceutical industry's development, were to liberalize the economy and to attach primary importance to attracting foreign capital to stimulate growth and technological progress.

Within this broad strategy the pharmaceutical sector attracted the particular interest of foreign investors, no doubt encouraged by the international pharmaceutical lobby. Soon various foreign actors, including some heads of state, were actively pressuring the new government to prioritize the 'opening' of this sector to greater foreign investments and competition. These pressures were welcomed by the government which was already committed to the very same policy changes that were being advocated from outside.

The government began by significantly liberalizing drug imports in a dramatic departure from the previous policy of import substitution. According to Dr. Galal, the MNEs eagerly submitted a list of the drugs that they wanted to import into Egypt. However, upon review of the list, he found that approximately 90 percent of the drugs were not essential for Egypt's needs and as such he refused to authorize their importation. However, his decision was rejected and subsequently overridden by the Minister of Health. Soon after, under pressure from the foreign industry, the Minister replaced Dr. Galal as head of the General Organization with the former Minister of Higher Education who, according to Dr. Galal, knew very little about the operations of the Organization. It 
was not long before all research projects were terminated and the Organization took on a strictly monitoring role leading staunch nationalists like Dr. Galal, to conclude that the government was undermining the local industry. However, according to the government, the purpose of all of these changes was to increase competition, to improve quality and to increase efficiency.

Initially these hopes appeared to be fulfilled since, starting in the late 1970 s, these market reforms led to massive investments in the pharmaceuticals industry by both foreign and local industrialists. ${ }^{43}$ However, the competition that emerged between these new players and the existing public sector producers did not serve to strengthen the latter, or to make them more efficient. In fact, Sadat's liberalization policies produced economic and technological changes that served to undermine the national industry ultimately rendering it highly inefficient. The truth was that the foreign firms had some overwhelming advantages. Thus, their massive advertising budgets allowed them to win market share by focusing on promotional activities, which local industry leaders could not afford, or unwisely dismissed as a waste of resources. Moreover, they were also able to introduce new products that were not produced in Egypt and to become monopolists in certain drug categories as a result. The domestic industry was unable to overcome these

\footnotetext{
43 Among the private firms established during this period were Pharco, Squibb and the ACDIMA group of companies. ACDIMA or the Arab Company for Drug Industries and Medical Appliances was established as a pharmaceutical holding company with the goal of creating a vertically integrated company with affiliates throughout the Arab world. Support for the projects by other Arab countries, however, was withdrawn when Egypt forged peace with Israel. The result was that most of the affiliated companies ended up being established in Egypt rather than throughout the Arab world.
} 
obstacles, especially since the linkages between local firms, raw material suppliers and national research institutes, were so very weak. And in the absence of effective cooperation and government support, the level of R\&D carried out by the industry remained negligible, despite a growing realization of the importance of such activities for their future ability to compete. Individual companies acting alone, found most $R \& D$ ventures too risky and therefore opted for licensing arrangements with MNEs instead - a preference that still exists today.

These tendencies were reinforced by the government's introduction of a de facto increase in patent protection for foreign firms in an attempt to attract even more foreign investments, while avoiding confrontation with local industry leaders who would have strongly rejected formal changes to the law. The government was already acutely aware that there were rumblings of discontent on account of its broad development approach but protests had largely remained fragmented as some industry leaders had found lucrative opportunities in the newly born private sector. Open and formal changes in Egypt's patent regime would have surely given rise to a strong and unified political opposition, which was something the government did not want to risk, given the fact that many of the leaders of the local industry had been soldiers in Egypt's liberation movement just two decades earlier and still had strong ties to certain elements in the state apparatus. Thus, enhanced patent protection could only be achieved by informal administrative means, whereby the Minister of Health simply slowed down the registration of generic drugs by delaying or denying market authorization. Unfortunately, this served to further undermine 
the potential benefits that the local industry could have derived from Egypt's ostensibly weak patent law.

\section{PHASE FOUR (1983-1992): EXPANSION WITHOUT FOUNDATIONS}

The fourth phase (1983-1992) of the industry's evolution is characterized by the declining policy autonomy of the Egyptian government on account of the economic crisis that it faced during the 1980 's, which facilitated the heavy intervention of its major creditors in domestic affairs. Thus, despite the fact that there was a growing realization among policy makers that the competition that had emerged between foreign and local pharmaceutical firms was premised on the latter's increasing dependence on technology licensing and vulnerability to adverse terms of trade, the government's ability to design or to implement an effective technology policy had become very limited. Indeed, the only area where it still seemed possible to tip the competitive balance in favour of the local industry, was the country's pharmaceutical patent policy. By reverting back to the previous policy of facilitating rapid generic approvals, the MOH guaranteed the renewed expansion of the locally owned private sector. However, this growth created the illusion that all was well, when in reality its underlying foundations were quite problematic because it encouraged an even heavier reliance on foreign technology licensing, without a comparative strengthening of autonomous technological capabilities. This dilemma was actually characteristic of many developing countries at the time. 
Indeed, concerns over the inability of developing countries to promote endogenous and autonomous technological development on account of abusive market behavior related to the transfer of technology, was at the center of international negotiations during the 1970s and early 1980s with Egypt playing an active role. During this time the developing countries had taken the lead in pressing for the creation of a code of conduct that would regulate such transfers and in demanding revisions of the Paris Convention (Sell 1998; 29). These countries argued that technology tended to be overpriced and that technology owners "engaged in unfair practices that limited the recipients control over the process" (Sell 1998; 29). They believed that government intervention was necessary to ensure that the best possible terms and the fairest conditions were obtained from technology suppliers.

However, the developed countries insisted that the creation of an international legal framework governing technology transfers was not only impossible but that the market was the only and most efficient mechanism for the acquisition of technology. As these negotiations proceeded the US became increasingly uncompromising and hostile to the code's rationale (Sell 1998; 97) especially as the US economy was experiencing a decline in its international competitiveness and a growing trade deficit during this period (see chapter two). In the end, American pressures brought the negotiations to an unsuccessful close in 1985.

The negotiations in WIPO concerning the Paris Convention (1980-1984) similarly ended with disappointment for the developing countries. In this instance, they had 
feverishly argued that the Paris Convention had been gradually changed since the 1930s to favour technology owners to the detriment of the collective goals of the developing world (Costa 1988; 62). But by the time formal negotiations had started, many industrial countries had already adopted a 'no compromise' approach, which doomed the enterprise to failure from the very beginning. In fact, by the end of these negotiations the US was militantly demanding stronger IP protection (Sell 1998; 139), a matter that it would henceforth pursue unilaterally and in the context of the GATT negotiations.

However, perhaps the single most important factor that weakened the negotiating power of the developing countries during this period, and that undermined their ability to translate the knowledge gained during these earlier negotiations into policy initiatives at home, was the onset of the debt crisis in the early 1980s. As explained in chapter two, much of the blame for the economic ills that befell the developing countries at this time was attributed to domestic policy failures by the World Bank and the IMF as a justification for their standard policy packages that called for an increased role of free markets and private enterprise and a reduction in the role of the state. As a direct result, the ability of developing countries to formulate effective technology policies that would necessarily require significant degrees of government intervention, were further limited.

Within this context, a strategic science and technology plan that was formulated by policy makers in Egypt's Academy of Scientific Research, following the momentum created by international negotiations in UNCTAD, did not find a receptive audience among the country's politicians. Heavy reliance on Bank and IMF financing and the 
urgent desire to seek relief and aid from the US, conditioned the government's rejection of the proposed plan. Indeed, according to Dr. Galal, who was now working at the Academy after having represented the Africa region in the UNCTAD negotiations, it was American pressure that ultimately induced the government to reject the plan altogether. After this, the one bright option that remained open to Egyptian policy makers wishing to promote the development of the local pharmaceutical industry in the time leading to the TRIPS Agreement was the informal readjustment of its IP regime. Indeed, the severe pressure to reduce public spending, including that on health care and drugs, highlighted the desirability of such a policy shift.

In fact, by 1985, the de facto increase in patent protection that foreign owned firms had enjoyed in Egypt due to the Ministry's 'go slow on generic drug approvals' policy came to an abrupt halt. According to one current MNE executive (interviewee) this shift occurred after the German-owned pharmaceutical company Bayer had demanded a very high price for a drug for schistosomiasis, an endemic disease in Egypt. Faced with this potentially serious threat to the country's public health, the Minister of Health was forced to reconsider the issue of generic drug approvals. Accordingly, the Ministry not only rejected the price proposal, but also arranged for the drug to be manufactured locally and supplied at 1/5 the price being demanded by Bayer, using active ingredients imported from South Korea rather than from the parent company. This experience encouraged the Ministry of Health to return to its earlier policy of promoting the manufacture of generic substitutes for the benefit of Egyptians. 
This change in $\mathrm{MOH}$ policy, combined with the relative profitability of the industry, gave impetus to the renewed rapid growth of locally owned private sector firms. However, in the absence of incentives to behave otherwise, these firms focused on shortterm goals, which were most readily achieved by licensing foreign technologies. Inhouse $R \& D$ was not given much priority and there were no longer any mechanisms in place to encourage these new companies to turn to local technology suppliers.

Moreover, the lack of in-house research capacity led to the industry's preoccupation with re-formulations of the same pharmaceutical substances into different preparations. This meant that much of the industry's resources went into the production of different versions of the same drug that only occasionally involved minor improvements. Although this behavior is characteristic of the early stages of development in the pharmaceutical industry and does produce important learning effects, it also led to the neglect of serious research on drugs to deal with the diseases of greatest national relevance. Yet without the concurrent development of the country's scientific and technological support structure, these firms were unlikely to change their strategy.

However, this problem remained invisible since success was not measured from an innovation perspective but rather from that of public health. The economic crisis of the eighties had resulted in severe pressures on the state's budget, and in significant cutbacks in social spending, so that the ability to maintain services in education and health greatly suffered. Moreover, as the government's health spending decreased, it became increasingly important for essential drugs to remain affordable, not only to enable 
continued government provision but also to reduce the burden on the poor, who were having to spend more of their very limited personal budgets on health. Thus the ability of the industry to produce affordable alternatives in sufficient quantities was clearly the main concern of the government.

By 1991 there were thirty drug producers in Egypt, eleven of which were public sector firms, fourteen locally owned firms and five joint venture firms and these were collectively satisfying 90 percent of local consumption. During this (and well on into the next) period, the market shares of both foreign owned and public sector firms continued to decline while that of the locally owned private sector continued to increase (see chapter six). However, the local industry's ability to continue to contribute to public health was based on fragile foundations, and would soon be called into question when Egypt's accession to the WTO-TRIPS altered the competitive balance between local and foreign firms.

\section{PHASE FIVE (1992-PRESENT): ALTERING THE BALANCE}

As with the previous phase of the pharmaceutical industry's development, the fifth phase has seen public policy being overwhelmed by increasing external pressures, which have impeded the state's ability to establish Egypt as a fully-fledged export-led market economy. Initially, the government's desire to privatize and deregulate the pharmaceutical industry was strongly reinforced by pressures from the World Bank and the IMF and this was soon followed by even stronger pressures linked to new obligations 
accepted by Egypt when it agreed to join the WTO. The economic reforms that Egypt has had to adopt in order to comply with the rules of the WTO, including those related to the TRIPS Agreement, have drawn intense criticism from many quarters, including local industry leaders and concerned public health officials. In the short term, this has led to a number of compromises as to the speed with which these new obligations could, and should, be met by the government.

Although the formal end of state-led industrialization could be traced back to 1974 when Sadat's 'open door' policies were introduced, it was not until after the Gulf War in 1991 that significant restructuring of the economy took place, as a result of the implementation of a comprehensive economic reform program at the behest of the World Bank and the IMF. With the passing of the Public Business Sector Law (Law 203) of 1991, the gradual privatization of state owned enterprises (SOEs), including all pharmaceutical firms, was mandated. In the first instance, the law sought to equalize the treatment of public and private sector firms. In order to accomplish this objective, the government adopted a two-pronged approach (UNCTAD 1999; 25). First, SOEs were to be given greater managerial autonomy, i.e., they were to be separated from their Ministries and reorganized into separate, financially independent holding companies. The pharmaceutical SOEs were to be placed under the directorship of a newly created Pharmaceuticals Holding Company, which was, however, still to operate under the authority of the Ministry of Public Enterprise. At the same time, new regulatory measures were to be introduced to govern both these 'new' SOEs and private sector 
firms, equally.

Clearly the initial focus of these reforms was therefore on the terms and conditions under which these public enterprises were to be run and managed. The question of ownership, as such, was addressed rather carefully especially in the pharmaceutical sector. In practice, the proportion of private ownership of SOEs was determined on a case-by-case basis by the government. In the pharmaceutical sector the government has insisted on retaining a 60 percent public interest so that it can continue to influence production and pricing decisions in accordance with social, and public health objectives. The government thus set a 40 percent limit on the privatization of these firms, with 10 percent reserved for employee stock options. As of 1999, five of the eleven public sector pharmaceutical firms had been partially privatized on these terms.

Not surprisingly, there are some who wish to see the privatization process accelerated and they have repeatedly criticized the government's cautious policy on the ownership question. According to these critics, the poor profitability, the relative inefficiency and the low labour productivity of the public companies show that the government should not remain actively involved in drug production (Subramanian and Abdel Latif 1997; 23). These critics can point to data that suggests that public sector pharmaceutical companies receive LE150 million per year in subsidies, and carry a potentially unserviceable debt of up to LE350 million ${ }^{44}$. However, it is important to

\footnotetext{
${ }^{44}$ However, under pressure from the World Bank, Egypt has agreed to suspend subsidies on local pharmaceuticals. But the need to ensure social accessibility to essential imported products with no local substitutes has forced the government to maintain limited support for these products (Galal, N. 1999; 15).
} 
recognize that these public sector firms satisfy approximately 30 percent of local drug consumption needs by supplying essential drugs at affordable prices. In other words, some of these companies may be unprofitable because they ensure that drugs like insulin remain accessible to most Egyptians who need them. These needs would not likely be more effectively, or efficiently, met either by the private sector producers in Egypt, or by expanded imports. The discussion in chapter six will also highlight other significant contributions of public sector firms, which among other things include the fact that they account for one-third of the country's exports in this sector.

In the course of the 1990s, the government's initially cautious approach to reform was gradually set aside, again with strong external support, or maybe even direction. Thus, in 1997 the government passed Investment Law No. 8, which was to clarify and extend the provisions contained in Law 230 of 1989. Among the extensive changes introduced by this law, two were of particular significance for the pharmaceutical industry: namely the legalization of 100 percent foreign participation in all types of businesses in the country, and the gradual elimination of price controls and profit margin limitations. ${ }^{45}$

This policy shift appears to have had the intended effect since several wholly owned subsidiaries were established in Egypt soon after it came into force. In fact, Egypt

\footnotetext{
${ }^{45}$ Other privileges include a guarantee against expropriation or suspension of license; tax incentives which include tax holidays that range between five and twenty years in duration depending on the location of the investment; customs and import incentives; exemption from certain Egyptian laws including specific labour requirements; and freedom to repatriate profits. The new law also provides for the establishment of free zones in Egypt, which considers the projects undertaken in these areas as offshore operations.
} 
now has 26 of the world's 100 largest MNEs operating within its borders, including Bayer, Glaxo Wellcome, Novartis, Du Pont and Rhone Poulenc ${ }^{46}$ in the field of pharmaceuticals.

However, the foreign pharmaceutical firms were not impressed by the speed at which the government was going to allow the prices of pharmaceuticals to rise to market determined levels (Ministry of Economy 1998; 8). In fact, they were especially incensed by the fact that exceptions were to be allowed in utilities and pharmaceuticals so that price controls could remain in place at least in the short to medium term. Indeed the government's decision to maintain pharmaceutical price controls had been formally challenged by the foreign firms who had approached the Ministry of Health, demanding equal treatment with other industries. However, the Ministry had rejected their demands and the case had eventually been brought before the State Assembly (the country's highest legal authority in such matters). There, the Ministry's decision was upheld allowing drug prices to remain under the effective control of the state, for the protection of society. $^{47}$

The state's insistence on retaining its power to influence drug prices in

\footnotetext{
46 It must be kept in mind that the size and structure of these companies are continually changing through mergers and acquisitions. In the course of this study alone several of these companies have merged and this has in some cases been accompanied by name changes. For instance, Hoechst Marrion Roussel merged with Rhone Poulenc to form Aventis in 1999 and more recently Glaxo Wellcome merged with Smith Kline Beecham to form Glaxo Smith Kline.

47 Only in 1991 and 1994 were prices deliberately increased by the government in response to industry pressures who demanded greater consideration by the government of the rate of inflation when determining drug prices.
} 
accordance with public health objectives shows that its adherence to the market oriented policies being so strongly promoted by the World Bank and the IMF, remained pragmatic to a degree. Indeed, its 'managed open door' policies did facilitate the development of a rather vigorous, if technologically limited, pharmaceutical industry. Indeed as the nineties progressed the MNEs operating in Egypt were faced with increasing competition and loss of market share to locally owned firms often producing lower cost generic drugs. In response they focused on two issues to enhance their position and their profitability. First, they sought to take full advantage of the discretionary nature of the price control regime, as discussed in the following chapter. Second, with the backing of the US government, they intensified their efforts to force Egypt to reform its lax IPRs regime in order to curb the ability of local firms to compete with their most profitable drugs with lower priced, therapeutically equivalent alternatives. These efforts were given special impetus after Egypt's 1995 accession to the WTO with its TRIPS Agreement.

In fact, the shadow of the TRIPS Agreement altered the context within which pharmaceutical policy was made, especially as the government came under intense pressures from abroad to forego the transition period provided for in the TRIPS Agreement and to implement its provisions more or less immediately. In effect, this led to the complete cessation of the 'unwritten rules', which had protected the interests of the multinationals to a significant degree in the past. It soon became clear that full enforcement of the TRIPS Agreement would raise the prices of patent protected drugs by prohibiting or delaying their imitation, thereby forcing the government either to import or 
to accept foreign firms as the sole source of domestic supply. In response, Dr. Ismail Sallam, the new Minister of Health who had been appointed in 1996, began to expedite the registration of drugs patented outside of Egypt, for which an application had not yet been made in Egypt. According to the Undersecretary for Pharmaceutical Affairs, Dr. Gamilla Mousa, under these circumstances the Ministry strongly encouraged the registration of new generic drugs during the transition period.

However, this situation changed dramatically after the government came under intense pressure from PhRMA, and from US diplomatic personnel, to restore the earlier system of de facto patent protection by delaying approvals for the introduction of generic drugs on the local market while expediting the approval of brand name products. Indeed, now generic approvals were to be delayed indefinitely by the Ministry of Health. In response, the local industry has accused the Ministry of Health of unjustly curtailing its legitimate rights during the transition period, including its right to manufacture existing patented drugs so long as they are using different production processes in which case they are not infringing the intellectual property rights of the originator under current Egyptian law. According to Dr. Galal Ghorab, "there is no longer any transparency in the pricing and registration of new drugs" (Esssam El-Din 2000). But these objections have not been successful in reversing the Ministry's policy, as US companies have pressed their demands that the Ministry of Health should refuse to register drugs developed in this way, even though they have a legal right to be registered until 2005 , the end of the transition period that Egypt has opted to utilize. 
The apparent acquiescence of the Ministry of Health to these foreign demands is reflected in the large number of generic drugs that have been denied registration in the past three years, and the speed with which they have granted market authorization to foreign firms both for locally produced and imported drugs, over this period (Abdelghaffar 2001; 10). However, today the Ministry is coming under pressure from the Health Committee of Parliament which has demanded that the government establish a specialized body, to be headed by the Prime Minister, and to include the Minister of Health and a number of senior medical and pharmacology experts. This body is to be tasked with the determination of the exact causes of the recent delays in generic drug approvals, and to expedite generic registrations until the expiration of the transition period.

But these attempts to stop the erosion of the rights granted to developing country governments by the provision of a transition period within the WTO Agreement, have faced fierce and growing opposition from abroad. Thus, long before this Health Committee could act, the government had been pressured into granting exclusive marketing rights (EMRs) and increased protection for the confidential data of MNEs that is required in the drug approval process. In fact, these provisions are incumbent upon countries seeking to make use of the transition periods granted in the Agreement, and they effectively limit the significance of this concession. EMRs obligate a country to accept the filing of all new patent applications during the transition period, and to grant each applicant an EMR for up to five years, or until the patent application has been 
granted or rejected. In order for the applicant to qualify for such an EMR the invention must merely have been granted a patent, and have received market authorization, in any other WTO member country. In effect, this nullifies the significance of the transition period and this has been a source of much confusion for developing country policy makers seeking to take advantage of the transition period.

It was within this context that the government drafted its new IPRs law in 2000. This law was soon approved by the Cabinet, but was actually only passed by the People's Assembly two years later, after intense national debate. While the new law fully conforms to the TRIPS Agreement and closely reflects US interests, since both WIPO and USAID had a considerable say in the final shape of the draft, it also contains some controversial provisions that are designed to promote industrial development and to protect public health, as will be discussed in chapter seven. Although the long-term implications of this law remain to be seen, the purpose of this study is to offer some guidance on what we can reasonably expect from it, given the state of key pharmaceutical/health aspects of Egypt's national system of innovation.

\section{CONCLUSION}

This chapter has outlined the main features of the evolution of Egypt's pharmaceutical industry before the arrival of the 'TRIPS challenge' in 1995. It described the emergence of a strong national industry, which eventually came to satisfy 93 percent of Egypt's domestic demand for pharmaceuticals. The growth of this industry was first 
stimulated by war, and at one stage - in the second phase under Nasser - it was part of a comprehensive nationalist strategy in which the public sector took the leading role and the potential for the country to develop an innovation based industry was revealed. Unfortunately, this soon gave way to a model that prematurely shifted the government's focus to the need to attract foreign investment and to use that as a vehicle for acquiring foreign technology and developing $R \& D$ capabilities. In the absence of a comprehensive science and technology plan, including suitable incentives to foster local innovation, neither foreign nor local firms were motivated to invest adequately in research and development.

Nevertheless, the maintenance of a lax patent regime, and a certain (though inconsistent) emphasis on the promotion of generic drug substitutes, did stimulate the growth of a national industry that was able to satisfy the bulk of the country's demand for pharmaceuticals. Although this growth was heavily based on the production of 'foreign drugs' under license, or on the production of generic substitutes, the local industry undoubtedly gained technical and business skills through this process. Historically, the maintenance of a lax patent regime had enabled the state to effectively deal with supply shortages and high prices on account of volatile relations with major foreign drug suppliers. Even in the 1980s and 1990s when such threats had become less real, the country's lax patent law had continued to stimulate growth and to promote domestic competition, thereby helping to keep prices in check.

In fact, the combination of Egypt's market liberalizing policies and its lax patent 
regime had encouraged the growth of a locally owned private pharmaceutical industry to such a degree that the international firms intensified their efforts to curb the growing market power of these national firms. To this end, they focused their attention on Egypt's lax patent regime, since the state was clearly unwilling, or politically unable, to deregulate pharmaceutical prices in the short or medium term. With Egypt's accession to the WTO, and especially with the promulgation of a new IPRs law that is fully consistent with the provisions of the TRIPS Agreement, it seems that the MNEs have essentially succeeded, with the strong support of the US government, the World Bank and the IMF, and of course, the pharmaceutical lobby. However, a formidable struggle on the part of locally owned and public sector firms and some concerned health officials continues to delay the full implementation of the TRIPS Agreement and thereby to give local firms a little time to try to better prepare for the situation that they are about to face when the new IP law drastically curtails their ability to compete with the MNEs.

Adopting the strong patent regime embodied in the TRIPS early is likely to pose a major, and potentially critical challenge to Egypt's nascent national system of innovation. There is no doubt that locally owned firms, both private and public, will find their position threatened by this policy shift, while the foreign owned firms will benefit significantly from this stronger patent regime, which will ceteris paribus improve their market power, their profitability and their dominance of R\&D. The truth is that Egypt's national industry is not yet ready to participate in reaping the potential benefits of this new regime. While it has grown impressively, and although it has 'learned by doing' to 
some degree, its development has been hampered by the fact that the government has had to give some priority to the need to manage the impact of its economic liberalization policies on Egypt's public health. Under these circumstances the maintenance of a lax patent regime had provided opportunities for the emergence of a national industry and for strong domestic competition, but in the short term this had not provided for the kind of development of autonomous technological capabilities that would be required for the development of a robust pharmaceutical industry that could derive significant benefits from the full implementation of the TRIPS.

In the following chapter we will consider these issues in greater detail. In particular we will consider the innovative capacity that has emerged in the local pharmaceutical industry, the strength of the supportive scientific and technological infrastructure and the adequacy and coherence of complementary government policies. These three key factors are ultimately critical if Egypt's pharmaceutical firms are to be able to reap net benefits from a stronger patent regime and thereby continue to contribute to the health of Egypt's people and economy. 


\section{CHAPTER SIX}

\section{STRONGER IPRS AND THE PHARMACEUTICAL INDUSTRY IN THE CONTEXT OF EGYPT'S NSI AS IT RELATES TO PHARMACEUTICALS AND HEALTH}

In this chapter I discuss how the pharmaceutical industry was affected by the country's traditional IP policy given some of the key pharmaceutical/health aspects of the national system of innovation. As discussed in chapter four, the maintenance of a relatively weak IP system had promoted the rapid development of the pharmaceutical industries in industrial countries by enabling them to draw freely on knowledge and technologies developed in other countries. However, it was also emphasized that IP policy represents only one element in a country's complex system of institutions and incentives that collectively shape a country's technological and economic performance. Here, I show the achievements of the Egyptian pharmaceutical industry and the challenges facing it, which come not only from foreign sources but also from weaknesses in the scientific and technological support structure and from the development of the pharmaceutical industry itself. The central purpose of the discussion is two-fold: first, to assess the plausibility of the claims being made by the proponents of stronger IPRs as discussed in chapter three, and to offer explanations as to why certain outcomes are deemed more or less likely; second, to identify those pharmaceutical/health aspects of Egypt's NSI that require improvement or transformation in light of these circumstances.

The NSI approach is appropriate for an assessment of the implications of the 
TRIPS Agreement for the pharmaceutical needs of developing countries because the ultimate justification for this global IP regime is based on the concept of dynamic efficiency to enhance public welfare. The argument is that restrictions on technological diffusion and higher prices should be accepted now, in order to promote long term innovation and development. However, for the developing countries the validity of this argument depends on whether they have the technological and institutional capabilities to respond to stronger IPRs by undertaking more effective and successful $R \& D$, which depends on the strength of their NSI. In effect this Agreement is not likely to promote dynamic efficiency or welfare at the national level in all those parts of the world where national systems of innovation are too weak to meet this challenge. Even the World Bank acknowledges that "because the overwhelming majority of intellectual property new inventions, proprietary commercial information, digital entertainment products, software, trade names, and the like - is created in the industrialized countries, TRIPS decidedly shifted the global rules of the game in favour of those countries" $(2001 ; 129)$. This chapter is divided into four main parts. The first part discusses the development of the domestic industry in terms of an overall appraisal of growth, investments and trade. In the second part I analyze the challenges facing the industry in relation to the way in which the industry had developed. In the third part I examine key pharmaceutical/health aspects of the country's national system of innovation by considering elements in the scientific and technological infrastructure and the coherence of government policies. As discussed in chapter four, all these issues need to be 
considered in order to assess the chances of a beneficial and successful transition to a TRIPS compliant regime for the pharmaceutical industry. The fourth section presents the conclusion of the chapter.

\section{THE DEVELOPMENT OF THE PHARMACEUTICAL INDUSTRY}

Production in the Egyptian pharmaceutical industry has been growing rapidly since the opening of the market to private investment in the late 1970s. Combined pharmaceutical production of the locally owned, foreign owned and public sector firms was estimated at LE 4.7 billion in 2000 , a figure over three times as great as at the beginning of the decade and over sixteen times as great as at the beginning of the $1980 \mathrm{~s} .{ }^{48}$ Pharmaceutical production is expected to keep growing in the double-digit range in the foreseeable future (UNCTAD 1999; 62). In 2000, total domestic production satisfied 93 percent of domestic consumption by value. As can be seen in Table 6.1 the locally owned private sector exhibited the most spectacular growth and had the greatest share of the industry's output at 48.8 percent in $1997 .{ }^{49}$ Although the value of output by foreign owned and public sector firms has also increased, their shares of the total market have diminished over the period $1981-1997$ by 10 percent and 33 percent respectively.

Throughout the past three decades, the industry has been one of the most competitive and profitable in Egyptian manufacturing. While gross profit margins

\footnotetext{
${ }^{48}$ According to Dr. Galal Ghorab, Chairman of the Pharmaceutical Holding Company, this is a gross underestimation of the true valuation of the sector because of Egypt's strict price controls.
} 
currently hover around 20 percent (Orabi and Nour el Din 1999; 2), in 1995 it was reported that the most profitable locally owned firm had a gross margin upon sales of approximately 44 percent compared with 43 percent for the best performing multinational firm and 18 percent for the best two public sector firms (Subramanian and Abdel-Latif $1997 ; 12) .{ }^{50}$ The figure for the foreign industry, however, may be misleading since subsidiaries are obliged to import raw materials form their parent companies at high prices so that reported costs usually incorporate a margin of profit (Subramanian and Abdel-Latif 1997; 12).

The high levels of capital investment in the industry have been reflected in both greater productivity and enhanced manufacturing capacity with commensurate advances in local learning that accompany the production of generics and off-patent drugs and the training of personnel to operate state-of-the-art technologies. Capital investments by locally owned firms increased at an average annual rate of 30.3 percent between $1990-$ 1997 (see table 6.2) allowing many of these firms to reach world class standards. Amoun, a locally owned firm acquired by Glaxo Wellcome in 1997, employs state of the art technologies. The former owner of the company, Dr. Sarwat Bassily, has since started up another local pharmaceutical giant that also employs the latest technologies. In fact, the approximately 15 locally owned firms that manufacture drugs in finished dosage forms are among the most successful and "employ the most advanced manufacturing

\footnotetext{
${ }^{49}$ All tables are located at the end of this chapter.

${ }^{50}$ According to Subramanian and Abdel-Latif $(1997 ; 12 \mathrm{fn})$ the "choice of firms was dictated by data availability, but they were all among the best performing firms in their respective categories, which
} 
systems in the country" (Fayez 1997; 4).

Capital investments by the foreign sector during the same period increased by an average annual rate of 14 percent, largely due to an increase in the number of firms operating in Egypt. Although foreign subsidiaries are largely credited with having introduced new management styles prioritizing productivity and quality, they have been heavily criticized for the slow pace at which they have generally upgraded their operations. $^{51}$

In contrast to the private sector, capital investment in the public sector has actually been decreasing by an average annual rate of 2.4 percent during the period of 1990-1997. This is generally attributed to the fact that the government had turned away from the idea of expanding the public sector and was, by now, strongly promoting privatization. However, according to Dr. Galal Ghorab it is also due to the fact that the Ministry of Health has "discriminated" against public sector firms by withholding payments in the order of LE 350 million for drugs purchased to cover the needs of its affiliated hospitals and the Health Insurance Plan (Essam El-Din 2000). Dr. Ghorab contends that this money could potentially generate LE 40 million per year in revenues if deposited in a bank, which could then be reinvested in these firms in order to help them cope with competition from the private sector (Essam El-Din 2000). Even so, the

\footnotetext{
provides a plausible basis for generalizing about the sectors."

${ }^{51}$ In fact, Glaxo Wellcome Egypt was the first company in the Middle East and Africa to introduce ISO standards into its manufacturing practice. According to UNCTAD $(1999 ; 68)$ other MNEs have since followed suit and are improving quality standards to achieve ISO 9000 certification and eventually full FDA (US) approval or are meeting EU GMP standards.
} 
government has put tremendous efforts into renovating and upgrading existing production facilities in an attempt to improve profitability and exports. Indeed, many public sector companies have achieved ISO certification ${ }^{52}$ and have expanded their product ranges to include more higher margin products like vitamins, veterinary products, and cosmetics.

Despite the broad success of the pharmaceutical industry in terms of growth in domestic production and investment over the past couple of decades, the industry continues to generate heavy net foreign exchange costs because imported inputs make up a significant share of the total cost of production at the same time as industry exports remain at a mere 5 percent of total domestic output, even though exports have grown rapidly over the past decade at an annual average rate of 27.7 percent (Subramanian and Abdel-Latif 1997; 7). ${ }^{53}$ Thus while the 1999 UNCTAD investment review of Egypt identified pharmaceutical products as one of Egypt's competitive exports, or 'rising stars', it also identified the sector as an 'underachiever' in terms of exports relative to the high growth in world imports between 1992 and 1996 (UNCTAD 1999; 17). Locally owned firms account for about two-thirds of Egypt's pharmaceutical exports, while the remainder is accounted for by the public sector (see table 6.3). According to Dr. Ghorab, the latter firms have adopted a goal of gradually increasing exports from the current level of slightly below 2 percent to 15 percent of their output annually. At this stage those

\footnotetext{
${ }^{52}$ For instance, Alexandria Pharmaceuticals, Nile Co., Cairo Pharmaceuticals and Arab Drug Co. have obtained ISO 9001 certification and are in the process of obtaining ISO 14001 for environmental standards (Arab Drug Co. has also obtained the latter).

${ }^{53}$ Jordan, for instance, exports approximately $40 \%$ of its pharmaceutical production but it must be kept in mind that it has a much smaller domestic market.
} 
exports are largely composed of generic products including aspirin, antibiotics, dermatologicals, geriatrics, cough syrups, and vitamins that are primarily bound for markets in Russia, Eastern Europe and some Arab countries where quality standards and regulatory requirements are not as strict as they are in key industrial country markets.

The fact that the multinationals have chosen not to export from Egypt is clearly a matter of concern. At this point these foreign subsidiaries are not exporting because of parent company restrictions (Galal N. 1999; 12, Orabi and Nour El Din 1999; 2, Subramanian and Abdel-Latif 1997; 11). The MNEs claim that Egypt's price controls create "artificial" or "unfair" export opportunities, so that they prefer to export from locations where there is greater price discretion. Defending the position of these firms, one MNE chairman explained that parent companies just want to avoid the possibility of their own subsidiaries (based in different countries) engaging in price competition in third country markets. ${ }^{54}$

Meanwhile, the situation in Egypt's domestic market is likely to change dramatically when the WTO rules are more fully applied. At present imports of finished pharmaceutical products account for only 7 percent of domestic pharmaceutical consumption and are basically limited to high technology products ${ }^{55}$, milk formula, disposable syringes and gauze. This largely reflects the success of past import substitution policies in building a strong domestic industry and in persuading foreign

\footnotetext{
${ }^{54}$ Please note that when the name of the interviewee is not mentioned that they requested confidentiality, kindly refer to the study's methodology.

${ }^{55}$ These include insulin, anti-cancer drugs or cytotoxics, cardio-vascular and eye disease treatments.
} 
firms to establish production facilities within Egypt. It is also, however, the result of import controls that limit the number of allowable drug substitutes to six versions, or to drugs that have no local equivalents. Such control is critical in the pharmaceutical sector where there are approximately 100,000 different pharmaceutical products in the global market, developed from about 5,000 active substances, that are produced by thousands of manufacturers (Saxenian 1994). The vast number of products on the market gives rise to "information problems relating to the quality of specific drug products and their costeffectiveness" (Saxenian 1994). Limiting the number of products on the market with similar therapeutic value to six versions at any point in time has helped the government to deal with this problem. Unfortunately, the removal of import quotas in accordance with WTO rules will have a dramatic effect on the government's ability to continue to do so with the consequent proliferation of brand name drugs with similar therapeutic effects competing in the domestic market.

A final reason why the Egyptian industry continues to incur a substantial foreign exchange deficit, despite its apparent success, is due to the fact that it remains highly reliant on imported raw materials. At present it imports over 85 percent of these requirements, mainly from India, China, Japan, South Korea, the EU and the US. Only 15 percent of these requirements are produced locally by two firms, El Nasr (public sector) and Gist Brocades (foreign owned). The industry's relative inability to produce a greater proportion of its raw material requirements domestically distinguishes it from its more mature counterparts in other developing countries like India, Argentina, Mexico, 
China and Korea who have the capabilities to manufacture the bulk of their raw material requirements locally (Oxfam 2001). ${ }^{56}$

Unfortunately, pledges made since the 1960 s by foreign subsidiaries to introduce the technologies required for the domestic manufacture of key pharmaceutical chemicals have remained unfulfilled (Fayez 1997; 4), which may not be so surprising since it is well known that MNEs use the trade in intermediate chemicals to transfer profits from one jurisdiction to another (Lall 1974; 156). Indeed, MNE records in Egypt show that the share of imported raw materials to total operating costs has been particularly high, inviting the strong suspicion that this trade is used for transfer pricing (Galal N. 1999; 12, Orabi and Nour El Din 1999; 10, Subramanian and Abdel-Latif 1997; 13).

Although the strong performance of Egypt's pharmaceutical industry is attributable to a number of factors, including the opening of the market to private investment in the late seventies and the implementation of Investment Law No. 8 in the early nineties which encouraged foreign investment by allowing full ownership, the country's pharmaceutical patent policy, with its limited scope and duration, was probably decisive in allowing and fostering the establishment of strong domestic production capabilities oriented to the supply of domestic pharmaceutical needs. This view is supported by the 1999 UNCTAD investment review of Egypt which states: "Owing to the nature of the governing patent law in Egypt (Law 132 of 1949) which allows patents to expire after ten years, the Egyptian pharmaceutical industry has excelled in terms of

\footnotetext{
${ }^{56}$ Based on a 1990 UNIDO study.
} 
manufacturing generics" (UNCTAD 1999; 61). The manufacturing capacity that emerged mainly took the form of the formulation and packaging of imported raw materials based on technologies that were almost entirely adopted and adapted from the developed countries. In this situation, the maintenance of a relatively lax patent regime was necessary to minimize the costs associated with this type of industrial development as more fully discussed in chapter four. Egypt's traditional pharmaceutical patent policy allowed local firms to invent around a patent relatively easily in order to produce generic equivalents, and when that proved impossible due to a lack of know-how, then the limited patent term reduced the time before the product could be legitimately imitated. These conditions allowed the growth of a vigorous domestic industry and encouraged the rapid emergence of multiple suppliers of most new drugs, which in turn encouraged effective price competition.

In fact, the industry derived a wide variety of benefits from the country's relatively lax patent regime. As noted above, foremost among these was the fact that it gave local firms the right to produce 'frontier' drugs using alternative processes while they were still under patent protection, or to copy them within a short time after the patent expired. It is estimated that such activities accounted for approximately 25 percent of their profits. Their profitability was further augmented by the fact that this weak patent regime only protected pharmaceutical processes, so that local firms could import raw materials from the lowest cost suppliers without fear of infringing the intellectual property rights of the multinational enterprises who often owned the patents on such 
products and their components. The ability of local firms to reduce production costs in this way, not only increased the competitiveness of their products in the domestic market, but also facilitated the steady growth of their generic pharmaceutical exports. From a public health perspective, local industrial leaders argued that their ability to enhance profitability as such allowed them to continue to produce less profitable products that were needed by society.

Moreover, one might expect that a lax IPR regime would have discouraged foreign investments in the pharmaceutical sector at least until the government had agreed to accelerate the implementation of the TRIPS Agreement. However, this does not seem to have been the case. The presence of a significant and growing market and the desire to counter each other's presence has tended to attract foreign investments in this sector, which tends to confirm the argument made in chapter four of this study that investment decisions are largely made to maintain technological leadership and market position irrespective of the availability of patent protection. According to Glaxo Wellcome's chairman, Dr. Negad Shaarawi, "if Egypt has no meaningful IPRs then we have to find other ways to gain a competitive edge. For me the answer is to increase resources, that is, to have properly supported operations regardless of IPRs." Thus, Glaxo Wellcome purchased Amoun Pharmaceuticals, a local company, for US\$1 17 million in 1999, the largest cross border acquisition in Egyptian history, which gave Glaxo Wellcome a 4 percent share in the booming generic drug market. In reality, this event was only the latest in a series of similar investment decisions made by other multinationals during the 
1990s. In 1994 Eli Lilly and its local agent Alkan acquired the plant of Roussel Uclaf Egypt and in 1995 a decision was taken to invest LE 45 million to establish a new facility in order to produce human insulin, the first of its kind in the Middle East (UNCTAD 1999; 64). In the late 1990s, Scherer, a global leader in the production of soft gels, built a new plant introducing the latest technologies and training techniques (UNCTAD 1999; 64). During the same period Rhone Poulenc acquired Amereya, a local pharmaceutical firm, and subsequently merged operations; and Bristol Myers Squibb expanded their operations in order double production by 2000 . It would thus appear as though the existence of a lax patent regime has actually attracted foreign investment, rather than deterred it, as some would have expected.

In fact, these investment decisions served to effectively undermine the foreign industry's efforts to pressure the Egyptian government to forego the grace period permitted by the TRIPS. Indeed, one frustrated IPR analyst working for a leading multinational in the region, was led to declare that rather than 'punish' the government, "MNEs continue to introduce almost all of their latest medicines which are vulnerable to imitation and perhaps even more problematic export piracy; they continue to increase spending on marketing and employment; they persist in licensing manufacturing to companies that engage in the piracy of other MNE products; and worse yet they continue to invest in local companies that pirate the products of other MNEs even after knowledge of the problem."

Based on this experience, some have expressed a real concern that as 
pharmaceutical patent policy is strengthened in Egypt as a result of the TRIPS, foreign firms may have less incentive to invest in the country because they will have profit guarantees that do not depend on such investment. Of course supporters of the TRIPS argue that the introduction of stronger IPRs can be expected to stimulate investment in more innovative activities by both local and foreign firms. However, this is unlikely to happen on a significant scale because of the way in which the domestic industry has developed and the absence of key pharmaceutical/health aspects of the national system of innovation to provide a conducive environment for such investments.

\section{CHALLENGES EMANATING FROM THE DEVELOPMENT OF THE INDUSTRY}

As discussed in chapter four, in-house R\&D is an important feature of modern pharmaceutical firms because it augments their capacity to adopt and adapt existing technologies. Even though an important amount of learning, and even of innovation, does occur simply as a result of being engaged in the process of production, inadequate levels of R\&D are nevertheless generally associated with relatively weak learning effects. This tends to reinforce continuing dependence on foreign technology licensing and to block the path to the endogenous development of more autonomous technological capabilities. Without such capabilities, an industry cannot hope to benefit significantly from the introduction of stronger IPRs, since its ability to generate patentable innovations will be relatively limited. According to the Director of the Patent and Trademark Office, 
Dr. Fawzy El Rifaie, Egyptian nationals submitted only 3 of the approximately 60 pharmaceutical patent applications made in July and August 2001. Under these circumstances, one can only agree with Subramanian and Abdel-Latif (1997; 4) when they contend that increases in patent protection will only serve to "displace local producers and render the market less competitive, leading to a rise in prices and consequent rent transfer from local consumers and producers to foreign title-holders. The absence of an appreciable $R \& D$ effect will mean the country will not derive any dynamic benefits in the form of reduced costs and prices, so that in welfare terms the country will be worse off."

The lack of adequate investment in $R \& D$ and the consequent weakness of the learning effects associated with the type of production investment that was established was undoubtedly the most serious shortcoming of the Egyptian pharmaceutical industry as it faced the new world of the TRIPS. In the Egyptian industry, firms spend less than 2 percent of revenues on $\mathrm{R} \& \mathrm{D}$, as compared with the $12-18$ percent spent by firms in more advanced industrial countries. Moreover, although some original research does take place ${ }^{57}$ much of this research activity is restricted to 'searching' for drugs that have been developed elsewhere and that can be adopted or adapted for the Egyptian market. When a local firm identifies a potentially interesting product, it normally asks its research

\footnotetext{
${ }^{57}$ For instance, EIPICO, one of Egypt's larger locally owned firms, plans to create a new company, EIPICO Tech, to manufacture anti-cancer drugs and drugs based on biotechnological advances. The head of the company's research unit informed me that since the company began research in biotechnology two years ago they have two original products in the pipeline. Moreover, several public sector firms have moved slowly toward marketing brand names (El-Sawy 1997; 13) and one company, Arab Drug Co., is exploring the production of a drug for the treatment of Hepatitis C (Orabi and Nour El Din 1999; 7).
} 
partners to determine whether it is suitable for the local market. If it is, and the company has the required production capabilities, then it arranges for its local development and production, either by using an alternative production process, or by obtaining a license from the technology owner.

Critics of the industry's development path argue that this simple process of searching, developing, and producing has not led to a sufficient understanding of the underlying knowledge and technology involved in drug innovation. According to Dr. Mohamed Baha El Din Fayez, Professor Emeritus at the National Research Centre in Cairo, "the business of imitation has not been taken with adequate seriousness. There exists a misguided belief that imitation is not an economically dynamic enterprise. Thus, reverse engineering is considered of limited use and leads to a 'bad reputation' for those who practice it." Dr. Fayez contends that this is largely why the industry has been unable to reduce its heavy reliance on licensing arrangements with foreign firms.

At the end of the nineties, locally owned and public sector firms produced approximately 40-50 percent of their products under license from foreign technology owners, with the remainder being generic copies. However, even this does not fully reflect the weakness of the industry's present capacity to innovate. To appreciate this one has to understand that, according to Dr. Fayez, the majority of these product licenses are for products whose patents have actually expired but which are still produced under license due to a lack of know-how or because of the need to obtain raw material ingredients from the original technology owner. It goes without saying that this situation 
has both financial and developmental costs for the industry and the economy. The direct financial costs stem from the need to pay unnecessary royalties, which put further strain on scarce foreign currency reserves. The developmental costs are linked to the lack of genuine learning that is associated with the majority of these licensing arrangements.

These problems are exacerbated because such production licenses are often obtained by individuals who do not, themselves, have any manufacturing capacity, but who will sell or lease the license to any available and willing manufacturer. The manufacturer will then produce, package and market the product in Egypt. In this process there is ultimately very little technology transfer and no real investments or R\&D. Moreover, there is little learning apart from that which inevitably occurs as a result of the production process itself. In the case of pharmaceuticals even this learning is often particularly limited since the production process often consists of little more than the mixing of several purchased inputs. In other words, most of the technology transfer agreements in this industry in Egypt have relatively little substance and transfer very little technology.

Unfortunately, few observers expect the industry's development path to change significantly in the near future especially since stronger patents and intensified competition will further constrain the capacity of firms to undertake long term oriented activities like R\&D. Of course because of the relatively small size of the plants, the firms and the market in Egypt, it would not be easy to develop a capacity for fundamental innovation. Indeed, if one accepted the industry's oft repeated claims that it costs up of 
US \$250-400 million or LE 850-1360 (almost half the revenue generated by the entire pharmaceutical industry) to develop a patentable drug it would be impossible. However, such estimates have been widely - and rightly - questioned. There are several factors that make the calculation of such costs questionable including: the refusal by pharmaceutical companies to allow independent verification of their R\&D figures, accounting assumptions and the arbitrary inclusion of risk (Story 2000; 4-5). Correa (2001; 4) also notes, "figures on R\&D provided by industry (about $\$ 500$ million per drug) does not correspond to actual expenditures, but to expenditures adjusted for costs of capital and to compensate for $R \& D$ failures. The assumptions made for these calculations are very controversial." It is also important to keep in mind that these estimates are based on US practices. In Japan, for instance, companies take approximately 25 percent less time and spend about 50 percent less money to develop and commercialize new products whose essential features have largely been previously discovered, or so-called 'me-too' drugs (Mansfield 1988; 19).

Indeed, those who focus on breakthrough innovations or 'blockbuster' drugs, which involve the development of new molecular entities, neglect that the early stages of development are largely characterized by minor continuous innovations that lead to important learning effects. In order to take advantage of these learning opportunities, Dr. Fayez suggests, that pharmaceutical research in Egypt can be directed toward following the advances of competitors who have the capabilities and resources to develop breakthrough drugs $(1997 ; 4)$. He contends that local research can successfully focus on 
developing compounds that result from incremental structural improvements or composition modifications to the pioneer product, which only involves trailing-edge research and generates 'me-too' drugs (Fayez 1997; 4). ${ }^{58}$ Indeed, many observers believe that Egypt can become a good base for the performance of low to intermediate R\&D activities, which in addition to that mentioned above could also involve the local performance of clinical trials and testing. "In general because industrial R\&D can be conducted in developing countries at a much lower cost, there is potential for the Egyptian pharmaceutical sector to capture a portion of this expenditure" (UNCTAD $1999 ; 65)$.

The focus on the capabilities and resources required for fundamental innovation in order to be able to significantly benefit from a stronger patent regime, however, has led others to conclude that "the prospects of developing a genuine $R \& D$ based industry in Egypt in the medium term are not very bright" (Subramanian and Abdel-Latif 1997; 19). Whether based on realistic or applicable estimates of drug development costs, many local firms believe that they cannot afford to undertake research into new pharmaceutical preparations (Al Alam Al Yom 1999; 3). It is also unlikely, even with the full implementation of the TRIPS Agreement, that foreign subsidiaries will perform significant R\&D or innovation in Egypt. According to one MNE chairman, "no efforts are being taken to build R\&D in Egypt by the foreign industry... R\&D will not likely be

\footnotetext{
${ }^{58}$ A similar strategy, albeit at a much more sophisticated level, is actually common among pharmaceutical giants who monitor the development of compounds in other rival firms and quickly establish similar projects (Michaels $2001 ; 12$ ). Thus, "when a breakthrough drug hits the market, it is normally just the
} 
improved in Egypt under any conditions in the foreseeable future, even with the passing of the draft [IPRs] law." ${ }^{59}$ For the leaders of these firms the problem in Egypt is only partly due to inadequate patent protection. It has much more to do with expected financial returns and a weak scientific and technological support structure. As they see it, in Egypt the limited purchasing power of consumers, government price controls, and intense competition in most therapeutic categories tends to limit R\&D incentives. A recent UK study reported that large pharmaceutical firms were "unwilling to pursue a line of research unless the potential outcome is a product with annual sales of the order of $\$ 1$ billion" (CIPR 2002; 37), which effectively excludes research into diseases of national relevance to many poor countries. In any case, according to several MNE chairmen more than 'adequate' financial returns are required. In effect what is needed is a strong NSI, according to the chairman of Gist Brocades, Mr. Derek Hennecke, who explained, "IPRs are only beneficial in the long run. Companies will likely wait and see that the laws are consistent before investing in new technologies. In pharmaceuticals the short term will not offer much change. Egypt offers a low cost haven but a poor institutional structure. For pharmaceuticals it is easier to operate where the costs are much higher but where institutions are reliable."

For countries like Egypt, with a significant market and the potential to develop a significant technological capacity, the unwillingness of MNEs to undertake significant research and development activities is particularly problematic because these firms 
exercise control over the great majority of the existing patents. Although they may not patent all of their products in all developing countries, they do tend to do so in countries like Egypt where there is some risk of local imitation (CIPR 2002; 41). Moreover, strong patent protection in such countries not only curbs local competition, but also limits competition internationally since it can inhibit exports through the control of distribution channels (CIPR 2002; 42). Hence, in Egypt, the enforcement of strong IPRs is likely to mean more patenting by the MNEs as they try to limit competition both at home and abroad.

For local firms, the gravity of this situation is heightened by the aggressive marketing strategies of MNEs, which are often successful in maintaining the market dominance of their products well beyond the expiration of their patents. ${ }^{60}$ In fact the combination of strong IPRs with the extensive power that can be exercised through marketing, allows the MNEs to consolidate their market power and secure their high profits. At least this appears to be the view of industry itself since it has not only been relentless in its pursuit of stronger IPRs, but it also has one of the highest ratios of promotion and advertising costs to sales, among all major industries. Indeed, international pharmaceutical companies spend approximately 35 percent of their sales revenues on marketing, which is double what they spend on research and development

\footnotetext{
${ }^{59}$ Confidential interview, see methodology.

${ }^{60}$ Marketing practices vary from company to company. In general, however, they include such perks as the provision of free samples to physicians, company rep visits, enticing mail literature, receptions for the introduction of new products, free trips, expensive gifts and media advertising. Unfortunately, in some cases they also involve disparaging the quality of lower priced or generic products. Foreign sector firms in Egypt often try to market their products as the 'real thing' to the detriment of perfectly equivalent generic
} 
(Hemsley 1997; 12). In Egypt the disparity is even greater since the foreign sector's $R \& D$ costs are approximately equal to just $1-2$ percent of annual sales, while marketing expenditures hover around 35 percent of sales. More recently it seems that these companies have supplemented their aggressive marketing campaigns with predatory pricing strategies that frequently discount drug prices by up to $30-40$ percent in order to undercut local competition (Zein el Abedien 2001; 3).

In the absence of effective government regulation of pharmaceutical marketing practices, local firms have been largely unable to provide an effective counter-balance to the marketing power of the multinational firms. Historically, local producers have tended to neglect marketing partly because they could not afford to invest heavily enough in such promotional activities and partly because they saw it as a waste of resources, not realizing quite how powerful it could be. Today the inability of local firms to compete in the marketing arena is undermining their position in the market and compromising their relations with physicians, other health care providers and consumers, in comparison with foreign firms. Thus, the current marketing advantage of MNEs with the introduction of strong IPRs will greatly challenge the future ability of the local industry to develop and expand.

products. 


\section{CHALLENGES EMANATING FROM THE PHARMACEUTICAL/HEALTH ASPECTS OF THE NSI}

The ability of the pharmaceutical industry to cope with changes in its competitive environment on account of the imposition of a strong IPRs regime will depend on the support it can derive from the key pharmaceutical/health elements in Egypt's national system of innovation. As discussed in chapter four, technological advance occurs through a community of actors that includes firms engaged in production and research, public research institutes and universities, government departments and financial institutions. Over the past four decades Egypt has developed an extensive scientific and technological infrastructure. Some of the key strengths of the system include the availability of educated and specialized personnel; a network of R\&D institutes; some well focused $R \& D^{61}$; and a tradition of government support for $S \& T$ institutions (UNCTAD 1999; 18). Nevertheless, the system has for various reasons remained relatively immature and highly diffuse. Among its key weaknesses are inefficient management structures, inadequate resources, weak quality control, design and standardization protocols; poor financial support services; and a marked isolation of S\&T institutions from the broader socio-economic context (UNCTAD 1999; 19). Moreover, weak communication networks and a lack of trust have greatly inhibited the potential of the country's extensive infrastructure and have reinforced dependence on foreign technology suppliers. The following section considers the characteristics of the major

\footnotetext{
${ }^{61}$ The Egyptian National Hypertension Project is a good example of such research (see Ibrahim 1996).
} 
actors in Egypt's NSI as it relates to the pharmaceutical sector in order to demonstrate how these are likely to affect that sector's ability to benefit from the imposition of stronger IPRs.

\section{Universities and Public Research Institutes}

Egypt has thirty-three universities most of which are publicly controlled and funded. University education is mostly oriented toward undergraduate studies with little incentives for innovation and creative enterprise. Students wanting to complete graduate studies usually travel abroad either at personal expense or that of the state if they choose to continue to work for the academic establishment. It is often the case, upon the graduate's return from such studies, that he is employed in a field other than his specialty because of a lack of a 'technological' match within the national science and technology system. Those who find research posts tend to perform work that is oriented toward attaining promotions rather than toward fulfilling social and market needs. ${ }^{62}$ Thus, projects that are undertaken are often short term (thesis oriented) and of poor quality, so that minimal learning is frequently involved.

There are many barriers to the performance of high quality scientific research in Egypt. Among the most serious of these are a lack of funds and poor access to scientific

\footnotetext{
${ }^{62}$ This is not to imply that all research should be exclusively market oriented. What is important to establish when considering the implications of the TRIPS Agreement is the extent of local support for local innovative activities by private firms. In the absence of supportive domestic research and fruitful academic collaborations it is unlikely that stronger IPRs will be of value locally as the possibility of developing new
} 
literature (Ibrahim 1996). Most university laboratories and public research institutes lack appropriate infrastructure, which includes proper equipment and state of the art technology. ${ }^{63}$ However, a key impediment to high quality research according to Ibrahim (1996) is a lack of adequate data and the absence of quality assurance measures. This situation has led to a general lack of interest and confidence on the part of industry in the system's R\&D capabilities.

Dealing with the persistent weaknesses of the domestic research system is particularly challenging given the lack of adequate funding for innovative enterprise from both public and private sources. In the view of UNCTAD this is one of the most serious challenges facing R\&D in Egypt (UNCTAD 1999; 69). Unfortunately, this situation undermines the fact that the government "exert[s] considerable effort on the upkeep of scientists and institutions, but significantly under spends on the actual conduct of R\&D" (UNCTAD 1999; 18). According to officials at the National Research Centre, R\&D financing in Egypt is "tragic". The fact is that the current system of numerous small government subsidies is simply not adequate to motivate the time and effort required for the adaptation of foreign technologies, let alone for more fundamental research into breakthrough treatments. Even the effectiveness of foreign funding is compromised by a lack of coordination (UNCTAD 1999; 40).

drugs by industry is greatly diminished.

63 This is something that has been acknowledged by the government in its current five year plan (19982003 ) where $\$ 7$ billion have been allocated to upgrade public research facilities with modern equipment (US Dept. of Commerce, National Trade Bank Data, Nov. 3. 2000). 
It is not surprising that members of the National Academy of Sciences should complain during interviews that their services were not being adequately utilized. They were eager to demonstrate the potential contribution that Egypt's S\&T system could make to the evolution of the pharmaceutical industry if they were given a "fair" chance, which largely meant being better funded. "All we need is to be useful, but we can't if the industry is not going to turn to us for R\&D support, we need the contracts" stated one interviewee. But, according to Mr. Mohamed Youssry El Nahas, Secretary General of the Egyptian Association of Design and Technology, "Egyptian industrialists are used to importing technologies and do not trust local ideas. That is something that needs to change if we are to achieve anything" (Al Ahram 2001).

Funding for public research is also adversely affected by the preference of national pharmaceutical firms to produce under license rather than to turn to public research institutes for support as they had for a brief period during the 1960s when the latter were often contracted to find alternative production processes for the local production of patented drugs. Lately, this preference has been given impetus by the private lending policies of local banks. Several interviewees reported that it is becoming increasingly popular for local firms to obtain bank loans by simply presenting drug feasibility studies based on licensing agreements with multinational companies. These arrangements involve minimal risk and largely offer guaranteed returns, which makes it easy for the company to get its desired financing for development and production. However, such behavior discourages support for local R\&D efforts that may have less 
definitive outcomes for both the company and its financial backer.

Several challenges face the pharmaceutical industry and threaten its ability to benefit significantly from the new IPRs regime, including serious weaknesses in the scientific and technological infrastructure, which is exacerbated by a general lack of financial support. Broadly speaking the research performed by universities and public research institutes lacks focus and direction and is poorly linked to the industry's needs. In addition, as in most developing countries today, the industry faces poor financial resources and support, which is reinforcing reliance on foreign technology suppliers rather than on local research institutes. The ultimate challenge lies in confronting these difficulties at the same time as accepting the need to ensure that pharmaceutical products remain within reach of the average Egyptian in the wake of the TRIPS Agreement.

\section{Complementary Policies}

Egypt's drive to integrate rapidly with the global economy, and its acceptance of a market driven economic development strategy has led to a 'laissez faire, laissez innover' orientation. In line with a certain kind of economic thinking, government officials increasingly believe that the role of government is merely to construct a national environment in which the efficient allocation of resources can be effected by market forces. From this perspective governments are not supposed to discriminate between industries and this thinking has governed Egypt's economic reforms over the last decade. Reforms have aimed at establishing a general and consistent set of incentives for the 
entire industrial base while eliminating targeted incentives for specific sectors including pharmaceuticals. This approach is now widely accepted, but it continues to be the subject of controversy, if only because the most successful developing countries of East Asia clearly did not heed this advice. Even within the World Bank (1992), there are those who disagree strongly with this view, suggesting that the most appropriate policies for the evolution of any industrial sector must be derived from the technological conditions prevailing within that sector, because it is these that will determine the steepness of the learning curve and the need for "special support" during the industry's formative years. Thus, it is argued that "market incentives may not provide correct signals for resource allocation or capability building if there are valid infant industry arguments for intervention" (World Bank 1992; 2).

In the case of pharmaceuticals, these arguments can be buttressed by another argument, namely, that a nation's basic pharmaceutical supplies are of sufficient strategic importance that a substantial domestic production capacity can be justified on those grounds alone. This too turns into an argument to justify a degree of targeting in the case of this industry. The fact of the matter is that without targeting of some kind for the pharmaceutical sector it is unlikely that this industry would thrive, and even less likely that it would develop a greater capacity to innovate.

In fact, in most OECD countries comprehensive pharmaceutical policies are aimed at promoting innovation and diffusion in existing technologies in this sector. Among the diverse measures used by governments in this respect are the enforcement of 
regulations to ensure effective technology transfer; the provision of subsidies and tax incentives; and the participation in jointly funded R\&D consortia with the private sector in addition to extensive direct involvement in R\&D activities (Freeman and Soete 1997; 378 , Correa 2001; 2). It is noteworthy that the discovery of drugs with significant therapeutic gain has often been made by public institutions, which then license their development to private actors (Correa 2001;2). In fact, at least 70 percent of such drugs were developed with some form of government support (UNDP 1999; 69).

In contrast, Egypt does not currently have a comprehensive pharmaceutical policy nor does it have a coherent technology policy, although President Mubarak has announced on several public occasions that a technology policy would be formulated soon. At present Law No. 43/1974, which gave the government the right to authorize technology transfers through joint ventures on a case-by-case basis, forms the basic legal framework in this respect. Egypt's increasing openness to foreign investment, however, has meant that recourse to Law No. 43 is diminishing while dependence on market forces to regulate technology transfer is increasing.

Yet, concern over the likelihood of market abuse regarding technology transfers, especially considering the asymmetric bargaining power between the technology owner and the technology purchaser which will be further augmented with the introduction of a stronger IPRs regime, has prompted the government to include provisions in its new trade law to govern such arrangements. The law, therefore, establishes the rights and obligations of both the technology importer and the technology owner. According to its 
provisions the transfer agreement must include all the relevant know-how including sufficient information about the S\&T capabilities required for the importer to make optimum use of the technology. In addition, the law stipulates the conditions under which a technology transfer contract can be nullified including any attempt by the technology owner to restrict the freedom of the importer to use, to adapt or to fully exploit the potential of the technology. These provisions are particularly critical in the area of pharmaceuticals where it has long been acknowledged that most of the value of a drug is found in its active components so that one can argue that if the industry is to advance it needs to acquire the knowledge to produce many of these components. Indeed, the domestic industry's weakness in this regard clearly exacerbates its dependence on foreign technology suppliers and heightens the need for strong policies regarding technology transfer particularly in the face of the TRIPS.

Unfortunately, the ability of the government to enforce these new technology transfer regulations is questionable. The new trade law does not include provisions to deal with violators of technology transfer agreements, which greatly compromises the ability of the law to act as a deterrent of abusive behavior. It is also likely that enforcement of the law will meet with strong opposition from technology owners who will use their asymmetric information and bargaining power to exploit the limited expertise of government regulators in order to undermine the law's effective implementation.

In any event, even if such measures are effectively implemented, they remain 
highly insufficient to address the diverse challenges facing the pharmaceutical industry.

What is needed here is a strategic plan aimed specifically at guiding the development of the sector toward higher value added research-based production (UNCTAD 1999; 69, Subramanian and Abdel-Latif 1997; 23). In the absence of this plan, efforts to encourage local innovation and to address weaknesses in the pharmaceutical/health aspects of the NSI will likely remain inadequate and fragmented (see box 2 below).

\section{BOX 2: Inadequate and Fragmented Responses to Weaknesses in the NSI The Establishment of the ERDC}

The background to the recent establishment of the Egyptian Research and Development Company (ERDC) shows how local actors have tried to cope with weaknesses in the national system of innovation in the absence of a coherent national vision to address the root causes of these problems. In the late nineties several locally owned and public sector firms, had come together to consider the creation of a joint $R \& D$ venture. Under the proposed scheme the government was to finance 50 percent of project costs, while the locally owned firms were to finance the other 50 percent. However, many leaders of the locally owned firms failed to make their promised financial contributions due to the absence of clear rules as to who would own the results of the research, or how the benefits would be shared. The initiative thus came to an unsuccessful end.

However, Dr. Galal Ghorab, Chairman of the Holding Company for Pharmaceutical Industries, who had been the lead negotiator for the public sector firms in the above initiative, was adamant that such cooperation was required if the industry was to advance. But rather than trying to resolve the problems that had prevented the local partnership from succeeding, Dr. Ghorab turned to foreign partners. Thus, the ERDC, that was established in 2001, is jointly owned by four American firms, the Pharmaceutical Holding Company, and the National Bank of Egypt, who respectively have a 40:40:20 stake in the company.

Moreover, the ERDC's mandate does not involve the performance of independent research as was planned under the former scheme. Instead, its mandate is merely to identify international scientific and technological developments that are suitable for the local market, to assess the potential demand for the technologies, and then to purchase or to license the technologies. The company then resells or licenses the technologies to local clients. 
In order to bring Egypt's pharmaceutical sector to the point where it could derive significant benefits from the TRIPS, Subramanian and Abdel-Latif (1997; 23-24) suggest that the government and the industry adopt a "graduated approach" to the development of the industry. According to their strategy, the first phase would involve the local industry's acquisition of capabilities to manufacture bulk generic drugs, perhaps in collaboration with foreign partners. In the second phase the industry would begin to invest in various $R \& D$ activities starting with improvements in drug quality and eventually leading to research in tropical diseases. In the third phase Egyptian companies would be well placed to establish research partnerships and other strategic alliances with foreign companies. It is argued that this is considered one of the later stages in industrial development because it does not simply depend on firm behavior but on 'national virtues' that create cross-border opportunities (Freeman and Soete 1997; 346) ${ }^{64}$ In fact, all the stages in this graduated approach are dependent on 'national virtues' to a greater or lesser extent.

As the full implementation of the TRIPS Agreement moves closer there has been much talk about the development of a more comprehensive pharmaceutical strategy. Recently, an expert committee was established under the chairmanship of Dr. Atef Sidqui (former Prime Minister) for this purpose. The goal of the committee's efforts will be to improve the competitiveness of the pharmaceutical industry, to protect local production

\footnotetext{
${ }^{64}$ In this regard, it is interesting to note that over $90 \%$ of technology transfer arrangements and alliances are made among companies based in the US, EU and Japan (Hagedoorn and Schakenraad 1991, Freeman and Hagedoorn 1992 in Freeman and Soete 1997; 348).
} 
and to expand export markets. The committee will also consider the various factors that threaten the development of the local industry, particularly those that emanate from international pressures and obligations. It is already anticipated that the committee will call for significantly increased supports for national research institutes, public sector firms and raw materials production; improved linkages between national and regional players; and participation in global strategic alliances.$^{65}$ Yet identifying such possibilities is only the first step. The greater challenge will be to find effective ways of implementing them, particularly given the complex nature of the interests involved and the new circumstances in which they have to be brought into existence.

Of course, any plan to guide the development of the pharmaceutical industry must be complemented by an appropriate and effective competition policy that takes due account of the recent restructuring of the industry and of the evolving marketing strategies of multinational firms combined with the imminent danger associated with the introduction of a strong IPR regime. Indeed, it is the latter that has given impetus to the formulation of an explicit competition policy in Egypt, which had traditionally relied on the presence of a dominant public sector to achieve social goals. The biggest danger is that this new IPR regime may be used in a manner that undermines the Egyptian industry

\footnotetext{
${ }^{65}$ The limited scope of this study has prevented it from considering the impact of regional collaborations and alliances on local innovation. It has been observed, however, that Egypt has not maintained its once prominent presence in the region, given that it was once an active player in the establishment of pharmaceutical industries in Iraq, Kuwait, Jordan, Saudi Arabia, and Yemen. Rather than managing to capitalize on the region's common economic, cultural and linguistic features, Egypt has not been able to develop or to maintain its links with these countries, or these industries, nor has it been able to provide ongoing support for its regional investments (Al Bassil et al 2002;21).
} 
and inhibits technology transfer with consequent adverse effects on public health, as has been widely recognized: "Though the patent system was devised in order to reward inventiveness, encourage technological progress and foster dissemination of innovations, patents are used in many cases as commercial tools in order to restrict or delay legitimate competition" (Correa 2001; 7). In the pharmaceutical sector this will primarily mean a rollback of generic manufacturing and that will compromise a key tool now used by governments worldwide to limit the costs of the patent system (CIPR 2002; 43). There is ample evidence to suggest that even in the industrial countries generic competition sharply reduces prices after a patent expires (CIPR 2002; 43). This is even truer in the developing countries, where generic producers usually supply most drugs (World Bank $2001 ; 137)$.

Moreover, even in the absence of deliberate attempts to eliminate legitimate competition, the provision of stronger patent protection in the field of pharmaceuticals has definitive outcomes that result in the monopolization of certain markets by foreign firms in developing countries (Harmsen and Subramanian 1994; 12). Indeed, both the World Bank $(2001 ; 137)$ and CIPR $^{66}(2002 ; 43)$ concur that the resulting increased market power of multinational firms will result in a consolidation and restructuring of domestic industries. Thus, according the World Bank $(2001 ; 137)$, "in most cases... local enterprises will come under pressure to close down or form alliances with larger firms,

\footnotetext{
${ }^{66}$ CIPR (the Commission on Intellectual Property Rights) is a group of international experts appointed by the British Government in May 2001 to examine how IPRs and development policy can be integrated with the aim of reducing poverty.
} 
resulting in a concentration of the industry." The TRIPS Agreement acknowledges the possibility of such anti-competitive outcomes and grants states certain rights to minimize these dangers.

Developing countries, including Egypt, require competition policies that address their respective developmental needs and that complement their development strategies. In this respect there is much to learn from the Japanese model particularly during the years 1950-1973, when that country was 'catching-up' so effectively to the leading industrial countries (Singh and Dhumale 1999; 10). During that period Japanese competition policy was an integral part of its industrial policy, which in turn was a central pillar of its development strategy. The main concern of Japan's industrial policy was to sustain high levels of private investment in building a strong, competitive and technologically sophisticated national industrial base. To this end, some restrictions were imposed on product market competition. Indeed, the explicit goal of competition policy was to attain an 'optimal', as opposed to a 'maximum', level of competition, where optimum was defined in terms of effectiveness in promoting the country's broader strategic objectives. In practice this frequently involved encouraging cooperation between certain firms or ensuring that competition did not become destabilizing and destructive.

Unfortunately, Egypt's efforts to establish a viable competition policy are still in their formative stages. According to Dr. Hassan El Badrawy, a justice in Egypt's Court of Appeals, and a member of the National Committee for the Follow-up of the Results of 
the Uruguay Round, Egypt is currently drafting a law to address competition and abusive monopoly behavior, although the exact details of this law were not yet in the public domain at the time. It seems that this process had actually started in 1997 when the Ministry of Trade had approached the Ministry of Justice, which had then sought UNCTAD's collaboration. The draft competition law is to contain provisions outlawing certain types of anti-competitive arrangements and other abuses of market power. As a result, mergers and acquisitions that could result in dominant market positions will be subject to scrutiny and approval. The policy is to be administered by a specialized competition agency.

Weaknesses in the institutional structure supporting the pharmaceutical industry and the absence of key policies needed to guide and to strengthen its future development make the introduction of stronger patent protection particularly problematic in Egypt. Without efforts to address the weaknesses in the S\&T system, the industry will likely continue to increase its reliance on foreign technology licensing on terms that may ultimately hinder its ability to develop autonomous technological capabilities that would allow it to derive significant benefits from the TRIPS in due course. With the introduction of stronger patent rights, this situation is likely to become more costly to Egypt because the bargaining power of the technology owners will be augmented as a result. Moreover, the absence of an effective competition policy will allow them to use that power to undermine many of the positive features of the present situation. Thus, the MNEs are currently instigating price wars to drive out smaller competitors by means of 
retailer rebates, while pursuing a range of mergers and acquisitions that will diminish competition in the domestic industry. These outcomes raise special concerns regarding the local industry's ability to continue to contribute to public health by providing reasonably priced pharmaceutical products in a reliable manner.

Indeed, the impact of stronger IPRs on the prices of pharmaceuticals is one of the most serious outcomes expected to result from the imposition of the TRIPS Agreement in the current context. The fact is that this agreement increases the monopoly privileges of MNEs and this will almost certainly lead to an increase in prices and an unnecessary lag between the appearance of the original drug and the introduction of cheaper therapeutic equivalents. Even the proponents of stronger intellectual property regimes admit that:

With IPP firms may expect to gain more control over prices and price changes for the products covered by patents once price regulation is relaxed. Firms may attempt to set introductory prices at a higher level than would be the case absent IPP... High prices may still represent cost savings versus the next-best-alternative such as surgery, but not compared to generic competition in the absence of IPP (Rozek and Berkowitz; 1998 26).

In Egypt generic drugs are on average 33 percent cheaper than brand name products. ${ }^{67}$ This is why changes to the country's patent regime have been intensely resisted by those officials who are primarily concerned with public health who point to the apparently paradoxical fact that in this case, protection has generally led to lower prices. In the words of one official: "In addition to being the near-exclusive supplier of

\footnotetext{
${ }^{67}$ An interesting example concerns the decision of Nile Pharmaceutical Company to produce two low cost generic drugs for treating AIDS and leukemia in July 2001. Prior to this move Egypt was an importer of cancer and AIDS drugs in retail and bulk (for local packaging). Both drugs are to be sold at a $40 \%$ discount compared to rival products, which is expected to make them competitive in Africa and the Middle East. Producing the drugs is in conformance with Egypt's current patent law, that is, pre-TRIPS (reported
} 
inexpensive drugs for the poor, and perhaps chiefly because of this fact, the pharmaceutical industry in Egypt has traditionally been a protected sector" (Fayez 1997;

2). Moreover, this is particularly significant when one considers that 85 percent of expenditures on pharmaceutical products come directly out of household budgets, with only 15 percent being covered by the National Health Insurance Plan which benefits only a small portion of the population. ${ }^{68}$ As in most developing countries, drug prices in the market place therefore have a disproportionate impact on the welfare of poor people, who are estimated to include 22 percent of the Egyptian population by the $\mathrm{MOH}$ (or as high as 40 percent by other sources), and who would be forced to delay or forgo treatments on account of high drug prices.

This is the context in which Egypt's former Minister of Health, Dr. Ismail Sallam, has repeatedly warned of the dangers posed by enhanced intellectual property rights for the human right to health, which requires drugs to be accessible. ${ }^{69}$ Although he acknowledges that drug policies must ultimately conform to political and economic realities, he has insisted that these competing claims have to be balanced in such a way that adequate access to drugs is ensured for the population at large (Salama 1997; 3). Dr.

\footnotetext{
by Reuters May 13, 2001).

${ }^{68}$ Egypt's per capita consumption of pharmaceutical products is low in relation to other MENA countries despite dramatic increases over the past couple of decades (Orabi and Nour el Din 1999; 4). Annual per capita consumption has increased from approximately LE 6.6 in 1980 to LE 71 in 1998 (Galal, N. 1999; 10). Although these increases are partially due to the drug price increases of 1991 and 1994 much of this growth has resulted from real growth in consumption. Such growth is attributed to government commitments to improve health services, increasing awareness by some of the more affluent groups in society and more intensive marketing efforts by industry (see table 6.4).
} 
Sallam was clear in his position that the TRIPS Agreement would impede drug access primarily because of its negative impact on the domestic industry with serious consequences for Egyptian consumers who are reliant on its relatively affordable drugs (Salama 1997; 3). These sentiments are echoed by Médécins Sans Frontièrs, the Nobel Prize winning humanitarian and medical agency, which believes that the implementation of the TRIPS Agreement will reduce reasonable access to medicines in developing countries because it will raise drug prices and impair local manufacturing capacity (Banta 2000).

Although the global pharmaceutical lobby continues to argue that stronger IPRs will ultimately benefit everyone, local MNE executives in Egypt were remarkably frank in admitting that for the time being their product and pricing policies totally exclude large parts of the population. But they did not see this as a problem since they simply assumed that it was the job of the government to deal with that problem. Of course what this ignores, is the fact that the government's ability to do that job is increasingly constrained by budgetary constraints, by rising drug prices in the market and by the increasing hostility to 'government subsidies' in the official international policy debate.

Representatives and leaders of MNEs in Egypt were therefore surprisingly forthcoming in their discussions of their prices and their pricing policies. Pfizer's Director of External Affairs and Health Policy set the tone of the discussion when he suggested that the majority of Egyptians could not afford MNE drug prices in any event,

\footnotetext{
${ }^{69}$ Dr. Ismail Sallam was replaced by Dr. Mohamed Awad in 2002.
} 
so that the industry contributes minimally to the health of the majority of the population. Meanwhile, Glaxo Wellcome's communications manager for Egypt estimates that only 13 percent of the population can afford their drugs. "We target the elites. The government can continue to target the have-nots. They can continue to provide low price, low quality drugs to support state run medical facilities." To illustrate the scale of the disparity, she noted that when Zantac (a popular antacid) came off patent protection in Egypt, generic companies provided a therapeutic equivalent for one-tenth of the original price. Indeed many of the MNE leaders interviewed for this study stated that they have not been "good national citizens" in this regard, though they would also argue that it was not their responsibility to deal with the special problems created by the fact that so many Egyptian people lack adequate purchasing power.

The pervasiveness of premium pricing for patented products is an inescapable fact. To suggest otherwise would be to have misunderstood what the fuss over pharmaceutical patents is all about. High price/low volume strategies for the introduction of new brand name drugs (whether or not they are therapeutically distinct) are common in the pharmaceutical industry, even when cheaper and equally effective alternatives are available. That is one of the reasons for the very high expenditures on advertising and marketing. Moreover, in this case the link between stronger IPRs and their "premium pricing policies' is not merely an abstract concern. It is a matter of explicit and active planning by the MNEs. Thus, according to an internal document provided by one of the MNEs, a strong emphasis on premium pricing for patented drugs will follow the full 
application of the new IPRs legislation in Egypt. ${ }^{70}$ In fact, MNE leaders were quite candid about their intention to press for higher prices with the change to Egypt's patent regime and the fact that many people could not afford their products was simply taken as a given and clearly not their concern. During one interview, a chairman of one MNE subsidiary stated, "if someone poor cannot afford the drug then that's life, it's too bad. We are an industry not a charity. Just because the average Egyptian is poor does not mean that prices should vary very much. I mean what is the government's role?"7l By implication it is therefore one of the government's roles to control drug prices either in general, or for certain segments of the market. As noted in chapter four, price control regimes for pharmaceuticals are found all over the world and in many cases they coexist with strong patent regimes helping to mitigate their impact on prices. In Egypt it is estimated that price controls keep drug prices at one fourth of those in the US, and at one-half those in other developing countries (Rozek and Berkowitz 1998; 13). As part of Egypt's reform program in the 1990s a new pricing method was implemented called the 'cost-plus' formula. According to this method a company is asked to submit the price at which it desires to sell a product to a committee headed by the Ministry of Health and comprised of members from the Ministry of Economy, the Ministry of Finance and industrial representatives. Companies are permitted to factor in a 15 percent profit margin on essential drugs (classified by the WHO), 25 percent on non-essential drugs (for non-life threatening diseases) and a 40 percent margin for over- the-counter drugs

\footnotetext{
${ }^{70}$ Confidential source.
} 
(mostly vitamins and pain-killers). The pricing committee has databases on the costs of raw materials and other processes involved in the manufacture of drugs in order to be able to review and verify company submissions and to exact the lowest prices.

When the product is therapeutically distinct there is greater price discretion. In such cases the price eventually agreed upon covers costs plus a handsome profit. In most other cases, however, the committee will push down the price irrespective of the company's demands after technical considerations have been taken into account. If a drug is categorized for the treatment of a chronic or life-threatening disease it is exempt from the value-added tax. According to one MNE chairman, companies often attempt to demonstrate this for all their drugs since approval is discretionary. The system also encourages companies to register drug variations in order to be eligible for price reviews. In the case where a company does not accept the price reached through negotiation the product is not given market authorization.

Egypt's price control system is coming under pressure by both domestic and foreign sources. Locally owned and foreign firms complain that the government's pricing policy does not take account of the rising costs of production. They argue that as products realize losses over time it becomes increasingly difficult to allocate resources to such activities as R\&D. MNEs also complain that this system encourages imitative behavior as local firms choose to copy new more lucrative products, developed by MNEs, until the financial rewards dwindle and the cycle is repeated with newer products.

\footnotetext{
${ }^{71}$ Confidential source, please see methodology.
} 
As a result, MNEs have been continually pressuring Egyptian authorities to eliminate price controls by threatening to move operations elsewhere, particularly to the Gulf countries (Al Bassil et al 2002; 20-21). Yet, despite these complaints, it appears as though foreign firms enjoy the greatest price discretion, which has sparked a bitter national debate and led to demands by local industry leaders for greater transparency in the pricing process.

Internationally, the global pharmaceutical industry has been active in attacking and threatening governments that continue to have price control regimes for pharmaceuticals and it has gone to great lengths to prevent governments from introducing new price cuts. Thus, in November 2001 a group of the world's largest multinational companies contributed $\$ 189$ million to Germany's state sponsored health plan in order to prevent the Ministry of Health from imposing a 4 percent price cut on prescription drugs, because they feared that this would have set a precedent for other European governments (Fuhrmans and Gautam 2002). Even so, Italy imposed a 5 percent price cut in May 2002, and the French government cut the prices of 100 drugs by as much as 15 percent while making it clear that it was willing to impose more cuts if drug price increases continued to put unreasonable pressure on health expenditures (Fuhrmans and Gautam 2002). It is notable that these rather surprising government interventions were aimed at some of the industry's costliest drugs which had been successfully promoted by massive marketing efforts that had led to widespread use of new, more expensive drugs, despite their limited therapeutic benefits over older versions (Fuhrmans and Gautam 2002). 
In retrospect it is clear that the arrangement reached with the German government, turned out to be the exception rather than the rule because it clearly did not stop other governments from doing what the German government had threatened to do. In most other cases, the industry has therefore responded to unacceptable price controls by threatening to deprive the country in question of new drugs that are developed. Thus, in 2001, Hank McKinnel, the CEO of Pfizer, attacked the pricing policies of many EU countries and indicated that such misguided policies could lead to "a denial of access to new treatments" (Pollard 2001). Other MNEs concur with this view and add the standard argument that price control policies are ultimately self-defeating because they undermine research in these countries, and encourage its relocation to more profitable countries like the United States (Pollard 2001). Similar threats are also echoed in the developing countries, as in one regional symposium, where Mohammad Salah Roushdie, the chairman of Pfizer Egypt, signaled the industry's willingness to withhold the introduction of new treatments until IPRs were strengthened and prices raised. To emphasize the point he pointed out that the entire MENA region represented a mere 1 percent of the global market, so that it would cost Pfizer next to nothing to wait for IP and price reforms (Al Alam Al Yom 1999; 3).

\section{CONCLUSION}

This chapter has examined the achievements and weaknesses of the Egyptian pharmaceutical industry in order to assess the likelihood of it benefiting from the 
imposition of the stronger IPRs implied by the full application of the TRIPS. It has shown that Egypt's traditionally lax pharmaceutical patent policy had been partially responsible for fostering a domestic pharmaceutical industry with significant participation of locally owned private and public sector firms. The lax patent regime had enhanced the ability of these firms to imitate foreign pharmaceutical products and processes, and to benefit from important learning effects as a result. Over time this contributed to domestic competition and to public health. Initially, the industry was able to develop very successfully. Indeed, by the late 1990s it supplied 93 percent of domestic needs at relatively low prices while remaining one of the more profitable industries in the country. However, although these firms had been among the greatest beneficiaries of Egypt's lax patent regime, together with the consumers of pharmaceuticals, their longerterm prospects were limited by major weaknesses in the country's scientific and technological support structure and the absence of key government policies. Today, those weaknesses have become more visible and more critical because they will prevent the local industry from being able to benefit significantly from the new TRIPS related IPRs regime or from being able to protect the public health system from adverse effects. It is evident from this analysis that, in order to give effect to the declared objective of the TRIPS Agreement (Article 7), to ensure that intellectual property rights "contribute to the promotion of technological innovation and to the transfer and dissemination of technology, to the mutual advantage of producers and users of technological knowledge and in a manner conducive to social and economic welfare, and 
to a balance of rights and obligations," developing countries will need more than just longer grace periods to reform their legal systems. Continued improvements in the level and nature of innovation in these countries is unlikely to occur in the presence of stronger, internationally harmonized patent rights, unless they are enabled to strengthen the pharmaceutical/health aspects of their national systems of innovation. Reforming and establishing such systems will necessitate a concerted effort on the part of government, research institutes, universities, industry and its federations or associations, the medical profession, pharmacists and other relevant parties. Unfortunately, the introduction of a stronger IPR regime will make this very challenging.

Recently, even the World Bank has suggested that the level of IPRs should vary in accordance with a country's income level (World Bank 2001; 129). More accurately, it should vary by the strength of their NSI difficult though that is to define. In this regard, CIPR $(2002 ; 10)$ recently concluded:

It is our contention that intellectual property systems may, if we are not careful, introduce distortions that are detrimental to the interests of developing countries. Very "high" standards of protection may be in the public interest in developed countries with highly sophisticated scientific and technological infrastructures (although we note, as above, that this is controversial in several respects), but this does not mean the same standards are appropriate in all developing countries. In fact we consider that developed countries should pay more attention to reconciling their own perceived commercial self-interest, with their own interest in the reduction of poverty in developing countries.

Egypt is a lower middle-income country with a relatively weak national system of innovation. ${ }^{72}$ The capabilities of its pharmaceutical firms to innovate have evolved over

\footnotetext{
${ }^{72}$ According to the Ministry of Economy (2000; 12), GDP per capita in 1999 totaled LE 3,830 or US\$1 128.
} 
time through learning by doing, but they remain weak in $R \& D$, one of the key indicators of innovative capacity. In fact, the entire industry continues to rely heavily, and in many cases unnecessarily, on production under license, with significant financial and development costs for the industry and the economy. A significant improvement in this performance will depend on its ability to create a viable scientific and technological complex, or NSI, that provides a sufficiently positive environment to allow the industry and the country to benefit from stronger IPRs.

However, the problem is not only that the present structure is weak. The future does not look much more encouraging since Egypt has no comprehensive or effective strategy for the development of its pharmaceutical industry, or for the attraction of more knowledge-intensive investments by foreign firms in this sector. Egypt's past policies can be said to have paid inadequate attention to the real long-term needs of the pharmaceutical industry having been more concerned with short run concerns. There were good reasons for this and the results have been rather positive to date, but the new TRIPS regime will pose a challenge that could undermine many of these gains because of the serious weaknesses in the national system of innovation that now exist in the country. Against this background, it appears that the substance and speed with which government policies are being implemented in the new era of the TRIPS, neglect many important aspects of the economic and institutional infrastructure that impact on processes of knowledge acquisition, diffusion, and utilization. In this environment a continued 'laissez innover' strategy coupled with stronger IPRs is likely to stifle and reverse the 
early gains that have been made in allowing foreign technologies to be mastered and improved. This in turn will place limits on the industry's and the country's long-term development (Freeman and Soete 1997, Romer 1994, Freeman and Perez 1988) and the improvement of living standards - and public health in particular.

The conclusions of this chapter are particularly disturbing for Egypt's fragile public health system, which is currently undergoing significant reforms. Reliance on pharmaceutical products is expected to grow in the coming years, and much of this expenditure will continue to come directly out of household budgets. Because of its expected negative impact on the prices of pharmaceutical products, the implementation of the TRIPS Agreement is likely to make the challenge of obtaining treatments even more desperate for the poor. Unfortunately, it is not likely that these costs will be offset by significant improvements in research on local diseases, or that technology transfer will accelerate or that the country will be able to strengthen the pharmaceutical/health aspects of its NSI. For the moment, Egypt continues to maintain a strict price control regime, however, it is uncertain how long it will be able to resist growing pressures and threats to dismantle this system.

The TRIPS Agreement essentially deprives developing countries of the opportunity to chart their own technological course in accordance with their national needs and priorities. Many developing countries are reforming or adjusting their development plans to reflect the unrelenting and largely inappropriate demands of this new IPR, and the global trade regime of which it is a part. The potential adverse 
implications of stronger pharmaceutical patent protection for public health have, however, struck a sensitive cord with developing country governments and with public health advocates worldwide. In fact, international concern over the TRIPS Agreement has been mainly focused on its likely impact on access to health-related treatments for the poor, rather than its likely impact on innovation and industry. The next chapter of this study shows how and why these two dimensions, industrial development and public health, are inseparable, and takes a closer look at the continuing controversy surrounding the TRIPS Agreement. 


\begin{tabular}{|c|c|c|c|c|c|c|c|}
\hline \multicolumn{8}{|c|}{$\begin{array}{c}\text { TABLE 6.1 } \\
\text { Changes in the Value of Production in the Public, Locally Owned and } \\
\text { Foreign Owned Sectors } \\
\text { in millions of L.E. (1981-1997) }\end{array}$} \\
\hline \multirow[b]{2}{*}{ Year } & \multicolumn{2}{|c|}{$\begin{array}{l}\text { Locally Owned } \\
\text { Sector }\end{array}$} & \multicolumn{2}{|c|}{$\begin{array}{l}\text { Foreign } \\
\text { Owned Sector }\end{array}$} & \multicolumn{2}{|c|}{ Public Sector } & \multirow[b]{2}{*}{ Total } \\
\hline & Value & $\%$ & Value & $\%$ & Value & $\%$ & \\
\hline $1981 / 82$ & 15.0 & 5.3 & 78.8 & 28.8 & 186.7 & 66.6 & 280.5 \\
\hline $1982 / 83$ & 22.6 & 6.5 & 96.6 & 27.7 & 229.4 & 65.8 & 348.6 \\
\hline $1983 / 84$ & 28.4 & 7.2 & 102.5 & 26.2 & 260.8 & 66.6 & 391.7 \\
\hline $1984 / 85$ & 61.9 & 12.8 & 117.5 & 24.3 & 304.0 & 62.9 & 483.4 \\
\hline $1985 / 86$ & 28.0 & 15.1 & 128.5 & 23.7 & 331.7 & 61.2 & 542.2 \\
\hline $1986 / 87$ & 146.2 & 21.6 & 158.2 & 23.5 & 370.1 & 54.9 & 674.5 \\
\hline $1987 / 88$ & 197.4 & 23.7 & 194.2 & 23.3 & 442.0 & 53.0 & 833.6 \\
\hline $1988 / 89$ & 284.4 & 27.9 & 215.6 & 21.1 & 520.6 & 51.0 & 1020.6 \\
\hline $1989 / 90$ & 334.9 & 30.1 & 224.7 & 20.2 & 553.8 & 49.7 & 1113.4 \\
\hline $1990 / 91$ & 543.3 & 37.2 & 288.6 & 19.8 & 628.3 & 43.0 & 1460.2 \\
\hline $1991 / 92$ & 751.7 & 40.2 & 352.6 & 18.9 & 763.8 & 40.9 & 1868.1 \\
\hline $1992 / 93$ & 960.1 & 43.3 & 410.5 & 18.8 & 840.2 & 37.9 & 2216.8 \\
\hline $1993 / 94$ & 1168.4 & 45.5 & 480.5 & 18.7 & 920.4 & 35.8 & 2569.3 \\
\hline $1994 / 95$ & 1376.8 & 46.6 & 544.4 & 18.5 & 1027.9 & 34.9 & 2949.1 \\
\hline $1995 / 96$ & 1585.2 & 47.6 & 608.3 & 18.3 & 11304 & 34.1 & 3328.9 \\
\hline $1996 / 97$ & 1793.6 & 48.8 & 672.2 & 18.1 & 1242.9 & 33.5 & 3708.7 \\
\hline \multicolumn{8}{|c|}{$\begin{array}{l}\text { Source: Academy of Scientific Research (1981-1993) } \\
\text { Ministry of Health and Population (1993-1997) }\end{array}$} \\
\hline
\end{tabular}




\begin{tabular}{|l|l|l|l|}
\hline \multicolumn{4}{|c|}{ TABLE 6.2 } \\
\begin{tabular}{|l} 
Capital Investment in the Egyptian Pharmaceuticals Sector \\
in 1000s of dollars with constant prices (1990-1997)
\end{tabular} \\
\hline \multirow{3}{*}{ Year } & Public Sector & $\begin{array}{l}\text { Locally Owned } \\
\text { Sector }\end{array}$ & $\begin{array}{l}\text { Foreign Owned } \\
\text { Sector }\end{array}$ \\
\hline & & & \\
$1990 / 1991$ & 959351.1 & 90823.4 & 311795.3 \\
$1991 / 1992$ & 892686.3 & 160821.2 & 397937.4 \\
$1992 / 1993$ & 1003367.6 & 213538.9 & 462492.8 \\
$1993 / 1994$ & 959471.9 & 267090.2 & 5240233.1 \\
$1994 / 1995$ & 913920.4 & 317624.2 & 571572.2 \\
$1995 / 1996$ & 872144.6 & 381115.6 & 631279.1 \\
$1996 / 1997$ & 830368.8 & 444607.0 & 690981.0 \\
\hline \multicolumn{4}{|c|}{} \\
Source: Information Centre of the General Organization of Industry \\
\hline \multicolumn{4}{|l}{}
\end{tabular}




\begin{tabular}{|c|c|}
\hline \multicolumn{2}{|c|}{$\begin{array}{c}\text { TABLE 6.3 } \\
\text { Changes in the Value of Drug Exports } \\
\text { in millions of L.E. }(1981-1998) \\
\end{array}$} \\
\hline Year & Value of Fxnorts \\
\hline $1981 / 1982$ & 4.20 \\
\hline 1982/1983 & 9.50 \\
\hline 1983/1984 & 7.10 \\
\hline $1984 / 1985$ & 8.60 \\
\hline 1985/1986 & 10.40 \\
\hline 1986/1987 & 12.60 \\
\hline 1987/1988 & 25.80 \\
\hline 1988/1989 & 37.10 \\
\hline $1989 / 1990$ & 29.10 \\
\hline 1990/1991 & 53.60 \\
\hline 1991/1992 & 103.6 \\
\hline $1992 / 1993$ & 129.0 \\
\hline 1993/1994 & 137.2 \\
\hline 1994/1995 & 148.2 \\
\hline 1995/1996 & 159.3 \\
\hline 1996/1997 & 170.6 \\
\hline $1997 / 1998$ & 350.0 \\
\hline \multicolumn{2}{|c|}{$\begin{array}{l}\text { Source: Academy of Scientific Research (1981-1993) } \\
\text { Ministry of Health and Population (1993-1997) } \\
\text { Egyptian Export Promotion Centre (1998) }\end{array}$} \\
\hline
\end{tabular}




\begin{tabular}{|c|c|c|c|}
\hline \multicolumn{4}{|c|}{$\begin{array}{c}\text { TABLE 6.4 } \\
\text { Changes in the Value of Drug Consumption at Market Prices } \\
\text { in millions of LE (1981-1999) }\end{array}$} \\
\hline Year & $\begin{array}{l}\text { Total } \\
\text { Consumption }\end{array}$ & $\begin{array}{l}\text { Portion of Local } \\
\text { Production }\end{array}$ & Portion of Imports \\
\hline 1981/82 & 226.2 & 216.8 & 49.9 \\
\hline 1982/83 & 408.5 & 300.8 & 107.7 \\
\hline $1983 / 84$ & 487.4 & 378.3 & 109.1 \\
\hline $1984 / 85$ & 584.3 & 452.6 & 131.6 \\
\hline $1985 / 86$ & 696.6 & 545.8 & 150.8 \\
\hline $1986 / 87$ & 778.1 & 616.8 & 161.3 \\
\hline 1987/88 & 954.0 & 762.2 & 191.8 \\
\hline $1988 / 89$ & 1094.2 & 930.8 & 163.4 \\
\hline $1989 / 90$ & 1217.8 & 1058.7 & 132.1 \\
\hline 1990/91 & 1395.1 & 1248.5 & 146.6 \\
\hline 1991/92 & 1766.6 & 1588 & 178.6 \\
\hline $1992 / 93$ & 2284.4 & 2101.6 & 182.8 \\
\hline $1993 / 94$ & 2655.6 & 2460.0 & 195.6 \\
\hline 1994/95 & 2786.0 & 2563.1 & 222.9 \\
\hline $1995 / 96$ & 2923.3 & 2689.4 & 233.9 \\
\hline 1996/97 & 3060.6 & 2846.4 & 214.2 \\
\hline 1997/98 & 3197.9 & 2974.1 & 223.8 \\
\hline 1998/99 & 4000.3 & 3700.3 & 300.02 \\
\hline
\end{tabular}




\begin{tabular}{|l|l|l|}
\hline \multicolumn{3}{|c|}{ TABLE 6.5 } \\
List of Pharmaceutical Companies Operating in Egypt by Ownership \\
\hline Foreign Owned & Locally Owned Private & Public Sector \\
\hline $\begin{array}{l}\text { Drug Producers } \\
\text { Pfizer }\end{array}$ & Drug Producers & Drug Producers \\
Hoechst Marion & ECDIMA Affiliates) & Cairo Pharma \\
Roussel Novartis & MUP & CID \\
Bristol Myers & MEPACO & Nile Pharma \\
Squibb & Sedico & Memphis Pharma \\
Arab Ohtsuka & (Non-Affiliates) & Misr Pharma \\
Glaxo Wellcome & Pharco & Alexandria Pharma \\
Eli Lilly & Amriya & Arab Drug Co. \\
Rhone Poulenc & Amoun & Production Related \\
Servier Egypt & Amoun Pharmaceuticals & El Nasr Company \\
& Minipharm & Packing Company \\
Production Related & Tenth of Ramadan & \\
Gist Brocades & October Pharma & Trade and Distribution \\
Hebi Health & Acapy & Egydrug \\
RP Scherer & Alkan & El Gomhorya \\
& & \\
& Production Related & \\
& (ACDIMA Affiliates) & \\
& Flexi-pack & Arab Glass \\
& Arab Gelatin & \\
\hline
\end{tabular}




\section{CHAPTER SEVEN}

\section{POLICY OPTIONS UNDER THE TRIPS: REALITY OR ILLUSION}

In the last chapter a number of conclusions were drawn, suggesting a need to broaden economic analysis concerning the TRIPS Agreement's impact on the pharmaceutical industries of developing countries, to include critical pharmaceutical/health aspects of their national systems of innovation. Indeed, the main purpose of this study has been to emphasize the importance of understanding the role of historical, social, cultural and political factors even when attempting to assess the specifically economic implications of that Agreement. On balance, the study has demonstrated that the short-term costs of this Agreement for the developing world are clear and substantial while the long-term gains are ambiguous and uncertain. The purpose of this chapter is twofold: (1) to analyze recent international events that have transpired as a result of the continuing disagreement between the developing and the developed countries over the impact of the TRIPS on national pharmaceutical industries and public health systems; and (2) to briefly examine key changes in Egypt's new patent law. My central argument rests on four main points:

1. It is evident that the developing countries have come a long way since the Uruguay Round negotiations when they were largely pressured and threatened into accepting the TRIPS Agreement, despite the fact that neither their local pharmaceutical 
industries nor their public health systems were adequately prepared to deal with its implications. Their increasingly sophisticated understanding of the TRIPS Agreement and its implications for their economies and their future technological development, combined with a better understanding of the international negotiation process, is evident in the policy process that led to the creation of the 'Declaration on the TRIPS Agreement and Public Health' at the Fourth WTO Ministerial Conference in Doha, Qatar, in November 2001..$^{73}$

2. Nevertheless, Doha also showed that despite this strengthening of the developing country position, the industrial countries largely delineated the scope and substance of these negotiations. Indeed, although the developing countries were said by some to have made substantial gains, in reality the industrial countries conceded nothing in the Doha Declaration that the TRIPS did not already permit, with the resolution of those contentious issues that were not already clearly stipulated in the Agreement, postponed to future negotiations.

3. From the perspective of this study, the most important outcome of this latest phase in the policy process was that it implied a problematic fundamental reaffirmation of the core requirements of the TRIPS Agreement by the developing countries. The success of the industrial countries in limiting the negotiations to a discussion of the so-called flexibilities already embedded within the TRIPS with respect to public health, effectively obscured the need for a more critical discussion of the impact of the core

\footnotetext{
73 From hereon the Declaration on the TRIPS Agreement and Public Health will simply be referred to as
} 
TRIPS requirements on innovation and technological diffusion in the developing world. In effect, the industrial countries insisted that the developing countries must accept that these negotiations could proceed only on condition that the TRIPS was accepted as a part of the solution to any public health problems, so that, under no circumstances, would discussion of the desirability of the TRIPS be reopened.

4. Given this reality, it is likely that the implementation of key provisions in Egypt's new patent law that were designed to protect and promote the development of the local pharmaceutical industry and public health, will continue to be challenged by the global pharmaceutical industry and by Egypt's stronger trading partners despite the conformance of these provisions with the policy options permitted under the TRIPS and confirmed at Doha.

This chapter deals with the events that began in the latter half of the 1990s, when there was growing confusion over the flexibilities embedded within the TRIPS, and that ended in November 2001, when Ministers of the WTO Member States adopted the Doha Declaration at the fourth WTO Ministerial session. It also discusses key changes in Egypt's new patent law that was passed soon after the Doha meeting. The discussion is presented in four main parts. The first deals with how the demand for clarification of the TRIPS Agreement emerged within the WTO TRIPS Council. The second deals with the events that unfolded during the latter half of 2001 as the developed and developing countries struggled to ensure that the text of the Doha Declaration would reflect their

the Doha Declaration. 
respective needs and priorities. The third part considers the practical implications of these events. The fourth and final part examines key changes in Egypt's new patent law and interprets them in connection with the issues dealt with in this study.

\section{THE DEMAND FOR CLARIFICATION OF THE TRIPS}

The TRIPS Agreement includes various provisions that in principle allow WTO members to take various measures in order to protect public health. As discussed in chapter four, the most significant provisions are those related to parallel imports, exceptions to exclusive rights and compulsory licensing. Yet, despite the existence of these provisions in the TRIPS Agreement, the developing countries have found it exceedingly difficult to make use of them to address serious public health concerns, not even in the case of genuine national health emergencies. This has been so because the United States government, responding to a strong pharmaceutical lobby, has led the industrial countries in pressuring them not to take advantage of these provisions, but to adopt a particular interpretation of the TRIPS, one that primarily serves its interests and those of its large multinational pharmaceutical firms.

In effect, the international pharmaceutical lobby has been relentless in its efforts to ensure that most of the concessions, which had been made to the developing countries in persuading them to sign the TRIPS, should not be utilized by them in actual practice. As a result, countries that attempted to invoke these legitimate provisions of the 
Agreement have quickly found themselves in conflict with the US government. Thus when the Thai government sought to make use of parallel imports and the compulsory licensing of certain drugs to fight a raging AIDS epidemic, the US signaled its strong disapproval and threatened economic sanctions until the government abandoned these policy instruments in 1999 (Moreau 1999; 24). ${ }^{74}$ The government's hands were further tied when it was also forced to terminate the operations of its Pharmaceutical Patent Review Board, which had the power to compel companies to divulge sensitive cost data thereby providing some protection against transfer pricing and anti-competitive behavior (Moreau 1999; 24). ${ }^{75}$

By early 2000 PhRMA was heavily lobbying the US government to intervene actively on its behalf in other countries where it considered IP protection to be insufficient. Thus, in its February 2000 submission to the USTR, PhRMA specifically demanded that Argentina, Egypt and India be placed on the US's Priority Watch List because in its view:

All three countries are out of compliance with WTO TRIPS obligations and all three adversely affect our industry's ability to market our products, and weaken efforts to carry out research and development into vital new therapies with adverse impacts worldwide. Furthermore, these countries have taken aggressive postures in international trade fora adverse to US government and industry interests (PhRMA 2000).

Although these three countries were the primary targets, they were not the only ones.

\footnotetext{
${ }^{74}$ AIDS is the number one killer in Thailand.

${ }^{75}$ It is important to recognize that the reasons for Thailand's capitulation to US demands were very complex and included difficulties resulting from the financial crisis, heavy reliance on the US market for Thai exports and dependence on IMF cash (Moreau 1999; 24).
} 
Indeed, the submission proceeded to identify thirty other countries for inclusion in the slightly less threatening USTR Watch List. ${ }^{76}$

In August 2000 sixteen of these thirty countries, including Egypt, were moved up to the Priority Watch List, while 39 others were placed on the less serious 'Watch List'. Meanwhile, between 1996 and 2000 the US had filed fourteen WTO complaints relating to an alleged inadequacy of foreign IP regimes (USTR 2000; 1). On this score, it appeared to be willing to do 'whatever it takes' to achieve its objectives. Thus, one US official told me in Cairo that if necessary the US government would be willing to set up a separate agency to keep up with these proliferating "global indictments". It was only when the issue of the inaccessibility of patented HIV/AIDS treatments for the poor in the developing world exploded on the global stage, that the US was forced to re-examine these callous policies, at least for a time.

It is by now well known that the developing world is facing a startling HIV/AIDS epidemic. Of the 33 million people infected with HIV/AIDS worldwide, 90 percent live in poverty-stricken regions of Africa, Latin America, and Asia where AIDS is a fatal, rather than a chronic disease, largely because HIV/AIDS treatments are priced well out of most people's reach. It was this stark reality that revealed the unacceptability of the demands by the US government and the global pharmaceutical industry for the accelerated implementation of the TRIPS in these poor countries. The issue was soon

\footnotetext{
${ }^{76}$ These countries included: Korea, New Zealand, Hungary, Israel, Pakistan, United Arab Emirates, Brazil, Canada, Dominican Republic, Australia, China, Hong Kong, Indonesia, Philippines, Thailand, Vietnam, Czech Republic, Estonia, Lithuania, Poland, Russia, Slovak Republic, Slovenia, Kuwait, Lebanon, Saudi
} 
brought to a head in two international cases, namely those of South Africa and Brazil.

\section{The Case of South Africa}

In an effort to improve access to HIV/AIDS treatments for its 4.2 million infected citizens, the South African government had passed the 1997 Medicines and Related Substances Control Amendment Act, authorizing parallel imports and encouraging generic substitution of branded pharmaceutical products. In response, the multinational pharmaceutical industry immediately began pressuring the South African government to rescind this law while urging the US government to reinforce its demands. It was not long before the US government did inform the South African government that it considered the law in question to be 'unacceptable' and then proceeded to impose some minor economic sanctions while threatening more severe reprisals by placing the country on its Priority Watch List (Mabry 1999; 25). However, initially the position of the South African government remained firm in spite of these threats, which led the South African Pharmaceutical Manufacturers Association (PMA) to take the South African government to court in March 2001.

In court the PMA argued that the provisions in the law concerning parallel imports and generic substitution granted excessive powers to the health minister, discriminated against the industry and violated the TRIPS Agreement. But these allegations had little basis in reality. The fact of the matter was that parallel imports were 
routinely used in many countries, particularly in Europe, while generic substitution had been a mainstay of US drug policy for two decades. Moreover, there could be no doubt that South Africa's AIDS crisis qualified as a national emergency under the TRIPS Agreement, which meant that the use of strong measures including parallel importing, generic substitution, and even compulsory licensing of certain drugs would not constitute violations of that Agreement. Indeed, this is why the South African Act had been carefully drafted to give the Minister of Health only the power to "prescribe conditions for the supply of more affordable medicines in certain circumstances so as to protect the health of the public" (Mabry 1999; 22).

As this court case proceeded, international criticism of the US and of the global pharmaceutical industry intensified, and many observers came to feel that the industry was doing irreparable damage to its already troubled image. But it was only when worldwide protests from HIV/AIDS and human rights activists threatened to disrupt Vice President Al Gore's presidential campaign that the US appeared to soften its stance (Abbott 2002; 471). Accordingly President Clinton issued an Executive Order in March 2000 , which declared that the US would not put pressure on developing countries that took measures to provide cheaper HIV/AIDS drugs to their populations, so long as they adhered to the TRIPS. The Bush administration subsequently announced that it would not be rescinding this policy. With its major ally partially withdrawing support, intensifying public criticism, and no real basis for its lawsuit, the PMA was essentially forced to announce on April 18, 2001, that it was withdrawing the suit. The South 
African government subsequently announced its intentions to move quickly to implement the law.

\section{The Case of Brazil}

On February 1, 2001 the WTO approved a US request to establish a dispute settlement panel to judge the compatibility of Article 68 of Brazil's 1996 industrial property law with the provisions of the TRIPS. The focus of the dispute was the stipulation that an IP holder is obliged to work his patent locally within three years of the issuance of the patent or else risk being forced to license the invention to others wanting to do so. The Article also stipulates that if the IP holder should choose to utilize his patent through importation, rather than working it locally, then others would also be permitted to import the invention from other "legal" sources as well.

The US, in its complaint, argued that this provision discriminated between imported and locally produced products and was therefore illegal under the TRIPS. According to US officials, exclusive patent rights could not be made conditional on the way in which a right holder chooses to service the local market, by working the patent in the country or by importing the product.

The Brazilians insisted that the law was fully compliant with the TRIPS and that the Article provided a necessary tool for the government to increase access to essential treatments particularly those related to HIV/AIDS. Indeed, Brazil had initiated a highly successful program providing for the universal distribution of HIV/AIDS medicines, 
which the Brazilians believed to be dependent on the local production of HIV/AIDS drugs and on their ability to negotiate favourable terms with the industry. The strong provisions for compulsory licensing in its patent law was rightly considered an important asset in their negotiations with the global pharmaceutical industry. Indeed, the threat to use the provisions of this law against the pharmaceutical companies has persuaded those companies to lower their prices on several occasions.

In addition, the Brazilians countered the US complaint with a complaint of their own by arguing that Articles 204 and 209 of Title 35 of the US Patent Code violated the non-discrimination principle under the TRIPS. These Articles stipulate that patents obtained for inventions backed by government subsidies or goods covered by federallyowned patents respectively, must be "substantially" produced in the United States in order to ensure patent protection (Yerkey and Pruzin 2001). However, this dispute was not pursued when the two countries reached an agreement concerning the Brazilian law.

Faced with another international public relations disaster when the "Brazilian" dispute came to be widely perceived as yet another US attack on a country struggling to meet its public health needs in the context of a severe humanitarian crisis, the US withdrew its case in June 2001. In a bilateral settlement, Brazil agreed to give advance notice to US authorities before issuing compulsory licenses in any industry. A joint communication issued by the two countries on June 25, 2001 stated:

Without prejudice of the U.S. and Brazil's different interpretations of the consistency of Article 68 with the TRIPS Agreement, the U.S. Government will withdraw the WTO panel against Brazil concerning the issue, and the Brazilian Government will agree, in the event it deems necessary to apply Article 68 to 
grant compulsory license on patents held by U.S. companies, to hold prior talks on the matter with the U.S.. These talks would be held within the scope of the U.S.-Brazil Consultative Mechanism, in a special session scheduled to discuss the subject. $^{77}$

However, in an effort to stem possible emulation of the Brazilian law by other developing countries, the USTR issued a clear statement that it viewed "local manufacturing requirements as being inimical to the principles of free trade and inconsistent with various WTO rules, including the TRIPS Agreement," (Yerkey and Pruzin 2001). It also went on to warn: "The U.S. government will aggressively engage other countries that impose or maintain such requirements and, if appropriate, pursue WTO dispute settlement" (Yerkey and Pruzin 2001).

\section{Demanding Change}

These unfortunate experiences, when added to the growing disappointment due to the slow progress in implementing the WTO related agreements on textiles and agriculture, had a decisive impact on the perception of the WTO and the TRIPS in many developing countries. In essence these countries came to believe that the industrial countries were reneging on the fundamental tradeoff on which their acceptance of the WTO and the TRIPS had been based. That tradeoff had involved their acceptance of stronger patent regimes and more liberalization of trade in services in return for more liberal trade regimes for textiles and agriculture. But now it seemed that they were not

${ }^{77}$ Available on the CPT Page on Brazil: http://www.cptech.org/ip/health/c/brazil/statement06252001.html 
achieving any of the promised concessions. In fact, the United States and Europe continued their protectionist agricultural policies and have even increased farm subsidies since the Uruguay Round, while demanding that developing countries should continue to eliminate all such barriers to trade. Similarly, very little progress had been made in opening up Northern markets to developing country textiles with only a few products having been taken off quota lists. Thus, it appeared to these countries that the stronger WTO members had scarcely implemented their end of the bargain, but were actively insisting that the developing countries should not only implement stronger IPRs through the TRIPS, but that they should do so in an accelerated manner with little technical and financial support because that suited industrial country interests.

As a result, many frustrated developing countries came to the conclusion that a renegotiation of the WTO Agreement and its various constituent elements was needed to address these various implementation issues. Unfortunately, the stronger industrial powers and the WTO bureaucracy considered this demand to be unacceptable, undoubtedly in part because the industrial countries feared that the substantial gains that they had made during the Uruguay Round negotiations would likely be compromised. "It is impossible to re-negotiate the Uruguay Round. It will lead to an unraveling of the whole process, for you cannot re-negotiate parts of it," declared Paul-Henri Ravier, Deputy Director General of the WTO (Macan-Markan 2001). However, such intransigence only strengthened the resolve of the developing countries to develop a (Nov. 3, 2002). 
strong common policy position, despite the significant differences in their interests and circumstances. In the debates that followed, it was common to find India, Pakistan, Egypt or Brazil taking the lead and trying to speak on behalf of the group as a whole. The unified front that emerged among the developing (and least developed) countries was most evident at the TRIPS Council meeting in April 2001 when they demanded a special session to clarify the 'room for maneuver' within the TRIPS, and especially the nature of the relationship between the TRIPS rules and a country's access to drugs. These had become pressing issues because many developing countries felt that recent international pressures to enforce stronger global IPRs had called into question the effectiveness and the usefulness of many of the concessions and safeguards that they had negotiated originally. The constant demands for accelerated implementation and the threat of retaliation from their stronger trading partners, particularly the United States, whenever they tried to make use of the flexibilities in the TRIPS had led this group of countries to conclude that a clarification of the rights and obligations conferred by that Agreement was urgently needed.

The fact that the WTO acceded to this demand was largely the result of three factors: increased unity in the developing country ranks, as a result of the disappointing results to date; the unifying effect of the South African AIDS experience, which served to highlight certain fundamental conflicts between the owners and users of today's technology, especially in the pharmaceutical field; and the desire of some of the strongest members of the WTO to launch a new round of trade negotiations. The formation of a 
more coherent and stable developing country coalition has complementary explanations. ${ }^{78}$ The first is that experience was teaching the developing countries that institutional objectives could not be achieved without a degree of political unity and the ability to articulate a clear and coherent policy position. Abbott $(2000 ; 480)$ argues that this realization emerged in part out of the controversial process that resulted in Supatchi Panitchpakdi succeeding Michael Moore as Director General of the WTO. It seems that the developing countries had entered those negotiations with a clear awareness that efforts would be made to weaken their coalition, and that they had to resolve to resist them if they wished to succeed (Abbott 2002; 480). However, in part, this realization had begun to emerge even earlier as it became increasingly clear that the TRIPS had been created primarily as a result of the concerted efforts of global corporations. In any event, whatever the reasons may have been, the united front that was established and maintained by these countries throughout the negotiations that led to Doha was an outstanding achievement which sent the unambiguous message that they were serious about finding a collective solution to the potential threat posed by the TRIPS to public health.

Their task was made easier by the fact that the TRIPS Agreement had rather similar implications for public health in almost all developing countries. Although these did vary somewhat from country to country, depending on the country's domestic pharmaceutical manufacturing capacities, ultimately all of them were experiencing difficulties with rapidly rising health care costs, struggling and beleaguered local

\footnotetext{
${ }^{78}$ Please note that when I refer to the developing country coalition it includes least developed country
} 
industries, and unrelenting foreign pressures to strengthen their IPR regimes and to expedite full implementation of the TRIPS.

Finally, the emergence of an effective coalition among the developing countries was also due to their realization that individually they would not have been able to defend their interests due to their limited human and financial resources. "For many developing country delegations in Geneva, a few individuals (if that) may be called upon to attend not only to all WTO matters, but to matters at various other international institutions" (Abbott 2002; 479). Indeed, in some cases it is only because of funds provided through technical assistance from industrial countries that developing countries are even able to send delegations to attend meetings of the WTO and of other international organizations. Under these conditions the unified front that emerged among the developing countries was a remarkable achievement. However, it was not the only reason why the industrial countries acceded to the demand for the Doha discussions of the TRIPS.

The second significant reason for the WTO's acceptance of the developing country demand for a review the TRIPS, stemmed from the international concern raised by the dispute over South African access to anti-AIDS drugs. This case had triggered the mobilization of activist organizations worldwide in support of developing country efforts to increase drug accessibility to the chronically ill. NGOs like Oxfam, Médécins Sans Frontièrs (MSF), Health GAP Coalition, Consumer Project on Technology (CPT), Third World Network (TWN) and Treatment Action Campaign (TAC) made tremendous efforts 
to use the South African case to focus the world's attention on the pain that could be inflicted by the strict application of the TRIPS on the poorer countries of the world.

The activities of these NGOs were not limited to raising public awareness. MSF was successful in influencing the European Commission to adopt a more moderate approach to the problem of access to patented medicines in the developing world (Abbott 2002 ; 478). Both MSF and TAC also played a role in facilitating the importation of “cheaper" anti- AIDS treatments into South Africa from Brazil (Abbott 2002; 478). Others, including CPT, Oxfam and TWN, have assisted in the production and distribution of influential position and policy papers, and have offered advice to developing country officials on their rights and obligations under the TRIPS. These efforts helped to subject the WTO to extreme public scrutiny and led many to wonder whether the Organization could be relied upon to fairly serve the interests of all of its members, and not just the rich and powerful ones. This was the context within which the WTO agreed to address the possible links between stronger patents and access to drugs within the WTO TRIPS Council. To have rejected the developing country request under these conditions would undoubtedly have damaged the Organization's credibility in the eyes of many.

The third reason why the WTO agreed to the Doha discussions was that several of its strongest members, including the US, EU, Canada and China, whose accession to the WTO was soon to be announced, were keenly interested in launching a new round of trade negotiations at the next ministerial conference because they were anxious to further expand international market access for agricultural products, manufactured goods and 
commercial services. A willingness to discuss concerns over the TRIPS and its implications for public health appeared to be a necessary concession to achieve agreement on this demand, given the strength of the developing country coalition, which could otherwise have blocked the effort to launch a new round of trade talks.

In fact, the serious disappointment of most of the developing countries with the early results of the Uruguay Round, suggested that the industrial countries needed to show a willingness to go far beyond a mere review of the TRIPS. Mike Moore, the Director General of the WTO, was among those who began calling for a 'development round', or a 'development friendly round', which basically meant a round which encouraged and facilitated the full participation of the developing countries and which would yield outcomes that take their needs and their demands more fully into account. Of course only time would tell if this was rhetoric or reality, though the tough line taken by the industrial countries and the WTO until that time did not augur well. On the other hand, it should be noted that by agreeing to the need for a 'development friendly' round, the leaders of the Organization were implicitly acknowledging that the original negotiations and outcomes had not been 'development friendly', which is essentially the thrust of the argument presented in this thesis. Of course, the fact that these leaders were acknowledging the need for a wide-ranging reassessment meant that a review of the TRIPS and its links to public health had to be accepted as part of those discussions. After all, it would have been impossible to talk of a 'development friendly' round without addressing one of the key concerns of the developing countries. 
Not surprisingly, it quickly became apparent that the willingness to search for 'development friendly' alternatives would have to be confined rather narrowly since there was agreement from the very start among the most influential WTO members that the TRIPS could not be re-opened at these proposed talks so that discussions would be limited to a clarification of the flexibility provided for in the existing Agreement. The constraints that this imposed on the Doha discussions ensured that the discourse that emerged with regard to the implications of a stronger global IPRs regime differed markedly form that which had emerged during the Uruguay Round. At that time the main concerns revolved around the broader implications of stronger global IPRs for technological and economic development, and by association, for public health. That discussion had concluded that the impact would be positive, but that developing countries would need significant grace periods for phasing in the new rules if they were to be able to take advantage of the opportunities potentially afforded by stronger IPRs.

Alternatively, the discourse around Doha was largely concerned with the interpretation and implementation of the TRIPS Agreement and on the extent to which "exceptions" could be invoked to safeguard public health. As a result, fundamental questions regarding the suitability of stronger IPRs for development were explicitly ruled out of these talks.

When the developing countries sought to raise more fundamental issues when discussing their public health concerns at Doha it was made clear by the industrial country representatives that these issues were not "on the agenda." Indeed, Brazil's attempt to link public health issues to its long term need to develop a strong local 
pharmaceutical industry, was immediately challenged by the pharmaceutical industry representatives and by some industrial country governments, as evidence of an unacceptable 'hidden agenda'. In short, the agreement to review the implications of the TRIPS at Doha was strictly on the condition that members must accept the TRIPS as is, and that the discussion must focus on its interpretation and its impact on access to medicines. This is the context in which the ensuing discussions and their outcomes must therefore be assessed.

\section{CLARIFYING THE TRIPS AGREEMENT}

The attempt to clarify those provisions of the TRIPS that allow members to take certain measures to protect public health, led to an intense struggle between the developed and developing countries, with each side seeking to ensure that any resulting declaration would reflect its particular interpretation. The relative inexperience and weakness of the negotiating teams representing the developing countries during the WTO phase of the Uruguay Round had now changed dramatically, as evidenced by their ability to sustain a more or less united front and their success in using the threat to block the proposed new trade round, if the link between IP and health was not satisfactorily addressed. Of course, the narrow terms of reference imposed on the discussions meant that the developing countries ended up merely seeking a reaffirmation of things that the TRIPS already permitted, but that were being denied to them practice. In other words, there were no new demands to be negotiated; the focus was on interpreting the existing 
agreement.

In fact the US and its more militant allies were on rather shaky ground because they had insisted that fundamental issues were off limits, and yet their position was in fact based on their rejection of a fundamental element of the original agreement, namely its acceptance of the idea that 'special interventionist' policies could be adopted by members under certain conditions. It was because of this underlying contradiction in their position that most of the counter proposals that were tabled by the industrial countries during these negotiations were clearly meant to frustrate and to prolong the negotiations, rather than to make meaningful contributions to the search for a mutually acceptable resolution. This is one reason why the industrial country coalition often appeared fragmented, with the more moderate EU position openly at odds with that of the US and its more militant allies. Indeed, the 'hard line' adopted by the US often made it easier for the EU to present compromise proposals that allowed it to gain developing country support for its broader trade agenda. The following sections take a closer look at the negotiation process, after which an analysis of the resulting declaration is presented.

\section{A Brief Overview of the Negotiation Process}

The negotiations to clarify the flexibilities permitted under the TRIPS and the relationship between the TRIPS and access to medicines can be said to have formally started in June 2001, although internationally, concerns about these issues had been expressed much earlier. Between June and November 2001, the TRIPS Council 
convened a series of formal and informal meetings in an effort to reconcile the divergent views of the developed and developing countries on these matters. The magnitude of this challenge can be appreciated when one considers that initially the two sides struggled over whether there should even be a declaration and what form such a declaration should take.

It is important to recognize that the negotiations that followed were strongly influenced by the fact that there was a deep division within the developed country ranks. So much so that it is more accurate to say that there were three broad voices at the table including the developing countries, a US led coalition of 'hard line' developed countries, including Canada, Switzerland, Australia and Japan, and a more moderate EU, which attempted to act as a 'broker' between the other two groups. On the whole, the developing countries put forward tightly argued proposals urging the need for greater flexibility in interpreting the existing TRIPS Agreement. The US led coalition, on the other hand, staked out a 'hard line' position that, at least implicitly, challenged things that the TRIPS had explicitly permitted. While the EU position was closer to that of the developing countries, it remained unclear or silent on certain key issues. So divergent were these opening positions that as the November Ministerial session approached many policy makers and analysts described the negotiations as having 'stalled', or being at an 'impasse'. Some even believed that they had 'collapsed', making agreement at Doha impossible. Despite such pessimism, a declaration did emerge which dealt with many of the developing country concerns, though with a few very important exceptions. 


\section{The Developing Country Position}

The position of the developing countries was clearly set out in a non-paper ${ }^{79}$ 'Ministerial Declaration on TRIPS and Public Health' presented to the TRIPS Council meetings of September $19-21 .^{80}$ In the preamble it asserted that the protection and promotion of public health and nutrition was a fundamental obligation of any state and that measures to that end remained within the sovereign power of governments under the terms of the TRIPS, as it now stood. ${ }^{81}$ Moreover, it argued that states were not meeting that obligation when high drug prices prevented large segments of the population from access to needed treatments. Indeed, such a situation was said to violate fundamental human rights and could threaten the economic and social balance of states. Hence, if and when the TRIPS Agreement impacted negatively on the availability and affordability of needed medicines, this raised legitimate national and international concerns and tended to give national governments the right to take corrective action.

However, recent international events had cast doubt on the freedom of governments to adopt corrective measures under such circumstances even when these were formally consistent with their obligations under the TRIPS Agreement. Thus, in accordance with the principles stated in the preamble of the TRIPS, the developing

\footnotetext{
${ }^{79}$ A non-paper is a document that is proposed informally with the understanding that its specific language is open to negotiation.

${ }^{80}$ The developing country draft proposal can be view at: http:/www.wto.org/english/tratop e/trips e/mindecdraft w312 e.htm

${ }_{81} \mathrm{~A}$ preamble in international agreements is 'used to ascertain the intention of the parties in the process of interpretation, and is part of the context of the agreement" (Abbott 2002).
} 
countries sought to remind other members that intellectual property rules should "not themselves become barriers to legitimate trade." To this end, the draft explicitly acknowledged the "vulnerability of developing and least-developed country Members to the imposition or threat of imposition of sanctions and to the prospect of being deprived of incentives or other benefits... beyond the framework of the WTO." This statement was meant to highlight the fact that the TRIPS was intended to "reduce tensions by reaching strengthened commitments to resolve disputes on trade-related intellectual property issues through multilateral procedures" as stated in the Agreement's preamble.

Therefore, all actions beyond the framework of the WTO, e.g., the use of Section 301 by the Americans, should be condemned as a clear violation of one of the key purposes of the TRIPS.

The submission therefore called upon members to "refrain from imposing or threatening to impose sanctions and refrain from employing the grant of incentives or other benefits in a manner which could curtail the ability of developing and least developed country Members to avail themselves of every possible policy option to protect and promote public health." Moreover, members were called upon to "exercise utmost restraint in initiating and pursuing dispute settlement proceedings" with respect to measures taken by other members to address perceived public health needs.

The developing country proposal also sought a reaffirmation of the fundamental importance of the objectives and principles of the TRIPS Agreement as set out in Articles 7 and 8. According to the objectives of the TRIPS, the protection of IPRs "should 
contribute to the promotion of technological innovation and to the transfer and dissemination of technology...". Yet the developing countries argued that there was a glaring deficiency in research and development in diseases of primary relevance to them, in addition to low levels of technology transfer that was needed to develop their pharmaceutical manufacturing capacities. This was particularly essential in the short term as the availability and affordability of medicines could only be maximized if global R\&D was complemented by local R\&D and by sustained, or expanded, local production of generics.

According to the principles of the TRIPS Agreement, members may "adopt measures necessary to protect public health and nutrition... provided that such measures are consistent with the provisions of this Agreement." Based on this, the developing country draft suggested that "nothing in the TRIPS Agreement shall prevent Members from taking measures to protect public health." Specifically, every member should be understood to have the right to establish its own exhaustion regime (rules governing parallel imports) and complete freedom to determine when there was a need to grant compulsory licenses. ${ }^{82}$ However, the developing countries were deeply concerned with the question of how those member with little or no pharmaceutical manufacturing capacity could make use of the compulsory licensing provision under the TRIPS given the condition stipulated by Article 31 (f) that "any such use [of a compulsory license] shall be authorized predominantly for the supply of the domestic market of the Member

\footnotetext{
${ }^{82}$ Please see chapter four for a complete discussion of these concepts and relevant provisions under the
} 
authorizing such use," which effectively meant that countries without production capabilities could not use compulsory licensing to address public heath needs. The developing countries thus suggested that provision be made for the possibility that a compulsory license issued by one member could be given effect by another, if the issuing member was unable to manufacture the needed drug themselves.

The draft text also called for an extension of transition periods for the least developed countries, as is consistent with Article 66.1 of the TRIPS Agreement. Here it is stated that "the Council for the TRIPS shall, upon duly motivated request by a leastdeveloped country Member, accord extensions of this [the initial ten year grace period] period." Therefore, as with its other proposals, the developing country draft remained largely within the framework of the TRIPS Agreement.

On balance, the main goal of the developing country proposal was to ensure that the TRIPS be interpreted in such a way that did not obstruct the ability of members to address public health needs by means of suitable policies of their choosing both during and after the grace period provided. Moreover, they were also to have the right to help each other in times of crisis. Unfortunately, the response of the US led coalition of industrial countries was very hostile to these interpretations, leaving the developing country negotiators frustrated and creating a rift between it and the EU. 


\section{The Position of the US-led Coalition}

Faced with a relatively unified stance among the developing countries, the developed countries found it difficult to establish a common policy position in these negotiations although they did agree on a few key issues including limiting the scope of the negotiations to exclude public health/nutrition and the outright rejection of demands for a moratorium, or even due restraint in disputes concerning public health. However, beyond these admittedly important points of agreement it proved very difficult to find common ground particularly between the US and EU. The US took a hard line from the outset, initially attempting to block support for a ministerial declaration altogether.

However, once it realized that this was probably unwise in the prevailing global environment, it made substantial efforts to achieve the same outcome at a lesser cost to its reputation by seeking to persuade the EU, Canada and Japan (also known as the QUAD) to sponsor its views. This proved difficult however. Although Canada and Japan showed greater solidarity with the United States in the draft resolutions, this support seemed inconsistent with their contributions in the discussion sessions, in which they showed a considerable understanding of the concerns raised by the developing countries.

Meanwhile, the EU insisted on taking a consistently more conciliatory line. This debate became even more difficult after the tragic events of September 11,2001 when both Canada and the US took swift measures to ensure that the TRIPS rules would not impede their access to needed drugs to deal with the anthrax scare that followed on its heels.

Not surprisingly, in the run up to Doha, the QUAD governments were intensively 
lobbied by the global pharmaceutical industry as its representatives arranged for urgent meetings with senior government officials in all key QUAD countries, while holding numerous seminars and press conferences to warn officials and the public of the negative consequences that would result from a relatively liberal interpretation of the TRIPS. They were particularly concerned that the coming negotiations might lead to a 'reopening' of the Agreement, which could jeopardize the gains they had made during the WTO/TRIPS phase of the Uruguay Round. Harvey Bale, IFPMA's Director General set the tone of the ensuing debate when he declared that any "easing up on the terms of the 1994 TRIPS accord could open the door for governments to abuse patents on all protected drugs by declaring national health emergencies when none existed" (Evans 2001).

However, the industry's main substantive line of argument was articulated by Dr. Rolf Krebs, chairman of the German pharma giant Boehringer Ingelheim, and President of the IFPMA, when he stated that "more flexibility in TRIPS would be disastrous for continuing investment in research and development on AIDS" (Evans 2001). Moreover, industry representatives and supporters claimed that stronger patents had little or nothing to do with the widespread lack of access to needed treatments. Instead, this problem lay squarely with inadequate health care services and deficient health care infrastructure in the developing countries, as the USTR emphasized repeatedly during the course of the negotiations.

Thus, industry representatives were adamant in demanding that the flexibilities 
embedded in the TRIPS had to be limited by interpreting the Agreement in the narrowest possible way. Accordingly, they argued that it should not be possible to extend compulsory licenses to a third country even if the country in need of certain medicines did not have the necessary manufacturing capacity. This argument was backed by a narrow interpretation of Article 31 (f). On the question of exhaustion they went even further by suggesting that parallel imports should be generally regarded as counter productive in that they interfered with the R\&D funding plans of big firms.

As it turned out, the pharmaceutical industry's demands and arguments were faithfully reflected in the draft proposal tabled by the US at the September 19-21 TRIPS Council meetings. ${ }^{83}$ Its strenuous efforts to obtain the endorsement of its allies, eventually led Australia, Canada, Switzerland and Japan to add their names as signatories to this text. The proposal fell so far short of developing country expectations that many feared agreement would prove impossible. Indeed, in some respects this proposal even seemed to restrict actions which were explicitly permitted by the existing Agreement.

A major source of disappointment arose because both in its title and in the preamble the document insisted that discussion of the flexibilities under the TRIPS should be limited to access to medicines for diseases like HIH/AIDS, tuberculosis and malaria, that is, to cases of extreme human tragedies or pandemics. Yet, as just noted, Article 8 of the TRIPS Agreement unequivocally states that members are allowed to "adopt measures necessary to protect public health and nutrition... provided that such

${ }^{83}$ This proposal can be viewed on the WTO website at: 
measures are consistent with the provision of this Agreement." In essence the US and its co-signatories had little grounds on which to base their insistence that these discussions of the flexibilities embedded in the Agreement should be limited to "access to medicines for HIV/AIDS and other pandemics."

More generally, the document emphasized the fact that drug prices were only one of several equally important determinants of access to treatments, while failing to acknowledge that stronger IP protection could have a significant impact on drug prices. Instead, it chose to focus on the alleged long-term benefits of the Agreement by asking members to "recognize that strong, effective and balanced protection for intellectual property is a necessary incentive for research and development of life-saving drugs and, therefore, recognize that intellectual property contributes to public health objectives globally." Accordingly, members of the WTO were called upon to reaffirm the belief that the TRIPS Agreement will ultimately contribute to greater availability of medicines and thereby to reaffirm their commitment to the existing Agreement and its implementation. While it acknowledged that the TRIPS did contain provisions that allowed members to introduce a number of special measures, it implied that this was legitimate only when dealing with pandemics. Moreover, it suggested that discussions within the Council 'have clarified' members' views of such flexibilities, so that no further discussion was required beyond Doha.

Beyond that, the document contained specific TRIPS clarifications regarding rules

http://www.wto.org/english/tratop_e/trips_e/mindecdraft_w313_e.htm 
of interpretation, compulsory licensing and parallel imports. In the first regard, it noted that the TRIPS should be read in accordance with the customary rules of interpretation of public international law, but made no mention of the Agreement being read in accordance with its own principles and objectives (Articles 7 and 8). Indeed, even in the discussions that followed, the US was not prepared to acknowledge the paramount importance of these provisions even when other members of its coalition sought to do so in their interventions. For instance, a presentation by the Canadian delegation pointed out that "both provisions [Articles 7 and 8] are important for recognizing and understanding the delicate balance and flexibility provided in the TRIPS Agreement. They may rightly be called upon in interpreting various provisions of the TRIPS."

With regard to compulsory licensing, the draft text acknowledged that the TRIPS did not establish grounds, but rather procedures, for their issuance. However, the draft implied that compulsory licenses could only be used legitimately in cases of major pandemics. US intransigence toward countries that sought to make use of compulsory licenses under any other circumstances, even in times of national emergency, emphasized the highly restricted degree to which the US was ready to respect the freedom of members to define national emergencies on their own. In its view, this was to be strictly limited to "pandemics of life-threatening communicable diseases such as AIDS, tuberculosis and malaria".

The remainder of the declaration was devoted to the issue of the exhaustion of rights. Here, the US attempted to circumscribe the use of parallel imports by asserting 
the primacy of Article 28.1, which provides for exclusive importation rights for the IP holder, over Article 6, which clearly leaves the choice of the exhaustion regime up to national authorities. In fact, in a footnote to Article 28.1 in the TRIPS Agreement it is made clear that "this right [exclusive importation], like all other rights conferred under this Agreement in respect of the use, sale, importation or other distribution of goods, is subject to the provision of Article 6." Thus, it is Article 6 that clearly takes precedence over Article 28. At the same time, the US attempted to assert a very narrow definition of exhaustion by implying that intellectual property rights are exhausted in "a market", as soon as the protected goods are sold in "that market", meaning that the purchasers are then free to dispose of the goods as they wish. Although US trade officials claimed that such language was neutral since "a market" could be read to mean global, regional or national, the extent of the discussions that revolved around the US's choice of words between QUAD negotiators reflected disagreement regarding the neutrality of such language, particularly since the TRIPS Agreement imposed no such definitions.

Soon after the US-led coalition had presented this draft declaration, MSF, Oxfam and TWN felt compelled to issue the following joint press statement: "The USsponsored paper presented yesterday, which was not even a complete draft, showed disdain for the concerns of the developing world, and risks bringing the TRIPS Agreement into further disrepute ... a unique opportunity to ensure that TRIPS does not prejudice public health in poor countries is being wasted" (MSF, Oxfam and TWN 2001). It was indeed the case that the US-led coalition's very narrow, interest-laden 
interpretations of the TRIPS defeated the basic purpose of the Doha exercise, which was to discuss the concerns that had arisen internationally as a result of the fact that, in practice, the relevant provisions of the TRIPS were being interpreted so narrowly that members did not have sufficient leeway for addressing legitimate public health concerns.

\section{The Position of the EU}

In general the EU took a relatively more moderate approach that was more sympathetic to the concerns of the developing countries. However, its voice was rather less effective because it had difficulty in presenting a clear, unified position. Hence at the September meetings, the Commission presented a non-paper in the form of a draft declaration that had not yet been approved by member states, and that was later withdrawn. The draft appeared to be in line with the developing country proposals in major respects even though in some others it echoed those in the US draft.

Of great significance for the developing countries was the fact that the preamble of the EU draft acknowledged explicitly that "accessible price" is one of the important determining factors of access to medicines; that IP protection has a "bearing" on the price of medicines; and that compulsory licensing and parallel imports can be used to ensure affordable access. In addition, the preamble also acknowledged that there was legitimate concern over inadequate research and development efforts on diseases of primary relevance to the developing world and that an IPR regime should encourage innovation and technology transfer in and to the developing world. More generally, it accepted that 
this was the intent of the TRIPS, as stipulated under Article 7, as was the notion that IP protection should not be allowed to become a barrier to legitimate trade, nor should it neglect the special needs of the least developed countries for maximum flexibility in devising domestic laws to encourage technological development.

In conformance with the developing country view, the EU proposal suggested that the TRIPS Agreement should be implemented in ways that actively promoted wide access to affordable medicines in the context of national public health policies. Most importantly, it stated that the TRIPS should be read in accordance with the objectives and principles as set out in Articles 7 and 8. The text also affirmed that members had complete freedom to determine the grounds for granting compulsory licenses and to choose the exhaustion regime that best suited their intellectual property objectives. Finally, it urged industrial country members to consider extending the transition periods for least developed countries, consistent with Article 66.1 of the TRIPS.

Not surprisingly, this document met with hostility from US trade officials and pharmaceutical industry critics. The senior vice president for international affairs at PhRMA, Shannon Herzfeld, is reported to have said that the "EU's 'self-imposed' role as a mediator in the dispute... was not particularly helpful as far as the U.S. pharmaceutical industry is concerned" (Yerkey and Pruzin 2001a). The fact that the draft had sought a reaffirmation of a commitment to the TRIPS Agreement and its implementation and the recognition that IPRs contributed to public health objectives globally in line with the US proposal, was not satisfactory given the overall thrust of the 
draft that tended to support the developing countries on key issues. Supporters and representatives of the pharmaceutical industry immediately accused the Commission of softening its stance on IPRs in order to gain the support of the developing countries on other issues, such as the environment, investment and competition rules, which the EU wanted to include in a new trade round (Pruzin 2001).

The paper's hostile reception was soon followed by its withdrawal by the EU. Although there is no clear explanation as to precisely why it was withdrawn, it is safe to say that it was due to the combined opposition of the pharmaceutical lobby, the US government and the co-signatories of its draft, and several of the main European states, especially those with large pharmaceutical industries. Indeed, an earlier proposal to facilitate the use of compulsory licenses in developing countries was dashed by Germany and the UK, whose drug industries would have stood to lose the most as a result. US opposition was naturally very strong given the hard line that it was taking in these discussions. In addition, it has been suggested by Abbott $(2002 ; 486)$ it may also have been withdrawn because the developing countries felt that it "did not incorporate some of the concepts more favorable to developing countries that had been floated in previous position papers." However, that would make sense only if the developing countries saw the possibility that this might influence the EU to draft a new proposal that was more favourable to their concerns, which was not very likely.

Thus, as Doha neared, the differences between the major players seemed irreconcilable, even as the US, Canada and Japan intensified their negotiations with the 
EU in a desperate attempt to develop a QUAD consensus on an acceptable wording of the declaration. Establishing such a consensus prior to the Doha meeting would have greatly bolstered the industrial country position and, the US's unrelenting hard line position, if it succeeded in having it accepted as the QUAD position.

\section{The Anthrax/Cipro Affair}

The continuous efforts of the US-led coalition to deny the claims of the developing countries that the TRIPS should give a relatively high degree of latitude to national governments in dealing with public health crises, appeared to have been greatly compromised when both Canada and the US took swift measures to deal with fears of bioterrorism in the aftermath of the September 11 attacks on the World Trade Center in the US. The issue arose when several envelopes containing anthrax spores were sent through the US mail infecting and killing a handful of people and triggering widespread concern on both sides of the border. Moreover, when it turned out that the most popular antibiotic for the treatment of anthrax, ciprofloxacin (cipro), was under patent to Bayer, both governments responded immediately by threatening Bayer with the compulsory licensing of cipro, if the company was not prepared to supply the needed amount of the drug at a "reasonable price," even though there was no evidence of a national emergency or even a situation of extreme urgency. One might have thought that this graphic reminder of the fundamental validity of the concerns of the developing countries might have softened the coalition's position in the countdown to Doha but that was not to be. 
The coalition maintained its obstinate hard line, thereby greatly strengthening the perception, or the realization, that these negotiations were primarily about power and self-interest.

Ultimately the incident was useful in revealing the double standards of the coalition. While denying developing countries the right to unilaterally invoke 'national health emergencies', the Canadian government immediately entered into a contract with a local generics firm to make generic copies of cipro, to ensure adequate supplies of the drug in case of an anthrax outbreak. This, despite the fact that not a single Canadian had been infected and that only a handful of people had died in the United States. Admittedly, the Canadian government later changed that decision and agreed to purchase the drug from Bayer in exchange for the company agreeing not to sue the government for patent infringement. But the point had been clearly made. Faced with a threat, or rather a perceived threat to public health, the Canadian government had assumed that it had the power to override Bayer's patent rights. On the other hand, the fact that it reversed this decision because it would have found it hard to justify its behavior by claiming that anthrax constituted a national emergency, or situation of extreme urgency, also indicated a recognition that such power cannot be assumed arbitrarily.

The US government's behavior, on the other hand, was even more sharply and more clearly at odds with its hard line position via-a-vis the developing countries on this issue. It too immediately told Bayer that it would not hesitate to override its patent on cipro if prices weren't cut sharply. Secretary of Health and Human Services, Tommy 
Thomson, warned that "if Bayer did not cooperate, he would ask Congress for new powers that would allow the US to violate the patent without paying damages to Bayer" (Alden et al 2001). Yet, "cipro, it turned out, was not the only drug that could be used to treat anthrax; there was no epidemic of cases; and there was no shortage of cipro," (Waldmeir 2001; 14). Nevertheless, on October 24, 2001 Bayer reached a "historic" agreement with the US government whereby the company would supply up to 300 million tablets of cipro at a steeply discounted price (Bayer Press Release 2001).

Much of the world witnessed this affair in utter amazement. To many it was disturbing to see two of the countries that were playing such an obstructionist role during the TRIPS review, so easily willing to take 'necessary' measures to protect the health of their citizens against a perceived, but rather hypothetical, threat. Meanwhile, they were continuing to prevent developing country governments from employing similar measures to protect and promote public health under more critical circumstances in which thousands of people were dying each day. Paulo Teixeira, director of the Brazilian government's AIDS programme, observed that "it smacks of one rule for the north, another for the south... The anthrax outbreak is very distressing but I hope it will make them reflect more about our position that compulsory licensing is an entirely legitimate instrument if there is a problem of access to a crucial drug," (Dyer and Michaels 2001). Unfortunately, this was not the case. 


\section{THE DOHA DECLARATION}

Differences between the developed and developing countries over clarification of the TRIPS persisted up until the November meeting in Qatar. Informal discussions of the draft proposals circulated by the General Council Chair in the last week of October, in a last ditch attempt to narrow the gap between the two sides, only revealed the extent of continuing disagreement. Even the title of the declaration, "Elements for a Draft Declaration on Intellectual Property and [Access to Medicines] [Public Health]", remained bracketed, meaning that there was still no agreement as to the desired coverage of the declaration. Moreover, the fact that the title referred to intellectual property as opposed to the TRIPS in particular reflected the reluctance of the US led coalition to deal with the specifics of the TRIPS. Indeed, just days before the Doha Ministerial it seemed almost impossible to think that there could be agreement on a declaration by the end of it. Intense negotiations, however, continued for the duration of the November 9-14 meeting and by the close a consensus text had emerged. Some official sources suggested that a deal finally became possible when Brazil, one of the leading voices in the developing country camp, reached a key compromise with the US in a closed-door session. The compromise largely involved the substitution of the legally binding language preferred by the developing countries that the TRIPS Agreement "shall not" prevent member states from protecting public health to the TRIPS Agreement "does not" and "should not" prevent members from protecting public health, which merely constituted a political declaration. Moreover, at this same meeting it was agreed that the 
inability of countries with insufficient domestic manufacturing capacity to make effective use of compulsory licensing under the TRIPS, should be postponed for future discussion.

Despite some concern that Brazil had breached the pact of solidarity maintained by the developing countries since the start of the negotiations, the resulting compromise text received the support of all of the developing country members and both the Canadian and international press gave very positive coverage to the resulting TRIPS Declaration. Many analysts concluded that this document represented a significant breakthrough, which should be seen as a signal that WTO members could successfully reach consensus on controversial issues that were of vital importance to the developing world. According to one reporter writing from Doha, "their [developing countries] biggest prize was US backing for an assurance that WTO rules on trade-related aspects of intellectual property rights (Trips) would not enable patent laws to be used to block poor countries' access to essential medical supplies" (de Jonquiere 2001; 6).

In reality, the Doha process left the developing countries in a position that was not very different from that in which they had found themselves when the TRIPS was first negotiated. The concessions that had been made to them at that time were more or less reaffirmed, which was a victory of sorts since it meant that the attempt by the US led coalition to devalue many of those concessions by subjecting them to extremely narrow definitions, had largely failed. On the other hand, it also meant that they did not make any significant progress in these discussions and, at the end of the day, they remain vulnerable to the same problem that bedeviled them the first time around, since they still 
have no enforcement mechanism to prevent the US and its closest allies from devaluing those 'paper concessions' in practice.

Of course, the situation after Doha was different from that after the first introduction of the TRIPS, if only because a number of issues had now been more explicitly discussed so that the provisions of the Agreement were necessarily somewhat less ambiguous as a result. This was a gain for the developing countries. Yet, on a few issues one could argue that they had effectively lost some ground in the Doha process, since the interpretations that were most widely accepted as a result of these discussions, were rather narrower than they might have hoped for at the outset. A detailed look at the Agreement reveals some pluses and some minuses, within the context of an overall situation that had not changed much. Unfortunately, the prognosis for the future looks rather discouraging if the US's unilateralist tendencies continue to grow in an increasingly polarized and conflict ridden world.

Possibly the greatest victory for the developing countries, lay in the fact that the title of the declaration made reference to the 'TRIPS Agreement and Public Health' because this meant that the attempt by the US-led coalition to limit the declaration simply to a question of access to medicines for pandemics had largely failed. Since Article 8 of the TRIPS Agreement explicitly allows members to "adopt measures necessary to protect public health and nutrition," these attempts by the US-led coalition to restrict the rights given by the TRIPS, turned out to be a waste of resources which only served to cast an even deeper shadow over the reputation of the US government in these international 
debates. However, it is important to understand that what appeared as a hard won victory for the developing countries, was no more than a recognition of that which was already part of the TRIPS.

In accordance with this acknowledgement, members reaffirm their commitment to the TRIPS and agree that it "does not and should not prevent Members from taking measures to protect public health" and that it "can and should be interpreted and implemented in a manner supportive of WTO Members' right to protect public health..." In truth, this rather simplistic assertion of the 'good intentions' that the TRIPS does not and should not prevent members from taking measures to protect public health appears almost absurd given the circumstances that gave rise to these negotiations at this time. In this context, the reiteration of essentially unconditional, even thoughtless, allegiance to the TRIPS Agreement appears rather incongruous at a meeting designed to assess its impact on public health and economic and technological development more broadly. Unfortunately, a closer look at the Declaration reveals that much of it is little more than a legalistic paraphrase of the original TRIPS.

Thus, when the Declaration turns to consider the policy flexibility that is made available to member countries by the TRIPS, it again appears to lend strong support to the developing country view. To this end, the declaration recognizes that: (1) the TRIPS should be read in accordance with its objectives and principles; (2) each member has the right to grant compulsory licenses and the freedom to determine the grounds on which such licenses are to be issued; (3) each member has the right to determine what 
constitutes a national emergency or situation of extreme urgency; and (4) each member is free to establish its own exhaustion regime without challenge. Although these interpretations conform closely to the proposals of the developing countries, they were also essentially reiterating the original TRIPS Agreement. Yet, perhaps the reaffirmation of these rights was important if it can help to put an end to continued efforts by the global pharmaceutical industry backed by the US government, to put pressure on developing country policy makers who wish to exercise these rights, as has clearly been the case for Egyptian and other health policy makers.

The Doha Declaration also reaffirmed the "commitment of the developed country members to provide incentives to their enterprises and institutions to promote and encourage technology transfer to least developed country members pursuant to Article 66.2" of the TRIPS and extended transition periods for this group of countries to 2016 , without prejudice to their right to ask for further extensions as under Article 66.1. However, the value of such a commitment is questionable given the extremely limited capacity of this group of countries to absorb such transfers. Indeed, some would argue that the developed countries need to demonstrate their 'good faith' by being more forthcoming in their willingness to promote effective technology transfer to those developing countries that do actually have the capabilities to effectively absorb modern technologies in the short and medium terms. Indeed, one of the major demands of the developing countries in the negotiations following Doha was for the developed countries to encourage technology transfer to them in order to enable them to build stronger 
domestic research and manufacturing capabilities (ISCTD 2002a). Finally, as regards the extension of transition periods for the least developed countries, this was a welcome gesture though it is, once again, something that is already clearly provided for in the TRIPS because of "their economic, financial and administrative constraints, and their need for flexibility to create a viable technological base..." (TRIPS Article 66.1). Yet, these are the provisions that can be considered as 'pluses' for the developing countries. Indeed, if there was a victory, it merely consisted of successfully avoiding a roll back of rights.

In fact, most of the "issues" that were ambiguous before continue to be so now, though possibly to a slightly lesser degree. For the developing countries, it was important that the preamble of the Declaration recognize that the developing and least developed countries face grave public health problems which need to be addressed. However, by specifically naming HIV/AIDS, tuberculosis and malaria, the US led coalition managed to keep open the possibility that the right to take certain actions should be triggered only by problems on a truly disastrous scale.

Next, the Declaration stresses the need for the TRIPS to be a part of a wider national and international program of action to address many of these problems. Once again the meaning of this passage is open to widely differing interpretations. Thus, some analysts, like Abbott $(2002 ; 491)$, believe that this statement declares that the "TRIPS Agreement should not stand as an obstacle to addressing public health concerns" and that 
there is an important role for key international organizations, like the WHO, in addressing international public health crises. I regard it as a reaffirmation of the developed country claim that the TRIPS should be understood as being an important part of the solution to such public health concerns especially in the longer run. This provision would make it difficult to focus on the potentially negative impact of stronger IPRs on drug availability and affordability particularly in the short to medium term. In other words, this formulation implies that in the absence of wider national and international action to address these public health issues in the developing countries, stronger IPRs cannot reasonably be singled out for blame.

This upbeat focus on the assumed long-term benefits of the TRIPS is sustained when IPRs are described as being critically important for the development of new medicines while "concerns about its effects on prices" are mentioned only in passing and without further specification. This passage was clearly a concession on the part of the developing countries to the US-led coalition and the pharmaceutical industry since the developing countries had consistently argued that stronger IP protection does not appear to be encouraging $R \& D$ of relevance to them, while frequently being associated with significant price increases which reduced the ability of their populations to access much needed treatments. In the declaration these concerns are effectively marginalized because the positive impact of stronger IPRs on the development of new medicines is stated as a fact, while their effect on prices in the developing world, is mentioned only as a mere concern. 
However, the most disappointing outcome of the Doha process for many developing countries was that no agreement had been reached on the question of how members with insufficient manufacturing capacity can make effective use of compulsory licensing under the TRIPS. Instead, the TRIPS Council was instructed to find an expeditious solution to this problem and to report to the General Council before the end of 2002. As noted earlier, the main problem is found in Article 31 (f) of the TRIPS which states that "any such use [of a compulsory license] shall be authorized predominantly for the supply of the domestic market of the Member authorizing such use," which effectively places a limit on the export of medicines manufactured under a compulsory license. Both the US and EU had blocked agreement to use the 'exceptions to exclusive rights' provided under Article 30 of the TRIPS Agreement to resolve the issue during the Doha meeting.

Although several proposals have been forwarded since that meeting with regard to this problem, there is as yet no agreement. The US vehemently rejects the possibility of amending the TRIPS arguing that this "might unhinge the balance of rights and obligations negotiated during the Uruguay Round" (ICTSD 2002a). Instead, the US has proposed that members accept a temporary moratorium on dispute settlement when a member grants a compulsory license to export medicines to a country that is lacking manufacturing capacity (ICTSD 2002a). Moreover, it has emphasized that this potential resolution be restricted to addressing diseases referred to in the Doha Declaration, such as HIV/AIDS, tuberculosis and malaria and should further not apply to the developed 
countries or countries that choose not to manufacture a specific drug (ICTSD 2002a). The developing countries have strongly rejected this proposal on the grounds that it does not offer a "sustainable or legally predictable solution" (ICTSD 2002b).

The Europeans have focused on the possibility of formulating an exception to Article 31 (f) but in a similar vein to the US, have emphasized that this would only apply to products that were intended to deal with public health crises in the developing and least developed countries that approximated the magnitude of the HIV/AIDS, tuberculosis and malaria epidemics. Although the developing countries have shown some preference toward the European proposal, they nevertheless favour establishing an authoritative interpretation of Article 30 'exceptions to patentability', as they had suggested during the Doha meeting.

In essence the Doha Declaration can therefore be described as a document in which the developed countries say to the developing countries, 'we will admit you have a problem, if you admit the problem is best addressed by 'business as usual'. In other words, the developed countries agree to admit that the developing countries were facing tremendous health problems, even over and above the HIV/AIDS, tuberculosis and malaria tragedies, and that national and international cooperation was required to address this situation. In return the developing countries were asked to agree that the TRIPS was actually a major part of the solution in its present form. This is why they were asked to pay repeated homage to an Agreement with which they had become extremely unhappy in the preceding years. 


\section{Realistic Expectations}

When the immediate orchestrated euphoria surrounding the alleged victory of the developing countries at Doha had subsided, a few moments of sober reflection soon made painfully apparent to many analysts and activists that there had actually been little value added. "Developing countries came to Doha to extract a clear declaration that public health and access to medicines are more important than protecting commercial interests of pharmaceutical companies. At the end of the day, opposition from rich countries crippled the legally binding language sought by the majority of WTO countries," noted Asia Russel of Health GAP Coalition (ACT UP Paris 2001).

There is no doubt that the real success of the negotiations will ultimately depend on the willingness of the developed countries to desist from exerting strong economic or legal pressures on poor countries to prevent them from exercising the rights given to them by the TRIPS and to push them to accept policies that may adversely affect their national

health systems. However, this will probably prove very difficult, as competitive pressures in the global economy remain intense. Indeed, the negotiations had scarcely ended when US officials and pharmaceutical representatives made public statements denigrating the Doha Declaration as merely a political statement that did not have any relevance to disputes that might arise when a government decided to override an existing patent.

By November 20,2001, only one week after the end of the Doha meeting 
developing countries were further alarmed over a bill, the Trade Promotion Authority, that was introduced into the US House of Representatives and that was explicitly designed to restrict their abilities to address public health needs (Kamath 2001). This bill suggested that, once again, the concessions made on paper would not be translated in actual rights that could be exercised by developing country governments. Indeed, if passed, this bill would run rough shod over Doha since it called for accelerated implementation of the TRIPS Agreement and the elimination of all measures such as price controls and reference pricing, that inhibit full market access for US firms (Kamath 2001). Clearly little of substance had changed.

By the time the final version for the Trade Promotion Authority had been drafted, a bad situation had become worse. Unfortunately it seems, however, that this language is reflective of the US position in discussions over international agreements. As it stands "the text requires the USTR to push for patent monopoly protection far in excess of WTO rules, and negates much of the value of the Doha Declaration on TRIPS and Public Health that enabled the launch of the new round," (Davis 2001). According to a New York Times editorial, "the rules governing poor countries' ability to get affordable medicines," were described as a "mess". It went on to state, "last November in Doha, Qatar, Washington agreed to more flexible language. But drug companies have reinstated old formulas into the bill" (New York Times 2002).

Thus, one year after Doha, an Oxfam (2002) review of the US government's bilateral policies on patents and medicines found that, "overall the number of bilateral 
complaints against developing countries relating to patents and medicines made by the pharmaceutical companies to the US government has not fallen; nor has the number of complaints which the US government takes up." In fact, the review found that the US government included 66 percent of the countries identified by PhRMA's annual submission in its Section 301 report, compared with 61 percent in 2001.

The unrelenting hard line taken by the US and several other developed countries in and after the negotiations underscores the need for the developing countries to adopt and defend their own positions in these international decision making processes. Although the developing countries always had the right under the TRIPS to enact and to implement intellectual property policies in support of their national health policies, so long as these policies were consistent with that Agreement, the Doha Declaration did heighten awareness of and support for these rights. It did not, however, offer anything more than what was already largely permissible under the TRIPS Agreement. In addition, it did not introduce any means of enforcement that might make the powerful members of the WTO live up to the spirit, not just the letter, of that Agreement. Moreover, the Doha Declaration did not address the potentially adverse implications of the TRIPS Agreement on the development of local industries and by association public health. Indeed, because it was so narrowly circumscribed, this debate tended to obscure wider concerns related to technology, innovation and diffusion, the raison d'être of the TRIPS Agreement. This, in turn, created the false impression that the so-called policy flexibilities within the TRIPS could only be legitimately used to address 
public health emergencies. In other words, concerns related to the development of local pharmaceutical industries were now effectively treated as inadmissible.

\section{RECENT CHANGES IN EGYPTIAN PATENT POLICY}

On May 29, 2002, the People's Assembly (lower House of Parliament) passed Egypt's new IPRs law, Law 82/2002, after two years of deliberations. An analysis of two key provisions in the law's chapter concerning patents shows how those who drafted the law aimed to take full advantage of the flexibilities provided for in the TRIPS in order to balance Egypt's obligations with the need to promote the development of the pharmaceutical industry and to protect public health. These provisions concern (1) acts that shall not constitute infringements and (2) compulsory licenses.

On the first point, Article 10, which outlines Egypt's exhaustion regime, defines the limits of the patent holder's rights. In other words, it determines what rights the patent holder may or may not retain over the use of a product, once they have sold the product in the patent protected market. As noted above, controversy frequently arises when firms sell patented products at different prices in different markets, which creates an incentive for the 'higher price' country to import from the 'lower price' country. Egypt's law insisted that the original patent holder's rights are fully extinguished by the first transaction, leaving purchasers free to use and resell the patented product at their discretion. Specifically, the Article states that "the patentees rights to exclude others from importing, using, selling or distributing the product shall be exhausted if the 
patentee marketed and/or licensed the invention to third parties." In short, the law defines an international exhaustion regime under which the right holder's first transaction or sale exhausts his/her rights to control the subsequent exploitation of the product. In other words, selling, using, distributing or importing the product, shall not constitute infringements thereafter. This provision is critically important because it allows the admission of parallel imports from third countries where a drug is marketed at a lower price.

With regard to compulsory licenses, Article 23 boldly establishes wide-ranging grounds for the issuance of compulsory licenses as permissible under Article 31 of the TRIPS Agreement and confirmed in the Doha Declaration. It also draws on the allowance in Article 8 of the TRIPS Agreement that members may in "amending their laws and regulations, adopt measures necessary to protect public health and nutrition, and to promote the public interest in sectors of vital importance to their socio-economic and technological development...". The law therefore stipulates that such licenses may be granted by the Patent Office after approval by a ministerial committee, when the product is to be used (1) for non-commercial public use for the purpose of preserving national security, as well as for promoting health, nutrition and environmental safety; (2) to deal with emergency situations or situations of extreme urgency; and (3) to promote the public interest by promoting sectors of vital importance to socio-economic and technological development.

In seeking to clarify the government's intentions with regard to the ways in which 
the provisions for compulsory licensing of pharmaceutical inventions should be interpreted, Article 23 suggests that rather broad definitions are intended. Thus, the Article states that in the event of "insufficient supply of a patented drug to satisfy the country's needs, or because of a decline in its quality, or irregular increases in its price, or in the event that a drug is related to critical cases, or chronic or endemic diseases..." a compulsory license may be issued if deemed necessary. Moreover, Article 23 also states explicitly that compulsory licenses can be issued in cases where IP holders do not "adequately work" their patents in the domestic market, a similar provision to the one that instigated the dispute settlement procedure between Brazil and the US, as discussed earlier.

In addition to these key provisions that affected the content of the new patent policy, certain changes in the law also affected the regulatory structure. An important institutional change gave the $\mathrm{MOH}$ firm control over all patents related to public health, making it responsible for strategic IP decisions in this sphere. It has in effect, been given central responsibilities in the implementation of the patent regime as it affects pharmaceutical products and other medical inventions, with the power to approve or oppose patent grants.

The concentration of this power in the hands of the MOH is significant because it is the ministry responsible for ensuring drug accessibility, and it is in the best position to assess the impact of specific pharmaceutical patents on public health, in conformance with Article 2 of the new patent law. Here, the law prohibits from patentability any 
invention that "harms the life or health of humans, animals or plants." The MOH is most keenly aware of the needs of the public health system, particularly at a time when it is undertaking major reforms as part of is Health Sector Reform Program (HSRP), which calls for the creation of a comprehensive national policy to encompass all aspects of the pharmaceutical sector in Egypt, including the provision of IPRs for pharmaceutical products.

However, the new authority vested in the $\mathrm{MOH}$ has been a major point of contention with American trade officials who have insisted that the government address certain "deficiencies" in the law. In the words of the USTR (2002) "the United States continues to strongly urge Egypt to correct the reported deficiencies in the draft copyright and patent laws before these laws are enacted by the legislature. The United States remains concerned, in particular, about the possible insertion in the draft patent law of a previously rejected provision calling for health-related patents to be reviewed by the Ministry of Health which would appear to contradict the TRIPS requirement to provide patent protection without discrimination as to the field of technology." In fact, as the Egyptian authorities pointed out, this provision does not discriminate against pharmaceuticals as such, or as a "field of technology," it merely establishes a procedure for patent approvals in this sector which takes account of their impact on public health. ${ }^{84}$

\footnotetext{
${ }^{84}$ Indeed, pharmaceuticals are not the only 'field of technology' singled out under the new patent law as the USTR statement implies. Under the law, if a patent is related to "military affairs, or military production, or national security" they are to be reviewed and approved or rejected by the Ministries of Defence, Military Production and Interior respectively. In each case the specialized ministry is given final adjudication authority over such patents given their sensitive subject matter and hence the need for specific expertise.
} 
It remains to be seen what the USTR will do now that the new law has been enacted with this provision still intact.

Meanwhile the law has come under further attack from the head of the USAID SIPRE (Strengthening Intellectual Property Rights in Egypt) project, Ms. Judy Winegar Goans, who alleges that it violates the TRIPS in other regards. She contends that although the law "accomplishes a number of important improvements... the legislation contains a number of items that are not consistent with the TRIPS Agreement," especially in its provisions for compulsory licensing and parallel imports (Fawzy 2002). While Egyptian officials have rejected these charges, they are clearly concerned that the application of the law may create many problems (Fawzy 2002). The extent of such problems and the willingness and ability of the government to deal with them, however, remains to be seen.

On balance, it seems that the pressures to persuade the developing countries to forgo many of the rights that they had negotiated in the TRIPS, continue to be exerted by those who would like to see an accelerated, full implementation of the TRIPS. Doha was meant to resolve those issues, but as we have seen, its potential to do so was greatly diluted. Now Egypt will be one of the first test cases to see whether any real progress was made. In this regard, the Commission on Intellectual Property (CIPR) recently reminded the industrial countries that:

... so far as possible developing countries should not be deprived of the flexibility to design their IP systems that developed countries enjoyed in earlier stages of their own development, and higher IP standards should not be pressed on them without a serious and objective assessment of their development impact (2002; $10)$. 
This should serve as a timely reminder that industrial countries, and particularly the US, need to accept that developing countries have the right to try, as best as they can within limits imposed by the TRIPS, to ensure that their new IP regimes foster, rather than hinder, the development of their innovative capabilities, their local pharmaceutical industries and their levels public health. It is important for the developed countries to honour the spirit of the Doha Declaration by complementing their great wealth with some semblance of humanity by valuing the basic human rights of the people living in developing countries.

\section{CONCLUSION}

This chapter has argued that despite the notable improvement in the negotiating strength of the developing countries since the Uruguay Round, the industrial countries were still able to define the terms of reference for the negotiations over possible links between the TRIPS and public health, which were held during the Fourth WTO Ministerial Conference in Doha, Qatar. Thus, although the developing countries were successful in getting many of their most pressing concerns on to the agenda, they were not as successful in shaping the scope and substance of the negotiations or determining the outcome. As a result these countries ultimately gained much less from these negotiations than was hoped and needed given the tremendous public health burdens currently being faced by many of them.

The greatest benefit to the developing countries may have been the experience that they gained in establishing and maintaining a strong and united coalition throughout 
these negotiations. Their ability to develop a common policy position sent a clear message to the industrial countries indicating that they were serious about defending their interests in the WTO. Unfortunately, the potential harm of having agreed repeatedly within these negotiations that the TRIPS formed an important part of the solution to their public health concerns may ultimately outweigh the benefits that accrued from the entire process. The problem was that the terms of these negotiations were so narrowly defined that the question of the impact of the TRIPS on the scope for the development of a strong local pharmaceutical industry, to underpin a government's public health policies, was simply ruled out of court. Yet this should have been a major focus of the discussion since that is where the impact of the TRIPS is potentially greatest.

In reality it was the industrial countries that emerged victorious from these negotiations. By using their power, their extensive resources and their access to sophisticated negotiating tactics, these countries were successfully able to create much ado about nothing. From the outset, they made it clear that their willingness to participate in these discussions depended on the acceptance of terms of reference, which made it impossible to reopen the 'sacred text' of the TRIPS, leaving the discussions to deal solely with the flexibilities in that Agreement. Ultimately, the developed countries conceded nothing that the TRIPS did not already permit, while they managed to persuade the developing countries to renew their public commitment to the TRIPS in its present form.

However, despite all this, the Doha Declaration also attests to and confirms the 
policy options that are available to national legislators under the TRIPS Agreement. Moreover, the debate surrounding the TRIPS has heightened awareness of developing country policy makers of the substance of the TRIPS Agreement and of its potential implications for their economies and public health systems. Yet, in the absence of a fundamental renegotiation of the core provisions of the TRIPS Agreement, it is up to national legislators to ensure that their national IPR laws takes full advantage of the policy flexibility reaffirmed in the Doha Declaration. This appears to be the case with Egypt's new patent law where key provisions concerning parallel imports and compulsory licensing have aimed to take full advantage of the policy options permitted under the TRIPS.

Although there is little doubt that the Egyptian government has only reluctantly adopted relatively high intellectual property standards, including the provision of a twenty-year patent term and onerous compulsory licensing procedures, at an early stage in its development, the new patent law seeks to make full use of provisions in the TRIPS to protect and promote national interests. Nevertheless, the inherent limits imposed by the Agreement's minimum standards represent a serious obstacle to the future development of innovation in the country's pharmaceutical sector. Moreover, the problem is almost certainly worse than a simple reading of the law would suggest. This is so because of the fact that the law merely seeks to define the legal ramifications of certain actions associated with intellectual property protection. It cannot, however, guarantee effective implementation given the pressures that will inevitably be exercised 
by the other protagonists in this ongoing struggle. 


\section{CONCLUSIONS}

This study has examined the implications of the TRIPS Agreement for Egypt's pharmaceutical industry and public health sector using a national system of innovation approach. The study was centred on four main points: (1) there is no robust method of determining the appropriate balance between innovation and technological diffusion, known as the core intellectual property tradeoff, without specifying numerous parameters, which tends to subject intellectual property policies to political influence rather than economic calculation; (2) attempts to establish positive and reliable links between strong IPRs and R\&D, FDI, technology transfer and trade have not yielded robust conclusions so that they are often qualified by references to other significant national factors; (3) thus, in order to adequately understand the implications of stronger patent protection for the pharmaceutical industries of developing countries we must consider relevant aspects of each country's national system of innovation; and (4) the intimate relationship of the pharmaceutical industry to public health warrants a consideration of stronger IPRs from this perspective as well.

The study was born of an interest in examining the implications of an international agreement about which there continues to be considerable disagreement. Thus, chapter two was concerned with exactly how this agreement came into existence and to this end, it examined the policy process through which it was created. The discussion revealed that the global pharmaceutical industry has been aggressively 
pursuing changes in the international IPRs regime since the $1980 \mathrm{~s}$. The intensification of these efforts can be attributed to changes in technology and to intensifying global competition from generic drug producers in the developed and the developing countries. Despite the fact that generic drug producers generally provide more affordable alternatives for consumers around the world, the strength of the global pharmaceutical industry, when combined with that of other so-called IPR-sensitive industries, has allowed it to gain the upper hand in the international policy process. Indeed, it has allowed the industry to play an unprecedented role in the history of the GATT. Ultimately, however, it was the willingness of the United States government to threaten, or to impose, sanctions on countries that refused to accept their demands for stronger patent protection, and the broad support of the World Bank and the IMF for such policy changes, that had a definitive impact on the creation of a strong global IPRs regime.

Under such significant pressures, the developing countries only reluctantly accepted the negotiation of a new global IPRs regime in the Uruguay Round. Many countries, including Egypt, believed that the inclusion of the more traditional areas like agriculture and textiles would somewhat balance industrial country demands for new rules regarding IPRs and services. However, this did not alleviate major concerns over the potential adverse implications of stronger patent protection for local pharmaceutical industries and for public health. This is why the Egyptian government chose to take full advantage of the grace period allowed by the TRIPS Agreement.

In order to assess the claims of the proponents of a stronger and globally 
harmonized IPRs regime and the concerns of its opponents, chapter three analyzed the theoretical foundation of IPRs with a focus on patents. It was argued that striking a balance between innovation and technological diffusion, the basic IPR tradeoff, depends on the specification of numerous parameters in any particular setting. Because of the complexity of this task different analysts have often reached conflicting conclusions regarding the optimal strength of patents, i.e., their duration and scope. This ambiguity has meant that in the real world patent policies cannot simply be derived from economic analysis but are significantly subject to the influence of competing special interests as had been demonstrated in chapter two.

From this perspective it became clear that the demand for pharmaceutical patents, as embedded in the TRIPS Agreement, was not primarily based on insights from economic theory. Indeed, economic studies that have sought to establish the link between stronger patent regimes and R\&D, FDI, technology licensing and trade have failed to establish consistent or reliable conclusions and to provide a convincing economic justification for the new IPRs regime, particularly for the developing world. Instead, these studies have ultimately served to draw attention to the importance of the wide range of factors that collectively influence the nature of these four relationships. Both the theory and the evidence that were reviewed, suggested that any serious evaluation of the likely impact of the TRIPS, must be based on a broad understanding of a particular technology and sector, and key aspects of the national environment within which they are embedded in addition to the nature of the innovation process in a 
developing country setting. In essence, the chapter established that innovation is far too complex a process to be attributed to any one particular incentive, including patents, as most mainstream intellectual property models imply.

Chapter four therefore developed a national system of innovation (NSI) approach to assessing the implications of stronger patent protection for the pharmaceutical sectors of developing countries. The NSI approach views patents and IPRs more broadly, as only one element in the complex system of institutions and incentives that are embedded in the historical, linguistic and cultural experience of a nation, and which consequently shape its technological and economic performance. In particular, this approach highlighted the importance of three key factors that must all be assessed in order to determine whether a developing country will be capable of capturing some of the potential benefits (or of minimizing some of the potential costs) associated with stronger IPR regimes. They are the structure and capabilities of its pharmaceutical firms, the scientific and technological infrastructure, including its universities and public research institutions, and the existence of coherent and stable government policies, relating to the pharmaceutical industry. It was acknowledged that the diversity of such an approach makes generalizations regarding the specific implications of the TRIPS Agreement very difficult. However, it does permit a contextualization of patent policy reform and offers a more realistic view of the complexity of the innovation process.

Our discussion of the innovation process in this chapter revealed that it is actually an evolutionary process, as opposed to the linear view of technical change that is implicit 
in most mainstream IP analyses, one that is based on a complex and interactive process of learning, searching, exploring and utilizing existing knowledge. From such a perspective diffusion is not something separate that happens after innovation has occurred, but something that tends to play a significant role in innovation itself. In fact the international diffusion of technology is almost certainly closely related to innovation, technological progress and economic growth, especially in the developing countries where innovation is initially generally based on imitation, which is facilitated by the existence of lax patent regimes, among other things.

In chapters five and six this framework is applied to the case of Egypt in order to assess the implications of the TRIPS Agreement on its pharmaceutical industry, and on its health sector. Chapter five focused on examining key aspects of the evolution of Egypt's pharmaceutical industry, since that has shaped the context for contemporary responses and outcomes of TRIPS related patent policy reforms. There are basically five phases that characterize the evolution of the pharmaceutical industry. An examination of each phase showed that Egypt's domestic industry has undergone quite revolutionary changes as it sought to cope with the radically different policies of three different military regimes, ranging from state led import substitution policies to market led export promotion policies.

The discussion demonstrated that a relatively weak pharmaceutical patent policy has been instrumental in fostering the emergence of a vigorous domestic industry that has come to satisfy a great proportion of domestic demand. However, it was only during a 
brief episode in the 1960 s, when this patent policy was complemented with a comprehensive pharmaceutical plan, that the innovative potential of the industry was revealed. It also became clear that the industry that did emerge in this process, achieved approximate national self-sufficiency in ways that were desirable from a public health point of view, in the sense that it supplied needed drugs relatively reliably and at affordable prices. Finally, it was shown that the industry that emerged in this way had limited innovative capacities, which is not surprising given the strategy that was adopted starting with the 'open door' policies of the Sadat regime. These historical realities have conditioned domestic response to a strengthened patent regime today.

Chapter six was concerned with an examination of how the pharmaceutical industry was affected by the country's traditional IP policy given some of the key pharmaceutical/health aspects of the national system of innovation. It demonstrated that Egypt's traditionally lax pharmaceutical patent policy had been partially responsible for fostering a domestic pharmaceutical industry with significant participation of locally owned private and public sector firms. The lax patent regime had enhanced the ability of these firms to imitate foreign pharmaceutical products and processes, and to benefit from important learning effects as a result. Over time this contributed to domestic competition and to public health. Initially, the industry was able to develop very successfully. Indeed, by the late 1990 s it supplied 93 percent of domestic needs at relatively low prices while remaining one of the more profitable industries in the country. However, although these firms had been among the greatest beneficiaries of Egypt's lax patent regime, together 
with the consumers of pharmaceuticals, their longer-term prospects were limited by major weaknesses in the countries scientific and technological support structure and the absence of key government policies. Today, those weaknesses have become more visible and more critical because they will prevent the local industry from being able to benefit significantly from the new TRIPS related IPRs regime.

These conclusions are particularly disturbing for Egypt's fragile public health system, which is currently undergoing significant reforms. Reliance on pharmaceutical products is expected to grow in the coming years, and much of this expenditure will continue to come directly out of household budgets. Because of its expected negative impact on the prices of pharmaceutical products, the implementation of the TRIPS Agreement is likely to make the challenge of obtaining treatments even more desperate for the poor. Unfortunately, it is not likely that these costs will be offset by significant improvements in research on local diseases, or that technology transfer will accelerate or that the country will be able to strengthen the pharmaceutical/health aspects of its NSI. For the moment, Egypt continues to maintain a strict price control regime, however, it is uncertain how long it will be able to resist growing pressures and threats to dismantle this system.

The potential adverse implications of stronger pharmaceutical patent protection for public health have struck a sensitive cord with developing country governments and with public health advocates worldwide. In fact, international concern over the TRIPS Agreement has been mainly focused on its likely impact on access to health-related 
treatments for the poor, rather than its likely impact on innovation and industry. Chapter seven therefore considered recent international events that have transpired as a result of the continuing disagreement between the developing and the developed countries over the impact of the TRIPS on national pharmaceutical industries and on public health systems; and key changes in Egypt's new patent law that were designed to address concerns over these issues.

This chapter argued that despite the notable improvement in the negotiating strength of the developing countries since the Uruguay Round, the industrial countries were still able to define the terms of reference for the negotiations over possible links between the TRIPS and public health, which were held during the Fourth WTO Ministerial Conference in Doha, Qatar. Although the developing countries were successful in getting many of their most pressing concerns on to the agenda, they were not nearly as successful in shaping the scope and substance of the negotiations or determining the outcome. As a result these countries ultimately gained much less from these negotiations than was hoped and needed, given the tremendous public health burdens currently being faced by many of them.

The greatest benefit to the developing countries may have been the experience that they gained in establishing and maintaining a strong and united coalition throughout these negotiations. Their ability to develop a common policy position sent a clear message to the industrial countries indicating that they were serious about defending their interests in the WTO. Unfortunately, the potential harm of having agreed repeatedly within these negotiations that the TRIPS formed an important part of the solution to their 
public health concerns may ultimately outweigh the limited benefits that accrued from the entire process. The problem was that the terms of these negotiations were so narrowly defined that the question of the impact of the TRIPS on the scope for the development of a strong local pharmaceutical industry to underpin a government's public health policies, were simply ruled out of court. Yet this should have been a major focus of the discussions since that is where the impact of the TRIPS is potentially greatest.

However, despite all this, the Doha Declaration attests to and confirms the policy options that are available to national legislators under the TRIPS Agreement. Moreover, the debate surrounding the TRIPS has heightened awareness of developing country policy makers of the substance of the TRIPS Agreement and of its potential implications for their economies and public health systems. Yet, in the absence of a fundamental renegotiation of the core provisions of the TRIPS Agreement, it is up to national legislators to ensure that their national IPR laws takes full advantage of the policy flexibility reaffirmed in the Doha Declaration. This appears to be the case with Egypt's new patent law where key provisions concerning parallel imports and compulsory licensing have aimed to take full advantage of the policy options permitted under the TRIPS.

Although there is little doubt that the Egyptian government has only reluctantly adopted relatively high intellectual property standards, including the provision of a twenty-year patent term and onerous compulsory licensing procedures, at an early stage in its development, the new patent law seeks to make full use of provisions in the TRIPS 
to protect and promote national interests. Nevertheless, the inherent limits imposed by the Agreement's minimum standards, represent a serious obstacle to the future development of innovation in the country's pharmaceutical sector. Moreover, the problem is almost certainly worse than a simple reading of the law would suggest. This is so because of the fact that the law merely seeks to define the legal ramifications of certain actions associated with intellectual property protection. But it cannot guarantee effective implementation given the pressures that will inevitably be exercised by the other protagonists in this ongoing struggle.

Over four decades of relatively lax intellectual property policy in Egypt have nurtured a domestic pharmaceutical industry that has contributed invaluably to public health. This industry has been maturing, but successive governments have failed to address the developmental problems of this growth. There is little doubt that some changes in IP policy were warranted to improve the industry's innovative performance and competitiveness, however, the imposition of industrial country standards is not appropriate given the current state of the key pharmaceutical/health aspects of Egypt's NSI, and more generally, its economic situation. In this environment it is likely that most local firms will adjust production and resort to even greater licensing activities, while foreign firms will continue with business as usual, only with guaranteed higher profits. No one is likely to embark on research projects of national relevance because of the changes in IP policy. In the end, consumers will have to suffer a greater burden as drug costs increase without significant social benefits in return. Unfortunately, the inadequacy 
of the TRIPS transition period is likely to magnify the social costs associated with this policy shift, particularly, given the current state of the economy. ${ }^{85}$

85 Egypt is currently facing major economic difficulties, including an onerous public debt, serious balance of payment problems, and rising unemployment, poverty and inequality (see El Essawi 2000). 


\section{BIBLIOGRAPHY}

Abdelghaffar, Mohamed (2001), 'Danger Threatens Pharmaceutical Production', Akhbar Al Yom, Sept. 29, p. 10.

Abbott, Frederick (2002), 'The Doha Declaration on The TRIPS Agreement and Public Health: Lighting a Dark Corner at the WTO', Journal of International Economic Law, Vol. 5, No. 2, pp. 469-505.

Act Up Paris (2002), 'Accelerating Access: Serving Pharmaceutical Companies and Corrupting Health Systems', Press Release, May 15, www.actupp.org/article498.html, (May 20, 2002).

Aghion, Phillipe et al (2002), 'Competition and Innovation: An Inverted U Relationship', http://post.economics.harvard.edu/faculty/aghion/papers/comp_and innov.pdf, (Oct. 5, 2002).

Aith, Marcio (2000), 'Patent laws can generate conflict with US', Folha de Sao Paulo, Feb. 12, http://www.cptech.org/ip/health/c/brazil, (Oct. 15, 2002).

Al Ahram (2001), 'Flying Machines and Electric Toothbrushes', Al Ahram Weekly Online, No. 539, Jun. 21-27.

Al Alam Al Yom (1999), 'After the Minister of Economy Insists on the Grace Period the Debate Over Drug Production Intensifies: Intensification of the Debate over the Future of Drug Production', Al Alam Al Yom, Jul. 27, p. 3.

Al Ansari, Mahfouz (1999), 'Mubarak and Drugs, Egyptian Health, the NATO Alliance and the Copenhagen Alliance', Al Ahram Daily Newspaper, Feb. 27, p. 13.

Al Bassil, Abd Al Azim et al (2002), 'Problems Re: Drug Access and Public Health in Egypt - Beyond IP', Al Ahram Daily Newspaper Special Report, Jun. 15, pp. 2021.

Alden, Edward et al (2001), 'Manufacture of antibiotics: Bayer Urged to Cut Price of Drugs to Help America in its Fight Against Anthrax', Financial Times, Oct. 24, 2001. 
Alt, James E., Randall L. Calvert and Brian D. Humes (1986), 'Game Theory and Hegemonic Stability: The Role of Reputation and Uncertainty', Political Economy Working Paper 106, St. Louis: Center in Political Economy, Washington University.

Andersen, Esben Sloth and Bengt-Ake Lundvall (1988), 'Small National Systems of Innovation Facing Technological Revolutions: An Analytic Framework', in Christopher Freeman and Bengt-Ake Lundvall (eds.), Small Countries Facing the Technological Revolution, London: Pinter, pp. 9-36.

Arrow, Kenneth (1962), 'Economic Welfare and the Allocation of Resources for Invention', in Universities-National Bureau Committee for Economic Research, The Rate and Direction of Inventive Activity: Economic and Social Factors; A Conference of the Universities-National Bureau Committee for Economic Research and the Committee on Economic Growth of the Social Science Research Council, Princeton: Princeton University Press, pp.609-625.

Baba, Yasunori and Ken-ichi Imai (1992), 'Systemic Innovation and Cross Border Networks: The Case of the Evolution of the VCR Systems', in Frederick M. Scherer and Mark Perlman (eds.), Entrepreneurship, Technological Innovation, And Economic Growth: Studies in the Schumpeterian Tradition, Ann Arbor: University of Michigan Press, pp. 141-152.

Barr, Stephen (1999), 'Pfizer Defiant - How David Shedlarz Challenges the Analysts', CFO: The Magazine for Senior Financial Executives, Jul., pp. 36-42.

Barzel, Yoram (1968), 'Optimal Timing of Innovations', Review of Economics and Statistics, Aug., pp. 348-355.

Bayer (2001), 'Bayer to Supply Government by Year End with 100 million Tablets for $\$ 95$ million', Bayer Press Release, Bay News International, www.news.bayer.com/News/News.nsf/id/01-0350, (Oct. 24, 2001).

Benko, Robert P. (1987). Protecting Intellectual Property Rights, Washington D.C.: American Enterprise Institute for Public Policy Research.

Bessen, James and Eric Maskin (2000), 'Sequential Innovation, Patents and Imitation', Working Paper, Department of Economics, No. 100-01, Jan., MIT.

Bonin, Bernard (1991), “Oligopoly, Innovation, and Firm Competitiveness', in Jorge Niosi (ed.), Technology and National Competitiveness: Oligopoly, Technological Innovation, and International Competition, Montreal: McGill University Press, 
pp. 267-281.

Brown, Lawrence A. (1981), Innovation Diffusion - A New Perspective, London: Methuen.

Chambers, R. (1983), Rural Development: Putting the Last First, London: Longman.

Chesnais, Francois (1991), 'Technological Competitiveness Considered as a Form of Structural Competitiveness', in Jorge Niosi (ed.), Technology and National Competitiveness: Oligopoly, Technological Innovation, and International Competition, Montreal: McGill University Press, pp. 142-176.

Chesnais, Francois (1992), 'National Systems of Innovation, Foreign Direct Investments and Other Operations of Multinational Enterprises', in Bengt-Ake Lundvall (ed.), National Systems of Innovation - Toward a Theory of Innovation and Interactive Learning, London: Pinter Publishers, pp. 265-295.

CIPR (2002), Integrating Intellectual Property Rights and Development Policy - Report of the Commission on Intellectual Property Rights, London: Commission on Intellectual Property Rights, http://www.iprcommission.org.

Clemente, C.L. (1988), 'A Pharmaceutical Industry Perspective', in Charles E. Walker and Mark A. Bloomfield (eds.), Intellectual Property Rights and Capital Formation in the Next Decade, London: University of America Press, pp. 127134.

Correa, Carlos A. (1998), 'Implementing TRIPS in Developing Countries', http://www.twnside.org.sg/souths/twn/title/ment-cn.htm, (April 25, 1998).

Correa, Carlos A. (2000), 'The Strengthening of IPRs in Developing Countries and Complementary Legislation', report prepared upon request of DFID (UK), Oct.

Correa, Carlos A. (2001), 'Some Assumptions on Patent Law and Pharmaceutical R\&D', Occasional Paper No. 6, Geneva: Quaker UN Office.

Correa, Carlos A. (1995), 'Intellectual Property Rights and Foreign Direct Investment', International Journal of Technology Management, Special Issue on the Management of International Intellectual Property, Vol. 10, No. 2/3, pp. 173-199.

Costa, Mauricio E.C. (1988), 'A View from Brazil', in Charles E. Walker and Mark A. Bloomfield (eds.), Intellectual Property Rights and Capital Formation in the Next Decade, London: University of America Press, pp. 57-64. 
Dasgupta, Partha (1986), 'The Theory of Technological Competition', in Joseph Stiglitz and G. Frank Mathewson (eds.), New Developments in the Analysis of Market Structure, Cambridge: MIT Press, pp. 519-547.

Dasgupta, Partha (1988), 'The Welfare Economics of Knowledge Production', Oxford Review of Economic Policy, Vol. 4, No. 4, pp. 1-12.

Davis, Paul (2002), 'RE: URGENT: Fast Track Vote Against Affordable Meds and PWAs Probable TODAY', Ip-health listserv, http://lists.essential.org/pipermail/ip-health/2002-July/003330.html, (July 26, 2002).

De Almeida, Paulo R. (1995), 'The Political Economy of Intellectual Property Protection: Technological Protectionism and Transfer of Revenue Among Nations', International Journal of Technology Management, Special Issue on the Management of International Intellectual Property, Vol. 10, Nos. 2/3, pp. 214229.

Deardorff, Allan V. (1992), 'Welfare Effects of Global Patent Protection', Economica, Vol. 59, pp. 35-51.

De Jonquieres, Guy (2001), ‘All Night Haggling in Doha Ends in Agreement', Financial Times, Nov. 15, p. 6.

Doern, Bruce G. and Markus Sharaput (2000), Canadian Intellectual Property: The Politics of Innovating Institutions and Interests, Toronto: University of Toronto Press.

Dosi, Giovanni (1988), "Sources, Procedures, and Microeconomic Effects of Innovation', Journal of Economic Literature, Vol. XXVI, Sept., pp. 1120-1171.

Dyer, Geoff and Adrian Michaels (2001), 'A Bitter Pill for the Drug Makers', FT.com Financial Times, Oct. 24, www.ft.com, (Oct. 26, 2001).

Eggertson, Thrainn (1990), Economic Behavior and Institutions, Cambridge: Cambridge University Press.

El Essawi, Ibrahim (2000), 'From Reform to Recession', Al Ahram Weekly Online, Apr. 27 - May 3, Issue No. 479, http://www.ahram.org.eg/weekly/2000/479/op2.htm, (Oct. 22, 2002). 
El Sawy, Tayseer M. (1997), TRIPS and the Egyptian Drug Market: Final Report, May

1, Cairo: National Information Centre for Health and Population.

Ernst, Dieter, Lynn K. Mytelka and Tom Ganiatsos (1998), 'Technological Capabilities in the Context of Export-led Growth: A Conceptual Framework', in Dieter Ernst, Tom Ganiatsos and Lynn Mytelks (eds.), Technological Capabilities and Export Success in Asia, London: Routledge, pp. 5-45.

Essam El-Din, Galal (2000), 'The Wrong Prescription', Al Ahram Weekly On line, Apr. 20-26, Issue No. 478, www.ahram.org.eg/weekly/2000/478/ec2.htm, (Nov. 1, 2002).

Evans, Robert (2001), 'Drug Companies Warn AIDS Research Could Dry Up', Reuters Limited, Sept. 19, http://www.spectrum.ieee.org/news/cache/ReutersOnlineScience/09 192001. ro mtal116-story-bcsciencescienceaidsdrugsdc.html. (Sept. 21, 2001).

Fawzy, Nahla (2002), 'New Law Strengthens Investment Climate', Egyptian State Information Service, Jul. 29, www.sis.gov.eg, (Sept. 21, 2002).

Fayez, Baha El Din (1997), Implications of WTO Rules for Technology Transfer to The Pharmaceutical Industry in ESCWA Member Countries, with Emphasis on the the Case of the Arab Republic of Egypt, Cairo: National Research Centre.

Ferrantino, Michael J. (1993), 'The Effect of Intellectual Property Rights on International Trade and Investment', Weltwirtschaftliches Archiv, Vol. 129, pp. 300-331.

Frank, Andre G. (1989), 'The Socialist Countries in the World Economy: The East South Dimension', in Brigitte H. Schultz and William H. Hanson (eds.), The Soviet Block and the Third World: The Political Economy of East South Relations, Boulder: Westview Press.

Freeman, Christopher (1987), Technology Policy and Economic Performance - Lessons from Japan, London: Pinter Publishers.

Freeman, Christopher and Luc Soete (1997), The Economics of Industrial Innovation, Cambridge: MIT Press.

Fuhrmans, Vanessa and Gautam Naik (2002), 'In Europe Drug Makers Fight Against Mandatory Price Cuts', Wall Street Journal Online, http://online.wsi.com/article/011SB1023410062557115600100.html?mod=Pagep ercent200n, (Oct. 5, 2002). 
Gadbaw, Michael R. and Timothy Richards (1988), Intellectual Property Rights: Global Consensus, Global Conflict? London: Westview Press.

Galal, Essam E. (1983), 'National Production of Drugs: Egypt', World Development, Vol. 11, No. 3, pp. 237-241.

Galal, Nourhan (1999), The Egyptian Pharmaceutical Sector, Cairo: Commercial International Brokerage Company.

Gallini, Nancy (1992), 'Patent Policy and Costly Imitation', Rand Journal of Economics, Vol. 23, pp. 52-63.

Gilbert, Richard and Carl Shapiro (1990), 'Optimal Patent Length and Breadth', Rand Journal of Economics, Vol. 21, pp. 106-112.

Grabowski, Henry and John Vernon (1986), 'Longer Patens For Lower Imitation Barriers: The 1984 Drug Act', $R \& D$, Innovation, and Public Policy, Vol. 76, No. 2, pp. 195-198.

Grossman, Gene and Elhanan Helpman (1991), Innovation and Growth in the Global Economy, Cambridge: MIT Press.

Haagsma, Auke (1988), 'A View from the European Community', in Charles E. Walker and Mark A. Bloomfield (eds.), Intellectual Property Rights and Capital Formation in the Next Decade, London: University of America Press, pp. 65-76.

Harmsen, Richard and Arvind Subramanian (1994), 'Economic Implications of the Uruguay Round', in Naheed Kirmani (staff team leader), International Trade Policies: The Uruguay Round and Beyond Volume II. Background Papers, Washington: IMF, pp. 1-31.

Hassan, Tarek Mohamed Ali (1997), 'Strategic Planning for the Improvement of Quality in Egyptian Drug Production in the Shadow of the WTO', MA dissertation, Ain Shams University, Cairo.

Hemsley, Devlin J. (1997), 'Management Views on Industry Issues, Pressures and Consultants', Script Magazine, Jun. 17.

Henderson, Rebecca, Luigi Orsenigo and Gary Pisano (1999), 'The Pharmaceutical Industry and the Revolutions in Molecular Biology: Interactions Among Scientific, Institutional and Organizational Change', in David Mowery and 
Richard Nelson (eds.), Sources of Industrial Leadership: Studies of Seven Industries, Cambridge: Cambridge University Press, pp. 267-311.

Hoekman, Bernard (1994), 'Services and Intellectual Property Rights',in Susan M. Collins and Barry Bosworth (eds.), The New GATT: Implications for the United States, Washington D.C.: The Brookings Institute, pp.84-122.

Hudec, Robert E. (1987), Developing Countries in the GATT Legal System, Sydney: Gower.

Hudec, Robert E. (1991), Enforcing International Trade Law: The Evolution of the Modern GATT Legal System, Austin: Butterworth Legal Publishers.

Ibrahim, Mohsen M. (1996), 'Future of Research in Hypertension in Developing Countries', Eastern Mediterranean Health Journal, Vol. 2, No. 2, pp. 202-205, http://www.emro.who.int/Publications/EMHJ/0202/02.htm, (Nov. 16, 2002).

ICTSD (2002a), 'Divisive Debate over TRIPS and Public Health Continues in TRIPS Council', Bridges Weekly Trade News Digest, Vol. 6, No. 9, Mar. 12, http://www.ictsd.org/weekly/02-03-12/story2.htm, (Mar. 20, 2002).

ICTSD (2002b), 'Access to Medicines in Spotlight at TRIPS Council', Bridges Weekly News Digest, Vol. 6, No. 24, Jun. 26, http://www.ictsd.org/weekly/02-0626/story 3.htm, (Mar. 20, 2002).

Industry Canada (1997), Sector Competitiveness Frameworks: Pharmaceutical Industry, Part 1 - Overview Prospects, Ottawa: Industry Sector Health Industries.

Jacobzone, S. (2000), 'Pharmaceutical Policies in OECD Countries: Reconciling Social and Industrial Goals', Labour Market and Social Policy - Occasional Papers No. 40, Paris: OECD.

Jaffe, Adam (2000), 'The US Patent System in Transition: Policy Innovation and the Innovation Process', Research Policy, Vol. 29, pp. 531-557.

Kamath, Gauri (2001), 'US Bill May Deprive Developing Nations of Cheap Drugs', The Economic Times, Nov. 20, http://economictimes.indiatimes.com/cms.dll/xml/comp/default? (Nov. 20, 2001 ).

Keefauver, William L. (1988), 'Communications: an Industry Perspective', in Charles E. Walker and Mark A. Bloomfield (eds.), Intellectual Property Rights and Capital Formation in the Next Decade, London: University of America Press, pp.143-150. 
Keohane, Robert (1984), After Hegemony: Cooperation and Discord in the World Political Economy, Princeton: Princeton University Press.

Kirim, Arman (1985), 'Reconsidering Patents and Economic Development: A Case Study of the Turkish Pharmaceutical Industry', World Development, Vol. 13, No., 2, pp. 219-236.

Klemperer, Paul (1990), 'How Broad Should the Scope of Patent Protection Be?' Rand Journal of Economics, Vol. 21, pp. 113-130.

Lall, Sanjaya (1974), 'The International Pharmaceutical Industry and Less Developed Countries with Special Reference to India', Oxford Bulletin of Economics and Statistics, Vol. 36, No. 3, Aug., pp. 143-172.

Leahy, Patrick J. (1988), 'U.S. Congressional Approaches to Reconciling Intellectual Property Rights', in Charles E. Walker and Mark A. Bloomfield (eds.), Intellectual Property Rights and Capital Formation in the Next Decade, London: University of America Press, pp.77-82.

Lesser, William (1990), 'An Overview of Intellectual Property Systems', in Wolfgang E. Siebeck et al (eds.), Strengthening Protection of Intellectual Property in Developing Countries, Washington: World Bank, pp.5-15.

Lipsey, Richard (1991), Economic Growth: Science and Technology and Institutional change in a Global Economy, Toronto: The Canadian Institute for Advanced Research.

Loury, Glenn C. (1979), 'Market Structure and Innovation', Quarterly Journal of Economics, Vol. 93, No. 3, pp. 395-410.

Love, James (2001), 'Access To Medicine And Compliance with the WTO TRIPS Accord: Models For State Practice In Developing Countries', Paper prepared for the United Nations Development Programme, Jan. 21, www.cptech.org/ip/health/cl/recommendedstatepractice.html, (Mar. 31, 2001).

Love, James (2002), 'Access to Medicines: Solving the Export Problem Under TRIPS', Bridges, May, Year 6, No. 4, p. 3, http://www.cptech.org/ip/wto/bridgesexports.html, (Jun. 5, 2002).

Lundvall, Bengt-Ake, (1992), 'Introduction', in Bengt-Ake Lundvall (ed.), National Systems of innovation - Towards a Theory of Innovation and Interactive 
Learning, London: Pinter Publishers, pp. 1-22.

Mabry, Marcus (1999), 'Give Us This Day Our Daily Meds', Newsweek International, Vol. 134, No. 1, Jul., pp.22-25.

Macan-Markar, Marwan (2001), 'Trade: Asian Governments Want Clear WTO Agenda', IPS, Sept. 28.

Malecki, Edward J. (1997), Technology and Economic Development - The Dynamics of Local, Regional and National Competitiveness, Edinburgh: Longman.

Mansfield, Edwin (1988), 'Intellectual Property Rights, Technological Change, and Economic Growth', in Charles E. Walker and Mark A. Bloomfield (eds.), Intellectual Property Rights and Capital Formation in the Next Decade, London: University of America Press, pp. 3-26.

Mansfield, Edwin et al (1971), Research and Innovation in the Modern Corporation, New York: Norton.

Maskus, Keith and Mohan Penubarti (1995), 'How Trade-Related are Intellectual Property Rights?' Journal of International Economics, Vol. 39, pp. 227-248.

Maskus, Keith (1998), 'The Role of Intellectual Property Rights in Encouraging Foreign Direct Investment and Technology Transfer', Duke Journal of Comparative International Law, Vol. 9, No. 1, p. 109.

Mc Donagh, Patrick (2001), 'Taking McGill to Market', McGill News Alumni Quarterly, Winter 2000-2001, Vol. 80, No. 4, http://www.mcgill.ca/news/archives/winter2000/market/ (May 10, 2001).

McKelvey, Maureen (1991), 'How Do National Systems of Innovation Differ? A Critical Analysis of Porter, Freemen, Lundvall and Nelson', in Geoffrey Hodgson and Ernesto Screpanti (eds.), Rethinking Economics - Markets, Technology and Economic Evolution, Aldershot: Edward Elgar, pp. 117-137.

Michaels, Adrian (2001), 'The Race for a Drug is a Close One', Financial Times, Sept. 2, p. 12.

Mohieldin, Mahmoud (2002), 'A Stitch in Time', Al Ahram Weekly Online, Mar. 21- 27, Issue No. 578.

Moreau, Ron (1999), 'Thailand Plays by the Rules', Newsweek International, Jul. 5, p.24. 
MSF, Oxfam, TWN (2001), 'RE: TRIPS Council Special Discussion on Access to Medicines, September 19, 2001', Ip-health listserv, http://lists.essential.org/pipermail/ip-health/2001-September/001874.html, (Sept. $20,2001)$.

Mytelka, Lynn K. (1999), Competition, Innovation and Competitiveness in Developing Countries, Paris: OECD Publications.

Mytelka, Lynn K. (1998), 'Competition, Innovation, and Competitiveness: Learning to Innovate Under Conditions of Dynamic Industrial Change', Paper prepared for the International Conference: The Economics of Industrial Structure and Innovation Dynamics, Centro Cultural de Belem, Lisbon, 16-17 Oct.

Namfua, Macel W. and Abdulqawi A. Yusuf (1991), Africa and the TRIPS Negotiations in the Uruguay Round, UNCTAD/UNDP Project RAF/87/157.

Nelson, Richard (1993), National Innovation Systems: A Comparative Analysis, New York: Oxford University Press.

Nelson, Richard (1996), The Sources of Economic Growth, Cambridge: Harvard University Press.

Nelson, Richard and Nathan Rosenberg (1993), 'Technical Innovation and National Systems', in Richard Nelson (ed.), National Innovation Systems: A Comparative Analysis, New York: Oxford University Press, pp. 3-28.

New York Times (2002), 'A Fairer Trade Bill', New York Times on the Web, Jul. 25, www.nytimes.com/2002/07/25/opinion/25THU3.html?pagewanted=print\&positio n=bottom, (Jul. 28, 2002).

Nogues, Julio (1990), 'Patents and Pharmaceutical Drugs: Understanding the Pressures on Developing Countries', Journal of World Trade, Vol. 24, No. 6, Dec., pp. 81 104.

Nogues, Julio (1993), 'Social Costs and Benefits of Introducing Patent Protection for Pharmaceutical Drugs in Developing Countries', The Developing Economies, Vol. XXXI, No. 1, Mar., pp. 24-53.

Nordhaus, William S. (1969), Invention, Growth and Welfare: A Theoretical Treatment of Technological Change, Cambridge: MIT Press. 
OECD (1971), The Conditions for Success in Technological Innovation, Paris: OECD.

OECD (1992), Technology and the Economy - The Key Relationships, Paris: OECD.

Orabi, Mahitab and Mohamed Nour El Din (1999), Egypt: Pharmaceutical Sector Review, Cairo: EFG-Hermes.

Ostry, Sylvia and Richard Nelson (1995), Techno-Nationalism and Techno-Globalism: Conflict and Cooperation, Washington D.C.: The Brookings Institute.

Oxfam (2001), 'Fatal Side Effects: Medicine Patents under the Microscope', Oxfam GB Policy Paper, Feb., www.oxfam.org.uk/cutthecost/downloads/policy3.rtf, (July 10, 2001).

Oxfam (2002), 'US Bullying on Drug Patents: One Year After Doha', Oxfam Briefing Paper, No. 33, Nov., http://www.oxfam.org.uk/policy/papers/33bullying/33bullying.pdf, (Nov. 16, 2002).

Pack, Howard and Larry Westphal (1986), 'Industrial Strategy and Technological Change: Theory Versus Reality', Journal of Development Economics, Vol. 22, pp. 87-128.

Pavitt, K. and P. Patel (1988), 'The International Distribution and Determinants of Technological Activities', Oxford Review of Economic Policy, Vol.4, No. 4, Winter, pp. 35-55.

Pearl, Daniel (1996), 'No Quick Cure, Big Drug Makers Push Egypt, Other Nations to End Their 'Piracy', Wall Street Journal, Dec. 17, pp. 1 \& 12.

Perez, Carlota (1988), 'New Technologies and Development', in Christopher Freeman and Bengt-Ake Lundvall (eds.), Small Countries Facing the Technological Revolution, London: Pinter, pp. 85-97.

PhRMA (2000), 'Submission of PhRMA for the 'Special 301' Report on Intellectual Property Barriers', Feb. 18, http://www.phrma.org/policy /aroundworld/special301, (Feb. 25, 2000).

Pollard, Stephen (2001), 'Business Europe: Big Pharmaceuticals take the Gloves Off', Wall Street Journa Europel, Dec. 17. 
Porter, Michael (1990), The Competitive Advantage of Nations, New York: The Free Press.

Primo Braga, Carlos A. (1990), 'Guidance from Economic Theory', in Wolfgang E. Siebeck et al (eds.), Strengthening Protection of Intellectual Property in Developing Countries, Washington: World Bank, pp. 17-32.

Primo Braga, Carlos A. (1991), 'The North-South Debate On Intellectual Property Rights', in Murray G. Smith (ed.), Global Rivalry and Intellectual Property: Developing Canadian Strategies, Halifax: Institute for Research on Public Policy, pp. 173-182.

Primo Braga, Carlos A. and Carsten Fink (1997), 'The Economic Justification of the Grant of Intellectual Property Rights: Patterns of Convergence and Conflict', in Frederick Abbott and David J. Gerber (eds.), Public Policy and Global Technological Integration, London: Kluwer Law International, pp. 99-122.

Primo Braga, Carlos A. and Carsten Fink (2000), 'International Transactions in Intellectual Property and Developing Countries', International Journal of Technology Management, Vol. 19, Nos. 1/2.

Primo Braga, Carlos A. et al (1998), 'Intellectual Property Rights and Economic Development: Background Paper to the World Development Report 1998', http://www.vita.org/technet/iprs/ipr-dcom.htm, (May 1, 1998).

Pruzin, Daniel (2001), 'WTO Talks on TRIPS, Public Health Declaration Stalls Over Compromise Text', International Trade Daily, Oct. 24, http://www.bna.com/products/corplaw/tdln.htm, (Oct. 25, 2001).

Richards, Timothy (1988), 'Intellectual Property Rights: Reconciling Divergent Views', in Charles E. Walker and Mark A. Bloomfield (eds.), Intellectual Property Rights and Capital Formation in the Next Decade, London: University of America Press, pp.93-98.

Rifkin, Jeremy (1998), The Biotech Century, New York: Penguin Putnam Inc.

Rodrik, Dani (1999), 'The New Global Economy and Developing Countries: Making Openness Work', Policy Essay No. 24, Washington: Overseas Development Council.

Romer, Paul (1994), 'Two Strategies of Economic Development: Using Ideas and Producing Ideas', Proceedings of the World Bank Annual Conference on 
Development Economics, New York: Word Bank, pp. 63-91.

Rosegger, Gerhard (1986), The Economics of Production and Innovation: An Industrial Perspective, New York: Pergamon Press.

Rosenberg, Nathan (1976), Perspectives on Technology, Cambridge: Cambridge University Press.

Rosenberg, Nathan and David Mowery (1989), Technology and the Pursuit of Economic Growth, Cambridge: Cambridge University Press.

Rozek, Richard and Ruth Berkowitz (1998), The Effects of Patent Protection on the Prices of Pharmaceutical Products: Is Intellectual Property Protection Raising the Drug Bill in Developing Countries? Washington: National Economic Research Associates.

Sabater, Luisa (1995), 'Multilateral Debt of Least Developed Countries', UNCTAD Discussion Paper No. 107, Geneva: UNCTAD.

Salama, Adel Mohsen (1997), 'The Game of the Giants in Drug Manufacture', Al Ahram (Arabic Newspaper) Mar.

Saxenian, Helen (1994), 'Getting the Most Out of Pharmaceutical Expenditures', Human Resources Development and Operations Policy Working Papers No. 37, Sept., www.worldbank.org/html/extdr/hnp/hddflash/hewp/hrwp033.html, (Mar. 10, 1999).

Scherer, F.M. (1977), The Economic Effects of Compulsory Patent Licensing, New York: New York University Press.

Schumpeter, Joseph (1934), The Theory of Economic Development, Cambridge: Harvard University Press.

Schumpeter, Joseph (1942), Capitalism, Socialism and Democracy, New York: Harper.

Segal, Aaron (1987), Learning by Doing: Science and Technology in the Developing World, Boulder: Westview.

Sell, Susan (1998), Power and Ideas - North-South Politics of Intellectual Property and Anti-trust, New York: State University of New York Press. 
Shahidullah, Shahid M. (1991), Capacity Building in Science and Technology in the Third World, Boulder: Westview.

Sherwood, Robert M. (1996), 'The TRIPS Agreement: Implications for Developing Countries', Study on the Financial and Other Implications of the Implementation of the TRIPS Agreement for Developing Countries commissioned by the World Intellectual Property Organization, Sept.

Singh, Ajit (1995), 'How Did East-Asia Grow So Fast? Slow Progress Toward and Analytical Consensus', UNCTAD Discussion Paper No. 97, Geneva: UNCTAD.

Singh, Ajit and Rahul Dhumale (1999), 'Competition Policy, Development and Developing Countries', Trade-Related Agenda, Development and Equity Working Papers No. 7, Nov., Geneva: South Centre.

Stalson, Helena (1987), Intellectual Property Rights and US Competitiveness in Trade, Washington: National Planning Association.

Stoneman, Paul and J. Vickers (1988), 'The Assessment: The Economics of Technology Policy', Oxford Review of Economic Policy, Vol. 4, No. 4, Winter, pp. i-xvi.

Stiglitz, Joseph (1986), 'Theory of Competition, Incentives and Risk', in Joseph Stiglitz and G. Frank Mathewson (eds.), New Developments in the Analysis of Market Structure, Cambridge: MIT Press, pp. 399-446.

Stiglitz, Joseph (2002), 'Globalism's Discontents', American Prospect, Jan. 14, www.globalpolicy.org/globaliz/econ/2002/0114stiglitz.htm, (Feb. 10, 2002).

Stoneman, Paul (1987), The Economic Analysis of Technology Policy, Oxford: Clarendon Press.

Story, Alan (2000), 'The Oxfam 'Access to Essential Medicines' Project: Some Patent and Research and Development Issues', report prepared for Oxfam International, London: Oxfam International.

Subramanian, Arvind (1995), 'Putting Some Numbers on the TRIPS Pharmaceutical Debate', International Journal of Technology Management, Special Issue on the Management of International Intellectual Property, Vol. 10, Nos. 2/3, pp. 252268.

Subramanian, Arvind and Mostafa Abdel-Latif (1997), 'The Egypt-EU Partnership Agreement and the Egyptian Pharmaceutical Sector', Working Paper, No. 11, 
Mar., Cairo: The Egyptian Center for Economic Studies.

Sykes, Allan O. (1992), 'Constructive Unilateral Threats in International Relations: The Limited Case for Section 301', Law and Policy in International Business, Vol. 23, No. 2, pp. 263-330.

Taylor, Christopher T. and Aubrey Silberston (1973), The Economic Impact of the Patent System: A Study of the British Experience, Cambridge: Cambridge University Press.

Toft, A. (1990), 'The New Roles and Facilities of the World Bank', IDS Bulletin, Vol. 21, No. 2, Sussex: Institute of Development Studies, pp. 38-41.

UNCTAD (1997), The TRIPS Agreement and Developing Countries, New York: United Nations.

UNCTAD (1999), Investment Policy Review: Egypt, Geneva: United Nations.

UNDP (2001), Human Development Report 2001: Making New Technologies Work for Human Development, Oxford: Oxford University Press.

USTR (2002), 'Special 301 Country Reports - Priority Watch List', USTR/Sectors Intellectual Property, www.ustr.gov/reports/2002/special301-pwl.htm\#egypt, (Oct. 13, 2002).

Von Wartensleben, Aurelie (1983), 'Major Issues Concerning Pharmaceutical Policies in the Third World', World Development, Vol. 11, No. 3, pp. 169-175.

Waldmeir, Patti (2001), 'Patents and Panics', Financial Times, Nov. 1, p. 14.

Williamson, John (1994), The Political Economy of Policy Reform, Washington: Institute for International Economics.

World Bank (1992), 'World Bank Support for Industrialization in Korea, India, and Indonesia', A World Bank Operations Evaluation Study, Washington D.C.: OED World Bank.

World Bank (2001), Global Economic Prospects and the Developing Countries 2002: Making Trade Work for the World's Poor, New York: World Bank, http://www.worldbank.org/prospects/gep2002. 
Yerkey, Gary G. and Daniel Pruzin (2001), 'United States Drops WTO Case Against Brazil Over HIV/AIDS Patent Law’, Bureau of National Affairs Inc., Jun. 26, http://www.cptech.org/ip/health/c/brazil/bna06262001.html, (Nov. 2, 2002).

Yerkey, Gary G. and Daniel Pruzin (2001a), 'WTO Provisional Agreement on TRIPS Reached at WTO Ministerial in Doha', International Trade Reporter, BNA Inc., http://www.bna.com/itrnews/story7.htm, (Nov. 5, 2002).

Zein El Abedien, Ghada (2001), 'TRIPS for Drugs - Between Patents and Monopoly', Akhbar Al Yom, Jun.11, p.3. 


\section{LIST OF PERSONS INTERVIEWED}

Dr. Abdel Aziz Abdel Rahim El Sayed

Head of R\&D, EIPICO

Dr. Ahmed Aboul Enein

Chairman, SEDICO

Established Nile Co. for Pharmaceuticals and CID Pharmaceuticals

Former advisor to UNIDO

Dr. Mohammed Baha-El-Din Fayez

Head of the National Subcommittee on IPRs

Professor Emeritus Pharmaceutical Chemistry

Former Director of the National Centre for Scientific Research

Dr. Sarwat Bassily

Chairman and CEO, Amoun Pharmaceuticals

Dr. Hassan El Badrawy

Justice, Court of Appeals

Member of the National Committee on the Follow-up of the Results of the Uruguay

Round

Key participant in the drafting of Egypt's new competition patent policies

Mr. Sayed El Bous

Minister Plenipotentiary

Commercial Affairs Advisor to the Minister of Economy

Dr. Moustafa El Hadary

Chairman, Drug Policy and Planning Centre, Ministry of Health (until May 2002)

Member of the National Committee on the Follow-up of the Results of the Uruguay

Round

Dr. Ahmed El Hakim

Director of External Affairs and Health Policy, Pfizer Egypt

Dr. Amr El Kady

Head of Research EFG-Hermes 
Dr. Fawzy El-Refaie

Acting Vice President for Technology Development and Scientific Services

Director, Patent and Trademark Office

Dr. Osama El Saady

Chairman, Hoechst Marion Roussel Egypt

Dr. Mohamed Taysir El Sawi

Director General, National Information Centre for Health and Population

Dr. Abdel Aziz A. El Sayed

Director, R\&D and Quality Control, EIPICO

Mrs. Rasha Ezz El Din

Senior Committee Liaison, American Chamber of Commerce

Dr. Mahmoud Farghal

Assistant to the Minister of Foreign Affairs

Director of the Institute of Diplomatic Studies

Mr. Roger Freeman

First Secretary, Embassy of the United States of America (Cairo)

Dr. Zakaria Gadd

Chairman, Medical Unions Pharmaceuticals

President of the Syndicate of Egyptian Pharmacists

Dr. Essam Galal

Professor Emeritus of Pharmacology, Development and Strategic Studies

Former Head of the General Organization for Pharmaceuticals (Nasser Regime)

Former Third World Negotiator, UNCTAD, WHO

Dr. Gamal Ghali

Chairman, Arab Medical Packing Company (Flexipack)

Dr. Galal Ghorab

Chairman, Pharmaceuticals Holding Company

Mr. Mohamed Halabi

Privatization Assistant, Public Enterprise Sector 
Dr. Hany Hamroush

Scientific Affairs Specialist, Embassy of the United States of America (Cairo)

Dr. Tarek Hatem

Professor of Business, American University in Cairo

Mr. Derek Hennecke

Chairman, Gist-Brocades Egypt

Dr. Thanaa Ibrahim Ali Saleh

Director General of Statistics and Information, National Information Centre for Health and Population

Dr. Hossam Kamel

Chairman, Merck Sharp and Dohme Egypt

Mr. Jeffrey Kemprecos

Director of External Affairs, Health Care Middle East

Merck, Sharp and Dohme

Dr. Hossam A. Loutfy

Chairman, Park-Davis Egypt

Dr. Mahmoud Mohieldin

Senior Advisor to the Minster of Economy

Mrs. Jaleen Moroney

Deputy Chief of Party, SIPRE Project (Nathan Associates Inc. / USAID)

Dr. Gamilla Mousa

Undersecretary of Pharmaceutical Affairs

Ministry of Health

Dr. Mahitab Orabi

Research Analyst, EFG-Hermes

Dr. Abdelfatah Saad

Manager, Product Stewardship and Registration

Novartis

Ms. Sherin Saba

Communications Manager, Glaxo Wellcome Egypt 
Dr. Samia Salah

Chairman, Drug Policy and Planning Centre, Ministry of Health (after May 2002)

Dr. Negad Shaarawi

Chairman, Glaxo Wellcome Egypt

Former President of Squibb Egypt

Dr. Magda Shahin

Deputy Assistant Minister for International Economic Relations

Ministry of Foreign Affairs

Mr. Hisham Shuair

Egyptian-European Partnership Unit

Ministry of Foreign Affairs

Mr. Shareef Teymour

Finance Specialist, EFG-Hermes

Mrs. Judy Winegar Goans

Chief of Party, SIPRE Project (Nathan Associates Inc. / USAID)

Mr. Alaa Z. Youssef

Second Secretary, Ministry of Foreign Affairs

Dr. Mounir Zahran

Ambassador

Head of Egyptian Delegation to the Uruguay Round

Ministry of Foreign Affairs 